

\section{María Gladis Agudelo Gil(Pereira, Colombia, 1965).}

Doctora en Ciencias de la Educación de Rudecolombia, Magíster en Lingüística de la Universidad de Antioquia y Licenciada en Español y Comunicación audiovisual de la Universidad Tecnológica de Pereira. Profesora titular de la Universidad Universidad Tecnológica de Pereira, adscrita a la Facultad de Ciencias de la Educación. Coautora de los libros La lectura y la escritura en la Universidad (2010) y Pensamiento y Palabra (2014). Ha publicado artículos en revistas especializadas nacionales e internacionales. Coordina el grupo de investigación GELE (Grupo de estudio en Lectura y Escritura).

$$
\text { magu@utp.edu.co }
$$

\section{Luz Marina Henao Restrepo(Pereira, Colombia, 1971).}

Doctora en Ciencias de la Educación de Rudecolombia, Magíster en Lingüística de la Universidad de Antioquia y Licenciada en Español y comunicación Audiovisual de la Universidad Tecnológica de Pereira. Profesora asociada de la Universidad Tecnológica de Pereira adscrita a la Facultad de Ciencias de la Educación. Coautora del libro La realidad reiniciada, crisis de las certezas y pensamiento transversal (2009) Ha publicado artículos en revistas especializadas nacionales e internacionales. Pertenece a los grupos de investigación: Lenguaje, literatura y Política, estudios tranversales y GELE (Grupo de estudio en lectura y escritura).

luzmarh@utp.edu.co 


\title{
BATERÍA PARA EL DIAGNÓSTICO Y CARACTERIZACIÓN LINGÜÍSTICA DE LAS AFASIAS EN EL CONTEXTO RISARALDENSE
}

\author{
María Gladis Agudelo Gil \\ Luz Marina Henao Restrepo
}

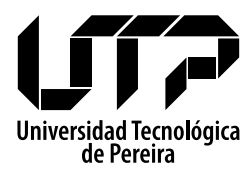

Colección Trabajos de Investigación Facultad de Ciencias de la Educación 2020 
Agudelo Gil, María Gladis

Batería para el diagnóstico y caracterización lingüística de las afasias en el contexto risaraldense / María Gladis Agudelo Gil y Luz Marina Henao Restrepo. - Pereira : Editorial Universidad Tecnológica de Pereira, 2020.

204 páginas. Ilustrado -- (Colección Trabajos de investigación).

eISBN: 978-958-722-389-7

1. Afasias 2. Trastorno del lenguaje 3. Trastorno del aprendizaje 4. Neurolingüística 5. Neuropsicología 6. Trastorno del habla 7.

Trastornos cognitivos

CDD. 616.855206

CMaría Gladis Agudelo Gil, 2020

CLuz Marina Henao Restrepo, 2020

CUniversidad Tecnológica de Pereira

Primera edición

\section{Trabajo de Investigación}

Proyecto: "Evaluación y rehabilitación de las afasias desde una perspectiva lingüística en el departamento de Risaralda"

Código: $4-13-4$

Imagen de cubierta tomada de: https://plumaslibres.com.mx/2017/01/06/ cerebro-sigue-creciendo-la-edad-adulta/ Adaptada por: Luz Marina Henao Restrepo

Ilustraciones: Luz Marina Henao Restrepo y José García

Universidad Tecnológica de Pereira

Vicerrectoría de Investigaciones, Innovación y Extensión

Editorial Universidad Tecnológica de Pereira

Pereira, Colombia

Coordinador editorial:

Luis Miguel Vargas Valencia

luismvargas@utp.edu.co

Teléfono 3137381

Edificio 9, Biblioteca Central "Jorge Roa Martínez"

Cra. 27 No. 10-02 Los Álamos, Pereira, Colombia

www.utp.edu.co

\section{Montaje y producción:}

Recursos Informáticos y Educativos CRIE, diseno@utp.edu.co

Universidad Tecnológica de Pereira

\section{Impresión y acabados:}

Publiprint

Pereira 


\section{Dedicatoria}

Dedicado a nuestros brillantes Maestros: Jaime Rojas Ortíz y J. Mario Cardona honrándolos por su elevado sentido de la vocación y por ser cómplices de nuestra posibilidad trascendente.

$Y$, por supuesto, a nuestras familias, donde la vida comienza y el amor nunca termina, por ser quienes siempre nos han apoyado

incondicionalmente día a día en el transcurso de nuestras carreras profesionales. 



\section{CONTENIDO}

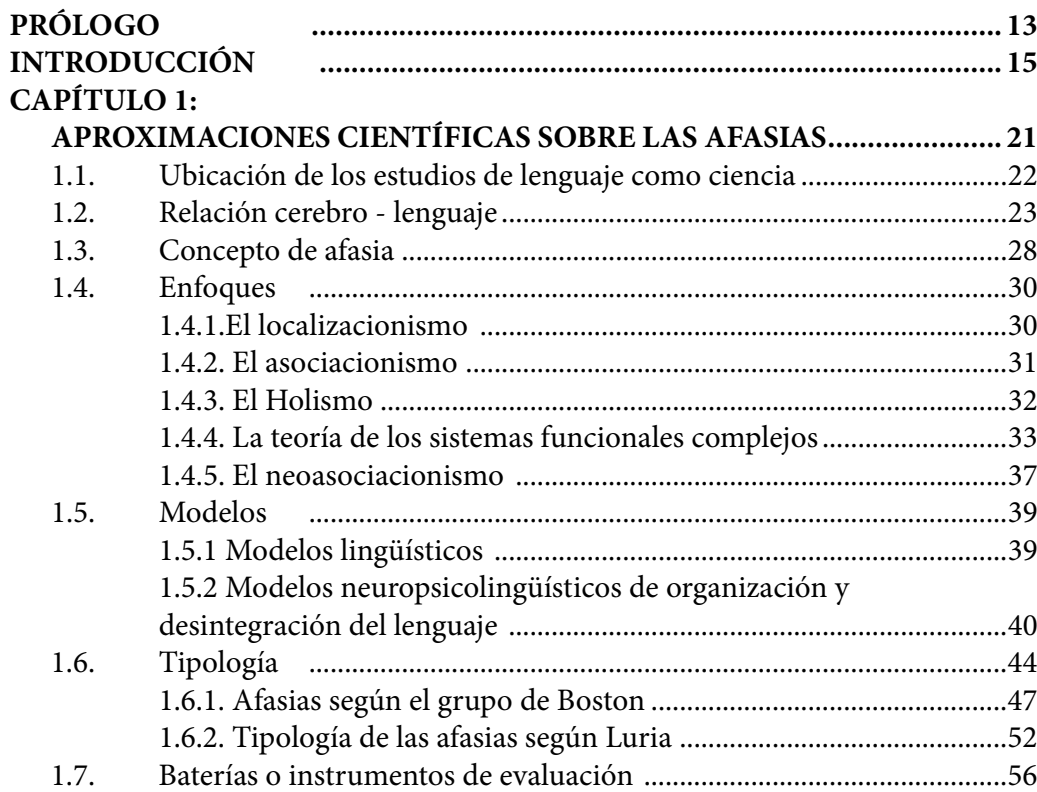

\section{CAPÍTULO 2:}

BATERÍA PARA EL DIAGNÓSTICO Y LA CARACTERIZACIÓN

LINGÜÍSTICA DE LAS AFASIAS EN EL CONTEXTO RISARALDENSE 67

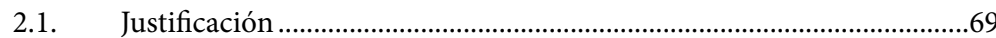

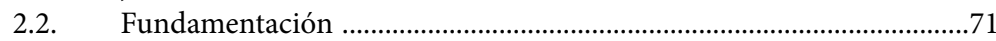

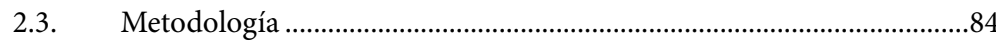

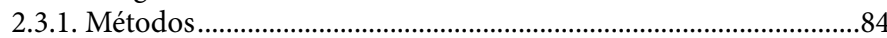

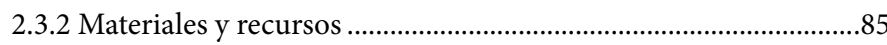

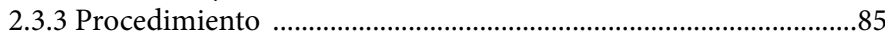

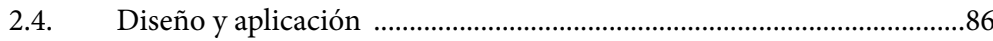

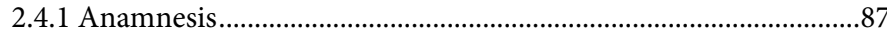

2.4.2 Prueba de desempeño en actuación lingüística ...............................88

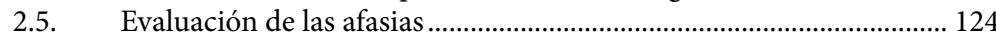

2.5.1. Calificación de las prueba ......................................................... 124

2.5.1.1. Formatos de calificación para el análisis cuantitativo ........... 124

2.5.1.1.1. Rendimiento deficitario en cada subproceso psicolingüístico evaluado ................................................................... 124

2.5.1.1.2. Rendimiento deficitario en cada subproceso psicolingüístico evaluado: representación gráfica................................ 132

2.5.1.1.3. Rendimiento deficitario en cada subproceso psicolingüístico evaluado: representación gráfica unificada .............. 136

2.5.1.2. Observaciones para el análisis cualitativo ............................... 137

2.5.2. Análisis de los resultados: diagnóstico ........................................ 140 


\section{CAPÍTULO 3:}

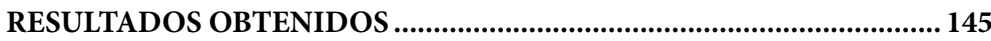

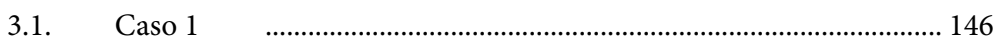

3.1.1. Anamnesis.................................................................................... 146

3.1.2. Calificación de la prueba: Formato para análisis cuantitativo 149

3.1.3. Procesos conservados y procesos alterados: Formato para análisis cualitativo ................................................................................. 160

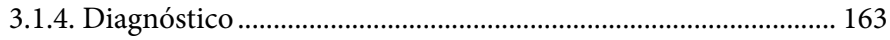

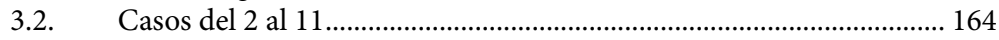

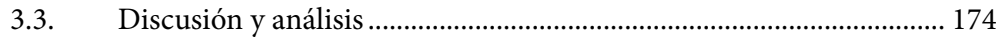

3.3.1. Tipo de afasia predominante ................................................. 174

3.3.2. Otros casos presentados ............................................................... 178

3.3.3. Reporte de un caso de disartria............................................... 180

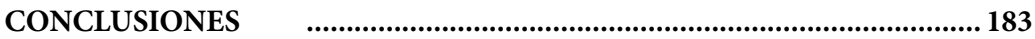

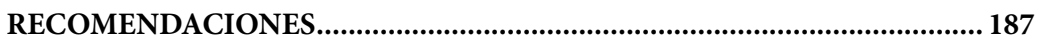

GLOSARIO $\quad$...................................................................................... 189

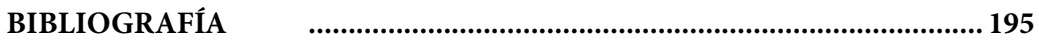




\section{LISTA DE TABLAS}

Tabla 1. Esquema sobre la reproducción del lenguaje ................................................44

Tabla 2. Clasificación de las afasias hasta mediados del siglo XX ............................57

Tabla 3. Aspectos del lenguaje generalmente incluidos en una evaluación de las Afasias.

Tabla 4. Aspectos para evaluar las afasias (Ardila 2005) a través de los procesos neuropsicológicos del lenguaje.

Tabla 5. Rendimiento deficitario en cada subproceso del Lenguaje expresivo (Expresión verbal)

Tabla 6. Rendimiento deficitario en cada subproceso del Lenguaje receptivo (Comprensión verbal)/Hojas 1 y 2

Tabla 7. Rendimiento deficitario en cada subproceso del lenguaje memorizado (almacenamiento de la expresión verbal) Hojas 1 y 2

Tabla 8. Rendimiento deficitario en cada subproceso del lenguaje reproducido (Proceso reproductivo de la expresión verbal) Hojas 1, 2 y 3

Tabla 9. Subprocesos de los procesos psicolingüísticos conservados. Caso No 1

Tabla 10. Subprocesos de los procesos psicolingüísticos alterados. Caso No 1 ... 139

Tabla 11. Diagnóstico Caso No 1 . Después de aplicación de Batería de Diagnóstico y Caracterización de las afasias.

Tabla 12. Rendimiento deficitario en cada subproceso del Lenguaje expresivo (Expresión verbal): Caso № 1

Tabla 13. Rendimiento deficitario en cada subproceso del Lenguaje receptivo (Comprensión verbal) Caso No 1 / Hojas 1 y 2

Tabla 14. Rendimiento deficitario en cada subproceso del lenguaje memorizado (Almacenamiento de la expresión verbal) Caso $\mathrm{N}^{\circ} 1$ / Hojas 1 y 2 .....

Tabla 15. Rendimiento deficitario en cada subproceso del lenguaje reproducido (Proceso reproductivo de la expresión verbal). Caso o 1 / Hoja 1, 2 y 3 ....... 154

Tabla 16. Diagnóstico Caso No 1 . Después de aplicación de Batería de Diagnóstico y Caracterización de las afasias 163

Tabla 17. Diagnóstico Caso No 2. Después de aplicación de Batería de Diagnóstico y Caracterización de las afasias 165

Tabla 18. Diagnóstico Caso No 3. Después de aplicación de Batería de Diagnóstico y Caracterización de las afasias.

Tabla 19. Diagnóstico Caso No 4. Después de aplicación de Batería de Diagnóstico y Caracterización de las afasias

Tabla 20. Diagnóstico Caso No 5 . Después de aplicación de Batería de Diagnóstico y Caracterización de las afasias. 168

Tabla 21. Diagnóstico Caso No 6. Después de aplicación de Batería de Diagnóstico y Caracterización de las afasias.

Tabla 22. Diagnóstico Caso No 7. Después de aplicación de Batería de Diagnóstico y Caracterización de las afasias

Tabla 23. Diagnóstico Caso No 8. Después de aplicación de Batería de Diagnóstico y Caracterización de las afasias 
Tabla 24. Diagnóstico Caso No 9. Después de aplicación de Batería de Diagnóstico y Caracterización de las afasias......................................................................... 171

Tabla 25. Diagnóstico Caso No 10. Después de aplicación de Batería de Diagnóstico y Caracterización de las afasias...................................................... 172

Tabla 26. Diagnóstico Caso No 11 . Después de aplicación de Batería de Diagnóstico y Caracterización de las afasias.......................................................... 173 


\section{LISTA DE FIGURAS}

Figura 1. Franz Gall y su mapa de las áreas cerebrales relacionadas con distintos

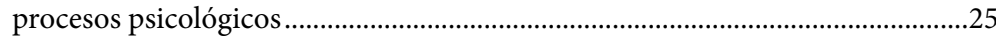

Figura 2. Paul Broca. Ubicación en el cerebro del Área de broca .............................26

Figura 3. Carl Wernicke. Localización en el cerebro del área de Wernicke.............27

Figura 4. Alexander Luria. Unidades funcionales del cerebro ..................................28

Figura 5. Afasias según el grupo de Boston .............................................................4

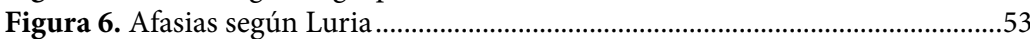

Figura 7. Batería de diagnóstico y caracterización de las afasias en el contexto

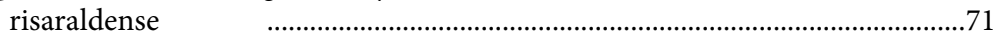

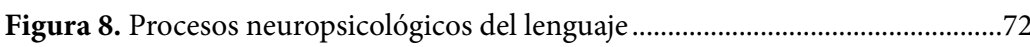

Figura 9. Eslabones en la expresión verbal o codificación ..........................................73

Figura 10. Eslabones de la comprensión verbal o decodificación................................74

Figura 11. Fases del almacenamiento de la expresión verbal ....................................75

Figura 12. Procesos reproductivos de la expresión verbal ..........................................76

Figura 13. Fases en la lectura como proceso reproductivo de la expresión verbal..............................................................................................

Figura 14. Niveles en la Escritura como proceso reproductivo de la expresión verbal............................................................................................

Figura 15. Batería diseñada para diagnosticar y caracterizar las afasias ...................89

Figura 16. Apoyo para medir el lenguaje monologado ilustrativo en la prueba $\quad$...................................................................................... 111

Figura 17. Apoyo para valorar el lenguaje monologado narrativo en la prueba. 112

Figura 18. Apoyo para valorar la comprensión de palabras en tanto identificación de partes del cuerpo

Figura 19. Apoyo para valorar la comprensión de estructuras lógico-gramaticales, caso relaciones espaciales

Figura 20. Apoyo para valorar lenguaje memorizado, caso denominación de objetos y seres en dibujos ................................................................................. 116

Figura 21. Apoyo para valorar lenguaje memorizado, caso denominación de objetos y seres en dibujos ................................................................................... 117

Figura 22. Apoyo para valorar lenguaje memorizado, caso denominación de objetos y seres en dibujos

Figura 23. Apoyo para valorar lenguaje reproducido, caso texto entero................ 123

Figura 24. Perfil del rendimiento deficitario en su Expresión verbal. Caso $\mathrm{N}^{\circ}$

Figura 25. Perfil del rendimiento deficitario en su Comprensión verbal. Caso $\mathrm{N}^{\circ}$

Figura 26. Perfil del rendimiento deficitario en su Almacenamiento de expresión verbal. Caso $\mathrm{N}^{\circ}$

Figura 27. Perfil del rendimiento deficitario en su Reproducción de la expresión verbal Lectura. Caso No

Figura 28. Perfil del rendimiento deficitario en su Reproducción de la expresión verbal Escritura. Caso No

Figura 29. Perfil del rendimiento deficitario en su Reproducción de la expresión verbal Repetición. Caso No 
Figura 30. Perfil del rendimiento deficitario en su Reproducción de la expresión verbal. Caso $\mathrm{N}^{\circ}$

Figura 31. Perfil del rendimiento deficitario en sus Procesos psicolingüísticos. Caso $\mathrm{N}^{\circ}$

Figura 32. Perfil del rendimiento deficitario en su Expresión verbal Caso No 1

Figura 33. Perfil del rendimiento deficitario en su Comprensión verbal Caso No 1

Figura 34. Perfil del rendimiento deficitario en el Almacenamiento de su expresión verbal Caso No 1.

Figura 35. Perfil del rendimiento deficitario en la Reproducción de su expresión verbal: Lectura Caso № 1

Figura 36. Perfil del rendimiento deficitario en la Reproducción de su expresión verbal: Escritura Caso No 1

Figura 37. Perfil del rendimiento deficitario en la Reproducción de su expresión verbal: Repetición Caso № 1

Figura 38. Perfil del rendimiento deficitario en la Reproducción de su expresión verbal Caso $\mathrm{N}^{\circ} 1$

Figura 39. Perfil del rendimiento deficitario en sus Procesos psicolingüísticos Caso $\mathrm{N}^{\circ} 1$ 


Prólogo

$\mathrm{E}$ sta obra centra su atención en la creciente importancia de la investigación cerebral sobre el lenguaje , los trastornos de la organización y funciones del lenguaje en pacientes con lesión cerebral, las afasias. Intenta reunir, sin ser exhaustiva, los resultados más sorprendentes de la investigación neurolingüística con el fin de ajustarlos más precisamente a los modelos lingüísticos contemporáneos, y situar en primer plano el punto de vista de la afasiología en la realidad del contexto risaraldense. El objetivo fundamental y más innovador de esta investigación es la creación de una batería de evaluación y diagnóstico de las afasias diseñada para el contexto risaraldense y aplicada en diferentes hospitales en la ciudad de Pereira.

El resultado de esta obra será especialmente útil para los neurólogos y los lingüistas, para quienes enfrentan problemas prácticos de trastornos del lenguaje y su rehabilitación, pero podría interesar, además, a quienes toman decisiones sobre políticas nacionales sobre el lenguaje y sus alteraciones en el aula. 
La obra Batería para el diagnóstico y caracterización lingüística de las afasias en el contexto risaraldense, de Luz Marina Henao y María Gladys Agudelo, logra llenar el vacío que dejan los compartimentos estancos, la lingüística que ignora el asiento físico del lenguaje, el cerebro y la neurología que ignora las reglas lingüísticas de funcionamiento y funciones del lenguaje. Las autoras miran el lenguaje de manera integral, gracias a sus excelentes logros como egresadas de un Magíster en Lingüística y a sus productivas carreras como docentes universitarias.

Jaime Rojas Ortíz Director Maestría en Lingüística Universidad de Antioquia 
Introducción

7 nuestra cotidianidad hay preocupación por las dificultades

-1 tomadas como retraso normal en el aprendizaje de la lectura, de la escritura, y aún por las que puede presentar un niño en su adquisición y desarrollo del lenguaje. Dificultades atendidas por logopedas, fonoaudiólogos, fonetistas, psicólogos, profesores y hasta padres de familia.

Ahora bien, el haber adquirido y desarrollado el lenguaje no garantiza que nos acompañe siempre, pues una lesión cerebral (interna o externa) puede ocasionar daños parciales o totales en las áreas encargadas de la comprensión y la producción del mismo, arrojando así una expresión oral confusa, frenada, poco fluida, y a veces agramatical; o una comprensión muy limitada de lo que se escucha. Las lesiones cerebrales también comprometen la lectura (produciendo alexia) y la escritura (produciendo agrafia), así su aprendizaje hubiera tenido niveles adecuados de realización.

En este sentido, el lector encontrará un acercamiento a las afasias como patología del lenguaje, entendida como "Un déficit en 
la comunicación verbal resultante del daño cerebral" (Hécaen, 1977, citado en Ardila, 2005, p.35). Es un asunto que cobra vigencia, por ser una consecuencia de trauma a la cual ninguna edad, condición ni género escapa, y se incluye dentro de una preocupación integral por el Lenguaje, reconociendo su doble función: Cognitiva (Chomsky, 1977) y comunicativa (Halliday, 1978), funciones necesarias para que el ser humano sea humano, como lo afirma Heidegger (citado en Conesa y Nubiola, 1999): “El hombre es, a diferencia de la planta y la bestia, el ser vivo capaz de hablar [...] Es el propio lenguaje lo que hace al hombre capaz de ser el ser vivo que es en tanto que hombre" (1959, citado en Conesa y Nubiola, 1999. p.17).

Así, dada la relevancia del lenguaje en la vida humana, el objetivo fundamental de este acercamiento a las afasias es abordar tal alteración con un riguroso grado de cientificidad, y proponer una batería o un instrumento que permita caracterizarlas desde una perspectiva lingüística en el contexto risaraldense. De esta manera, tanto el abordaje como el instrumento de evaluación del lenguaje serán un gran apoyo para entidades de salud y profesionales que se ocupan del diagnóstico de las diferentes patologías del lenguaje. Además, por el énfasis en lo lingüístico, constituye en un punto de partida, para que especialistas del ramo busquen alternativas de rehabilitación para cada caso.

Con el ánimo de cumplir tales cometidos, se revisó la literatura sobre afasias, encontrando diversas teorías acerca de la relación cerebro-lenguaje, las cuáles señalan específicamente qué áreas de la corteza cerebral se encargan de la producción y comprensión del mismo; teorías como la localizacionista, la asociacionista y la holista, con representantes como Broca (1861), Wernicke (1874), Luria (1978) y Llinás (2001), respectivamente, quienes tienen posiciones diferentes al respecto. Se encontraron también explicaciones de la neuropsicología que correlaciona, para la clasificación de afasias, la ubicación de la lesión cerebral y las alteraciones en la actuación lingüística, como afirma Luria (1980), basándose en Jakobson (1964).

Este acercamiento, a nivel teórico, permitió avanzar hacia el diseño de un instrumento que caracterizara las afasias desde una perspectiva lingüística. Es decir, que permitiera evaluar cualitativa y cuantitativamente las actuaciones lingüísticas de los hablante-oyentes 
patológicos, dada su nueva condición de lenguaje a consecuencia de la lesión cerebral sufrida; instrumento que no fuera ajeno a las realizaciones lingüísticas, producto de la idiosincrasia y las costumbres colombianas y risaraldenses a la vez.

Para la validación de este instrumento, se tuvo un acercamiento a hablante-oyentes de la ciudad de Pereira, que habían sufrido lesiones de origen interno o externo en su cerebro, y perdieron sus facultades para producir y/o comprender lenguaje, como lo venían haciendo antes de sufrir tal lesión. En este acercamiento se pudo notar que no son pocos estos casos: unos, quienes sufrieron su lesión cerebral hace ya algún tiempo, no están recibiendo atención alguna para sus dificultades de comunicación. Otros, con un reciente traumatismo cerebral, vinculados todavía a los centros hospitalarios de atención que procuran estabilizarlos en relación con sus traumas físicos, quedando relegada a un segundo lugar su dificultad de uso del lenguaje. Esta población se encuentra seriamente afectada, por su aislamiento familiar, social y laboral, condición que prevalece, pues con estos pacientes no se está adelantando ningún tratamiento de rehabilitación que les permita recuperar sus roles en la familia y en la sociedad.

De este grupo de pacientes, se eligieron, de manera aleatoria, diez casos, a quienes se les aplicó el instrumento, lo cual hizo posible caracterizar sus afasias, desde la perspectiva lingüística.

Los resultados obtenidos en el desarrollo de estos tres momentos: Revisión a nivel teórico sobre las afasias, diseño de instrumento para diagnosticarlas y caracterizarlas, y validación de dicho instrumento, permitieron estructurar los tres capítulos que se presentan en este libro. 



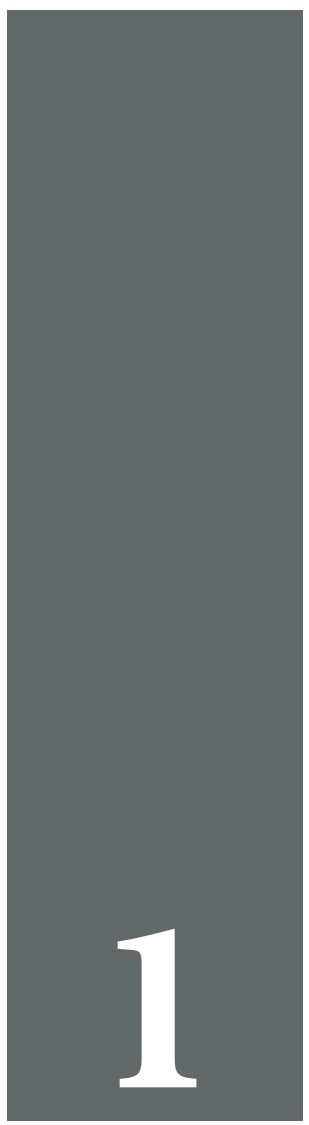

CAPÍTULO

UNO 



\section{Aproximaciones científicas sobre las afasias}

$\mathrm{D}$ ado nuestro interés por el papel fundamental que cumple el lenguaje en la vida del ser humano, la evolución que han tenido sus abordajes en relación con los procesos de producción y comprensión por parte de los hablante-oyentes, y la preocupación que hay cuando este lenguaje es alterado en su comprensión y producción después de haber sufrido lesiones en las áreas cerebrales encargadas de esta función, en este capítulo se abordarán asuntos que permitirán entender desde el punto de vista teórico qué está sucediendo cuando una persona que sufre una lesión cerebral produce enunciados visiblemente agramaticales o no comprende enunciados; son siete los apartados donde se desarrolla de manera breve y respectiva cada uno de estos asuntos:

- Ubicación delos estudios del lenguaje como ciencia. Interrogantes que se formulan las teorías surgidas en el siglo XX, estatus de cientificidad a los estudios del lenguaje, paso de lo estructural o formal a un interés por el uso, y en forma consecuente, la oración como unidad de análisis en un primer momento, desplazada por el texto, en un momento actual.

- Referentes conceptuales que dan cuenta de la relación cerebrolenguaje, con las diferentes miradas de los expertos: Gall (1796) retomado por Fajardo y Moya (1999), Broca (1861), Wernicke 
(1874) y Luria (1974), lo cual permitirá entender posteriormente la clasificación de las afasias.

- Concepto de afasias, desde el inicio de sus estudios, hasta explicaciones actuales, y diferenciación con las disfasias.

- Enfoques que explican los mecanismos cerebrales del lenguaje: localizacionismo, asociacionismo, holismo, teoría de los sistemas funcionales complejos y neoasociacionismo.

- Modelos lingüísticos que dan cuenta de las regularidades y reglas que forman estructuras en las cuales se fundamenta la comprensión y la producción del lenguaje: Modelo lingüístico (Jackobson, 1967), modelo de la teoría estándar (Chomsky, 1976) y modelos neuropsicolingüísticos de organización y desintegración del lenguaje (Luría, 1980).

- Tipologías de afasias, de acuerdo con la ubicación de la lesión cerebral y las características de realización lingüística de los hablante - oyentes con dicha lesión. Éstas desde el Grupo de Boston y desde Luria.

- Baterías o instrumentos de evaluación y diagnóstico de las afasias.

\subsection{Ubicación de los estudios de lenguaje como ciencia}

El estudio del lenguaje se convirtió en un asunto científico en el siglo XX, con los aportes de Ferdinand De Saussure (1913), quien al parecer se preguntó ¿cómo es la lengua? y posteriormente, con los aportes de Noam Chomsky (1976) a quien le interesó saber ¿Cómo es posible que un hablante-oyente produzca y comprenda enunciados? De Saussure (1913) proporcionó una mirada estructural a la lengua, pues apuntó a teorizar sobre cómo está constituida ${ }^{1}$. Chomsky (1976) centró también sus análisis y propuestas en el sistema (competencia) más que en el uso (actuación) de la lengua, avanzando con su interés hacia quien produce dichos enunciados: qué intencionalidades tiene,

1 Para ello, estableció unas dicotomías: Lengua/ habla, paradigma/sintagma, significante/significado e hizo referencia los niveles: fonético, fonológico, morfológico, sintáctico y semántico. 
qué necesidades de comunicación, qué conocimientos yacen en su intelecto (estructura profunda), antes de comunicarlos a través de unos enunciados bajo la forma de estructuras gramaticales (estructura superficial), correspondientes a la lengua que elige para comunicarse (materna o segunda lengua).

Con estas dos alusiones teóricas se aprecia un paso de lo lingüístico (con De Saussure) a lo psicolingüístico (con Chomsky), por el evidente interés en esta última, de revisar qué sucede en el intelecto del hablante en relación con su lengua, 0 , en otras palabras, establecer la relación entre actividad mentaly lengua, como sistema de signos que ayudan a constituir un mensaje. Ya a partir de los años 60, los estudios del lenguaje toman un nuevo giro, concibiendo la posibilidad de estudiar su uso, conscientes de sus condiciones asistemáticas, heterogéneas e individuales, contrarias a las que había optado por estudiar el estructuralismo. Es así como aparecen una serie de disciplinas cuyos objetos de estudio se centran en el lenguaje en su relación con aspectos biológicos y sociales del hombre (la antropología lingüística), con las costumbres y tradiciones de los pueblos (la etnografía de la comunicación), con la sociedad (la sociolingüística), con su uso (la pragmática), con su puesta en escena en el texto (el análisis del discurso), con una unidad de análisis que supera a la oración (la lingüística textual) en tanto unidad de análisis, y con el cerebro (la neurolingüística), como posibilitador principal de la comprensión y producción del lenguaje.

\subsection{Relación cerebro-lenguaje}

La evolución nos ha dado al cerebro como el órgano responsable de muchas conexiones que hacen posible una memoria más amplia, un léxico y la creación de sistemas nuevos para representar la realidad. Es así como "Gracias al desarrollo de las funciones neuropsicológicas superiores, entre las que se cuenta el lenguaje, los seres humanos somos capaces de desarrollar procesos de abstracción, conceptualización y representación del mundo" (Fajardo, 2008, p.94). Dicho de esta manera el lenguaje humano no implica unicamente el asunto simbólico y de representaciones, también involucra aspectos fisiológicos relacionados directamente con distintas funciones del cerebro, como lo señalan Berko y Bernstein (1999, p.68): 
El lenguaje no es el único aspecto diferencial que posee el comportamiento comunicativo humano respecto a otras especies; el discurso es también un acto específico de la conducta humana (Dingwall, 1975). Darley et al. (1975) han comprobado que el lenguaje articulado requiere, al menos, el movimiento de 100 músculos, cada uno de ellos controlado probablemente por el mismo número de motoneuronas. Con una cadencia de discurso normal, de unos 14 sonidos por segundo, se precisaría la activación de 140.000 procesos neuromusculares cada segundo para poder hablar.

Las reflexiones sobre la relación cerebro-lenguaje son el objeto de estudio de la neurolingüística, un campo interdisciplinar en el que se entrecruzan el estudio del cerebro (neuro) y cómo esta estructura neuroanatómica hace posible el lenguaje (lingüística). Así entonces, la neurolingüística "estudia más al usuario del lenguaje en sí, analizando ya sea el lugar cerebral en el que se produce el comportamiento verbal relacionado con la codificación y decodificación, o las conexiones neuronales que posibilitan este mismo comportamiento verbal, ya sea normal o patológico" (Jiménez Ruiz, 2001, p.400).

El origen de esta disciplina se remonta al siglo XIX. Los pioneros en este campo fueron los médicos que observaron las correlaciones entre los trastornos del lenguaje como consecuencia de las lesiones cerebrales y las particularidades de esas lesiones. Uno de estos médicos, Franz Gall, a comienzos del siglo XIX, postuló que todas las cualidades morales e intelectuales son innatas y que su ejercicio y sus manifestaciones dependen de la morfología del cerebro. Sus aportes fueron decisivos al plantear en forma explícita que toda la actividad cognoscitiva, por compleja que sea, es una resultante de la actividad cerebral (Ardila y Rosselli, 2007, p.2). Gall desarrolla nuevas teorías para la época, que quebraban radicalmente con las ideas medievales en relación a cuerpo y mente; se estaban gestando avances en la ciencia sobre la relación cerebro-lenguaje, pero la sociedad no estaba preparada para entenderlos, puesto que aún la concepción teocéntrica estaba muy arraigada.

Aunque Gall realizó importantes contribuciones a la neuroanatomía, como la distinción entre: la materia gris del cerebro que contiene cuerpos celulares (neuronas) y la materia blanca que contiene 
fibras (axones) y del cruce en $\mathrm{X}$ de las pirámides, localizaba funciones mentales sin basarse en investigaciones neuropatológicas, sino en la pseudo ciencia de la craneometría (más tarde llamada frenología), señalando que era posible localizar varias funciones psicológicas, a través de la palpación y sintiendo la forma del cráneo. Construyó un mapa que contenía 27 diferentes organizaciones cerebrales, cada uno asociado a una capacidad mental especifica (Figura 1). Propuso que el centro del lenguaje hablado estaba ubicado inmediatamente detrás de los ojos.

Ya en la segunda mitad del siglo XIX, y todavía en el siglo XX, aparecen teóricos que lanzan sus posiciones frente a su visión de qué parte del cerebro se encarga de las funciones que hacen posible la comprensión y la producción del lenguaje. Se encuentran aquí Broca (1861), Wernicke (1874), Hughlings (1878) y Luria (1974); retomados por Ardila (2005). En las Figuras 2, 3 y 4 pueden apreciarse estas posiciones, respectivamente.

Figura 1. Franz Gall y su mapa de las áreas cerebrales relacionadas con distintos procesos psicológicos
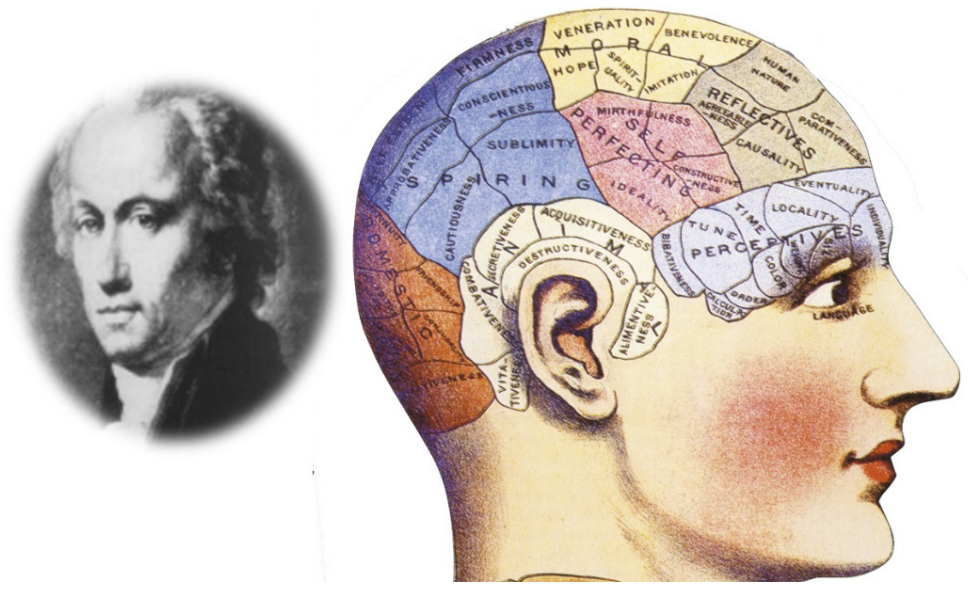

Fuente: Barona (2014). Franz Joseph Gall: la frenología y las funciones del cerebro. Metode, 47. Extraído desde: https://metode.es/revistasmetode/secciones/historias-cientificos/franz-joseph-gall-la-frenologia-ylas-funciones-del-cerebro.html 
Paul Broca, célebre cirujano y antropólogo francés, estremeció la época de 1861 cuando afirmó encontrar en uno de sus pacientes (Leborgne) que presentaba un impedimento del lenguaje expresivo, una lesión en la tercera circunvolución del lóbulo frontal izquierdo. Broca llamó la atención del mundo científico sobre el hecho de que cuando un paciente perdía la capacidad para hablar, la patología se localizaba en el hemisferio izquierdo, en tanto que las lesiones que comprometían la misma región en el hemisferio derecho, no llevaban a una pérdida en la capacidad lingüística. Afirmó que ambos hemisferios eran asimétricos en cuanto a sus funciones y que el hemisferio izquierdo contenía el área del lenguaje en la mayoría de los seres humanos.

Figura 2. Paul Broca. Ubicación en el cerebro del Área de Broca
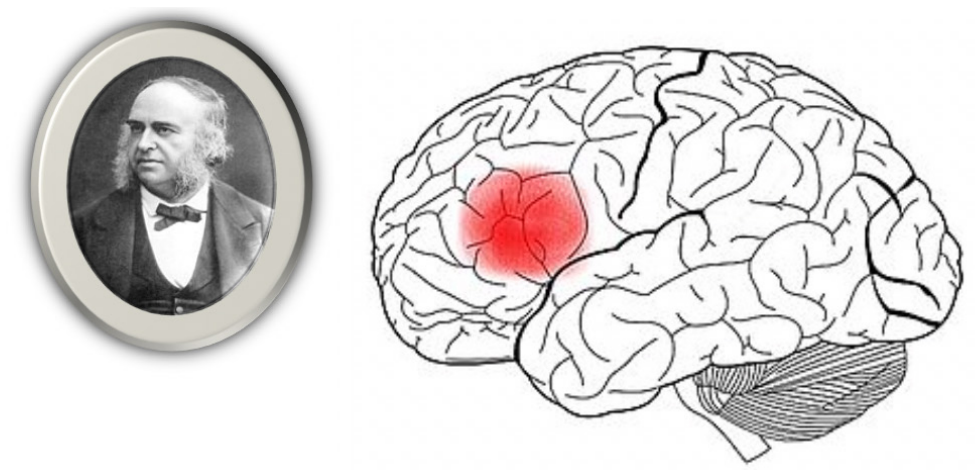

Fuente: Fontes. M (2018). Área de broca: consideraciones. Extraído desde: https://knoow.net/ciencsociaishuman/psicologia/area-brocaconsideracoes/

La publicación de la tesis doctoral del estudiante alemán Karl Wernicke, en 1874, constituyó un gran avance en el enfoque localizacionista del lenguaje, y por lo tanto de toda la actividad cognoscitiva (Ardila y Rosselli, 2007). Wernicke propuso la existencia de dos tipos de afasia: motora y sensorial, separables clínicamente. Apoyó su punto de vista con base en correlaciones clínico-anatómicas. En El síndrome afásico (1874) describió lo que más tarde se denominaría afasia sensorial (imposibilidad para comprender el significado del lenguaje hablado o escrito). 
Figura 3. Carl Wernicke. Localización en el cerebro del área de Wernicke
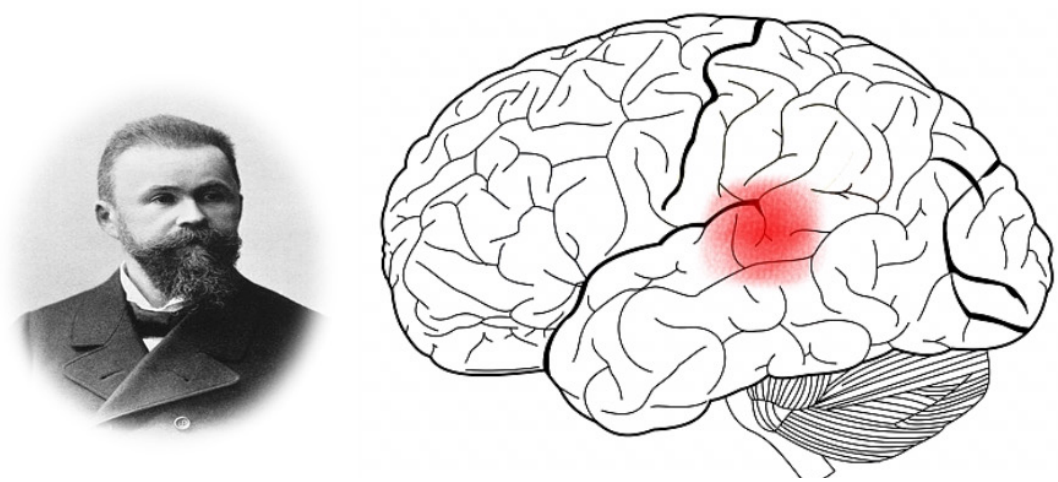

Fuente: Anónimo. (s.f) Área de Wernicke. Extraído desde: https:// es.wikipedia.org/wiki/\%C3\%81rea_de_Wernicke

Durante el periodo de la Segunda Guerra Mundial, y en los años posteriores, no solo en los países europeos sino también en todo el resto del mundo, el flujo creciente de pacientes heridos de guerra con alteraciones lingüísticas resultantes de lesiones cerebrales, incrementó la demanda de procedimientos diagnósticos y rehabilitativos. El primer resultado importante posterior a la Segunda Guerra Mundial fue la aparición del libro de A. R. Luria La afasia traumática, publicado en 1974, el cual presenta una serie de propuestas originales acerca de la organización cerebral del lenguaje y de su patología, basadas en la observación sistemática de centenares de pacientes heridos de guerra durante el periodo bélico.

Luria propuso que la actividad mental tiene lugar en el trabajo concertado de distintas estructuras cerebrales, y que conforman sistemas funcionales complejos (SFC) que actúan como un todo. La primera consideración para Luria es entender que los procesos mentales no están localizados, sino que son posibilitados por la integración de distintas estructuras que actúan concertadamente conformando sistemas. 
Su influencia en las interpretaciones teóricas y clínicas de las afasias ha sido inmensa. Los puntos de vista de Luria fueron posteriormente sistematizados en sus libros El cerebro humano y los procesos psicológicos (1966), Las funciones corticales superiores en el hombre (1976), El cerebro en acción (1974) y Fundamentos de neurolingüística (1976).

Figura 4. Alexander Luria. Unidades funcionales del cerebro
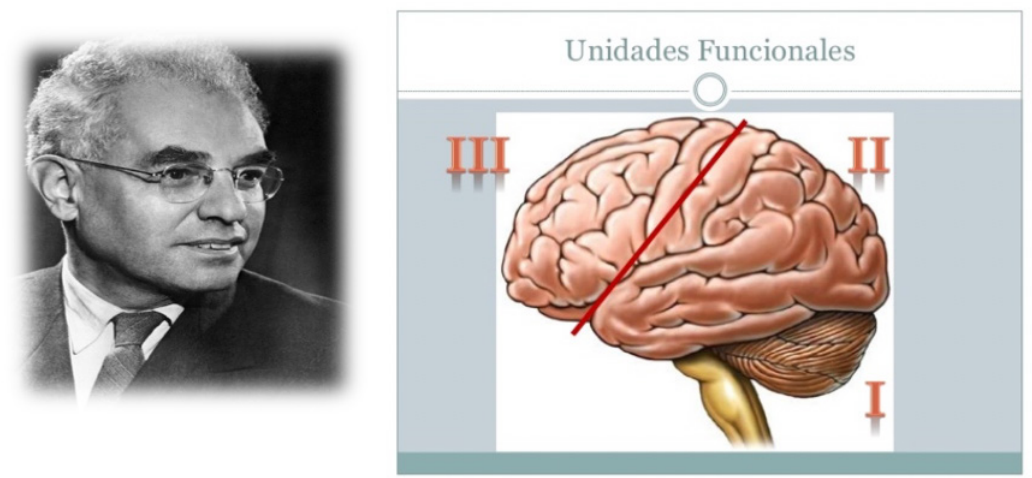

Fuente: Méndez. A (2013). Organización funcional del cerebro. Extraído desde: https://es.slideshare.net/abemen/organizacin-funcional-delcerebro

\subsection{Concepto de afasia}

Dentro de la terminología relacionada con lenguaje, específicamente en la que se refiere a sus alteraciones, encontramos términos con cierta similitud morfológica: es el caso de disgrafia, agrafia; dislexia, alexia; discalculia, acalculia; y disfasia, afasia, donde lo que las diferencia, es precisamente la naturaleza de la causa de dichas alteraciones.

Así, la disfasia es un trastorno congénito caracterizado por un inicio tardío en el comienzo y/o producción del lenguaje, tanto en su forma expresiva como comprensiva, que no puede ser explicado por retraso mental, trastornos neurológicos, psiquiátricos o auditivos. Sus efectos alteran no sólo al lenguaje, también a sus relaciones sociales, capacidad de atención y comportamiento. Es una alteración del lenguaje duradera, con consecuencias graves en el ámbito escolar. Se trata de un trastorno idiopático, es decir, no se produce por consecuencias orgánicas. Es 
esencial subrayar que no existe una lesión cerebral clínicamente demostrable. Se origina cuando el lenguaje aún se está desarrollando y puede darse en la comprensión del lenguaje (tipo receptivo), en la expresión o en ambos (mixto). A diferencia de la disfasia, la afasia hace referencia a la pérdida de las facultades del lenguaje una vez han sido adquiridas, por causa de una lesión cerebral.

Las primeras contribuciones científicas al estudio de las afasias tienen un poco más de un siglo. Varios fueron los investigadores que se interesaron por el estudio acerca de la organización cerebral del lenguaje y el análisis de sus alteraciones en caso de traumatismo craneoencefálico. Las alteraciones del lenguaje o afasia, que resultan como consecuencia de lesiones locales del cerebro, es uno de los objetos de estudio más antiguo de la neurología, la psicología y la fisiología. El estudio sistemático de la afasia se inició hace más de un siglo y actualmente ha adquirido un gran significado, al grado de que muchos investigadores la consideran como una rama independiente del conocimiento: la afasiología.

Benton (1964) señala que la primera referencia que reconoce claramente el papel del cerebro en las pérdidas verbales se encuentra en el corpus de Hipócrates, alrededor de 400 a.C. Hipócrates se refiere a dos tipos diferentes de alteraciones: áfonos y anaudos como subtipos de pérdidas lingüísticas. En la tercera parte del tratado, se encuentran sus ideas biológicas básicas, donde habla sobre las enfermedades y la teoría humoral. En sus trabajos quirúrgicos sobre las fracturas, luxaciones $y$ heridas en la cabeza, se observa un cabal conocimiento de huesos, de articulaciones y sobre la fisiología del movimiento. Por ejemplo, se observa una asociación entre las alteraciones del lenguaje y la parálisis del lado contrario del cuerpo.

Desde la neuropsicología (Rojas, 2002, p.72), el término afasia significa sin lenguaje (del griego a: negación, y phasis: lenguaje); su evolución como concepto clínico ha estado en estrecha relación con las consideraciones sobre su naturaleza, a lo largo de la historia. Algunos autores han considerado que la afasia afecta fundamentalmente el intelecto o la formulación y expresión simbólicas (Marie, 1969; Head, 1926), mientras que para otros autores las alteraciones de otras funciones psicológicas no tienen ninguna relación con la afasia (Geschwind, 1966; Benton, 1971). 
Bein y Ovcharova (1970) definen la afasia como una alteración en la capacidad para utilizar el lenguaje, Hécaen (1977) la define como un déficit en la comunicación verbal resultante del daño cerebral; Benson (1979) considera que es un trastorno en el lenguaje causado por un daño cerebral, y Kertesz (1985) asegura que es una pérdida adquirida del lenguaje como resultado de algún daño cerebral, caracterizada por errores en la producción, fallas en la comprensión y dificultades para hallar las palabras.

En consecuencia, la afasia se refiere a un trastorno del lenguaje que se debe a un daño cerebral localizado, el cual puede dar lugar a problemas a la hora de comprender y/o generar formas lingüísticas.

\subsection{Enfoques}

Las relaciones del cerebro y del lenguaje tuvieron una orientación científica desde las descripciones sustentadas de Pierre Paúl Broca en 1861. Desde entonces, este tipo de estudios han tomado desarrollos $\mathrm{y}$ enfoques que dan una imagen real y sugestiva de los mecanismos cerebrales del lenguaje, presentándose, a lo largo del estudio de estos fenómenos, periodos destacados como: el localizacionismo, el asociacionismo, el holismo, la teoría de los sistemas funcionales complejos y el neoasociacionismo. A continuación, se hará referencia detallada de cada uno de estos periodos.

\subsubsection{El localizacionismo}

En el año 1861 Pierre Paúl Broca (1824-1880) relacionó la pérdida de la palabra de uno de sus pacientes, con el reblandecimiento y la destrucción parcial del lóbulo frontal izquierdo: Louis Víctor Leborgne había perdido la capacidad de hablar y sufría parálisis de la mano derecha, que le impedía escribir. Fue imposible determinar su nivel intelectual con precisión, aunque se tuvieron indicios de que comprendía casi todo lo que se le hablaba y expresaba sus sentimientos y deseos solamente por medio de movimientos de la mano izquierda, realizando también gestos incomprensibles. Independientemente de la pregunta que se le formulara, Leborgne repetía "tan, tan".

La historia permitió suponer a Broca, que una lesión en la región frontal media, tercera circunvolución del hemisferio izquierdo, era la 
causa de la pérdida del lenguaje y la parálisis de la mano derecha. Este paciente había sufrido una alteración súbita del conocimiento, de lo cual se recuperó, quedando con pérdida del habla o afemia, según la terminología de Broca.

En 1865 Broca había estudiado un total de diez casos de afonía, según los cuales, situó claramente como centro del lenguaje articulado, la parte posterior del tercer giro frontal, y definió como características clínicas de la afonía, conocida hoy como afasia motora o afasia de Broca, la pérdida de la palabra sin parálisis de los músculos de la articulación y sin trastornos de la inteligencia.

Hizo también un análisis claro de la lateralización del lenguaje y del principio de la dominancia cerebral, la cual es considerada como determinada por factores biológicos y se basa en el análisis comparativo de la corteza cerebral de ambos hemisferios en el feto. Broca, además, expuso las razones de los pocos casos en que se produce la afemia como resultado de lesiones del hemisferio derecho. La región del cerebro señalada por Broca, lleva su nombre y la alteración se conoce como afasia de Broca.

\subsubsection{El asociacionismo}

En el año 1874, el neuropsiquiatra alemán Karl Wernicke publicó una monografía titulada El complejo sintomático de la afasia. A diferencia de los pacientes de Broca, los de Wernicke tenían muchas palabras, pero estas eran a menudo anormales e inadecuadamente utilizadas, la lesión no comprometía el lóbulo frontal sino el primer giro temporal.

Wernicke supuso la existencia de un área cerebral para la elaboración del lenguaje, mucho más amplia que la descrita por Broca, y comprendía la corteza alrededor de la fisura de Silvio, entre el tercer giro frontal y el primero temporal, incluida la corteza de la ínsula. En su funcionalidad, el tercer giro frontal es motor con representación de los movimientos del habla y la zona temporal es sensitiva con el centro de las imágenes sonoras de las palabras.

Según su interpretación, la afasia puede resultar por lesión de cualquiera de los centros o de sus conexiones y el cuadro clínico variará según la parte comprometida. La lesión en el área de Broca interfiere con 
los mecanismos motores, mientras que la del lóbulo temporal produce afasia sensitiva por compromiso del centro que almacena las imágenes sonoras de las palabras.

Entre las distintas conexiones de su esquema, Wernicke insistió en lo que une el centro de las imágenes sonoras de las palabras con el de las imágenes motoras de las mismas. Una lesión en esta vía produce como resultado un paciente que puede oír y comprender el significado de las palabras y que no tiene dificultad articulatoria, pero que no puede repetir lo que acaba de oír. A este cuadro clínico se le conoce como afasia de conducción.

Por lesión de otras asociaciones, explicaba Wernicke la existencia de fenómenos asociados a la afasia, como la agrafia y la alexia. En estos últimos casos, las lesiones interrumpirían la relación de los centros del lenguaje con los centros visuales. Luego Wernicke, con la misma concepción asociacionista, describió otras variedades de afasia: transcortical motora y transcortical sensitiva, en las cuales, los centros motor y sensitivo del lenguaje están indemnes, lo mismo que sus conexiones mutuas, en tanto que están lesionadas sus uniones con otra parte de la corteza. En estos tipos de afasia, la repetición es normal, pero, hay limitación en la expresión del lenguaje espontáneo o en la comprensión.

\subsubsection{El Holismo}

A las interpretaciones localizacionista y asociacionista que identifican áreas corticales o centros con funciones propias independientes asociadas por vías nerviosas definidas, se opuso la interpretación holística de las funciones del cerebro, según la cual, éste funciona como un todo integrado.

El inglés John Hughlings Jackson se cuenta entre los más destacados representantes de esta tendencia. Basó sus críticas en los aspectos psicológicos y dinámicos del lenguaje, iniciando un enfoque diferente en la problemática de la afasia. Consideraba el lenguaje, no como el funcionamiento de zonas restringidas del cerebro, sino de su totalidad, y a la afasia, como manifestación de un déficit intelectual resultante de la lesión cerebral. 
Basado en la disociación del lenguaje de los pacientes afásicos, en el lenguaje automático y el lenguaje voluntario, dedujo que en la afasia no había propiamente pérdida de la memoria de las palabras, sino la pérdida de un nivel de funcionamiento superior, intelectual y abstracto. Jackson consideró que lo esencial en la afasia no era la pérdida de la palabra sino la pérdida de la comprensión de lo que las palabras significan, o sea, de la facultad de proposicionalización: "hablar no es simplemente emitir palabras [...] Hablar es efectuar proposiciones" (Jackson, 1866, p.134).

Explicó, además, que este defecto no solo se presenta en el lenguaje hablado sino también en el lenguaje interior, sustentando así la naturaleza psicológica del problema, y el por qué el paciente no puede escribir, teniendo la escritura como una función ligada a la función primordial del lenguaje: la formulación de proposiciones.

\subsubsection{La teoría de los sistemas funcionales complejos}

Para el periodo moderno (1945-1975) se incrementaron los procesos de diagnóstico y rehabilitación en afásicos. Alexander R. Luria (1979) adoptó un punto de vista intermedio entre el localizacionismo y el antilocalizacionismo, señalando que los procesos psicológicos representan sistemas funcionales complejos, que requieren de muchos eslabones diferentes para su normal realización. Surge así, la teoría de los sistemas funcionales complejos, desarrollada en Rusia por Vigotsky y sus discípulos. En la escuela soviética se parte de una nueva representación de las funciones psicológicas y en especial del lenguaje, que se considera no sólo como un proceso psíquico más, sino como uno de los procesos psíquicos más complejos que mediatiza y reestructura al resto de los procesos psicológicos.

De acuerdo con estas teorías, las funciones mentales como sistemas funcionales complejos, no pueden localizarse en zonas restringidas del córtex en grupos celulares aislados, sino que están organizados en sistemas de zonas que trabajan concertadamente, cada una de las cuales ejerce su papel dentro del sistema funcional complejo, y pueden estar situadas a menudo muy distantes en el cerebro, según Luria (1979), quien, al respecto, lo explica así: 
No es el síntoma (que puede ser multívoco y producirse en focos distintos por su localización), lo que se debe hacer corresponder con una lesión del córtex cerebral, sino el factor que conlleva el surgimiento del síntoma. Este factor solo puede descubrirse en el caso de un exhaustivo análisis, o la cualificación del síndrome; es el eslabón necesario para utilizar la perturbación de las funciones psíquicas superiores en el diagnóstico topográfico (Christensen y Luria, 1979, p. 241).

El estudio de los trastornos de la sensación, los movimientos motores, el tono y los reflejos solo son los trastornos patológicos de una parte muy pequeña de la corteza y de las vías nerviosas, y se encuentran en las denominadas zonas primarias. En cambio, son inaccesibles, a los métodos neurológicos clásicos, las lesiones locales en las llamadas zonas cerebrales secundarias y terciarias, que abarcan en el hombre una gran parte de los hemisferios cerebrales y que serían las encargadas de los procesos gnósicos y práxicos del habla y del pensamiento.

Cuando el neurólogo tiene que hacer un diagnóstico para casos con lesiones en estas regiones cerebrales, se ve obligado a recurrir al análisis de los trastornos conductuales del sujeto, es decir, a métodos de investigación psicológica, suponiéndose con estos, el análisis de los trastornos gnósicos y práxicos del habla y del pensamiento.

Es difícil imaginar, desde lo teórico, que las neuronas que constituyen las zonas corticales estrictamente delimitadas puedan ser responsables de procesos tan complejos y desarrollados como la comprensión de objetos y acciones, el análisis y síntesis del lenguaje hablado, el uso activo del habla y las formas complejas del pensamiento, por tener estas neuronas un grado elevado de especificidad funcional al responder sólo a estímulos rigurosamente limitados (Fehlhaber, 2014). Por ello, se supone que los trastornos en la gnosis y la praxis, el habla, la lectura y escritura, e incluso los trastornos de la memoria y el pensamiento, podrían deberse a lesiones en áreas considerablemente más amplias de la corteza cerebral, lo que va mucho más allá de los límites de estos centros funcionales delimitados por la neurología clásica. Es preciso entonces, revisar la idea de función y la de localización de una función en áreas delimitadas del cerebro. 
Función es la capacidad de actuar propia de los seres vivos y de sus órganos [...] (RAE, 2017), es decir, la compleja actividad adaptativa del organismo, determinada por una tarea específica que termina en una operación también especifica. Esta actividad se produce por medio de un sistema funcional muy complejo, de procesos coordinados determinados por un plan biológico o psicológico progresivo (invariable).

La realización de la actividad se apoya en un amplio espectro de diversas operaciones y culmina en un efecto durable invariable. Si no se consigue la necesaria acción, entonces las señales de Feed Back reactivarán el sistema funcional, ya que estas señales alimentan los procesos dinámicos autorregulados en que se apoyan las operaciones de este tipo de sistema. Las funciones de la respiración y la locomoción sirven como ejemplos de estos sistemas funcionales. También se incluyen los procesos psicológicos complejos (gnosis, praxis, habla y pensamiento), que han sido elaborados a lo largo de la evolución sociohistórica, y que están basados en planes específicos que determinan el esquema para la continuación de la acción y se apoyan en el uso de modos de conducta complejos y variables.

Si puede localizarse una función, definida como función de un tejido especifico, en un área completa del sistema glandular, secretor o nervioso, obviamente no puede localizarse el sistema funcional en un área específica del tejido cerebral, pudiendo ser distribuido en un sistema completo de zonas de la corteza cerebral y de las estructuras subcorticales que cooperan en su acción. Cada una de las áreas contribuye muy específicamente a asegurar la acción del sistema funcional, por tanto, si una de las áreas sufre una lesión, ocasiona trastornos en el normal funcionamiento del sistema funcional del cual hace parte. Para realizar un diagnóstico local de la afección cerebral se debe cualificar el trastorno que se produce en una función concreta, es decir, analizar cuidadosamente el defecto desde un punto de vista psicológico o psicofisiológico.

Este análisis, así propuesto, es un objetivo básico de la nueva disciplina científica: la neuropsicología, que pretende analizar los trastornos de los procesos corticales superiores (habla impresiva y expresiva, lectura, escritura, aritmética, resolución de problemas y procesos mnemónicos), o los rasgos específicos de la actividad psíquica en cuestión (percepción o acción, habla, lectura o escritura, solución de problemas). Se deben 
describir selectivamente los componentes implicados en la actividad y analizar las condiciones neurodinámicas necesarias para llevar a cabo la acción. Esta disciplina se ha convertido en una importante ayuda para el diagnóstico de las lesiones cerebrales locales y la rehabilitación de las funciones complejas afectadas por dichas lesiones; se le puede considerar como un complemento de la neurología clásica.

La importancia de la neuropsicología no es solo práctica o clínica, tiene también gran interés para el avance de la teoría científica sobre la auténtica estructura de los procesos psíquicos o, lo que es lo mismo, para la fundamentación de una psicología científica. Hasta hace muy poco, la psicología solo ha tenido ideas muy generales sobre el desarrollo de procesos tales como: comprensión, memoria, habla, lectura y escritura, y resolución de problemas sobre los componentes intrínsecos de dichos procesos.

Con el desarrollo científico y tecnológico de las últimas décadas se ha observado un renacimiento simultáneo del interés por estudiar la relación entre las funciones mentales superiores y la organización cerebral. La aparición de mejores métodos de diagnóstico (la tomografía computarizada, la resonancia nuclear magnética, los estudios de flujo sanguíneo y otras) ha facilitado las posibilidades de establecer correlaciones más precisas entre las alteraciones de las funciones mentales y del comportamiento, con lesiones cerebrales localizadas, fundamento en el que se basan la mayoría de los estudios clínicos neuropsicológicos.

Una de las funciones mentales superiores más estudiadas en la neuropsicología es el lenguaje. El esfuerzo conjunto de lingüistas, psicólogos, biólogos y neurólogos ha permitido un gran avance en el conocimiento de las bases cerebrales de las funciones del lenguaje en el ser humano. La neurología, a través del estudio de las alteraciones del lenguaje en pacientes con lesiones cerebrales ha aportado a la lingüística buenas posibilidades para el estudio del lenguaje, hasta el punto de dar origen a una nueva disciplina, la neurolingüística.

En lo que concierne al interés de Luria por la neurolingüística, LuisBarraquer Borda en su prólogo a la edición española de "fundamentos de neurolingüística" (Luria, 1980, p.14) dice: 
Conceptualmente, la primera tarea a imponerse es plantearse las relaciones que tiene el disturbio que el enfermo presenta, con la función o capacidad normal. En este caso, por tanto, las relaciones entre la estructura del habla afásica completa de tal o cual enfermo y la estructura del habla normal. Esta es, evidentemente, una tarea neurolingüística, que requiere un previo conocimiento, siquiera sea esquemático, de la lingüística.

\subsubsection{El neoasociacionismo}

Norman Geschwind y la escuela de Boston (1966) han replanteado el aporte de Wernicke en relación con la idea de conexión entre los centros auditivos y expresivos en un enfoque neoasociacionista. Dentro del concepto de síndrome de desconexión, Geschwind intenta definir la identidad funcional de zonas de la corteza que normalmente están unidas por fascículos nerviosos definidos, mediante el análisis comportamental luego de la destrucción de estas uniones, que normalmente hacen parte de la substancia blanca del hemisferio. En su trabajo "disconnection síndromes in animals and man" Geschwind (1966) analizó con esta premisa la variada sintomatología del síndrome de Kluver y Bucy en los animales, y revivió los esquemas asociacionistas de Wernicke, de Dejerine y Lipman, enfatizando su validez anatomo-clínica, por lo cual su posición ha sido calificada como neoasociacionista, y se ha visto ampliamente reforzado por las relaciones de los trabajos de Sperry y Gazzaniga (1967).

Dentro de la línea asociacionista, Geschwind (1974) considera como el más significativo aporte de Wernicke su idea de conexión entre el área de Wernicke y el área de Broca. Aunque solo fue postulado teóricamente por Wernicke, la realidad anatómica de esta asociación ha sido asimilada a las fibras externas del fascículo longitudinal superior con el nombre de fascículo arqueado, y su destrucción sería determinante de la llamada afasia de conducción.

La escuela de Boston se constituye como un grupo de estudios interdisciplinarios y cuenta con neuropsicólogos como Benson, Ardila, Albert, Brown y Kertesz, psicólogos como Goodglass y Kaplan, lingüistas como Whitaker, y terapistas del lenguaje como Hilland y Walsser. Ahora bien, según el neurólogo J. Bustamante (1997, p.87): 
El estudio neurofisiológico de zonas restringidas de la corteza cerebral, ha rendido pocos frutos hasta el presente, desde el punto de vista del análisis del comportamiento. Considera que más fructífero ha sido el método anatomo-clínico que describe los cambios de conducta luego de una lesión definida en el cerebro, o el método experimental, basado en la estimulación y/o en la ablación de determinada estructura"

Se considera con Luis Barraquer Borda y Gainotti que la afasiología actual conoce varias líneas de cultivo, subrayando la primacía de la línea neurolingüística porque fusiona lo lingüístico y lo neurológico. Así pues, la afasiología se convierte en un lugar de convergencia porque permite análisis desde diferentes ópticas. La escuela de Boston, por ejemplo, destaca fuera del Neoasociacionismo de Geschwind, el Descriptivismo o Empirismo de Benson, el Evolucionismo de Brown y la Anatomoclínica de Kerstez, entre otras.

Sin embargo, el aporte de Luria a la neuropsicología y a la neurolingüística sigue en primer plano, y es necesario acercarnos a él para poder dar cuenta de los mecanismos neurológicos y los procesos psicológicos del lenguaje. Ha sido Luria, el neuropsicólogo que más ha insistido en el acercamiento de la afasiología a la lingüística. Con el lingüista Roman Jakobson, Luria propuso una tipología lingüística de afasias popularizada por Pribram, que relaciona la codificación y la decodificación del lenguaje con las áreas posterior-anterior de la corteza cerebral.

Barraquer Borda recuerda que la neurolingüística fue inaugurada en 1939 en la Salpetriere, cuando Alajouanine llevó a cabo el estudio del síndrome de desconexión fonética con la lingüista Durand y el psicólogo Ombredanne (1976). Todavía para el siglo XXI desde esta disciplina se trata de hacer una correlación entre las áreas cerebrales y la función lingüística tal como lo muestran Ardila, Bernal y Rosselli (2016, p.97) en el siguiente apartado:

Se encontró que existen dos sistemas lingüísticos diferentes en el cerebro: un sistema léxico/semántico, relacionado con el área de Wernicke, y que incluye un área de Wernicke central (reconocimiento de palabras) y un área de Wernicke extendida (asociaciones lingüísticas); y un sistema gramatical, dependiente 
del complejo de Broca (producción del lenguaje y gramática), en el lóbulo frontal, y que se extiende subcorticalmente. Se propone también que la ínsula desempeña un papel de coordinación de estos dos sistemas lingüísticos cerebrales.

En este orden de ideas, se entiende que neurólogos y psicólogos se acercan cada día más al rigor de la metodología de la lingüística, sin la cual no podrían conocer la estructura, el funcionamiento y las funciones del lenguaje, su naturaleza, adquisición, desarrollo y desintegración.

\subsection{Modelos}

\subsubsection{Modelos lingüísticos}

Los lingüistas, en general, dan cuenta de las regularidades y reglas que forman estructuras en las cuales se fundamenta la actuación lingüística. Los aspectos estructurales se basan en rasgos distintivos de los niveles de la lengua: fonológico, semántico y sintáctico.

Roman Jackobson fue el primer lingüista que se ocupó del estudio de las alteraciones del lenguaje ocasionadas por lesiones cerebrales y de trazar fundamentos teóricos para su interpretación desde el punto de vista lingüístico; influido por el modelo sindrómico-sistemático de Luria, planteó su hipótesis básica en una serie de trabajos publicados de 1955 a 1966 de acuerdo con los cuales todas las formas de alteración del lenguaje, por lesiones cerebrales focalizadas, pueden dividirse en dos grandes clases: alteraciones de la organización sintagmática del lenguaje y alteración de la organización paradigmática del lenguaje.

En otros términos, tres tipos de afasia (eferente, dinámica y aferente) se caracterizan por trastorno de la contigüidad con deterioro del contexto. Otros tres tipos (sensorial, semántico y amnésico) revelan trastornos de la semejanza con desarreglo del código. Considerados en términos de comportamiento verbal, esos dos mismos grupos se oponen entre sí, como perturbaciones de la codificación y perturbaciones de la decodificación. Entonces, una manera de analizar las relaciones entre estructura y funcionamiento es precisada por lo que Jackobson (1967) llamó "el doble carácter del lenguaje". Hablar, dice, supone seleccionar determinadas unidades lingüísticas y combinarlas en un nivel de complejidad mayor. Todo signo lingüístico se dispone de acuerdo a 
estas dos operaciones: la combinación de relaciones sintagmáticas y la selección de relaciones paradigmáticas y serán los dos modos posibles de generar todo discurso.

Luria (1980), en una de sus obras maduras del final de su vida, considera que el paso decisivo de la lingüística contemporánea: la gramática generativa transformacional (GGT) de Noam Chomsky, fue descubrir nuevos caminos, antes imperceptibles, hacia el análisis científico de las etapas del paso del pensamiento al habla exterior. La teoría de Chomsky (1976), aludida por Luria, es la estándar, cuyo principio básico dice que las estructuras profundas de la competencia lingüística se transforman en las estructuras superficiales de la actuación. Esta teoría relaciona los niveles de la lengua en tanto que los componentes fonológico y semántico son interpretativos de la información sintáctica, de tal manera que podría, no solo referirse a estructuras de la lengua, sino también a su funcionamiento; pero, Chomsky insiste en que las gramáticas como teorías de la lengua son hipótesis sobre la estructura lingüística y no sobre los procesos lingüísticos. Una gramática caracteriza en forma abstracta e idealizada el conocimiento intuitivo que posibilita la actuación lingüística, pero no los mecanismos en los que se realiza.

Barraquer Borda, al referirse a esta "compenetración neurolingüística", señala las dificultades del recurso a la gramática chomskyiana, ya que este creador insiste en el carácter autocritico y falseable de sus continuas hipótesis. El modelo de la teoría estándar ha sido refinado por la teoría de la reacción y el ligamiento y es considerado de increíble complejidad tecnológica. Promete derivar propiedades complejas de las lenguas naturales concretas a partir de los parámetros de la teoría lingüística general o gramática universal, haciendo hincapié en el sistema de principios de las reglas.

\subsubsection{Modelos neuropsicolingüísticos de organización y desintegración del lenguaje.}

Ni la lingüística, ni la psicología, ni la neurología disponen de métodos propios que permitan distinguir, independientemente, los componentes (y sus relaciones), de la producción, comprensión, almacenamiento, reproducción y desintegración del lenguaje. En conjunto, a la neuropsicolingüística le han interesado esos procesos y mecanismos implicados en el uso del lenguaje. Los test psicológicos, 
en general, evalúan procesos intrapsíquicos, inconscientes, que hablan de la dinámica de la personalidad. La evaluación neuropsicológica en cambio, trata de calificar el defecto y destacar los factores que le sirven de base. La neuropsicología cognitiva a partir de cuatro supuestos, según Valle Arroyo (1992), pretende solucionar los problemas residuales de la neuropsicología clásica. Se centra en el método de "caso único" para la observación de la disociación funcional intrasubjetiva. Considera dos niveles de actividad mental: el neurofuncional y el cognitivo en una relación de correspondencia compleja, en la cual los componentes de la red neuronal trabajan al servicio de los diferentes componentes de la función cognitiva.

A partir de Luria (1980), sabemos que el cerebro humano representa un sistema funcional complejo que trabaja con la participación permanente de tres bloques fundamentales, por lo menos. El primero asegura la vigilia de la corteza y posibilita la realización en el tiempo de formas selectivas de actividad, el segundo se ocupa de la recepción, elaboración y almacenamiento de la información y el tercero cuida de la programación, regulación y control de la actividad que se realiza. Según Luria, cada acto de conducta (una acción orientada hacia un objetivo, un proceso de percepción, de acuerdo o de pensamiento) se fundamenta en el trabajo conjunto de estos tres bloques funcionales y cada uno apropia y hace su contribución al proceso necesario. Estos hechos se evidencian en los análisis sistemáticos de los cambios psíquicos producidos por lesiones cerebrales. Este autor considera que la afectación de uno de estos sistemas cerebrales altera la actividad consciente de una forma específica, resultando alteraciones especifico modales de la elaboración de la información y se distinguen unas de otras (1980).

Utilizando el método neuropsicológico en el análisis de los procesos psíquicos, Luria y sus colaboradores lograron acercarse a los procesos psicolingüísticos, relacionando sus etapas con sistemas cerebrales, precisando cómo cambia la estructura de la actividad verbal en pacientes con lesiones cerebrales locales. En el caso del proceso de comprensión: el paso de la palabra al pensamiento o decodificación, se dan las siguientes etapas (De Vega y Cuetos, 1999, p. 26):

-Análisis de los estímulos físicos que llegan a los sistemas sensoriales e identificación de las unidades lingüísticas básicas (fonemas o grafemas). 
-Reconocimiento de palabras consultando el almacén de memoria en el que se encuentran las representaciones (léxico mental).

-Reconocimiento de la relación de las palabras entre sí.

-Extracción del mensaje de la oración eintegración con los conocimientos previos.

Las alteraciones de la comprensión verbal son múltiples y se deben a múltiples localizaciones de lesiones: en la afasia sensorial, de Wernicke, o acústico agnósica, existen compromisos del lóbulo temporal en la afasia semántica lesiones parieto-occipitales, se hace necesario puntualizar, además, alteraciones en pacientes con lesiones frontales masivas. Existen sospechas de alteraciones de este aparato paradigmático en la afasia motora eferente. En el caso de la producción, expresión verbal o codificación, el paso del pensamiento al habla exterior comporta varios eslabones. Es una producción donde intervienen procesos análogos a los de la comprensión, pero que operan en orden inverso (De Vega y Cuetos, 1999, p.27), donde el hablante:

- Tiene una intención comunicativa.

- Planifica el mensaje que pretende transmitir activando algunos de sus conocimientos.

- Selecciona la estructura sintáctica más adecuada para expresar el mensaje.

- Selecciona en su léxico mental las palabras que mejor encajan en la estructura.

- Ejecuta los programas motores destinados a producir los fonemas.

Las alteraciones de este aparato sintagmático, como dice Luria, serian producidas, neurolingüísticamente hablando, por lesiones en el lóbulo frontal, zona de Broca, en correlación con el test de Boston. Si la lesión se localiza en las áreas anteriores del lóbulo frontal, produciría la afasia dinámica motora transcortical, según el test de Boston, que se caracteriza fundamentalmente por la falta de iniciativa en el proceso comunicativo, fase de habla interna.

Pasando al proceso de almacenamiento, se entiende por memoria, según Ardila (1985), la conservación de la información, que es guardar 
y tener la información disponible una vez que la señal, o su acción han desaparecido. Este neuropsicólogo colombiano, discípulo de Luria, actual colaborador de la Escuela de Boston, distingue tres etapas de la memoria: una fase de retención o registro, en la cual el sujeto recibe la información, una fase de almacenamiento o de conservación de la información, y una última fase de evocación o de recuperación de las huellas de la memoria.

Este autor señala cómo las teorías activas del olvido insisten en que este es un problema de evocación y las teorías pasivas del olvido insisten en que hay desgaste de las huellas de la memoria, o sea, del almacenamiento, de la conservación de la huella de la memoria, como consecuencia del paso del tiempo. En relación con las afasias amnésicas, menciona la afasia acústica amnésica, que sería un tipo de afasia específica, un problema de almacenamiento: se olvidan las palabras, se olvida la estructura fonológica de las palabras y la secuencia de los sonidos que constituyen una palabra. Mientras que en la otra forma de afasia amnésica, en la anómica, el problema no es que la huella de memoria se haya perdido, sino que no es posible recuperarla, es un problema de evocación, porque la huella se hace inaccesible. Si se le presenta al paciente la figura de un objeto, este no es capaz de pronunciar la palabra correspondiente, no porque la palabra esté borrada, sino porque es imposible lograr el acceso a ella. La afasia nominal o anómica tiene una localización cerebral temporo-parieto-occipital, y la afasia acústico-amnésica se localiza generalmente en las áreas temporales medias.

Ya en los procesos reproductivos del lenguaje, la psicolingüística se ha encargado de investigar los elementos y las relaciones, los principios estructurales y las descripciones de sucesos cognitivos en los procesos del lenguaje. El otro acceso, también en caso de trastorno del lenguaje de origen central, es el de la neurolingüística, que, como quedó dicho, se interesa en los mecanismos de las funciones del lenguaje distorsionadas o intactas. Este ha sido el trabajo, entre otros, de la sociedad de psicología de la República Democrática Alemana (RDA).

Como recuerda Irina Weigl (1986), los procesos de las funciones de repetición, lectura en voz alta y escritura al dictado, contienen determinados componentes de la percepción y la producción del lenguaje y se fundamentan en procesos de transcodificación. Esquemáticamente, 
Weigl representa estos acontecimientos de transcodificación, como lo muestra la Tabla 1.

Tabla 1. Esquema sobre la reproducción del lenguaje (Weigl 1986)

\begin{tabular}{|l|l|l|l|}
\hline & \multicolumn{1}{|c|}{ Repetición } & $\begin{array}{c}\text { Lectura en voz } \\
\text { alta }\end{array}$ & \multicolumn{1}{|c|}{$\begin{array}{c}\text { Escritura al } \\
\text { dictado }\end{array}$} \\
\hline Input & $\begin{array}{l}\text { Auditivo-verbal } \\
\text { (Fonética) }\end{array}$ & $\begin{array}{l}\text { Visual-verbal } \\
\text { (Grafémica) }\end{array}$ & $\begin{array}{l}\text { Audio-verbal } \\
\text { (Fonética) }\end{array}$ \\
\hline \multirow{2}{*}{ Output } & $\begin{array}{l}\text { Verbo-motora } \\
\text { Articulación }\end{array}$ & $\begin{array}{l}\text { Verbo-motora } \\
\text { Articul a ci ón n } \\
\text { Fonética }\end{array}$ & Grafo-motora \\
\hline
\end{tabular}

Fuente: Weigl (1986, citado en Rojas (1999). Tratado sobre el lenguaje: lingüística, psicolingüística, neuropsicolingüistica, afasiología. Medellín:

\subsection{Tipología}

\section{Pragma Editores)}

Desde los tiempos de Wernicke, los investigadores clínicos han mostrado una tendencia notoria a separar variedades de afasia con base en las características del lenguaje. El resultado ha sido caótico. Frecuentemente se considera que los síntomas afásicos representan un grupo invariable de hallazgos lingüísticos que deben necesariamente aparecer en un orden específico. Un síndrome exacto es tan infrecuente en la afasia como en cualquier otro desorden neuropsicológico o neurológico, y muchos investigadores han interpretado esta variabilidad negativamente, considerando que los síndromes afásicos tienen poca validez.

Diferentes variedades de afasia han sido propuestas a la literatura, convirtiéndose (la afasia) en uno de los síndromes más sobreclasificados. Más aun, un mismo nombre ha llegado a ser utilizado en dos clasificaciones distintas para referirse a síndromes clínicos radicalmente diferentes. Los antilocalizacionistas, siguiendo la tradición de Marie, han intentado estudiar las afasias sin diferenciar grupos de síntomas, 
para hallar que aun así se requiere alguna sistematización. Se necesita un análisis cuidadoso de las clasificaciones de los síndromes afásicos para entender a cabalidad sus características clínicas. Una forma de sintetizar el problema ha sido la utilización de dicotomías sencillas. La mayoría de los investigadores contemporáneos utilizan una o varias de estas dicotomías: la más frecuente quizás es expresivo-receptivo utilizada por Weisengurg and Mc Bride (1935).

Otra dicotomía, ampliamente utilizada, es la división entre desórdenes de tipo motor y sensorial, propuesta inicialmente por Wernicke. Las regiones posteriores de la corteza realizan actividades sensoriales y las regiones anteriores desempeñan un papel motor, lo cual hace que la dicotomía relacione el lenguaje con una localización anatómico-básica. Esta última dicotomía desconoce muchas características propias de diferentes tipos de afasias. Sin embargo, al respecto de la diferencia entre las dos afasias provenientes de estos desórdenes (Broca y Wernicke, respectivamente), Pardo y Antúnez (2013, pp. 423-427) aseguran que:

A la par, evidencias de disrupción en la representación semántica en presencia de lesión cerebral posterior, que afectaba la comprensión y la producción del lenguaje demostró que las dificultades en la percepción de la información fonológica no era la causa real de los déficits de la comprensión. A partir de tales evidencias, la distinción entre la afasia de Broca y la afasia de Wernicke se concibió más como daño sintáctico versus daño semántico, que como daño motor versus daño sensorial, que era como se manejaba hasta el momento.

Lo mismo podría decirse de dos dicotomías frecuentemente utilizadas en décadas anteriores: la dicotomía fluente y no fluente de Benson (1967), y anterior y posterior de Goodglass y Kaplan (1972). Por su lado, Jackobson (1964) propone una dicotomía puramente lingüística entre desórdenes paradigmáticos y sintagmáticos del lenguaje, posteriormente incorporada con Luria (1980). En conjunto, se encuentran más de veinte clasificaciones diferentes de las afasias. A continuación, se presentan las principales categorizaciones propuestas. Sin embargo, es importante tener en cuenta que algunas de estas han jugado un papel sobresaliente en la práctica clínica y en la investigación, y que las confusiones parten básicamente de la denominación y la separación de los grupos de afasias, más que de los perfiles clínicos de los desórdenes en sí del lenguaje. 
Cualquier afasiólogo aceptaría que el daño en la tercera circunvolución frontal izquierda y las áreas adyacentes, se asocia con un desorden caracterizado por un lenguaje agramático, no fluente, no importa que se denomine afasia de Broca, afasia motriz eferente $o$ afasia expresiva.

Durante los últimos años se ha logrado un avance considerable en las correlaciones clínico-anatómicas de las afasias, gracias especialmente, a la introducción de la escanografía cerebral, resultando de ello una tendencia a distinguir subtipos en los distintos síndromes afásicos. Las clasificaciones que se traen obedecen a estudios de la corteza cerebral, y correlaciones entre la ubicación de las lesiones en determinadas áreas y las consecuencias que traían estas lesiones a nivel de comunicación; sin embargo, Barraquer y Peña (1983) aseguran que:

La introducción y difusión de técnicas imagenológicas a partir de la segunda mitad de la década del 70 e inicios de los 80 , implicó una revolución en las neuro-ciencias, que propició el descubrimiento de hallazgos sorprendentes en relación a las afasias que desafiaron el modelo tradicional. Tales hallazgos demostraron la pobre comprensión gramatical en la afasia de Broca [...]. Ello condujo a una redefinición del síndrome como reflejo de una disrupción sintáctica, que sería la causa de base del déficit de comprensión y de la expresión agramatical.

La clasificación de Luria parte del análisis del nivel del lenguaje alterado en una forma particular de afasia, mientras que la del grupo de Boston utiliza y desarrolla las ideas de Wernicke, y sus dos distinciones entre afasias fluentes y no fluentes, por una parte, y afasias corticales, transcorticales y subcorticales, por otra. Por ejemplo, la afasia de conducción, llamada por Luria Motora aferente, se caracteriza por tener una repetición pobre con presencia de parafasias literales, en medio de un lenguaje espontáneo fluente y una buena comprensión; Ardila (1992), por su parte, retomando a Benson, considera que cuando hay una alteración fundamental de la repetición como incapacidad del sujeto para reproducir los articulemas del habla, se trata de una apraxia quinestésica verbal.

Otro autor, inquieto por estudiar el cerebro, insiste en considerar al cerebro como "un sistema cerrado modulado por los sentidos. Según 
la neurobiología y la neurociencia, las semejanzas fenotípicas básicas intra o interespecies se relacionan con funciones neuronales semejantes.

Así, estas disciplinas suponen que el control de la estructura cerebral está determinado genéticamente. La cognición no solo es un estado funcional sino una propiedad intrínseca del cerebro y un " $a$ priori neurológico" (Llinás, 2003). En vista de que los propósitos de este trabajo son diseñar un instrumento para diagnosticar las afasias y caracterizarlas, lo cual incluye su clasificación, en los siguientes apartados se hace referencia a dos clasificaciones (Grupo de Boston y Luria), así: al comienzo se mencionan autores y generalidades concebidas respectivamente en cada una de ellas, y hacia la segunda parte, se enumeran las características de las afasias contenidas en cada clasificación.

\subsubsection{Afasias según el grupo de Boston}

Albert (1981), Benson (1979), Benson y Geschwind (19711985), Geschwind (1967), Goodglass y Kaplan (1972) distinguen tres tipos básicos de afasias corticales: De Broca, de Wernicke y de Conducción, como lo ratifica Ardila (2005, p.38). Los tipos de Broca y de Wernicke presentan formas motriz y sensorial de afasia cortical, respectivamente, desde hace varias décadas, el síndrome lleva el nombre de quien inicialmente lo describió.

El tipo de Conducción, en principio propuesto por Wernicke (1874) y descrito por Lichtheim (1885), explica las dificultades en el lenguaje repetitivo, basándose en una supuesta desconexión entre las áreas motrices y sensoriales del lenguaje. Además, se incluyen las afasias transcorticales, siendo este el tipo de afasias de las áreas limítrofes del lenguaje. La afasia transcortical consistiría en la interrupción del proceso de transferencia del material auditivo verbal al centro de los conceptos. Lichtheim (1885) insiste en que los conceptos no se localizan en ninguna área circunscrita, sino que son elaborados por un mecanismo cortical multisensorial. Las afasias transcorticales pueden ser sensoriales (trastorno de la comprensión con expresión verbal fluida), motoras (alteración de la expresión verbal con buena comprensión) o mixtas. El dato descollante de las afasias transcorticales es una repetición conservada (Vendrell, 2007). 
En los siguientes apartados se hará referencia a cada una de las afasias señaladas por el grupo de Boston (Figura 5), con el ánimo de caracterizarlas, respectivamente.

Figura 5. Afasias según el grupo de Boston

2. Conducción

3. Broca

4. Global

5. Transcortical motora

6. Transcortical sensorial

7. Transcortical mixta

8. Anómica

Fuente: Adaptación realizada por Luz Marina Henao a partir de: https://pixabay.com/es/vectors/cerebro-mente-pensamiento-a-me-

$$
\text { ai-2789698/ }
$$

\section{La afasia de Broca}

Se caracteriza por un lenguaje expresivo no fluido, pobremente articulado (Ardila, 2005, p.93), compuesto por expresiones cortas y agramaticales, y producido con gran esfuerzo. Está compuesto básicamente de sustantivos, con una marcada deficiencia o ausencia de estructura sintáctica y afijos (agramatismo). El nivel de comprensión del lenguaje es siempre superior a la producción verbal, aunque nunca normal, especialmente con relación a la comprensión gramatical. Respecto a la identificación de objetos y partes del cuerpo, no hay dificultad severa, pero si se les pide que señalen múltiples objetos o partes del cuerpo en un orden determinado, solo logran realizarlo 
hasta un nivel de unas dos o tres palabras. La repetición es inadecuada, con presencia de desviaciones fonéticas y parafasias literales. A pesar de esta dificultad, el lenguaje repetitivo puede ser superior al lenguaje espontáneo. La producción de series automáticas (contar, decir los días de la semana, entre otros) es superior al lenguaje espontáneo. El canto también frecuentemente mejora en la producción verbal.

Señalar y denominar, siempre son deficientes; sin embargo, señalar resulta superior a nombrar. Durante la denominación es usual encontrar dificultades articulatorias, desviaciones fonéticas que pueden aparecer como parafasias literales, omisiones o simplificaciones fonológicas. La presentación de claves fonológicas puede ayudar a la iniciación de la articulación. Para la lectura en voz alta, hay grandes dificultades. La escritura resulta seriamente alterada: se realiza con letras grandes pobremente formadas, con errores en el deletreo y omisiones de letras. Se encuentra afectada, tanto la escritura espontánea, como el dictado y la copia.

\section{La afasia de Wernicke}

El lenguaje expresivo tiene una fluidez normal, y aun puede existir un número excesivo de palabras por minuto. Puede observarse un incremento en su lenguaje, por adición de silabas a las palabras y de palabras a las frases (Ardila, 2005, p.106). La prosodia y la articulación son adecuadas. La producción puede ser tan excesiva (verborrea), que el paciente continúa hablando a menos que sea interrumpido por el examinador. La estructura gramatical usualmente es aceptable, aunque puede existir un número excesivo de elementos gramaticales (pragmatismo). Hay ausencia de palabras significativas, de tal manera que, a pesar de la gran cantidad de palabras producidas, no es posible reconocer las ideas que el paciente trata de expresar (habla vacía). Hay presencia de parafasias literales y verbales, y los neologismos son frecuentes. Un discurso donde converjan estas parafasias es denominado jergafasia, sin embargo, en este predominará lo verbal, lo literal o lo neologístico.

La comprensión del lenguaje oral es defectuosa, está limitada a comprender palabras simples o frases sencillas; si se incrementa su número, cesa su comprensión. Algunos pacientes muestran fallas en 
la discriminación de fonemas (percepción fonémica), en particular de fonemas acústicamente cercanos. La mayoría de los pacientes logran ejecutar órdenes que se refieren a movimientos corporales. La repetición está invariablemente alterada en forma correlativa a su defecto en la comprensión. Pueden fracasar completamente al denominar objetos, partes del cuerpo, etc., presentados visualmente. La lectura se encuentra alterada. La escritura es también anormal: las letras están combinadas en una forma no significativa, las palabras correctas son escasas, predominan las paragrafias literales, verbales y los neologismos.

\section{La afasia de conducción}

La caracteriza un lenguaje espontáneo, relativamente fluente, buena comprensión, pobre repetición con presencia de parafasias literales (Ardila, 2005, p.98). Frecuentemente incluye también: defectos en la denominación, alteraciones en la lectura, alteraciones en la escritura, apraxia ideomotora y anormalidades neurológicas. El lenguaje espontáneo puede fluctuar, en ocasiones es fluido y en otras ocasiones es no fluido, parafásico y difícil en su producción. Una o varias frases pueden ser producidas sin mayor dificultad, pero al llegar a una palabra particular, el paciente es incapaz de continuar.

Las parafasias se observan más frecuentemente durante la repetición, particularmente durante la repetición de logotomas, palabras de composición fonológica compleja y palabras de baja frecuencia. El lenguaje conversacional es fluido, pero la cantidad de lenguaje producido es menor que en la afasia de Wernicke. El paciente con esta afasia, no solo produce menos lenguaje, también hay más pausas, vacilaciones, aproximaciones y autocorrecciones en la producción de palabras. Su producción es interrumpida y disprosódica. El lenguaje seriado es adecuado si al paciente se le ayuda en su iniciación, la producción de palabras es mejor durante el canto que en el lenguaje conversacional.

En algunos casos su comprensión se dificulta cuando se trata de comprender estructuras gramaticales complejas o expresiones que contienen múltiples frases. Durante la denominación aparecen abundantes parafasias literales. La lectura en voz alta se caracteriza por interrupciones constantes con gran cantidad de paralexias literales. La lectura silenciosa es superior, en ocasiones prácticamente normal. La escritura esta siempre alterada. 


\section{La afasia global}

Es la forma más grave de afasia, debido a que todos o gran parte de los diferentes aspectos del lenguaje se encuentran afectados y alterados. La capacidad de articulación, la fluencia verbal y el uso del léxico y la gramática se ven severamente disminuidas y perjudicadas.Se caracteriza por las severas dificultades tanto en la comprensión como en la expresión oral y escrita; también en la capacidad de imitación. En la emisión de lenguaje oral es frecuente el empleo de área telegráfica y estereotipada, siendo pocas sus posibilidades de establecer comunicación por vía del lenguaje verbal, se presenta la comprensión de ciertas palabras o verbos.

La lectura y la escritura se ven muy afectadas. Quienes la sufren, tienden a ser incapaces de escribir o bien limitarse a un automatismo como la capacidad de firmar; es posible que puedan reproducir un texto copiándolo, aunque guiándose por las formas y no por su contenido. Debido a que la lesión que provoca la afasia global es masiva, suelen aparecer otros síntomas como apraxia ideomotora (no saben emplear los objetos para su auténtico propósito) e ideatoria (presentan incapacidad para seguir secuencias de acción en el orden correcto), hemiplejia o parálisis de medio cuerpo.

\section{La afasia transcortical motora}

Se caracteriza por un lenguaje no fluente, buena comprensión, y repetición normal o casi normal. La prosodia, la articulación y la gramática se encuentran preservadas. Sin embargo, el paciente presenta latencias largas en la iniciación verbal, expresiones poco elaboradas y en ocasiones parafasias verbales. Las respuestas a las preguntas del tipo sí o no son normales, pero las respuestas a preguntas abiertas son lentas, incompletas y con tendencia a la repetición de los mismos elementos utilizados por el examinador en la pregunta. Durante la fase aguda puede presentar mutismo y durante los primeros estados de la recuperación puede haber ecolalia y perseveración.

\section{Afasia transcortical sensorial}

El lenguaje conversacional es fluente, contaminado por una cantidad notoria de parafasias (sustituciones neologísticas y semánticas), y 
con características de habla vacía. Existe una excelente repetición y frecuentemente ecolalia. Hay alguna tendencia a la logorrea, el lenguaje seriado, una vez iniciado por el examinador es notoriamente bueno.

El nivel de comprensión es deficitario, en ocasiones es prácticamente nulo. Tareas tales como denominar, señalar, seguir órdenes verbales y responder preguntas del tipo sí o no, pueden ser imposibles para estos pacientes. El volumen de memoria puede en ocasiones hallarse discretamente limitado, y esto dificulta la repetición de secuencias verbales. La fonología se encuentra conservada y la semántica está severamente alterada. La lectura en voz alta puede estar conservada, pero la comprensión está seriamente alterada y la escritura está también alterada.

\section{La afasia transcortical mixta}

El paciente no presenta lenguaje espontáneo, su expresión está prácticamente reducida a la repetición de lo que el examinador dice (ecolalia). La articulación es sorprendentemente clara, la producción de series es buena una vez iniciada la tarea, su nivel de comprensión se encuentra severamente alterado. La denominación es imposible, aunque se pueden observar neologismos y parafasias semánticas. Igualmente, se observa una incapacidad prácticamente total para leer y escribir. Como cuadro afásico, solo se diferencia de una afasia global en su conservación del lenguaje repetitivo.

\section{La afasia anómica}

El rasgo principal es la dificultad para encontrar palabras, sobre todo sustantivos, en contextos de habla fluida y gramaticalmente correcta, con una ligera parafasia detectable en los circunloquios, y una comprensión prácticamente intacta.

\subsubsection{Tipología de las afasias según Luria}

Alexander R. Luria presenta una clasificación sindrómico-sistémica (Fajardo y Moya, 1999, pp. 81-82) como lo muestra la Figura 6. 


\section{La afasia motora eferente}

Aparece una inercia patológica en el sistema motor (al que Luria denomina analizador motriz), el paciente tiene dificultades para iniciar los movimientos del habla, así como para iniciar un paso rápido de una articulación a otra: necesita efectuar movimientos aislados y distintos para cada sonido particular, quedando la corriente del habla drásticamente entrecortada. A nivel gramatical, se observa una idéntica dificultad en lo que respecta a la desintegración del esquema dinámico expresivo en su conjunto. La comprensión está relativamente conservada, en tareas de denominación se observa anomia o aumento en el tiempo de respuesta, y la lectura y la escritura están muy limitadas.

Figura 6 . Afasias según Luria

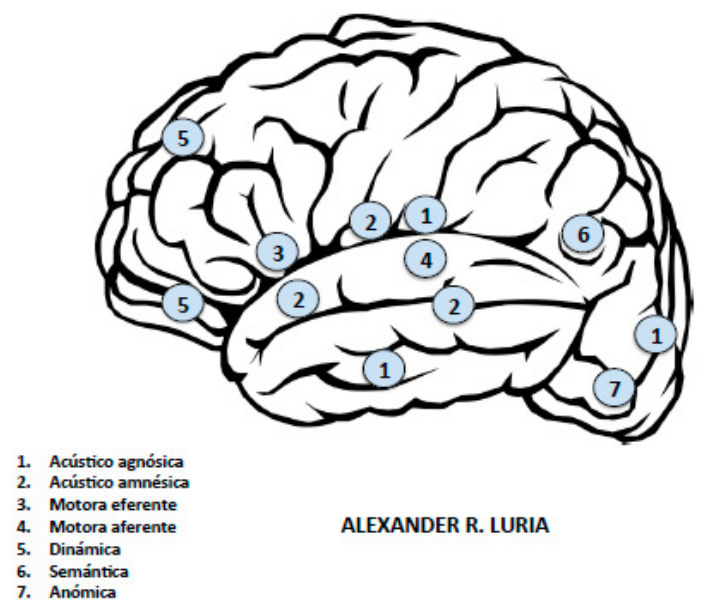

Fuente: Adaptación realizada por Luz Marina Henao a partir de: https://pixabay.com/es/vectors/cerebro-mente-pensamiento-a-meai-2789698/.

\section{La afasia motora aferente}

No existen dificultades primarias al iniciar el discurso, ya que el trastorno aparece en la retroalimentación cinestésica de las pautas motrices del habla. La retroalimentación se hace difusa y pierde 
especificidad, de modo que existen dificultades para que los órganos articulatorios adopten sus posiciones correctas. El signo más evidente puede ser la aparición de sustituciones de articulemas aislados, por ejemplo, dentro de la serie $b / \mathrm{p} / \mathrm{m} /$, sonidos que tienen en común el requerir el movimiento de los labios, pero que necesitan además una diferenciación específica (en términos de sonoridad, continuidad y nasalidad) que los distinga claramente. Dado que la lectura, la escritura y la audición dependen, en lo que respecta a la comprensión, del lenguaje interior, aparecen igualmente efectos secundarios en dichas modalidades.

\section{La afasia dinámica}

Al igual que la afasia eferente, manifiesta un trastorno en los procesos dinámicos de excitación nerviosa. De hecho, puede aparecer como un estadio en la recuperación de la afasia eferente, o bien como una forma independiente producida por lesiones en la parte anterior del cerebro. Las dificultades en la iniciación y las transiciones del habla ocurren no a nivel articulatorio, sino principalmente a nivel de frases y oraciones, de modo que este tipo de pacientes difícilmente llegan a producir secuencias de oraciones que sirvan para modelar los episodios de una historia. Debido a las dificultades iniciales, tiende a hacer eco a las palabras que su interlocutor ha iniciado por él, así como recurrir a frases habituales.

\section{La afasia acústico-amnésica}

Lesión en la circunvolución media crea incapacidad para retener el significado de series de palabras, hay una inestabilidad en la retención de rasgos, por lo que cada palabra inhibe a la siguiente. Los pacientes, al tiempo que intentan retener la audición fonémica, muestran dificultades en la denominación, particularmente cuando se trata de series y no hay deficiencias de articulación.

\section{La afasia semántica}

Lesión en el área donde se unen los lóbulos temporal, parietal y occipital. Está conservada la audición fonémica, al igual que la comprensión de palabras aisladas. Lo que queda perturbado es el 
sistema de conexión simultánea, que subyace al significado inmediato de las palabras, y las relaciones que las palabras establecen entre sí, cuando se hayan asociadas en frases y oraciones. El paciente presenta especial dificultad, cuando se le presentan en forma simultánea varios enunciados simples, para sintetizar y comprender su significado. No hay dificultades de articulación.

\section{La afasia acústico-agnósica o sensorial}

Según Boston, la Afasia de Wernicke es causada por lesiones en la circunvolución superior del lóbulo temporal. El problema mayor es la audición fonémica, es decir, la dificultad para distinguir los sonidos del habla. Esto produce efectos secundarios en el sistema de significados de las palabras: los distintos sonidos que forman la palabra resultan vagos e indiferenciados, siendo imposible discriminar el sentido.

El paciente tiene dificultades para distinguir silabas o palabras con sonido similar y encuentra muy difícil poder analizar los sonidos componentes de las palabras, así como también, el poder sintetizar sus elementos para constituirlas. Debido al efecto que esto tiene en el significado de las palabras, el paciente encuentra dificultades para la denominación de cosas, sin que pueda ayudársele, proporcionándole el sonido inicial. No hay dificultades de articulación.

\section{La afasia anómica o amnésica}

La alteración de la capacidad para denominar (anomia) es el más común de los trastornos afásicos. Cuando este trastorno es muy marcado, el lenguaje espontáneo se ve plagado de circunloquios que tratan de suplir la falta del nombre, o bien el paciente recurre a utilizar palabras 'de relleno' (sí, hombre; bueno; sabe usted; etc.) y generalizaciones inespecíficas (una cosa, aquello, etc.). La anomia es un dato semiológico importante que debe tenerse en cuenta y explorarse adecuadamente en cualquier tipo de afasia.

El rendimiento en las pruebas de denominación suele reflejar la gravedad de la afasia independientemente del tipo semiológico de esta. Pueden observarse problemas anómicos como consecuencia de lesiones en diversas localizaciones cerebrales, puesto que los 
mecanismos neuronales de la generación del nombre son procesos complejos interrelacionados con los restantes mecanismos cognitivos e intelectuales, y no se localizan específicamente en ninguna área focal determinada. No obstante, los trastornos anómicos más marcados se presentan en lesiones de la región angular (corteza de asociación multimodal de las áreas parieto-temporoccipitales) o de la zona posterior de la tercera circunvolución temporal (área 37) del hemisferio dominante. Los apartados anteriores permiten llegar a una clasificación general de afasias, como lo muestran Benson y Ardila (1996) en la Tabla 2.

\subsection{Baterías o instrumentos de evaluación}

Alexander Luria,, padre por excelencia de la neuropsicología, no estableció en su modelo sindrómico sistémico, una batería específica para la evaluación y el diagnóstico de las afasias, pese a la diversidad de técnicas que utilizaba el Instituto Burdenko de la Universidad de Moscú. Sin embargo, se han realizado algunos esfuerzos por estandarizar estas técnicas en el mundo occidental. Un ejemplo notable es el Diagnóstico neuropsicológico de Luria, introducido en los Estados Unidos en 1974 por Anne Lisse Chistensen. El test de Boston Evaluación de la afasia y de trastornos similares, elaborado y estandarizado en los Estados Unidos en 1970 por el psicólogo Harold Goodglass y la neuróloga Edith Kaplan, según el modelo neo asociacionista de Norman Geschwind, estableció una clasificación de los síndromes afásicos distinta a la de Luria. 
María Gladis Agudelo Gil - Luz Marina Henao Restrepo

\begin{tabular}{|c|c|c|c|c|c|c|c|c|c|c|c|}
\hline 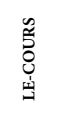 & $\stackrel{\mathscr{\infty}}{\stackrel{\infty}{\mathscr{S}}}$ & 总 & 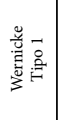 & & 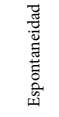 & 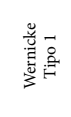 & & 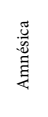 & & 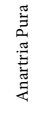 & \\
\hline $\begin{array}{l}z \\
\text { zon } \\
\text { 率 }\end{array}$ & まे & 总 & $\begin{array}{l}\text { 总 } \\
\text { 苛 }\end{array}$ & 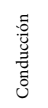 & 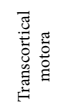 & 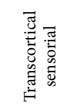 & 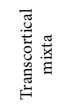 & 吾 & $\begin{array}{l}\bar{J} \\
\text { 흥 }\end{array}$ & 莺 & \\
\hline 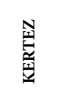 & Sิ & 愛 & 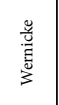 & 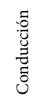 & 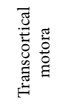 & 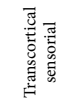 & 童 & 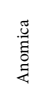 & $\begin{array}{l}\frac{\vec{J}}{\mathrm{~g}} \\
\frac{\mathrm{o}}{3}\end{array}$ & & \\
\hline 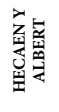 & $\stackrel{\infty}{\stackrel{\infty}{6}}$ & 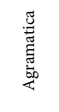 & 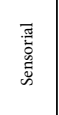 & & 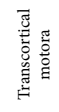 & 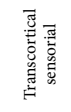 & & 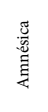 & $\frac{\tilde{y}}{\frac{1}{2}}$ & 䋨 & \\
\hline 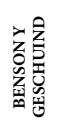 & 疍 & 总 & 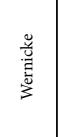 & 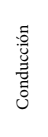 & 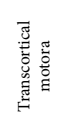 & & 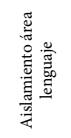 & 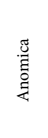 & $\begin{array}{l}\overrightarrow{\mathrm{g}} \\
\frac{\mathrm{g}}{\mathrm{O}}\end{array}$ & 葴 & \\
\hline 志 & ֻ & 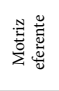 & 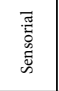 & 言菷 & 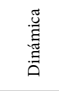 & & & 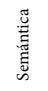 & & & 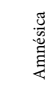 \\
\hline$\ddot{x}$ & Фू & 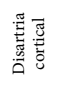 & 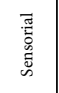 & & 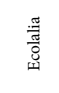 & & & $\begin{array}{l}\frac{5}{8} \\
\text { 量 }\end{array}$ & & & \\
\hline$\frac{z}{\frac{z}{\mu}}$ & $\stackrel{\vec{\sigma}}{\circ}$ & 吅 & $\begin{array}{l}\text { 劳 } \\
\text { के }\end{array}$ & 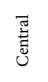 & & & & 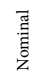 & 丞 & & \\
\hline 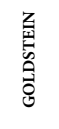 & $\stackrel{\infty}{2}$ & 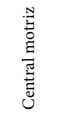 & 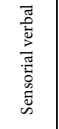 & 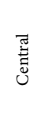 & & & 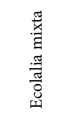 & 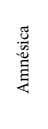 & & & \\
\hline $\begin{array}{l}\frac{5}{4} \\
\frac{4}{2}\end{array}$ & 范 & 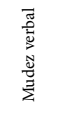 & 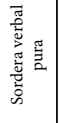 & 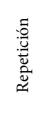 & 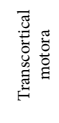 & & & 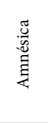 & & 㺃 & \\
\hline 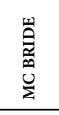 & 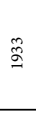 & 莺 & $\begin{array}{l}\text { 竞 } \\
\text { 产 }\end{array}$ & & & & & 吾 & 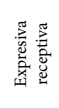 & & \\
\hline 추표 & 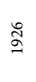 & 焉 & 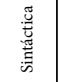 & & & 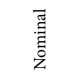 & & 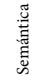 & & & \\
\hline 曾 & $\stackrel{m}{g}$ & 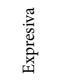 & 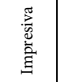 & & & & & & 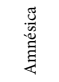 & 氶 & \\
\hline 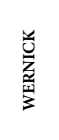 & 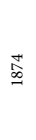 & 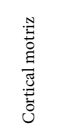 & 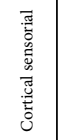 & 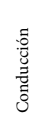 & 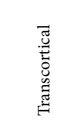 & 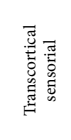 & & & 焉 & 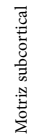 & \\
\hline 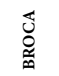 & 总 & 愛 & 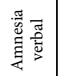 & & & & & & & & \\
\hline
\end{tabular}


Pese a su prestigio y poder en el mundo anglosajón, esta batería no es adecuada por su falta de economía administrativa y extrapolación ambiental y criticable a la luz de la teoría lingüística contemporánea. Entre Luria y Boston, Azcoaga (1981) plantea consideraciones de distintos modelos de exploración de trastornos del lenguaje en adultos, y propone para Argentina su Modelo fisiológico y fisiopatológico del síndrome afásico, que no se interesa por el diagnóstico diferencial.

Lázaro, Quintana y Solovieva (2010) propusieron un instrumento para evaluar las afasias en México, el cual aborda los mecanismos neuropsicológicos subyacentes en cada caso; una vez aplicado sus resultados se analizan desde lo cuantitativo y lo cualitativo, estudio que fue realizado con diez pacientes y se considera un instrumento útil y contextualizado para este entorno.

En Colombia, las orientaciones más influyentes se deben a Alfredo Ardila (1991) y a su modelo Enfoque neuropsicológico del diagnóstico del daño derebral que establece un puente entre Luria y Boston, pero no pretende, en forma sistemática, dar cuenta de las alteraciones en los niveles de la lengua ni en las funciones del lenguaje. Estos aspectos se empezaron a plantear en la ciudad de Medellín con una investigación multidisciplinaria llevada a cabo en el hospital San Vicente de Paúl, por Bustamante, Lopera y Rojas.

En la actualidad, los instrumentos utilizados son susceptibles de modificaciones metodológicas y precisiones temáticas. En Pereira aún se utiliza el Minnesota test para el diagnóstico diferencial de la afasia, publicado por Mildret Schuell en 1955, esta prueba se aplicó durante varios años en el Servicio Neurológico de Veteranos de Minneapolis. Las pruebas alcanzan 600 ítems y sus resultados se consideran simplemente como "positivos" o "negativos". La prueba que explora la conducta general del lenguaje es discutible en relación con la agrupación de los ítems, dados los hallazgos teóricos de la psicolingüística contemporánea.

Teniendo en cuenta las limitaciones anotadas, es importante la elaboración de baterías ambientadas al medio y aplicadas a pacientes inmersos en el circuito comunicativo humano, destinatarios y receptores de mensajes verbales en diferentes eventos comunicativos desde una perspectiva que puede llamarse neuropsicolingüística. En ella se tendrán en cuenta los modelos lingüísticos, psicolingüísticos 
y neuropsicolingüísticos considerados como los más adecuados, y especialmente las enseñanzas de Noam Chomsky, Luria y Roman Jakobson.

El examen de las afasias utiliza procedimientos clínicos, tomados de la neurología, y psicométricos, heredados de la psicología. La evaluación del lenguaje supone una observación cuidadosa de sus características, como desviaciones fonéticas, presencia de parafasias, agramatismo, etc. $\mathrm{Al}$ igual que la utilización de pruebas estandarizadas y normalizadas (psicométricas). Esta evaluación busca determinar si el lenguaje del paciente es normal o anormal, analizando, además, los síntomas (olvido de palabras) y signos (presencia de parafasias) presentes e identificando los síndromes subyacentes. Así mismo proponiendo procedimientos de rehabilitación o terapéuticos.

El primer autor que propuso la utilización de procedimientos estándar en la evaluación de las afasias fue Head (1926) y desde entonces, la normalización y validación de las pruebas de lenguaje ha constituido una preocupación permanente en el área de las afasias. Existen baterías o pruebas que permiten realizar una evaluación integral del lenguaje; las más utilizadas en la evaluación de las afasias, en español, durante el siglo XX son:

- Prueba de Boston

- Examen multilingüe

- Prueba de Minnesota

- Índice Porch de habilidad comunicativa (PICA)

- Batería de Western

- Batería EPLA

- Batería ELA

\section{Prueba de Boston}

Para el diagnóstico de las afasias esta es, probablemente, la prueba que con más frecuencia se utiliza durante los últimos años (Goodglass y Kaplan, 1972, 1986). La versión española fue realizada por García-Albea y Sánchez Bernardos (1986). Los objetivos que plantea esta prueba son: diagnosticar la presencia y el tipo de cuadro clínico, lo que ayuda a 
inferir el lugar de la lesión; determinar el nivel de actuación del sujeto a lo largo de un amplio rango de pruebas; y evaluar las capacidades de la persona con afasia en todas las áreas del lenguaje, de cara a diseñar estrategias de rehabilitación. Permite obtener un perfil general del lenguaje del paciente en diversas áreas:

Escala de severidad: se puntúan ocho características en una escala de siete puntos.

Comprensión auditiva: discriminación de palabras, identificación de partes del cuerpo, órdenes, material ideativo complejo.

Expresión oral: agilidad oral, secuencias automatizadas, recitado y ritmo, repeticiones de palabras, frases y oraciones, lectura de palabras, respuestas de denominación, denominación por confrontación visual, denominación de partes del cuerpo, nombrar animales, lectura de oraciones en voz alta.

Comprensión del lenguaje escrito: denominación de letras y palabras, asociación fonética, emparejar dibujo-palabra, lectura de oraciones y párrafos.

Escritura: mecánica de la escritura, recuerdo de símbolos escritos, encontrar palabras escritas, formulación escrita.

\section{Examen multilingüe}

Desarrollado por Benton y Hamsher (1976) y traducido a español por Rey y Benton (1991). Es una batería relativamente fácil y corta de aplicar, por lo que resulta muy práctica en la evaluación de las afasias. Incluye seis subpruebas: nombramiento visual, repetición de oraciones, asociación controlada de palabras, prueba de las fichas, comprensión auditiva de palabras y frases, y comprensión escrita de palabras y frases. Además, incluye una escala de evaluación articulatoria.

\section{Prueba de Minnesota}

Esta prueba (Schuell, 1953, 1973) contiene 59 subpruebas, agrupadas en cinco áreas diferentes: trastornos auditivos, trastornos visuales y de 
la lectura, trastornos del habla y el lenguaje, trastornos visomotores y de la escritura, trastornos de las relaciones numéricas y los procesos aritméticos. Esta extensa batería puede tomar varias horas en su aplicación.

\section{Índice Porch de habilidad comunicativa, PICA (Porch, 1983)}

El Índice Porch (PICA) (Porch, 1983) es de orientación conductista $y$ es usado frecuentemente en investigación. Mide el grado de déficit nominativo de la persona con afasia, ya que presenta un sistema de valoración de las conductas con una gran amplitud de matices. Contiene dieciocho subpruebas de diez ítems (cuatro de ellos verbales, ocho gestuales y seis gráficos). Tiene unas normas muy estrictas para su utilización y se supone que, teniendo en cuenta su formato rígido y su sistema de calificación, puede suministrar un sistema de medida muy sensible a cambios menores en las habilidades de comunicación de la persona evaluada. Sin embargo, se le ha criticado que algunas habilidades lingüísticas no son apropiadamente evaluadas y que no incluye ninguna prueba que valore el lenguaje espontáneo.

\section{Batería de Western}

En gran medida, representa un desarrollo ulterior de la prueba de Boston, para el diagnóstico de las afasias (Kertesz, 1979, 1982). De hecho, muchos de los ítems son tomados de la prueba de Boston. La batería incluye cuatro subpruebas de lenguaje oral que permiten derivar cinco puntajes. Estos puntajes se convierten en una escala de diez puntos, permitiendo crear un perfil de ejecución. Posteriormente, se puede calcular un cociente de afasia multiplicando por dos cada uno de los cinco puntajes escalares y sumándolos. Un puntaje normal o perfecto corresponde a 100. Las discrepancias con este puntaje total informan sobre la gravedad del trastorno afásico. Se incluyen adicionalmente pruebas de lectura, escritura, aritmética, praxis, habilidades construccionales y la prueba de matrices progresivas de Raven. Con esto se intenta tener una apreciación global sobre el estado general del paciente. 


\section{Batería EPLA}

Construida por Kay Lesser y Colther (1992), en inglés PALPA (Psycholinguistic Assessments of Language Processing in Aphasia). Tiene como objetivo la evaluación de las capacidades lingüísticas en los trastornos del lenguaje. El enfoque desde el que se ha elaborado EPLA es el de la neuropsicología cognitiva y permite a psicólogos y neuropsicólogos, de orientación tanto teórica como aplicada, conocer con bastante detalle las habilidades lingüísticas intactas y las que han sufrido algún deterioro. Evalúa los procesos léxicos que funcionan a nivel de oración; la mayoría están dirigidas a los procesos a nivel de palabra y, de hecho. Consta de 58 tareas agrupadas en cuatro bloques de subtests:

17 de procesamiento fonológico

27 de lectura y escritura

8 de comprensión de dibujos y palabras

6 de procesamiento de oraciones.

\section{Batería ELA}

Elaborada por Stark (1992). Está constituida por una colección de mil fotos que recogen actividades de la vida cotidiana y sobre las que se construyen las diferentes oraciones. Permite evaluar el proceso léxico denominación de dibujos y está especialmente diseñada para evaluar la comprensión y producción de oraciones.

Ya para el siglo XXI, entre los autores que han aportado a la evaluación de las afasias se puede mencionar a Ardila (2005), Vicario (2007), y Pasuy y Cisneros (2013). Para Ardila (2005), la evaluación clínica de las afasias supone la exploración de determinados aspectos del lenguaje, los cuales agrupa en su esquema: Aspectos del lenguaje generalmente incluidos en una evaluación de las afasias (Tabla 3). 
Tabla 3. Aspectos del lenguaje generalmente incluidos en una evaluación de las afasias

\begin{tabular}{|c|l|}
\hline Aspecto & \multicolumn{1}{|c|}{ Tipo de prueba } \\
\hline Producción & $\begin{array}{l}\text { Lenguaje espontáneo (hay o no lenguaje } \\
\text { espontáneo: cantidad, longitud de las frases, } \\
\text { fluidez, desviaciones fonéticas, agramatismo- } \\
\text { paragramatismo, parafasias, habla vacía, } \\
\text { neologismos, jerga, prosodia, características del } \\
\text { habla, agilidad oral y verbal, disartria, apraxia } \\
\text { del habla, etc). }\end{array}$ \\
\hline Comprensión & $\begin{array}{l}\text { Lenguaje conversacional. Señalar (objetos, partes } \\
\text { del cuerpo, colores, acciones) y cumplir órdenes } \\
\text { verbales progresivamente más complejas. }\end{array}$ \\
\hline Repetición & $\begin{array}{l}\text { Palabras pseudopalabras. Palabras una, dos, } \\
\text { tres, cuatro sílabas. Frases progresivamente más } \\
\text { largas (3, 4,...18 palabras). }\end{array}$ \\
\hline Denominación & $\begin{array}{l}\text { Objetos externos. Partes del cuerpo. Colores. } \\
\text { Acciones }\end{array}$ \\
\hline Lectura & $\begin{array}{l}\text { Letras, palabras, pseudopalabras, frases, textos } \\
\text { Comprensión. Paralexias, omisiones. Palabras } \\
\text { concretas-abstractas, nombres-elementos } \\
\text { gramaticales. }\end{array}$ \\
\hline Escritura & $\begin{array}{l}\text { Firma. Letras, palabras, frases (caligrafía, uso } \\
\text { del espacio, errores en la escritura de letras, } \\
\text { paragrafias, ortografía). Escritura espontánea. } \\
\text { Copia, dictado. Escritura de números }\end{array}$ \\
\hline
\end{tabular}

Fuente: Ardila, A. (2005.p. 253). Las afasias. México: Universidad de Guadalajara.

Por su parte, Vicario (2007) coordina un trabajo donde se sugiere un instrumento para realizar un Mínimo examen cognitivo (MEC), el cual incluye cinco test: test mínimo de examen del estado mental, test de orientación temporal, test del reloj, test seriales y test mínimo de denominación. En sintonía con los aportes de Ardila y Vicario: 
Una de las estrategias que debe utilizar el terapeuta para lograr un trabajo eficiente es la utilización de unas baterías, recomendablemente desde un enfoque cognitivo para lograr controlar una serie de variables psicolingüísticas que se derivan de la conducta del paciente y que permiten medir la frecuencia, la regularidad, la concreción/abstracción, la longitud, etc. En definitiva, se trata de una evaluación que explora un amplio número de tareas, cada una de ellas con un variado número de ítems (Pasuy y Cisneros, 2013, p.101).

Se considera pues como acertado, en este trabajo, valorar el rendimiento lingüístico del $\mathrm{H}-\mathrm{OP}$, en un principio, desde lo cognitivo, ya que pensamiento y lenguaje van unidos, son inseparables; al revisar sus desarrollos respectivos se encuentra que en un determinado momento de la vida del ser humano, sin superar sus dos o máximo tres años, su pensamiento se vuelve verbal y su lenguaje racional (Vigotsky, 1982, p.92). Al surgir la afasia no se cumplen estas máximas o se presentan de manera deficitaria, por lo tanto la afasia no es solamente un estado patológico del lenguaje, también lo es del pensamiento. En este sentido, Pasuy y Cisneros (2013, p.65) afirman:

Retomar los trastornos intelectivos en las afasias es hacer referencia a la relación que hay con la afasia semántica debido a que la unidad significante-significado, perdida o alterada en los deterioros semánticos, atañe a la función esencial del lenguaje como portador del pensamiento, en tanto que este queda prendido en red de formulación simbólica que el sistema del lenguaje es; es decir, el deterioro del lenguaje es el producto de una alteración semántica generada, de un sujeto que presenta tratornos intelectivos.

Las baterías de evaluación de las afasias presentadas en este capítulo, sumadas a las consideraciones cognitivas en su parte final, ofrecen un marco teórico y metodológico que permite estructurar una prueba para caracterizar las realizaciones lingüísticas de los hablante-oyentes nativos del español, específicamente en el contexto risaraldense, la cual se presenta en el capítulo dos de esta publicación. 


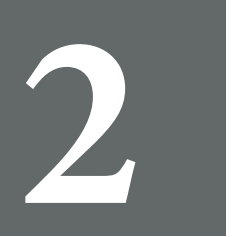

CAPÍTULO DOS 



\section{Batería para el diagnóstico y la caracterización lingüística de las afasias: diseño y aplicación}

n aras de profundizar acerca de esta patología del lenguaje,
se seleccionó una muestra aleatoria de diez pacientes de
una de las instituciones más emblemáticas de la ciudad de Pereira, pues recibe a usuarios provenientes de los catorce municipios del departamento de Risaralda. Se observó la atención que se les brinda a los pacientes cuando sufren una lesión cerebral (interna o externa). Pero, después de haber sido atendidos por la entidad de salud, algunos quedan padeciendo una patología del lenguaje, cual es la afasia, padecimiento cuyo tratamiento o rehabilitación, al parecer no está en las manos de dicha entidad, atender.

Es así como, con la muestra mencionada, se exploró el asunto de las afasias, primero a nivel teórico (ver capítulo uno de esta publicación) y luego a nivel de quienes las padecen, hecho que repercute directamente en sus vidas, apartándolos, en la mayoría de los casos, de sus entornos laborales y sociales, y hasta de los familiares y personales.

Las aproximaciones anteriores permitieron reconocer una necesidad apremiante de los pacientes afásicos que hicieron parte de dicha 
muestra y por extensión de quienes no lo fueron: un instrumento que le permitiera a las entidades de salud: a) diagnosticar las afasias, pues no todas las alteraciones en la comunicación son patologías del lenguaje. b) Caracterizar desde el punto de vista lingüístico las afasias sufridas respectivamente por los pacientes, pues de acuerdo con el nivel de lenguaje afectado o por la alteración presentada a nivel lingüístico, el profesional encargado de la rehabilitación del paciente diseñará el plan más adecuado, en el evento de que sí haya posibilidad de recuperación en algún grado.

Siendo entonces la pretensión, el diseño y aplicación de una batería o instrumento que diagnosticara y caracterizara desde el punto de vista lingüístico las afasias, aportando así al contexto risaraldense una posibilidad de evaluación de las mismas, y la base para que, profesionales del lenguaje, diseñen planes de recuperación, de acuerdo con cada caso, en el evento de que sí haya probabilidades de recuperación, lo cual dependerá de la severidad y ubicación de la lesión cerebral.

Cabe anotar que en el contexto clínico se nombra como pacientes a los usuarios del servicio médico, en este caso, a quienes después de haber sufrido una lesión cerebral, hayan quedado con alguna alteración en la comprensión y producción de su lenguaje; pero en el contexto lingüístico el término utilizado es hablante-oyente y en este caso no es el ideal como el señalado por Chomsky (1976) sino patológico, por la alteración de su lenguaje a consecuencia de dicha lesión cerebral. Por lo tanto, en adelante, no se hará referencia a los pacientes, sino a los hablante-oyente patológicos, denominación que se abreviará así: H-OP.

Para cumplir los cometidos ya mencionados, en este capítulo, se desarrollan cuatro apartados, así:

- Justificación, en la cual se dan razones de índole científico y sociocultural sobre la necesidad de tener una batería contextualizada que caracterice las afasias de los H-OP en el medio colombiano, específicamente en el risaraldense.

- Fundamentación: Se sustentan teóricamente las partes que estructuran la Batería de diagnóstico y caracterización lingüística de las afasias, donde se señalan los procesos neuropsicológicos 
del lenguaje, explicados por Luria (1980), retomados por Rojas (1999) para la evaluación del lenguaje, en su correlación también con los aspectos que señala Ardila (2005), como necesarios para la evaluación de las afasias.

- Metodología: Se señalan aquí los métodos que permiten un acercamiento cuantitativo y cualitativo a la actuación lingüística de los H-OP valorados. Se precisan también los materiales y recursos para este efecto y se hace referencia al procedimiento que se cumple para dicho cometido.

- Diseño y aplicación: donde se presentan las partes de la batería que permite diagnosticar y caracterizar desde el punto de vista lingüístico las afasias: la anamnesis y la prueba para valorar la actuación lingüística.

- Evaluación de las afasias: En esta parte se incluyen los dos momentos que constituyen esta evaluación: a) la calificación de las pruebas: Se presentan los formatos que, una vez diligenciados (cuando se termine la aplicación de la prueba), permiten el análisis cuantitativo, y se orienta al evaluador para realizar las observaciones que conllevan al análisis cualitativo. b) el análisis de los resultados: Se vuelve sobre la anamnesis y sobre los resultados obtenidos después de la aplicación de la prueba, y se diligencia el formato de Diagnóstico, el cual va cerrando el proceso de evaluación al H-OP. Este diagnóstico se diligencia en términos del nivel de la lengua alterado (aspecto lingüístico), del proceso psicolingüístico alterado (aspecto psicolingüístico) y de la afasia diagnosticada (aspecto neurolingüístico), de acuerdo con las características detectadas en los dos aspectos anteriores, y de acuerdo con la ubicación de la lesión cerebral, información que arroja la historia clínica correspondiente al caso que se esté estudiando.

\subsection{Justificación}

Se comparte con Lázaro, Quintanar y Solovieva (2010) su afirmación sobre la necesidad de diseñar instrumentos de evaluación de las afasias para hispano-parlantes, pues muchos de estos instrumentos fueron diseñados para poblaciones con características culturales, económicas y educativas distintas: 
La evaluación de pacientes hispano-parlantes con afasia frecuentemente se realiza con pruebas traducidas o adaptadas, muchas de las cuales no consideran las características específicas del idioma castellano. Por tal motivo, consideramos que es necesario elaborar instrumentos dirigidos a dicha población, que además permitan no sólo la descripción, sino el análisis de las dificultades que presentan los pacientes en la esfera verbal, con el objeto de identificar sus mecanismos subyacentes (p.33).

Teniendo en cuenta esta preocupación, se llevó a cabo una investigación focalizada en los pacientes atendidos por una de las instituciones de gran trayectoria encargadas de la salud en la ciudad de Pereira. Esta institución que no viene al caso mencionar, atiende a pacientes que han sufrido lesiones cerebrales internas o externas, en todo lo relacionado con su salud física, neurológica y fisiológica, hasta que el paciente logre una estabilidad o un bienestar aceptables; pero las alteraciones de su lenguaje (producción y comprensión) son una dificultad que persiste y se la debe llevar consigo, repercutiendo negativamente en su entorno laboral, social y familiar.

Situación que se repite una y otra vez, en las demás Instituciones de salud de la ciudad, en pacientes que acuden a ellas con un ACV o cualquier otro tipo de lesión cerebral. Es usual entonces, en nuestra cotidianidad, encontrar hombres o mujeres, niños o adultos, alfabetizados o no alfabetizados, padeciendo casos de afasia; desvinculados por completo de su mundo laboral, y en muchos sentidos, del social y familiar, y lo que es peor, sin ninguna alternativa o posibilidad de rehabilitación o de recuperación de su facultad perdida: la producción o la comprensión del lenguaje.

Estos casos son recurrentes en la población, es decir, todos estamos expuestos a lesiones cerebrales tanto internas como externas, las primeras por condiciones morbidas que las entidades de salud atienden constantemente y que ya se constituyó en interés nacional dar un manejo integral a los eventos cerebrovasculares. De proponer unas políticas públicas en este sentido se ocupa el observatorio de accidente cerebrovascular liderado por ACEMI (Asociación colombiana de empresas de medicina integral), la sociedad colombiana de cardilogía y la fundación colombiana del corazón. Y las segundas, porque también 
estamos expuestos a lesiones cerebrales externas por la accidentalidad y violencia que caracteriza a la región.

Por lo anteriormente expuesto, es evidente la necesidad, para la ciudad y por extensión para la región, de un Instrumento que permita: a) Diagnosticar las afasias, pues no en todos los casos la pérdida de la capacidad de producir o comprender lenguaje se cataloga como afasia. b) Caracterizar lingüísticamente la afasia sufrida por determinado $\mathrm{H}-\mathrm{OP}$. c) Tener una base que permita establecer un plan de rehabilitación para el H-OP, de acuerdo con la dificultad presentada (nivel del lenguaje alterado, ya en su producción, ya en su comprensión).

\subsection{Fundamentación}

Dada la necesidad de diagnosticar y caracterizar las afasias en la ciudad de Pereira, y por extensión, en el departamento de Risaralda, se diseñó un instrumento, el cual consta de dos partes, como lo muestra la Figura 7

Figura 7. Batería de diagnóstico y caracterización de las afasias en el contexto risaraldense: partes
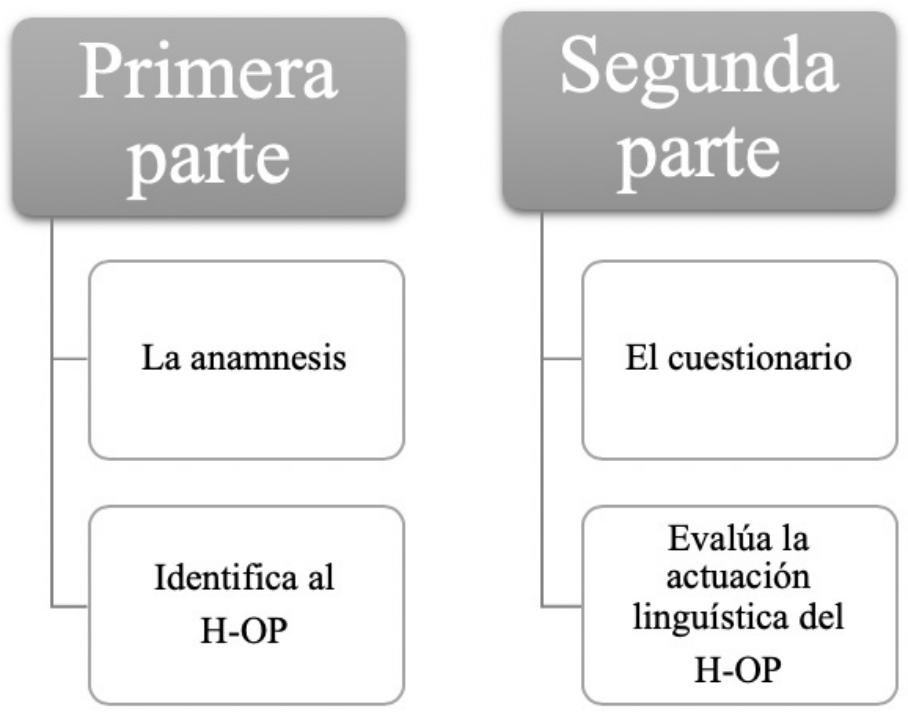
La primera parte, constituida por la anamnesis, posibilita un mayor acercamiento al H-OP y a su familia. Al H-OP para conocer su orientación autopsíquica y en tiempo y lugar, según el mínimo examen cognitivo (Vicario, 2007); y a sus familiares para establecer lo acontecido originándole la pérdida de su lenguaje y tener la descripción de lo que le está pasando, de sus manifestaciones más generales en su actuación lingüística, lo cual complementa los resultados del cuestionario que se le aplica para saber de manera directa cuál es su rendimiento en materia de producción y comprensión del lenguaje.

La segunda parte, compuesta por un cuestionario que compila las realizaciones lingüísticas del paciente en materia de los procesos neuropsicológicos del lenguaje, explicados por Luria (1980) y retomados por Rojas (1999) para la evaluación del lenguaje, como se visualiza en la Figura 8.

Figura 8. Procesos neuropsicológicos del lenguaje

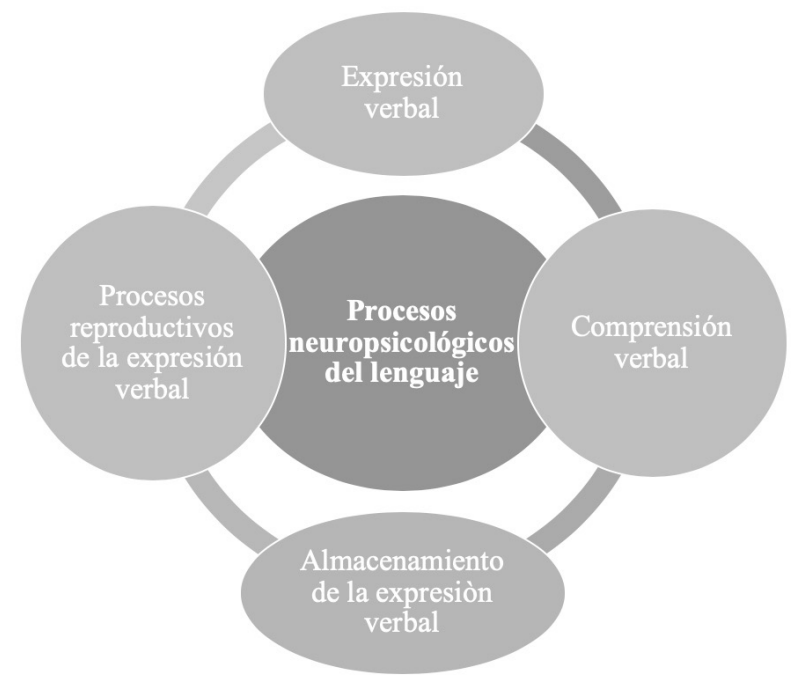

Fuente: Luria (1980, citado en Rojas, J. (1999). Tratado sobre el lenguaje: lingüística, psicolingüística, neuropsicolingüística, afasiología. Medellín: Pragma Editores) 
A continuación, se hará una breve alusión a cada uno de los procesos neuropsicológicos del lenguaje, mencionados en la Figura 8.

\section{Expresión verbal (lenguaje expresivo)}

El proceso psicológico de la expresión verbal es la codificación, es el paso del pensamiento al habla exterior y comporta los eslabones que se mencionan en la Figura 9.

Figura 9. Eslabones en la expresión verbal o codificación
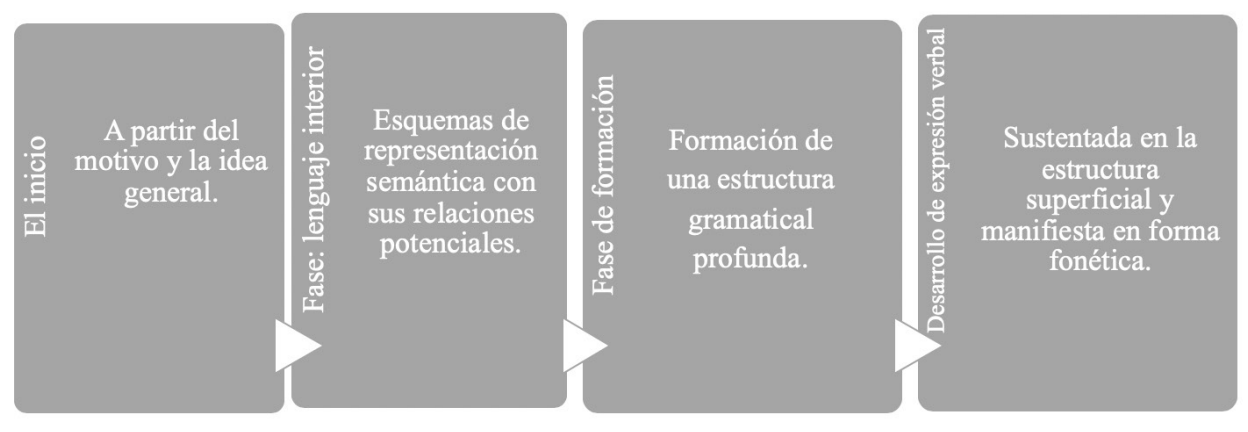

Fuente: Rojas, J. (1999, p.129). Tratado sobre el lenguaje: lingüística, psicolingüística, neuropsicolingüística, afasiología. Medellín: Pragma Editores.

Dos mecanismos neurológicos serían encargados de desarrollar este aparato sintagmático: el área de Broca en el lóbulo frontal izquierdo, mecanismo sintáctico por excelencia y el área prefrontal, anterior al área de Broca, encargada del lenguaje interior y de la iniciativa en el proceso comunicativo. Pero la conclusión fundamental de Luria es que la codificación de la expresión verbal se une a la adquisición y uso de los códigos del lenguaje e incluye una serie de factores psicofisiológicos (los motivos, los esquemas iniciales, la organización seriada de los procesos, la conversión de las informaciones sucesivas en esquemas simultáneos). Cada uno de estos factores opera con el trabajo mancomunado de distintos sistemas cerebrales. Por este motivo el déficit funcional de una zona concreta del cerebro hace inactivo a uno de estos factores particulares y como resultado se afecta el curso normal de las formas de 
la actividad verbal que dependen de la integridad de este factor. O sea que la expresión verbal también puede verse afectada por lesiones del lóbulo temporal (fonológico) y lesiones parietooccipitales (comprensión de relaciones lógico-matemáticas).

\section{Comprensión verbal (lenguaje receptivo)}

El proceso de comprensión verbal o decodificación es el proceso del paso del habla audible a su significado y luego a su sentido interno. Este proceso se caracteriza de manera inversa al proceso de expresión verbal y comporta por lo menos tres eslabones, los cuales se pueden apreciar en la Figura 10.

Figura 10. Eslabones de la comprensión verbal o decodificación

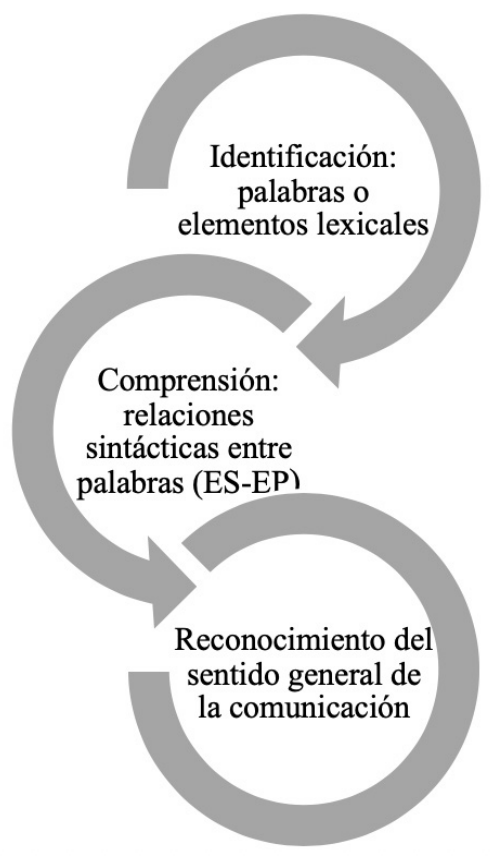

Fuente: Rojas, J. (1999, p.129). Tratado sobre el lenguaje: lingüística, psicolingüística, neuropsicolingüística, afasiología. Medellín: Pragma Editores. 
El área de Wernicke es el principal mecanismo neurológico para la comprensión de las bases fonológicas de la palabra. Sin embargo, para Luria, la decodificación o comprensión de la comunicación implica una serie de zonas cerebrales trabajando en estrecha relación, cada una encargada de un aspecto particular del complejo proceso además del lóbulo temporal, en la comprensión verbal interviene el lóbulo frontal y zonas parietooccipitales.

\section{Almacenamiento de la expresión verbal (lenguaje memorizado)}

De acuerdo con la definición de Ardila (1985), la memoria es la conservación de la información; memorizar es guardar y tener la información disponible una vez que la señal o la acción ha desaparecido. Este autor distingue tres etapas en la memoria, las cuales se señalan en la Figura 11.

Figura 11. Fases del almacenamiento de la expresión verbal

\begin{tabular}{|c|c|c|}
\hline $\begin{array}{l}\text { Retención o } \\
\text { registro }\end{array}$ & Almacenamiento & Evocación \\
\hline $\begin{array}{l}\text { El sujeto recibe la } \\
\text { informacón }\end{array}$ & $\begin{array}{l}\text { Conservación de } \\
\text { la información }\end{array}$ & $\begin{array}{l}\text { Recuperación de } \\
\text { las huellas de } \\
\text { memoria. }\end{array}$ \\
\hline
\end{tabular}

Fuente: Ardila (1985, citado en Rojas, J. (1999, p.131). Tratado sobre el lenguaje: lingüística, psicolingüística, neuropsicolingüística, afasiología. Medellín: Pragma Editores)

Con relación a la afasia amnésica, existe un problema de almacenamiento: se olvida la estructura fonológica de la palabra, se olvida la secuencia de los sonidos que constituyen una palabra. Es la afasia acústico-amnésica que se produce por lesiones en las áreas temporales medias. Existe otra forma de afasia amnésica llamada nominal o anómica, en la cual el problema no es que la huella de memoria se encuentre perdida, sino que no es posible recuperarla; es un problema de evocación, la huella se hace inaccesible. Si se le presenta al 
H-OP la figura de un objeto, este no es capaz de pronunciar la palabra correspondiente, no porque la palabra esté borrada sino porque es imposible lograr el acceso a ella. La afasia anómica se produce por lesiones temporo-parieto-occipitales.

Procesos reproductivos de la expresión verbal (lenguaje reproducido):

La reproducción de una palabra o de una estructura sintáctica en la repetición, en la lectura (en voz alta) y en la escritura (al dictado), basadas en la comprensión de la palabra o la estructura sintáctica, presupone la existencia de un registro intacto de unidades léxicas, un almacenamiento en la memoria a largo plazo para poder lograr la adecuada reproducción verbo-motora o grafo-motora. Los procesos reproductivos de la expresión verbal son los que se mencionan en la Figura 12.

Figura 12. Procesos reproductivos de la expresión verbal

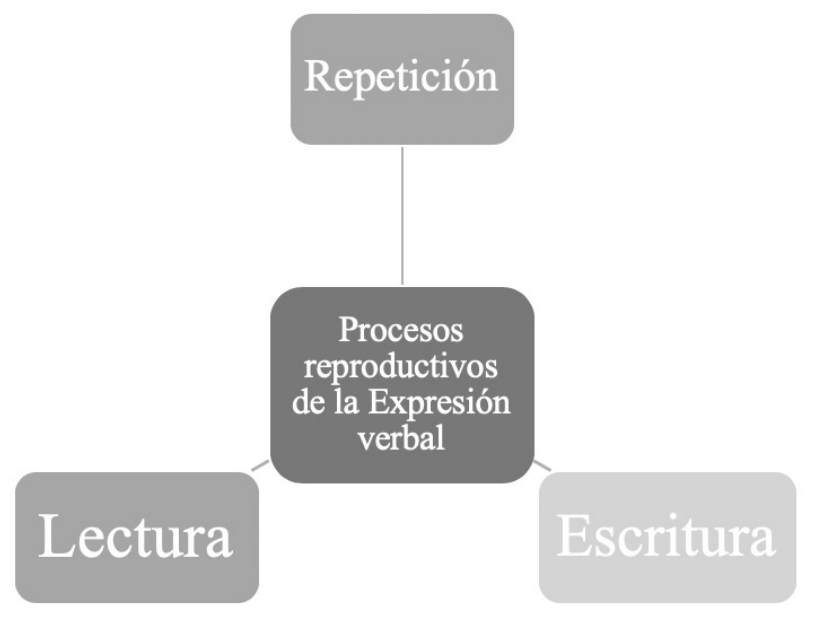

Fuente: Weigl. (1986, citado en Rojas, J. (1999). Tratado sobre el lenguaje: lingüística, psicolingüística, neuropsicolingüística, afasiología. Medellín: Pragma Editores) 


\section{- Repetición}

Para Ardila (1992), la afasia de conducción se caracteriza por una repetición pobre, con parafasias, en medio de un lenguaje fluente y una buena comprensión verbal. El trastorno de la repetición estaría acompañado por trastornos de la lectura y la escritura. Desde Wernicke se ha creído que este trastorno se debe a la desconexión del área de expresión (Broca) y el área de la comprensión (Wernicke) en el fascículo arqueado.

Luria (1980) no cree en esta desconexión, encuentra trastornos del lenguaje repetitivo en $\mathrm{H}-\mathrm{OP}$ con defectos acústico-articulatorios y en $\mathrm{H}$-OP con alteraciones acústico-amnésicas. En el primer grupo se afecta el córtex poscentral y la región temporal, y no la "hipotética desconexión", y el trastorno es más evidente en la repetición de sonidos y palabras. El segundo grupo presenta afectada la memoria acústico verbal a corto plazo y su gravedad depende de la cantidad de material presentado para ser repetido y de tiempos suficientemente largos. En conclusión, para Luria la llamada afasia de conducción no es una forma especial de afasia sino un síntoma que aparece a consecuencia de mecanismos diferentes, ligados estrechamente a los cambios en la tarea que se propone al $\mathrm{H}-\mathrm{OP}$.

\section{- Lectura}

La lectura, como la escritura, es un proceso analítico-sintético, que comprende el análisis de los sonidos y la síntesis de los elementos del discurso. En la lectura se observan cuatro fases, las cuales se señalan en la Figura 13. 
Figura 13. Fases en la lectura como proceso reproductivo de la expresión verbal (Rojas, 1999, p. 134)

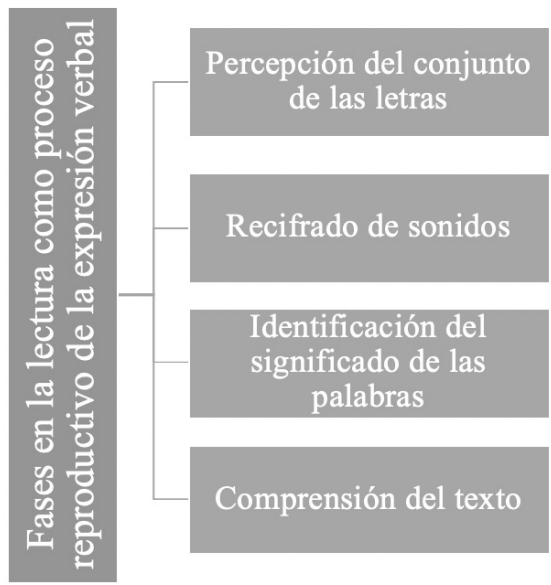

Fuente: Rojas, J. (1999, p.134). Tratado sobre el lenguaje: lingüística, psicolingüística, neuropsicolingüística, afasiología. Medellín: Pragma Editores.

Para Tsvétkora (1977) el proceso de la lectura entraña por lo menos tres factores cooperantes: el análisis y la síntesis sónico-literal, las conjeturas significativas y el proceso de confrontación de las hipótesis emanadas de la lectura con las palabras escritas. Todos estos eslabones solo pueden efectuarse por el movimiento de los ojos. La perturbación de la lectura producida por defectos de análisis y síntesis ópticos de las letras se manifiesta en alteraciones parieto-occipitales y se denomina alexia óptica. La alexia es una alteración de la actividad de leer, resultante de un daño cerebral. A diferencia de la dislexia, que es la incapacidad de aprender a leer a pesar de una inteligencia normal, instrucción adecuada y oportunidades socioculturales. La alexia literal (ceguera a las letras) es la incapacidad para leer las letras del alfabeto. La alexia verbal (ceguera a las palabras) es la incapacidad para comprender y leer las palabras en voz alta. 


\section{- Escritura}

La estructura de la escritura se relaciona con toda una actividad discursiva. Se inicia como una acción consciente ligada a operaciones aisladas e independientes: comprensión de sonidos, traducción a los grafemas correspondientes, trazado de las letras, etc. Pero a medida que la escritura evoluciona, su estructura psicológica cambia, el proceso de escritura se automatiza y gradualmente se convierte en un hábito. Para Twvétkora (1977), la formación y desarrollo de la escritura en el niño dan una idea clara de la complejidad de esta función mental. El proceso de la escritura consta, como mínimo de dos niveles, los cuales se mencionan en la Figura 14.

Figura 14. Niveles en la Escritura como proceso reproductivo de la expresión verbal

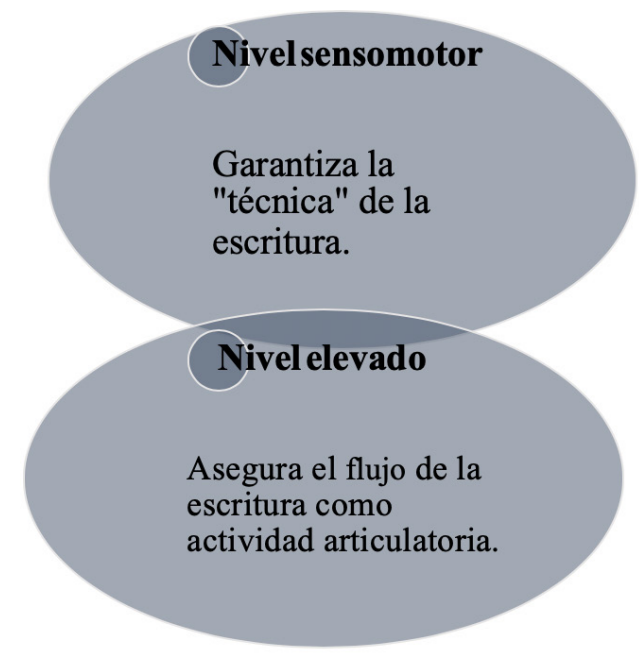

Fuente: Tsvétkora (1977, citado en Rojas, J. (1999, p.133). Tratado sobre el lenguaje: lingüística, psicolingüística, neuropsicolingüística, afasiología. Medellín: Pragma Editores) 
A la vez, el nivel sensomotor de la escritura es un proceso integrado por los siguientes eslabones:

- Análisis sónico de la palabra (traducción de sonidos a fonemas)

- Precisión y separación de los sonidos en la palabra (secuencia y orden de los sonidos)

- Correlación de cada sonido desglosado de la palabra con el grafema correspondiente

- Representación visual de la letra en trazos gráficos adecuados

Pero, a veces, no basta la presencia de los mecanismos sensomotrices de la escritura, es indispensable dominar las estructuras léxicas, semánticas y gramaticales y, a este nivel, el más elevado, la escritura actúa como actividad de un proceso cognitivo.

La agrafia es la pérdida total o parcial de la habilidad para el lenguaje escrito causada por un daño cerebral. Supone, la escritura normal, capacidad de convertir los códigos del lenguaje oral (fonemas) en los códigos del lenguaje escrito (grafemas). Fue Exner, en 1881, quien propuso la existencia de un centro de la escritura, localizado en la base de la segunda circunvolución frontal izquierda. Una patología en el área de Exner produciría agrafia pura, pero aún no está establecida esta patología. Se sabe sí que puede haber agrafias con afasias y agrafias sin afasias.

Es necesario recordar que tanto la lectura como la escritura exigen una competencia cognoscitiva, referida al conocimiento previo del ser humano ante la interacción lingüística. Esta competencia abarcaría el conocimiento previo del mundo gobernado por la memoria a largo plazo y la interacción lingüística del escritor-lector: manejo de estructuras textuales y reglas de funcionamiento. Los procesos neuropsicológicos del lenguaje, ya explicados, se constituyen en el marco que estructura la batería que aquí se propone para diagnosticar y caracterizar las afasias en el contexto risaraldense.

Ahora bien, para efectos del diseño del cuestionario que hace parte de este instrumento, se consideran aplicables los aspectos que Ardila (2005) señala como incluidos en una evaluación de las afasias, como se puede apreciar en la Tabla 4. Cabe aclarar finalmente, que los ítems que componen el cuestionario, y que atienden a los procesos ya mencionados, 
no trascienden a teorías contemporáneas de la lingüística del texto o la textolingüística dado que se trata de $\mathrm{H}-\mathrm{OP}$ que han perdido su facultad de comprender o producir lenguaje ocasionado esto por una lesión cerebral interna o externa, y se considera necesario y suficiente abordar estos procesos en su fase inicial: la decodificación y la codificación.

Haciendo una correlación con un instrumento similar aportado por González y Hornauer-Hughes (2014) para el contexto chileno, se encuentran valorados practicamente los mismos procesos en ambos instrumentos. En el chileno se evalúa lenguaje expresivo, lenguaje comprensivo, lectura y escritura; y en el que aquí se propone se evalúa: expresión verbal, comprensión verbal, almacenamiento de la expresión verbal y procesos reproductivos de la expresión verbal. Las diferencias radican en que en esta batería se visibiliza la repetición y al lado de la lectura y la escritura forma parte de los procesos reproductivos de la expresión verbal, mientras que en la propuesta chilena la repetición está ubicada dentro del lenguaje expresivo.

Lo mismo sucede con la memorización en esta batería, la cual se visibiliza como almacenamiento de la expresión verbal en una categoría independiente; en cambio en dicho instrumento se incluye como lenguaje automático en el lenguje expresivo. Esto para decir que ambos instrumentos valoran los mismos procesos y subprocesos de realizaciones lingüísticas, utilizando diferentes denominaciones para los procesos y diferentes ubicaciones para algunos subprocesos. 
Tabla 4. Aspectos para evaluar las afasias a través de los procesos neuropsicológicos del lenguaje

\begin{tabular}{|c|c|c|}
\hline \multirow{2}{*}{$\begin{array}{c}\text { Procesos } \\
\text { neuropsicológicos del } \\
\text { Lenguaje } \\
\text { Rojas (1999) basado } \\
\text { en Luria (1980) }\end{array}$} & \multicolumn{2}{|c|}{$\begin{array}{c}\text { Aspectos incluidos en una evaluación de las afasias } \\
\text { Ardila (2005) }\end{array}$} \\
\hline & Aspecto & \begin{tabular}{|c|} 
Tipo de prueba \\
\end{tabular} \\
\hline Expresión verbal & Producción & $\begin{array}{l}\text { Lenguaje espontáneo: hay o no lenguaje } \\
\text { espontáneo, cantidad, longitud de las } \\
\text { frases, fluidez, desviaciones fonéticas, } \\
\text { agramatismo-paragramatismo, } \\
\text { parafasias, habla vacía, neologismos, } \\
\text { jerga, prosodia, características del habla, } \\
\text { agilidad oral y verbal, disartria, apraxia } \\
\text { del habla, entre otras. }\end{array}$ \\
\hline Comprensión verbal & Comprensión & $\begin{array}{l}\text { Lenguaje conversacional. Señalar } \\
\text { (objetos, partes del cuerpo, colores, } \\
\text { acciones) y atender órdenes verbales } \\
\text { progresivamente más complejas. }\end{array}$ \\
\hline $\begin{array}{c}\text { Almacenamiento de la } \\
\text { expresión verbal }\end{array}$ & Denominación & $\begin{array}{l}\text { Objetos externos. Partes del cuerpo. } \\
\text { Colores. Acciones. }\end{array}$ \\
\hline \multirow[t]{2}{*}{$\begin{array}{c}\text { Procesos } \\
\text { reproductivos de la } \\
\text { expresión verbal }\end{array}$} & Repetición & $\begin{array}{l}\text { Pseudopalabras. Palabras de una, dos, } \\
\text { tres o cuatro sílabas. Frases } \\
\text { progresivamente más largas }(3,4, \ldots 18 \\
\text { palabras) }\end{array}$ \\
\hline & \multirow[t]{2}{*}{ Lectura } & $\begin{array}{l}\text { Letras, pseudopalabras, palabras, frases } \\
\text { y textos. }\end{array}$ \\
\hline & & $\begin{array}{l}\text { Comprensión. Paralexias, omisiones. } \\
\text { Palabras concretas-abstractas, nombres- } \\
\text { elementos gramaticales. }\end{array}$ \\
\hline & Escritura & $\begin{array}{l}\text { Firma. Letras, palabras, frases } \\
\text { (caligrafia, uso del espacio, errores en la } \\
\text { escritura de letras, paragrafias, } \\
\text { ortografía). Escritura espontánea. Copia, } \\
\text { dictado. Escritura de números }\end{array}$ \\
\hline
\end{tabular}

Fuente: Ardila, A. (2005 p. 253) "Las afasias". México: Universidad de Guadalajara. Rojas, J. (1999). Tratado sobre el lenguaje: lingüística, psicolingüística, neuropsicolingüística, afasiología. Medellín: 1 ra edición. Pragma Editores. 


\section{Validez y confiabilidad de la Batería}

La validez y confiabilidad de este intrumento, tanto en la primera parte (anamnesis) como en la segunda (prueba que evalúa la actuación lingüística), la dan los autores que se han tenido en cuenta para el respectivo diseño: en la anamnesis, bases del mínimo examen cognitivo (Vicario, 2007) y para la prueba, Luria (1980) y Rojas (1999), aportando los procesos neuropsicológicos del lenguaje que estructuran este cuestionario: expresión verbal, comprensión verbal, almacenamiento de la expresión verbal y procesos reproductivos de la expresión verbal; procesos que se correlacionaron con los aspectos incluidos en una evaluación de las afasis según Ardila (2005), mostrados en la tabla 4, los cuales permitieron finalmente el diseño de preguntas dentro de cada uno de dichos procesos. Además, el intrumento fue revisado por el afasiólogo Rojas Ortíz.

Una vez diseñada y revisada esta batería en las condiciones ya mencionadas se procedió a aplicarla a varios $\mathrm{H}-\mathrm{OP}$ para confirmar su efectividad en el sentido de caracterizar lingüísticamente las afasias y determinar su tipología. Esta última parte se logró con su aplicación a un total de diez H-OP. Realmente no hay un tiempo estipulado para aplicar ni la primera ni la segunda parte de esta batería. La primera parte (anamnesis) tendrá el tiempo que demande la entrevista con los familiares, con el H-OP mismo y la consulta a las historias clínicas ${ }^{2}$. La segunda parte (aplicación de prueba) tendrá el tiempo que demore el $\mathrm{H}$-OP en responder las preguntas formuladas; muchas veces contesta de inmediato, otras veces se toma su tiempo.

Los resultados que se presentan en el capítulo tres de este libro y que dan cuenta de la aplicación de la batería aquí propuesta, no pretenden dar datos estadísticos que se extiendan más allá de los casos valorados. Son una muestra de que la batería diseñada para el contexto colombiano específicamente el risaraldense, es aplicable y alcanza el objetivo para el cual fue diseñada, ya que hubo un caso adicional (reportado como caso once), según el cual se constata que esta batería aplica unicamente para pacientes afásicos, pues por tratarse de una disartría superó en su

2 Estas tres fuentes se constituyen en informantes alrededor de la batería que se diseñó para evaluar y caracterizar lingüísticamente las afasias en el contexto risaraldense: los familiares de los H-OP, los H-OP y las historias clínicas de cada uno de los H-OP. 
totalidad la actuación lingüística que allí se evalúa, encontrándose que su comprensión y producción de lenguaje, en cuanto a lo simbólico está intacta.

\subsection{Metodología}

La evaluación que se pretende hacer a los H-OP que, tras haber sufrido una lesión cerebral, presentan dificultades en la comprensión y producción de su lenguaje, tiene dos objetivos: a) diagnosticar las afasias, pues se puede estar ante un caso donde la producción del lenguaje se encuentre alterada, pero no a nivel simbólico, ni de almacenamiento de la información, sino a nivel del aparato de dicción, y la dificultad entonces sea más física que simbólica, como en el caso de las disartrias, donde la dificultad se centra en la articulación. b) caracterizar la afasia que esté padeciendo el $\mathrm{H}-\mathrm{OP}$ valorado, con el fin de ubicarla según las tipologías existentes y dar así una base lingüística sobre el nivel de lenguaje que está siendo afectado, al profesional que se vaya a encargar de la rehabilitación del caso.

\subsubsection{Métodos}

El análisis sindrómico sistémico aplica el método llamado “investigación neuropsicológica", el cual combina el método psicológico y el método psicofisiológico como lo asegura Rojas (1999), quien señala también dos consideraciones fundamentales para hacer posible una explicación clara y precisa de las alteraciones y el análisis de la desorganización estructural y procesal del lenguaje: "Cada paciente es un caso único y por lo tanto la investigación es única, y debe presentar los resultados como análisis cualitativo" (p.177).

Y, por su parte, el rendimiento lingüístico se evalúa cuantitativamente a través del análisis de las frecuencias de uso y las correlaciones significativas en la descripción de los niveles de la lengua alterados, evaluados a través de los procesos psicolingüísticos: expresión verbal, comprensión verbal, almacenamiento de la expresión verbal y procesos reproductivos de la expresión verbal, ejecutados por el $\mathrm{H}-\mathrm{OP}$ valorado. Con la intención de diseñar un instrumento que diagnosticara y caracterizara desde el punto de vista lingüístico las afasias, se tomó una muestra intencional de diez pacientes, algunos de ellos recluidos todavía en institución de atención medica, y los demás, pacientes que ya 
no estaban vinculados a centro de atención alguno. Todos, $\mathrm{H}-\mathrm{OP}$ que ya habían adquirido su lenguaje articulado.

\subsubsection{Materiales y recursos}

- Formato que corresponde a la anamnesis del paciente, con tres partes a saber: a) datos personales del H-OP valorado e información familiar, b) información sobre valoración clínica alrededor del episodio que le ocasionó su dificultad, y c) realizaciones lingüísticas del $\mathrm{H}-\mathrm{OP}$, relatadas por él mismo o por sus familiares.

- Prueba de desempeño en actuación lingüística para diagnosticar y caracterizar lingüísticamente las afasias, estructurado según los procesos psicolingüísticos: expresión verbal, comprensión verbal, almacenamiento de la expresión verbal y procesos reproductivos de la expresión verbal.

- Fichas para apoyar algunas preguntas de la prueba.

- Objetos de oficina (lápiz, bolígrafo, cuaderno, libros, entre otros) para apoyar algunas preguntas de la prueba.

- Formatos de registro cualitativo y cuantitativo de lo respondido en la aplicación de la prueba de desempeño para diagnosticar y caracterizar lingüísticamente las afasias.

- Una grabadora servirá como apoyo al momento de realizar la entrevista para la anamnesis, y también al momento de aplicar la prueba al H-OP valorado.

- Formato para levantar informe de cada caso evaluado.

\subsubsection{Procedimiento}

Con el fin de acceder a la evaluación de los $\mathrm{H}-\mathrm{OP}$ con alteraciones en su lenguaje, ocasionados por una lesión cerebral, se realizaron inicialmente entrevistas, incluyendo a sus familiares; información que se integró al formato de la anamnesis, el cual también indaga sobre la evaluación neurológica y clínica en general alrededor del episodio 
que originó dicha patología. Posteriormente se aplicó la prueba de desempeño en actuación lingüística para diagnosticar y caracterizar lingüísticamente la afasia sufrida por el $\mathrm{H}-\mathrm{OP}$ evaluado. Esta prueba se estructuró de acuerdo con los procesos psicolingüísticos: expresión verbal, comprensión verbal, almacenamiento de la expresión verbal y procesos reproductivos de la expresión verbal, propios de la actuación lingüística de los H-OP en condiciones normales de comunicación.

Estas dos partes (formato para la anamnesis y cuestionario para ser aplicado a los H-OP después de haber sufrido una lesión cerebral y presenten dificultades al comprender o producir lenguaje) se constituyen en la batería para el diagnóstico y caracterización lingüística de las afasias, y fueron diseñadas teniendo en cuenta los fundamentos de neurolingüística, específicamente los aspectos reconocidos como trastornos del lenguaje en el modelo de explicación y alteraciones del lenguaje (Luria, 1980), y teniendo en cuenta también los procesos neuropsicológicos del lenguaje según el mismo autor, en el mismo año. Se registraron los resultados de la aplicación de la prueba de desempeño en actuación lingüística, en formatos de registro cuantitativo y cualitativo, lo cual permitió visualizar qué proceso psicolingüístico está alterado. Finalmente, se levantan informes por cada uno de los casos evaluados, donde se correlaciona la información registrada en el formato de anamnesis y en los formatos de registro cualitativo, esperando como resultado la ubicación del H-OP como persona afásica, la ubicación de su afasia dentro de una tipología, y la constatación de qué característica está presentando dicha afasia.

\subsection{Diseño y aplicación}

La batería está diseñada para la evaluación de las alteraciones del lenguaje en su estructura y funcionamiento, y pretende la descripción y análisis de los trastornos de expresión, comprensión, almacenamiento y reproducción, con el fin de diagnosticar la afasia que esté padeciendo el H-OP valorado, y de caracterizar dicha afasia, de acuerdo con su desempeño lingüístico. La anamnesis y la prueba pueden posibilitar investigaciones psicológicas como niveles de conciencia, relación de antecedentes y consecuencias de la enfermedad, dolencias, reacciones frente al medio y hacia sí mismo, estados emocionales, orientación en el espacio y en el tiempo, entre otros, y posibilitará también el diseño 
de programas de rehabilitación del trastorno del lenguaje, si el caso lo permitiera.

Antes de realizar la evaluación se debe tener en cuenta: una corta conversación previa con el H-OP, saludarlo, presentarse y comunicarle el objetivo de la entrevista con el fin de evitarle ansiedades confusionales. Si el H-OP presenta un estado de somnolencia, excitación o confusión, debería aplazarse el examen, ya que la confiabilidad de los datos depende de cierto grado de alerta o niveles de conciencia, atención y concentración.

\subsubsection{Anamnesis}

La valoración del lenguaje se inicia con la anamnesis, la cual pretende reunir datos particulares y familiares de la historia de la persona valorada, anteriores y posteriores a su enfermedad. El examinador debe preparar una entrevista con sus familiares, para encontrar información acerca del comportamiento verbal de éste en el curso de su vida cotidiana antes del trastorno afásico. En este sentido, es necesario conocer otros asuntos como: estructura familiar, hábitos lingüísticos premórbidos, nivel de lectura, idiomas aprendidos, condiciones lingüísticas posmórbidas, nivel cultural y de escolaridad, ocupación y lateralidad o preferencia manual.

Así entonces, para un adecuado registro de los datos, es necesario conocer algunos hechos tales como: datos particulares y generales del H-OP, condición familiar (familia nuclear, historia de la mano dominante y de trastornos del lenguaje), motivo de consulta, cambios lingüísticos después de la lesión, cambios en las relaciones familiares y sociales, la historia previa (relato del accidente o del origen de la enfermedad) y la historia clínica posible (médica, neurológica, psicológica y de terapia de lenguaje). Es recomendable también, una entrevista inicial para darse cuenta del estado de conciencia del $\mathrm{H}-\mathrm{OP}^{3}$ y su función fática: capacidad de iniciar, mantener y terminar el proceso comunicativo, propio de la entrevista.

3 Retomando parte del Mínimo examen cognitivo (MEC) propuesto por Vicario (2007), específicamente el Test mínimo de examen del estado mental que evalúa la orientación autopsíquica en tiempo y lugar. 


\subsubsection{Prueba de desempeño en actuación lingüística}

Las siguientes son algunas recomendaciones previas a la aplicación de la prueba: es preciso que el $\mathrm{H}$-OP que va a ser examinado, cuente con suficiente agudeza auditiva, o en su defecto, reconocer por qué oído escucha mejor. Hay que cerciorarse que sepa leer y escribir, puesto que la prueba cuenta con algunos ítems donde lo debe hacer. Si, llegado el caso, el evaluado no sabe leer, hay que suprimir esta parte de la prueba y reemplazarla por una que esté al alcance de sus posibilidades comunicativas: programa radial, programa televisivo, situación cotidiana cercana a él, entre otras opciones.

La duración de la prueba es corta e incluye todos los aspectos del lenguaje que se pretenden evaluar, pero el investigador podrá diseñar otras pruebas relativamente estandarizadas que insistan en los trastornos dominantes o en un síntoma particular. Los temas y el lenguaje que se utiliza en la prueba están al alcance de $\mathrm{H}$-OP que inclusive sean incultos. Se aconseja que el examinador esté guiado por una actitud flexible y variable, y deba aprovechar al máximo todas las manifestaciones y los recursos comunicativos del $\mathrm{H}$-OP examinado; incluso que tome la iniciativa. Tener en cuenta, además, que hay alteraciones del habla de naturaleza no afásica como las afonías y las disartrias, que también pueden asociarse a la afasia como alteraciones aisladas.

La batería que se diseñó para el diagnóstico y caracterización lingüística de las afasias consta entonces de tres partes, como lo muestra la Figura 15. 
Figura 15. Batería diseñada para diagnosticar y caracterizar las afasias
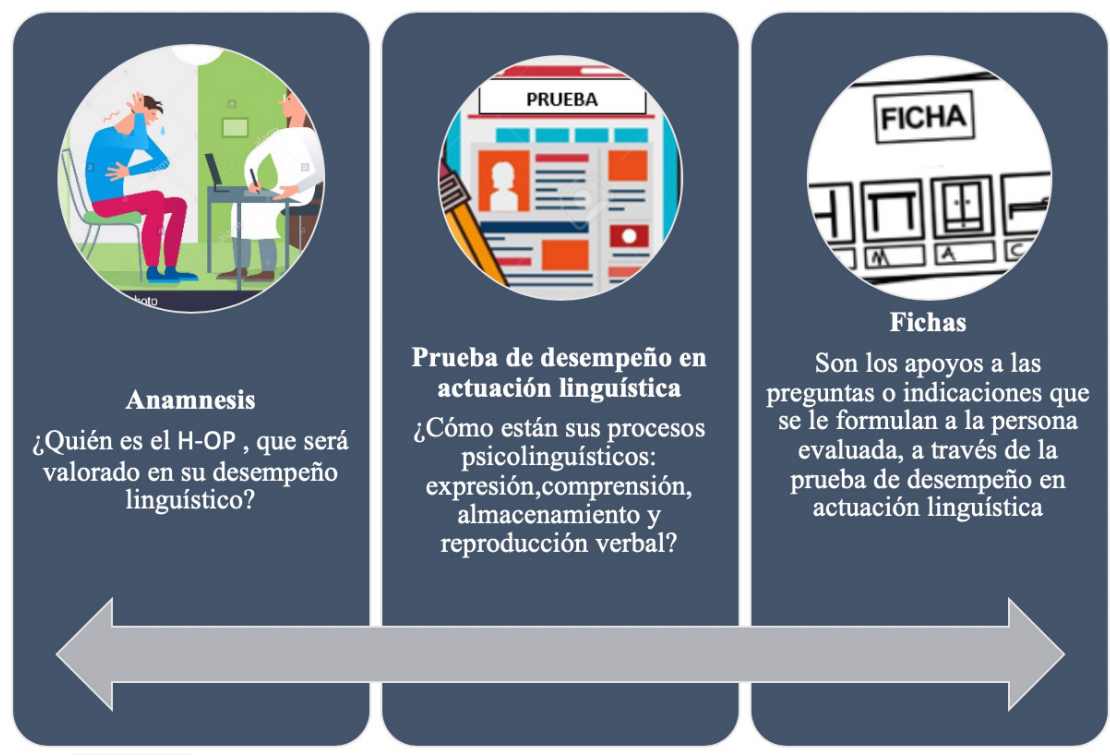

Fuente: Meganeura. (2018). Consultorio médico paciente consulta. Terapeuta médico examinar joven para el diagnóstico. Plano simple ilustración de dibujos animados. Extraído desde:

https://www.alamy.es/foto-consultorio-medico-paciente-consultaterapeuta-medico-examinar-joven-para-el-diagnostico-plano-simpleilustracion-de-dibujos-animados-173494110.html-

Yupiramos. (S.F) Foto de archivo - Muestra de ilustración vectorial teléfono inteligente prueba de dibujos animados hombre eps 10. Extraído desde:

https://es.123rf.com/photo_63322954_muestra-de-ilustraci\%C3\%B3nvectorial-tel\%C3\%A9fono-inteligente-prueba-de-dibujos-animadoshombre-eps-10.html -

Castaño, M y Díaz, S. (S.F). Léxico y lectoescritura - Fichas. Extraído desde:

http://aulaabierta.arasaac.org/materiales-caa-lexic-lectoescritura-fichas 


\section{Batería}

Diagnóstico y caracterización de las afasias

en el departamento de Risaralda

María Gladis Agudelo Gil

Luz Marina Henao Restrepo

Pereira

Universidad Tecnológica de Pereira

Proyecto

Evaluación y rehabilitación de las afasias desde una perspectiva psicolingüistica en el departamento de Risaralda

Código 4-13-4

2019 


\section{A N A M N E S I S}

Caso $\mathrm{N}^{\circ}$

fecha:

Lugar de la entrevista

\section{Identificación Personal}

Nombres y apellidos

Dirección y teléfono

Fecha de nacimiento

Edad

Lugar de nacimiento

Sexo

Estado civil

Número de hijos

Lateralidad

\section{Información Complementaria}

Educación formal

Ocupación

\section{Entrevista Familiar}

Nombres y apellidos del informante

Parentesco

Edad del informante Tel:

Conformación de la familia nuclear (padres, hermanos, entre otros):

Con qué miembros de su familia nuclear vive:

Profesión u oficio de las personas con quienes vive: 


\section{Historia Clínica}

Remitido por (Entidad de salud que atiende el caso)

Motivo de consulta:

Etiología (Traumática, vascular, tumoral, entre otras):

Atención psicológica:

Terapia del lenguaje:

\section{Condiciones Premórbidas}

Antes de la lesión ¿cómo eran sus procesos comunicativos? Descríbalos a continuación:

De expresión (al hablar con los demás):

\section{$\mathrm{Al}$ leer}

Al escribir

\section{Condiciones Posmórbidas}

Después de la lesión ¿cómo están sus procesos comunicativos? Descríbalos a continuación: ¿Cómo se comunica y qué recursos utiliza? 
¿Cómo es su trato hacia los demás y específicamente sus conversaciones con la familia?

\section{Trastornos Concomitantes a las Alteraciones de Lenguaje}

¿Qué otros trastornos trajo consigo la lesión o el episodio, diferentes a los de lenguaje?

\section{Entrevista al paciente}

Cuénteme que le pasó

¿Dónde estamos?

¿Qué día es hoy? 


\section{PRUEBA DE DESEMPEÑO EN ACTUACIÓN LINGÜÍSTICA}

\section{LENGUAJE EXPRESIVO (EXPRESIÓN VERBAL)}

CASO $\mathrm{N}^{\circ}$

FECHA:

LUGAR DE RESOLUCIÓN DE LA PRUEBA:

Pregúntele al H-OP:

a. ¿Por qué está usted aquí?

b. Cuénteme ¿Qué fue lo que le ocurrió?

c. Y ¿Cómo se siente ahora?

d. ¿Qué planes tiene para el futuro?

e. Y ¿Cómo lo ha tratado la familia?

\subsection{LENGUAJE DIALOGADO}

Establezca un diálogo con el H-OP:

a. ¿Qué hizo usted por la mañana?

b. Y ¿Qué va a hacer por la noche?

c. ¿Cómo se siente en la casa?

d. ¿Qué desayunó Usted hoy?

e. ¿Qué programas escucha en la radio o ve en la televisión? 


\subsection{LENGUAJE MONOLOGADO ILUSTRATIVO}

Pídale al H-OP valorado que le cuente ¿Qué está sucediendo en las situaciones de la Ficha $\mathrm{N}^{\circ} 1$ ? Situación a:

Situación b:

Situación c:

Situación d:

Situación e:

\subsection{LENGUAJE MONOLOGADO NARRATIVO}

Léale al H-OP la fábula "el caballo y el burro" (Ficha N²) y luego pídale que le cuente con sus propias palabras la historia que escuchó (Esperar la respuesta espontanea del H-OP, de lo contrario preguntar por los siguientes indicadores).

a. Personajes

b. Acciones del burro

c. Actitud del caballo

d. Moraleja

e. Relación Imagen-Texto

\subsection{LENGUAJE MONOLOGADO TEMÁTICO}

Pregúntele al H-OP sobre qué tema quiere hablar, y deje que lo desarrolle libremente (Esperar la respuesta espontánea del H-OP, de lo contrario preguntar por los siguientes indicadores):

a. (Para elegir el tema) ¿Le gustan los animales? ¿cuáles? ¿Qué aficiones tiene usted o qué es lo que más le gusta hacer? ¿Le gusta visitar Lugares? ¿Cuáles?

b. Descripción Característica 1 (Tema elegido)

c. Descripción Característica 2 (Tema elegido)

d. Descripción Característica 3 (Tema elegido)

e. Descripción Característica 4 (Tema elegido) 


\section{LENGUAJE RECEPTIVO (COMPRENSIÓN VERBAL)}

\subsection{COMPRENSIÓN FONÉMICA}

Pídale al H-OP que repita los sonidos que aparecen a continuación. Si presenta dificultades en la pronunciación, aplique pruebas de escritura o el principio de los reflejos condicionados o de cambio de estimulación.

a. Sonidos aislados
/ a /
$/ \mathrm{r} /$
$/ \mathrm{b} /$
$/ \mathrm{t} /$
/f /

\section{Observación del evaluador}

b. Sonidos correlativos

$/ \mathrm{p}-\mathrm{b} /$

$/ \mathrm{t}-\mathrm{d} /$

$/ \mathrm{k}-\mathrm{g} /$

$/ \mathrm{r}-\mathrm{r} /$

/ i-u /

\section{Observación del evaluador}

c. Sonidos disyuntivos

$/ \mathrm{a}-\mathrm{u} /$
$/ \mathrm{m}-\mathrm{f} /$
$/ \mathrm{n}-\mathrm{k} /$
$/ \mathrm{p}-\mathrm{r} /$
$/ \mathrm{x}-\mathrm{b} /$

\section{Observación del evaluador}

d. Diptongos crecientes

[ pjáno ] : piano

[ djénte ]: diente

[ djós ] : dios

[ kwátro ] : cuatro

[bwéno ] : bueno

\section{Observación del evaluador}

e. Diptongos decrecientes

[ xairo ] : jairo

[ réina ] : reina

[bóina ] : boina

[ láura ] : laura

[ páuta ] : pauta

Observación del evaluador 


\subsection{COMPRENSIÓN DE PALABRAS}

a. Identificación de objetos

Pídale al H-OP que señale (téngalos a disposición para que el H-OP los señale):

El lápiz.

El bolígrafo.

El cuaderno.

El libro.

El lápiz y el libro.

Observación del evaluador

b. Identificación partes del cuerpo

Pídale al H-OP que señale en sí mismo:

Las cejas

El mentón

Los ojos

La boca

La nariz

Observación del evaluador

c. Identificación partes del cuerpo

Pídale al $\mathrm{H}-\mathrm{OP}$ que señale en la ficha $\mathrm{N}^{\circ} 3$

Las cejas

El mentón

Los ojos

La boca

La nariz

Observación del evaluador

d. Definición

Pregúntele al H-OP que significa:

Tío

Soltero

Heladería

Alegría

Automóvil

Observación del evaluador

e. Oposición fonológica

Pregúntele al H-OP la diferencia entre:

Peso / beso

Oveja / abeja

Poso / puso

$\mathrm{Sal} / \mathrm{cal}$

Paso / piso

Observación del evaluador 


\subsection{COMPRENSIÓN DE ESTRUCTURAS GRAMATICALES SIMPLES}

Ordene al H-OP

a. Abra la boca.

(Lo hace correctamente: Sí __ No __ Parcialmente_)

b. Cierre los ojos.

(Lo hace correctamente: Sí No ___ Parcialmente__

c. Muestre los zapatos.

(Lo hace correctamente: Sí No ___ Parcialmente__

d. Con la mano derecha señale el hombro izquierdo.

(Lo hace correctamente: Sí No Parcialmente__

e. Señale el hombro derecho con la mano izquierda.

(Lo hace correctamente: Sí No Parcialmente_)

\subsection{COMPRENSIÓN DE ESTRUCTURAS GRAMATICALES COMPUESTAS} Ordene al H-OP:

a. Señale el lápiz y coja el bolígrafo.

(Lo hace correctamente: Sí No Parcialmente__

b. Señale el boligrato y coja el lápiz.

(Lo hace correctamente: Sí No __ Parcialmente__

c. Cierre los ojos y abra la boca.

(Lo hace correctamente: Sí No Parcialmente__

d. Coloque la mano izquierda sobre el cuaderno y con la mano derecha recoja el libro. (Lo hace correctamente: Sí No Parcialmente_)

e. Abra el libro y cierre la boca.

(Lo hace correctamente: Sí No Parcialmente_)

\subsection{COMPRENSIÓN DE ESTRUCTURAS COMPLEJAS}

Escuche con atención lo que le voy a leer: "El espía que llegó a Pereira, entregó el maletín que contenia el dinero a la morena de ojos verdes en la habitación del hotel". Pregunte:

a. ¿Quién llegó a Pereira?

(Lo hace correctamente: Sí No ___ Parcialmente__

b. ¿Qué contenía el maletín?

(Lo hace correctamente: Sí No ___Parcialmente__

c. ¿Quién recibió el dinero?

(Lo hace correctamente: Sí No Parcialmente_)

d. ¿Dónde quedaba la habitación?

(Lo hace correctamente: Sí No ___ Parcialmente__

e. ¿Quién tenía los ojos verdes?

(Lo hace correctamente: Sí No __ Parcialmente__ 


\subsection{COMPRENSIÓN DE ESTRUCTURAS LÓGICO-GRAMATICALES}

\section{Relaciones espaciales}

Pídale al H-OP que señale en la ficha $\mathrm{N}^{\circ} 4$ (lo preguntado para que señale es: a, b, c y d):

a. El recipiente con objetos debajo de la mesa

(Correcto _ Incorrecto___).

b. El recipiente a la derecha de la mesa

(Correcto _ Incorrecto __ ).

c. El recipiente encima de la mesa

(Correcto _ Incorrecto___).

d. El recipiente detrás de la mesa

(Lorrecio _ incorrecio __.).

e. En este momento estoy ¿A su derecha, a su izquierda, frente o detrás de usted?

(Correcto _ Incorrecto __ ).

\section{Relaciones temporales}

Pregunte al H-OP:

a. ¿La siesta se hace antes de la cena o después del almuerzo?

b. ¿La estudiante se viste para bañarse o se baña para vestirse?

c. ¿La bicicleta atropelló al niño antes del accidente, en el accidente o después del accidente?

d. ¿La tarde llega después de la mañana o la tarde antes de la mañana?

e. ¿El día martes es antes que el jueves o después del miércoles?

\section{Comparaciones.}

a. Si José es más flaco que Martín ¿Cuál de los dos es más gordo?

b. Si Ana es más rica que María y más pobre que Lucia ¿Cuál de las tres es más rica?

c. ¿Es lo mismo decir: “Juan besó a María” que "María besó a Juan”?

d. ¿Es lo mismo decir: "el estudiante abrió el libro" que "el libro fue abierto por el estudiante"?

e. Es lo mismo decir: "Jaime lee el poema" que "el poema es leído por Jaime" 
Caso atributivo genitivo .

a. ¿Qué es de Usted el padre de su hermano?

b. ¿Qué es de Usted el padre del padre de su hermano?

c. ¿Es lo mismo el padre del hermano que el hermano del padre?

d. ¿El tío es hermano del padre o es el primo de la madre?

e. ¿Es lo mismo el padre del primo que el hermano del padre?

\section{Absurdos}

Pregunte al H-OP si es cierto o falso:

a. Los cerdos vuelan de rama en rama en los arboles del bosque $\left(\mathrm{F} \_\right.$. V_

b. El león canta villancicos en navidad $\left(F_{-} \text {. V_ }\right)_{\text {. }}$

c. Los bomberos apagan el fuego con gasolina ( $\mathrm{F}_{-}$. V_ . .

d. Los niños ladran a los perros ( $F_{-}$. V_ $)_{\text {. }}$

e. Los arboles vuelan hasta las verdes estrellas $\left(\mathrm{F}_{-}\right.$. $\mathrm{V}_{-}$). 


\section{LENGUAJE MEMORIZADO (ALMACENAMIENTO DE LA EXPRESIÓN VERBAL)}

\subsection{RETENCIÓN DE SERIES DE SONIDOS}

Pídale al H-OP que repita:

a. Sonidos aislados

[a-t-r]

[b-r-d-f]

[k-1-u-m-g]

(Repite correctamente: Sí No Parcialmente__

b. Por parejas

[au-pt]

[bi-kg-dn]

[ap-gt-db-uf]

(Repite correctamente: Sí No __ Parcialmente__

c. Sílabas abiertas

[blo-tri-fru]

[kre-mo-pla-blu]

[tri-pla-blo-kre-fri]

(Repite correctamente: Sí No Parcialmente__

d. Silabas abiertas y cerradas

[tri- trik, blo- blon]

[pa- pan, bli- blik, fre - frel]

[lu - luk, fro- fron, pe, pen, gri - grik]

(Repite correctamente: Sí No Parcialmente__

e. Por segmentos

[pe ri ka li fra xi lís ti ko]

Pericalifragilístico

(Repite correctamente: Sí No ___ Parcialmente__

\subsection{RETENCIÓN DE SERIES DE PALABRAS}

Pídale al H-OP que repita:

a. Palabras cortas conocidas

- Pan - sol- rey

- Cal-lio- ron- mil

- Son - frío- rín- ley- sal

(Repite correctamente: Sí No Parcialmente__

b. Palabras largas conocidas

- Miércoles - cáscara- universitario

- Murciélago- lamentable- portafolio- precisamente

- Abecedario - rinoceronte- carrocasa- ensimismado- eternamente (Repite correctamente: Sí No Parcialmente

c. Palabras desconocidas

- Pánfilo- heteróclito- logopedia

- Ensalmo- jurel- mentecato- perenne

- Pericote- rebozó- chueca- diantre- epíteto (Repite correctamente: Sí No Parcialmente__ 
d. Palabras cortas, largas y desconocidas

- Pan - miércoles- pánfilo

- Sol - rinoceronte- epíteto- rey

- Portafolio- sal- heteróclito- ron- jurel (Repite correctamente: Sí __ No __ Parcialmente_)

e. Logotomas

- Garfintal- carable

- Garipillo- olicuscús- zanzibara

- Riminicuiqui- garipillo- pericalifragilistico- olicuscús (Repite correctamente: Sí No Parcialmente__

\subsection{RETENCIÓN DE ORACIONES}

Pídale al H-OP que repita:

a. El hombre busca una sonrisa. (Repite correctamente: Sí No ___ Parcialmente__

b. El niño busca más con el corazón que con la cabeza. (Repite correctamente: Sí No Parcialmente_)

c. El hombre y el niño aman íntimamente la poesía como alimento de sus vidas. (Repite correctamente: Sí No Parcialmente__

d. La altura del edificio es mayor que la que la de la casa. (Repite correctamente: Sí No Parcialmente_)

e. La niña gusta de practicar patinaje, mientras que el niño prefiere el fútbol. (Repite correctamente: Sí No Parcialmente__

\subsection{RETENCIÓN DE ACONTECIMIENTOS EN UN RELATO}

Léale al H-OP (Ficha 5) y luego pregúntele qué recuerda (Esperar la respuesta espontanea del H$\mathrm{OP}$, de lo contrario preguntar por los siguientes indicadores)

a. ¿Cuándo sucedió el naufragio?

b. ¿Cuántas personas naufragaron?

c. ¿Hacía dónde se dirigía la nave?

d. ¿Cuánto tiempo duró la búsqueda de los náufragos?

e. ¿Cuánto tiempo sobrevivieron finalmente? 


\subsection{LENGUAJE AUTOMÁTICO}

a. Series numéricas. Pídale al paciente que cuente del 1 al 10, y luego regrese del 10 al 1 . (Lo hace correctamente: Sí No Parcialmente__

b. Días de la semana (luego en forma progresiva).

(Lo hace correctamente: Sí No Parcialmente__

c. Meses del año.

(Lo hace correctamente: Sí No Parcialmente__

d. Pídale que diga el abecedario (a,b,c...) (Si el paciente no es alfabetizado, pedirle que cante su canción preferida)

(Lo hace correctamente: Sí No ___ Parcialmente__

e. Canto. Pídale que cante el Himno Nacional.

(Lo hace correctamente: Sí No Parcialmente__

\subsection{DENOMINACIÓN DE SUS PARTES DEL CUERPO}

Señale las siguientes partes del cuerpo y pídale al H-OP que las nombre:

a. Las cejas.

(Nombra correctamente: Sí No Parcialmente__

b. El mentón.

(Nombra correctamente: Sí No ___ Parcialmente__

c. Los ojos.

(Nombra correctamente: Sí No Parcialmente__

d. La boca.

(Nombra correctamente: Sí No Parcialmente__

e. La nariz.

(Nombra correctamente: Sí No Parcialmente__

\subsection{DENOMINACIÓN DE LAS PARTES DEL CUERPO EN UNA IMAGEN}

Pídale al H-OP que señale y nombre las siguientes partes del cuerpo en la ficha No. 3
a. Las cejas
(Lo hace correctamente: Sí No Parcialmente__
b. El mentón
(Lo hace correctamente: Sí No Parcialmente__
c. Los ojos
(Lo hace correctamente: Sí No Parcialmente__
d. La boca
(Lo hace correctamente: Sí No Parcialmente__
e. La nariz
(Lo hace correctamente: Sí No Parcialmente__ 


\subsection{DENOMINACIÓN DE SERES Y OBJETOS EN DIBUJOS}

Presente al H-OP las Fichas $\mathrm{N}^{\circ} 6,7$ y 8 , y pídale que nombre lo que ve.

Ficha $\mathrm{N}^{\circ} 6$ : a.

Ficha $\mathrm{N}^{\circ} 7$ : b.

c.

Ficha $\mathrm{N}^{\circ} 8$ : $d$.

e.

\subsection{DENOMINACIÓN POR DESCRIPCIONES}

Pídale al H-OP que diga cómo se llama:

a. Cada una de las 24 partes en que se divide el día

(Lo hace correctamente: Sí ___ No __ Parcialmente__

b. Un profesor que le haya enseñado

(Lo hace correctamente: Sí ___ No __ Parcialmente__

c. El presidente de Colombia

(Lo hace correctamente: Sí ___ No ___ Parcialmente__

d. Un vecino

(Lo hace correctamente: Sí __ No __ Parcialmente_)

e. Un amigo de infancia

(Lo hace correctamente: Sí ___ No __ Parcialmente__

\subsection{DEFINICIONES FUNCIONALES}

Pídale al H-OP que diga para qué sirve:
a. La peinilla
b. El cepillo
c. El jabón
d. El dinero
e. El vestido 


\section{LENGUAJE REPRODUCIDO (PROCESO REPRODUCTIVOS DE LA EXPRESIÓN VERBAL)}

\subsection{LECTURA}

Pídale al H-OP que lea en voz alta

Letras (Ficha No9).

a.

b.

c.

d.

e.

Silabas (Ficha $\left.\mathrm{N}^{\mathrm{0}} 10\right)$
a.
b.
c.
d.
e.

Palabras (Ficha Nº11)
a.
b.
c.
d.
e.

Oraciones (Ficha $\mathrm{N}^{\circ} 12$ )
a.
b.
c.
d.
e.

Texto entero (Ficha $\mathrm{N}^{\circ} 13$ )

Se califica esta lectura de acuerdo con los siguientes indicadores:

a. Articulación

b. Pausas respectivas de los signos de puntuación

c. Adición u omisión de letras, sílabas y palabras

d. Permutación de letras, sílabas y palabras

e. Sustitución de letras, silábas y palabras

\section{Observación del evaluador}




\subsection{ESCRITURA}

Pídale al H-OP que escriba:

Escritura al dictado (Proporciónele al H-OP papel suficiente para que escriba todo lo que se le dicta):

Escriba las siguientes palabras:
a. Mar
b. Árbol
c. Elefante
d. Democracia
e. Cardiovascular

Escriba las siguientes oraciones (oraciones simples):
a. Pedro estudia Arquitectura
b. Los tres enanitos llegaron juntos al bosque
c. El día de la madre se celebra en varios países
d. Bogotá es la ciudad capital de Colombia
e. Los estudiantes salen a vacaciones en diciembre

Escriba las siguientes oraciones (oraciones complejas):
a. María trabaja mientras que su hijo estudia en el Colegio
b. La Universidad es la institución donde se pueden formar todos nuestros jóvenes
c. Se requiere el diálogo para que nuestros pueblos vivan en armonía
d. Los ciudadanos tenemos derecho a la libre expresión y tenemos el deber de respetar las opiniones de los demás
e. El no pudo ir a trabajar, está enfermo.

Escritura espontánea seriada:
a. Escriba los números del 1 al 5
b. Escriba los nombres de los días de la semana
c. Escriba los nombres de cinco meses del año
d. Escriba su núcleo familiar
e. Escriba las primeras 5 letras del alfabeto. 
Escritura espontánea narrativa:

Escriba una anécdota que recuerde. Según lo que el H-OP escriba se valorarán los siguientes indicadores:

a. Legibilidad

b. Uso de conectores

c. Manejo de los tiempos a conjugar

d. Ubicación temporal

e. Ubicación espacial

\section{Observación del evaluador}

\subsection{REPETICIÓN}

Pídale al H-OP que repita después de usted:

Palabras

(Ficha Nº11)

a.

b.

c.

d.

e.

Oraciones

(Ficha $\mathrm{N}^{\circ} 12$ )
a.
b.
c.
d.
e.

\section{Observación del evaluador}





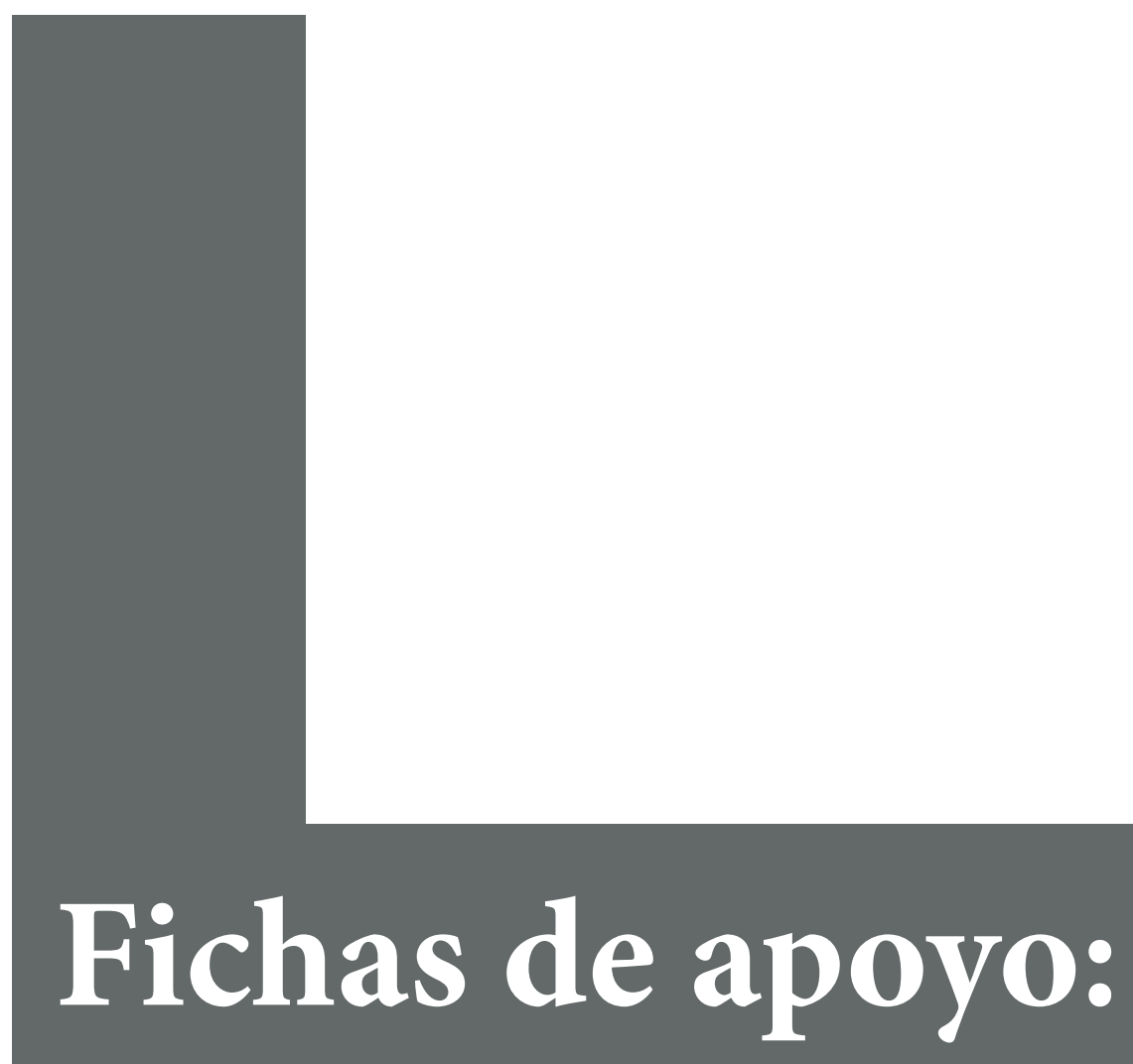

\section{PRUEBA DE DESEMPEÑO EN ACTUACIÓN LINGÜÍSTICA}





\section{Ficha $\mathbf{N}^{\mathbf{0}} \mathbf{1}$}

Figura 16. Apoyo para medir el lenguaje monologado ilustrativo en la prueba.
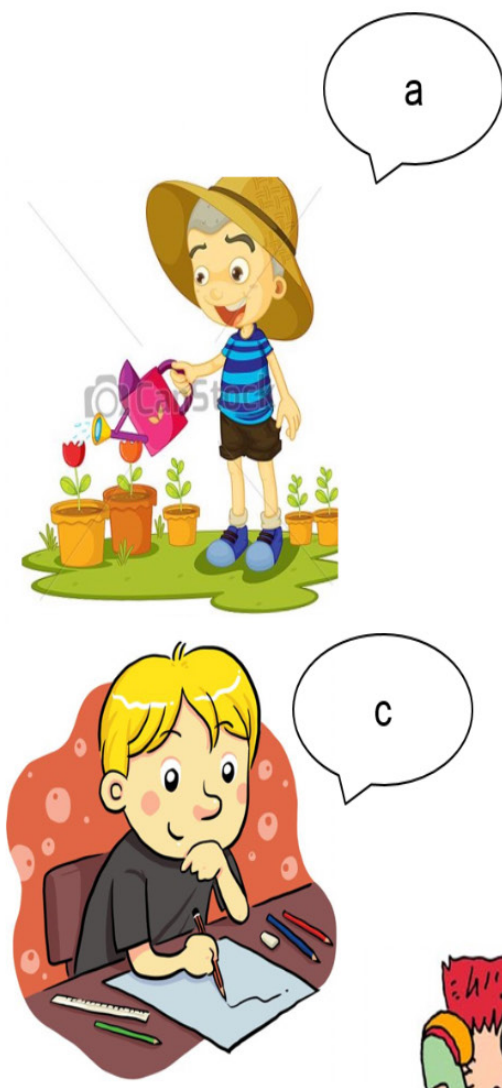

www.canstockphoto.es (niño regando el jardín) www.freepik.es (señora cocinando) www.okhosting.com (niño escribiendo) www.depositphotos.es (niña bajo la lluvia) www.let' smasterEnglish. es (niño habla por teléfono)
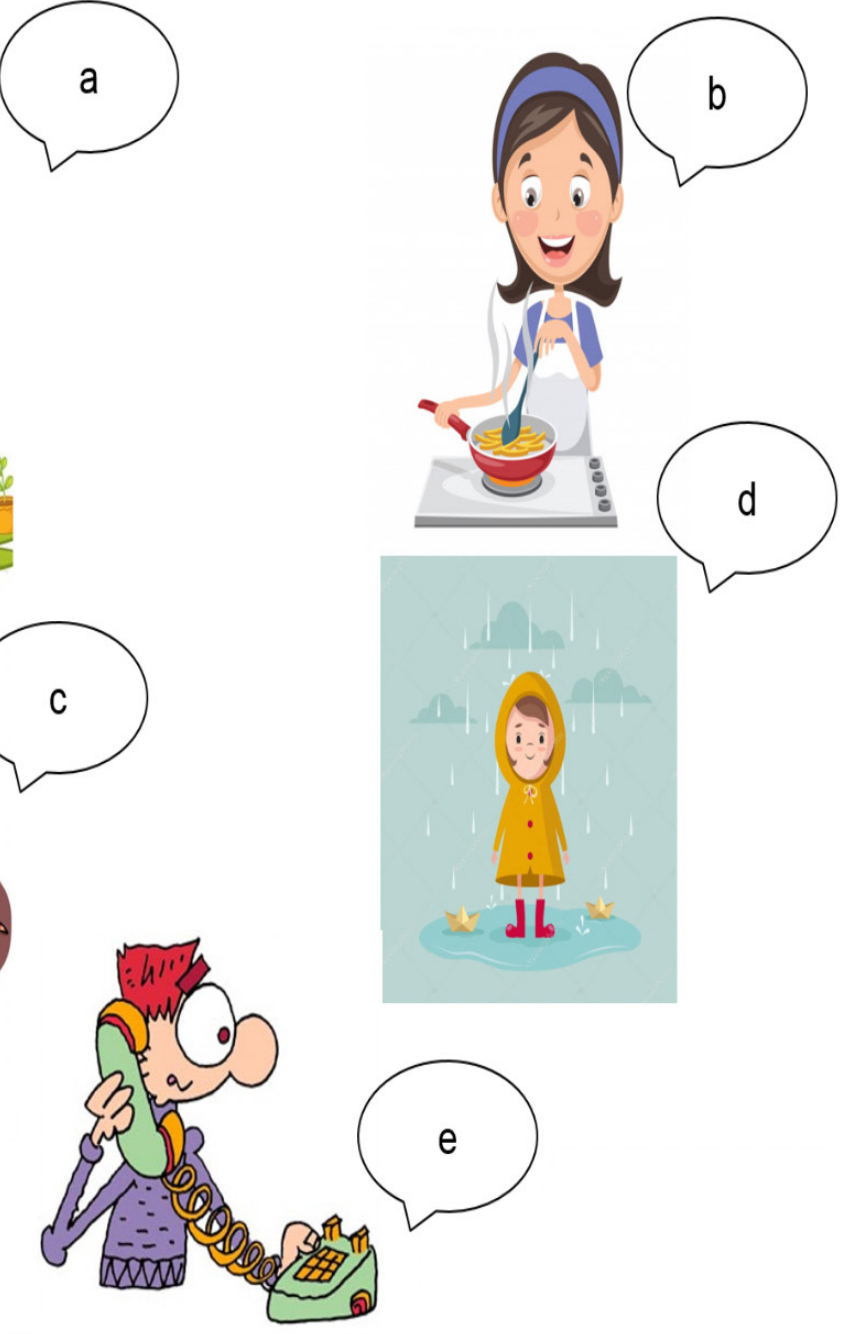

C

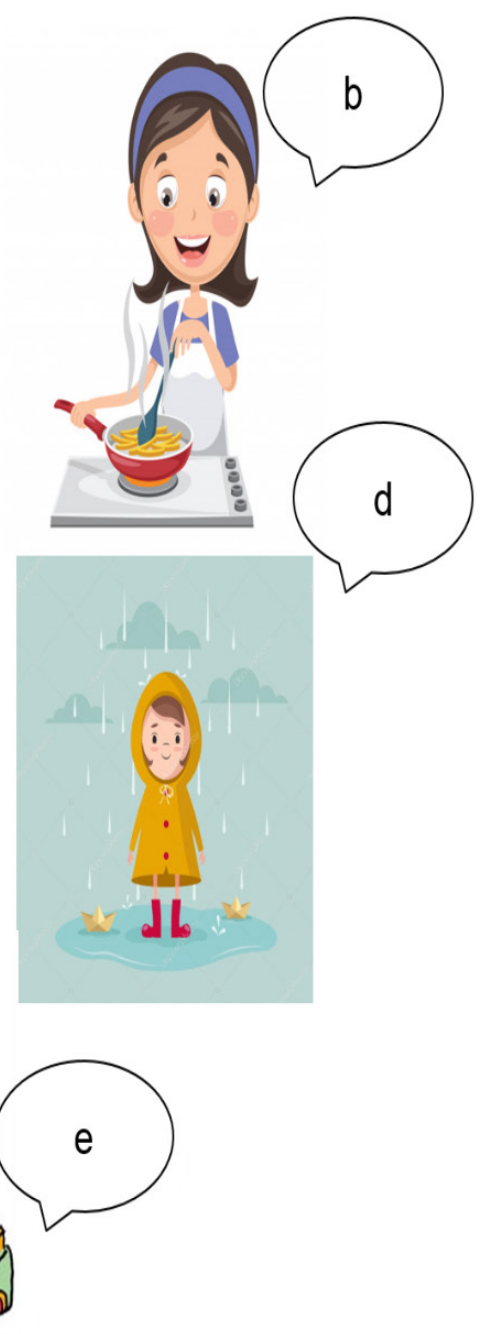




\section{Ficha $\mathbf{N}^{2} 2$}

Figura 17. Apoyo para valorar el lenguaje monologado narrativo en la prueba.

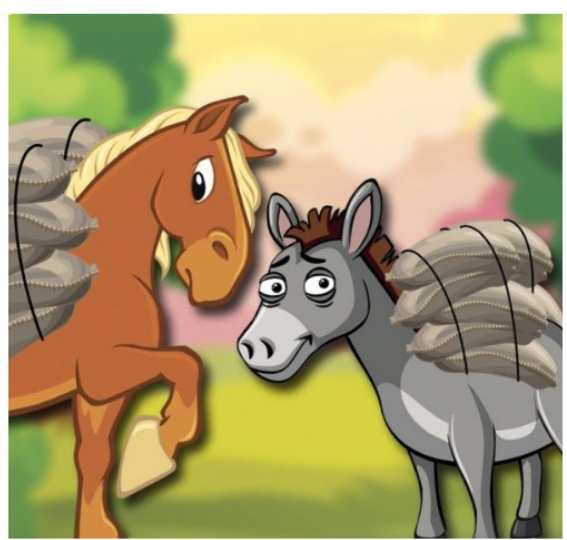

\section{EL CABALLO Y EL BURRO}

En este mundo hay que ayudarse unos a otros, porque si muere tu vecino, su carga caerá sobre ti.

Iba un burro caminando al lado de un caballo. El pobre burro llevaba una carga muy pesada, estaba cansado y a punto de caerse. El caballo sólo llevaba un bulto, iba contento y tranquilo.

El burro le dijo al caballo que le ayudara con su carga porque se sentía morir; el caballo no le ayudó y siguió su camino sin hacer caso.

Al rato, el pobre burro cayó al suelo muerto de cansancio; entonces vino el hombre y le dio al caballo toda la carga del burro y además el cuerpo del burro muerto.

www.guiainfantil.com (caballo y burro) 


\section{Ficha $\mathbf{N}^{\mathbf{0}} 3$}

Figura 18. Apoyo para valorar la comprensión de palabras en tanto identificación en partes del cuerpo

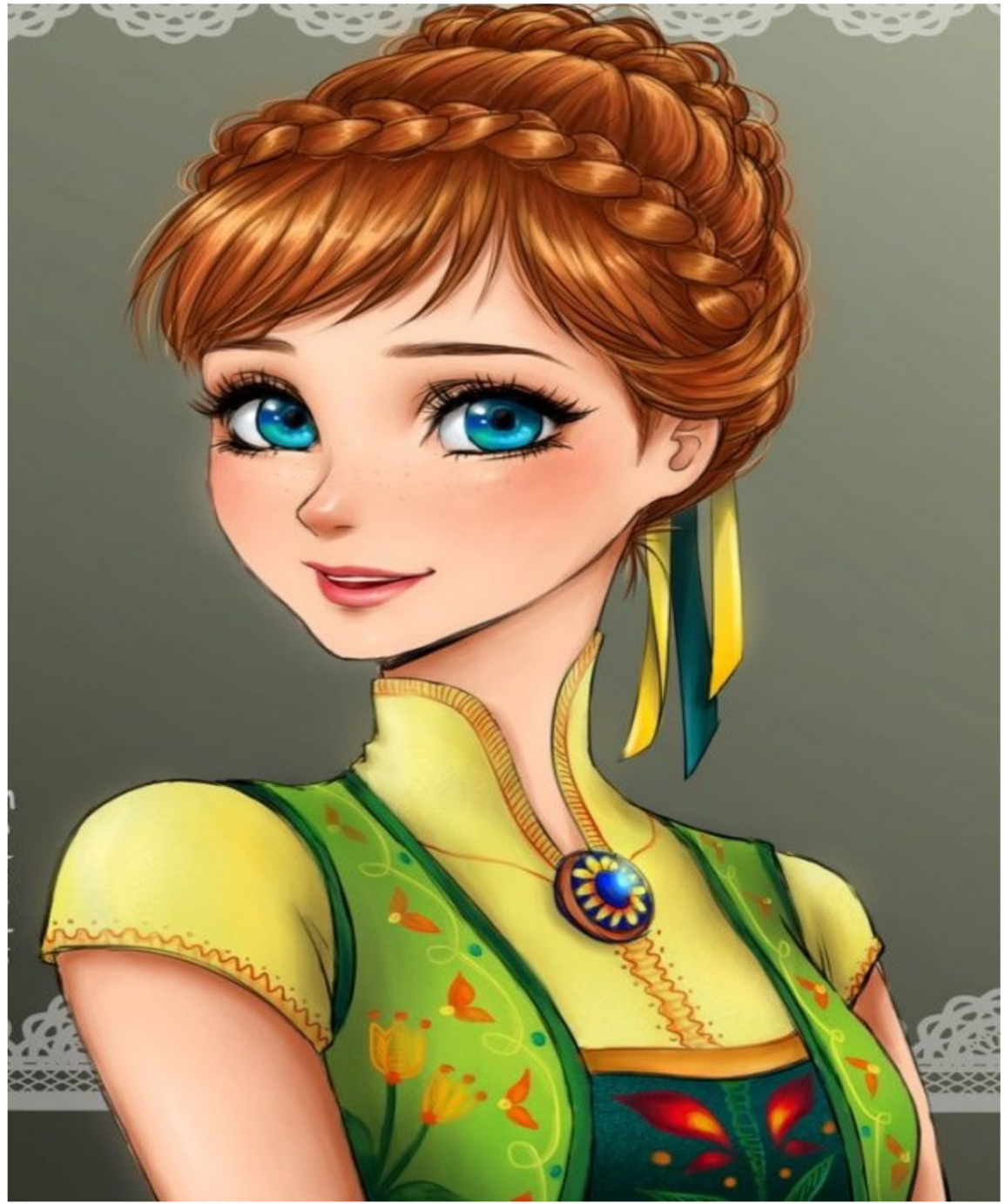

Fuente: Safdar, M. (S.F). I Draw Disney Princesses As Anime Characters. Extraído desde: https://www.boredpanda.com/disney-princesses-anime-style-maryamsafdar/?utm_source=google\&utm_medium=organic\&utm_campaign=organic 


\section{Ficha $\mathbf{N}^{\circ} 4$}

Figura 19. Apoyo para valorar la comprensión de estructuras lógico-gramaticales caso relaciones espaciales.
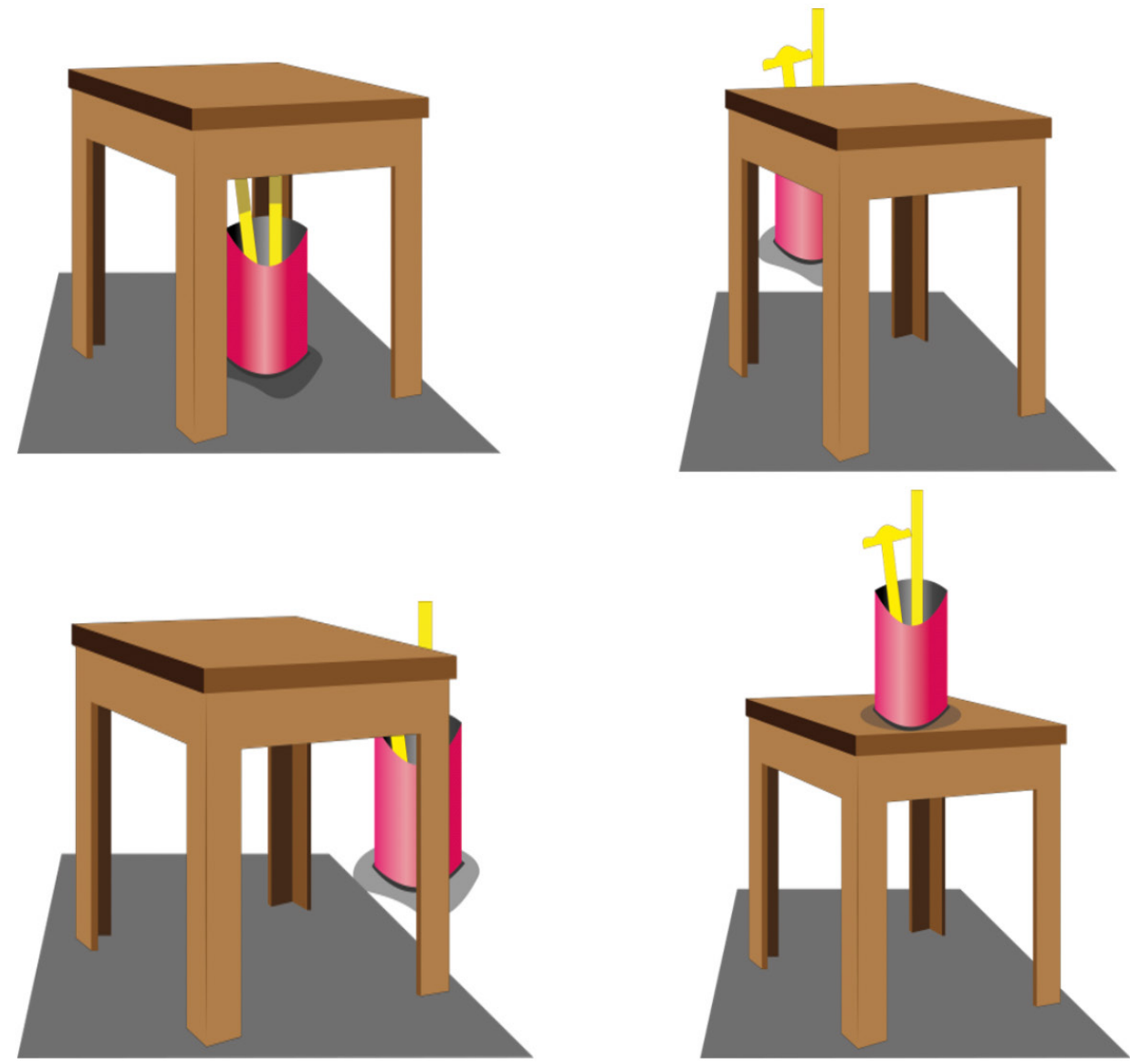

Fuente: José García (2018) 
Ficha $N^{\circ} 5$

\section{Fragmento inicial del "Relato de un náufrago"}

\section{Autor: Gabriel García Márquez.}

El 28 de febrero de 1955 se conoció la noticia de que ocho miembros de la tripulación del destructor "Caldas", de la marina de guerra de Colombia, habían caído al agua y desaparecido a causa de una tormenta en el mar Caribe. La nave viajaba desde Mobile, Estados Unidos, donde había sido sometida a reparaciones, hacia el puerto colombiano de Cartagena, a donde llegó sin retraso dos horas después de la tragedia. La búsqueda de los náufragos se inició de inmediato, con la colaboración de las fuerzas norteamericanas del Canal de Panamá, que hacen oficios de control militar y otras obras de caridad en del sur del Caribe. Al cabo de cuatro días se desistió de la búsqueda, y los marineros perdidos fueron declarados oficialmente muertos. Una semana más tarde, sin embargo, uno de ellos apareció moribundo en una playa desierta del norte de Colombia, después de permanecer diez días sin comer ni beber en una balsa a la deriva.

Disponible en: https://omegalfa.es/downloadfile.php?file=libros/relato-de-unnaufrago.pdf 
Batería para el diagnóstico y caracterización lingüística de las afasias en el contexto risaraldense

\section{Ficha $\mathbf{N}^{\circ} 6$}

Figura 20. Apoyo para valorar lenguaje memorizado, caso denominación de objetos y seres en dibujos.

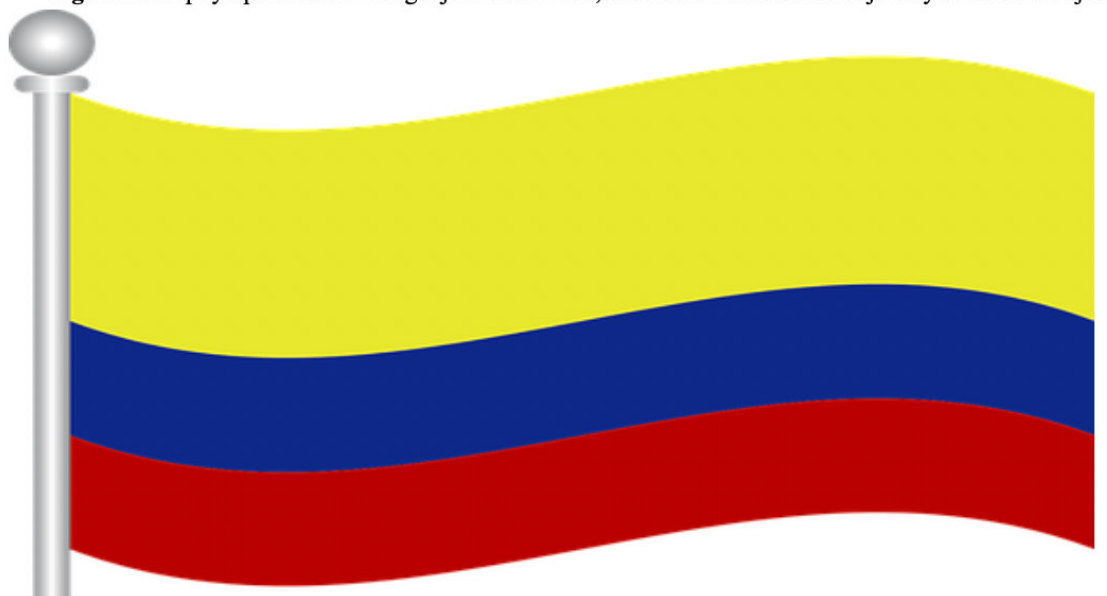

Fuente: Rashid, S. (2016). Bandera De Colombia. Extraído desde:

https:/pixabay.com/es/illustrations/bandera-de-colombia-bandera-colombia-1644474/ 


\section{Ficha $\mathbf{N}^{0} \mathbf{7}$}

Figura 21. Apoyo para valorar lenguaje memorizado, caso denominación de objetos y seres en dibujos.
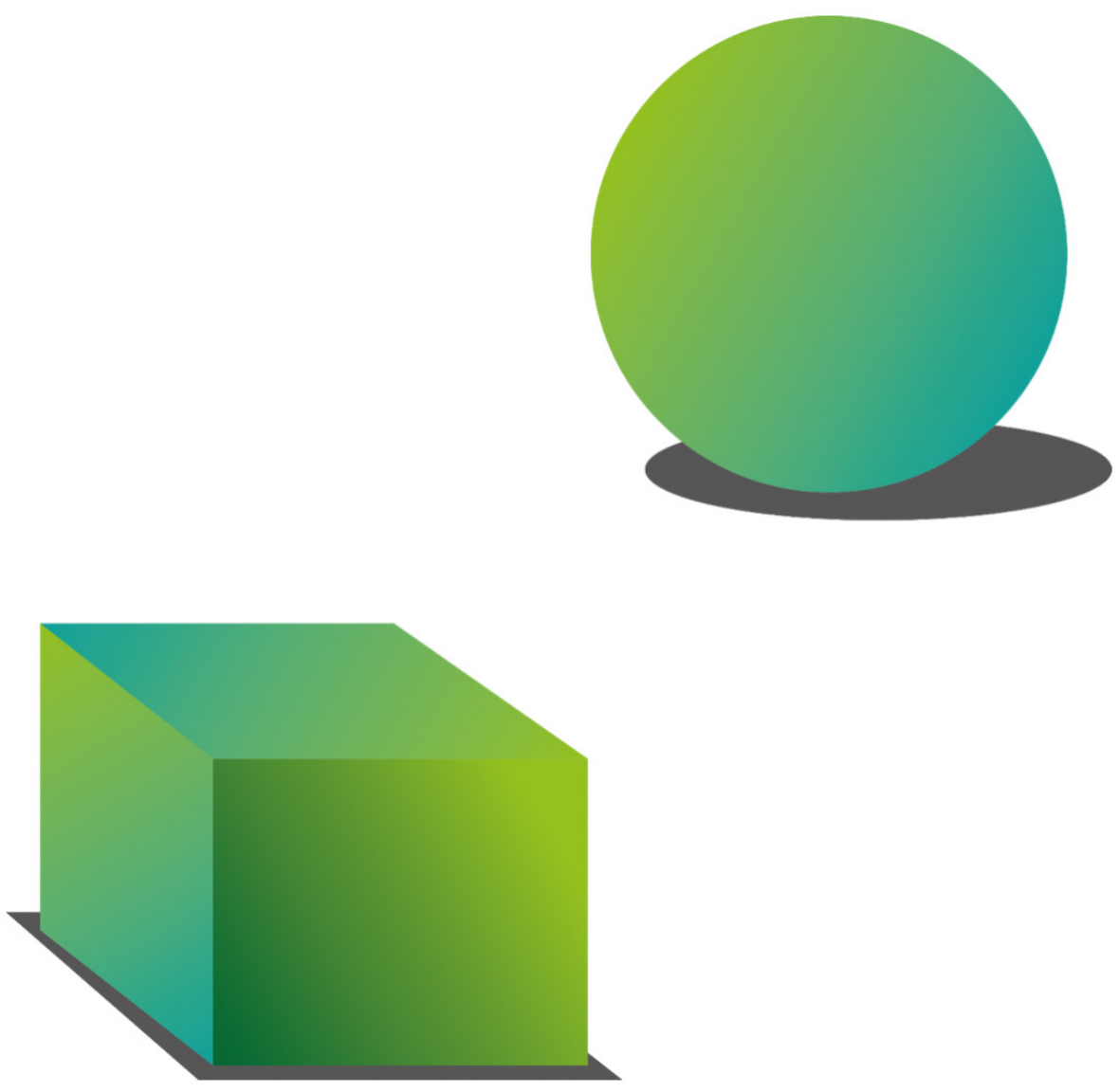

Fuente: José García (2018) 


\section{Ficha $\mathbf{N}^{\circ} 8$}

Figura 22. Apoyo para valorar lenguaje memorizado, caso denominación de objetos y seres en dibujos
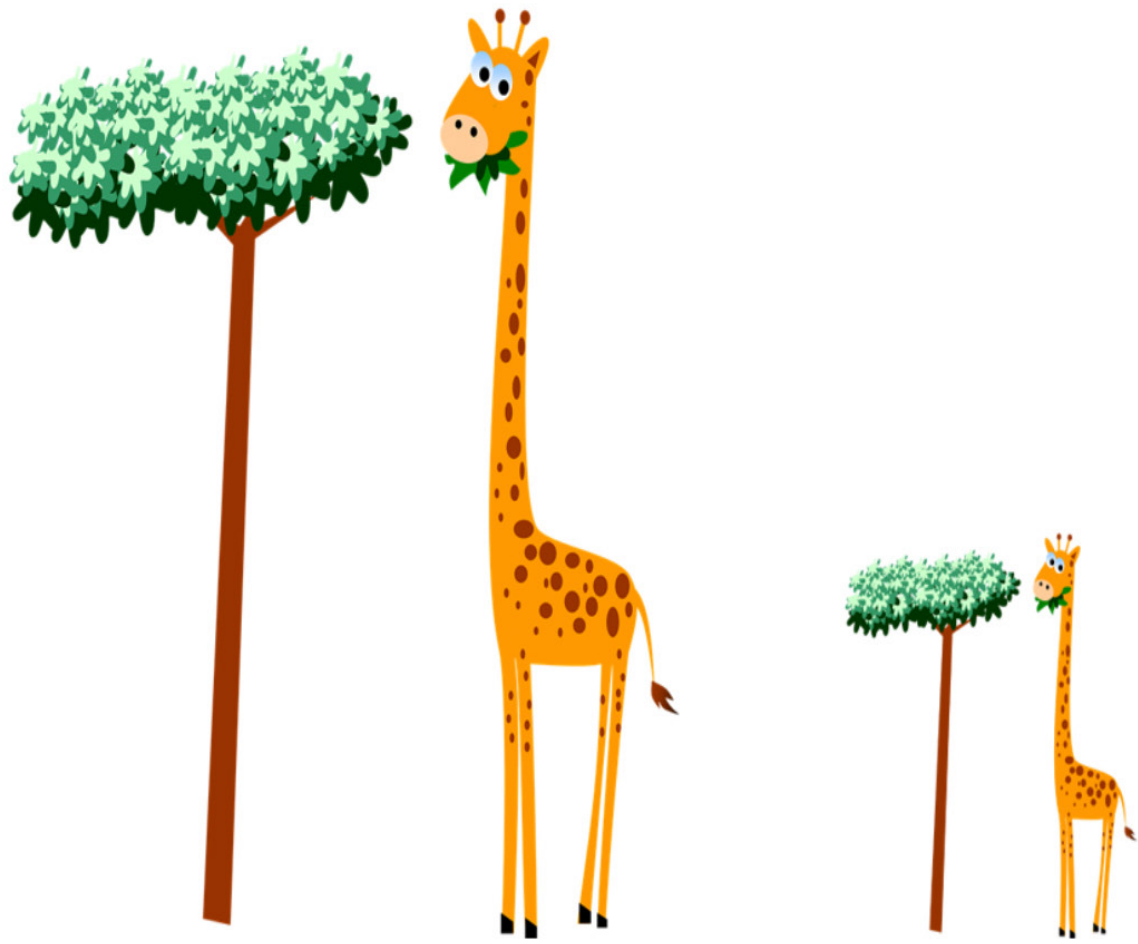

Fuente: Bologna, J. (2016). Jirafa El Cuello Dibujos Animados La Vida Silvestre. Extraído desde: https://pixabay.com/es/illustrations/jirafa-el-cuello-dibujos-animados-1732428/ 
Ficha $\mathbf{N}^{\circ} 9$

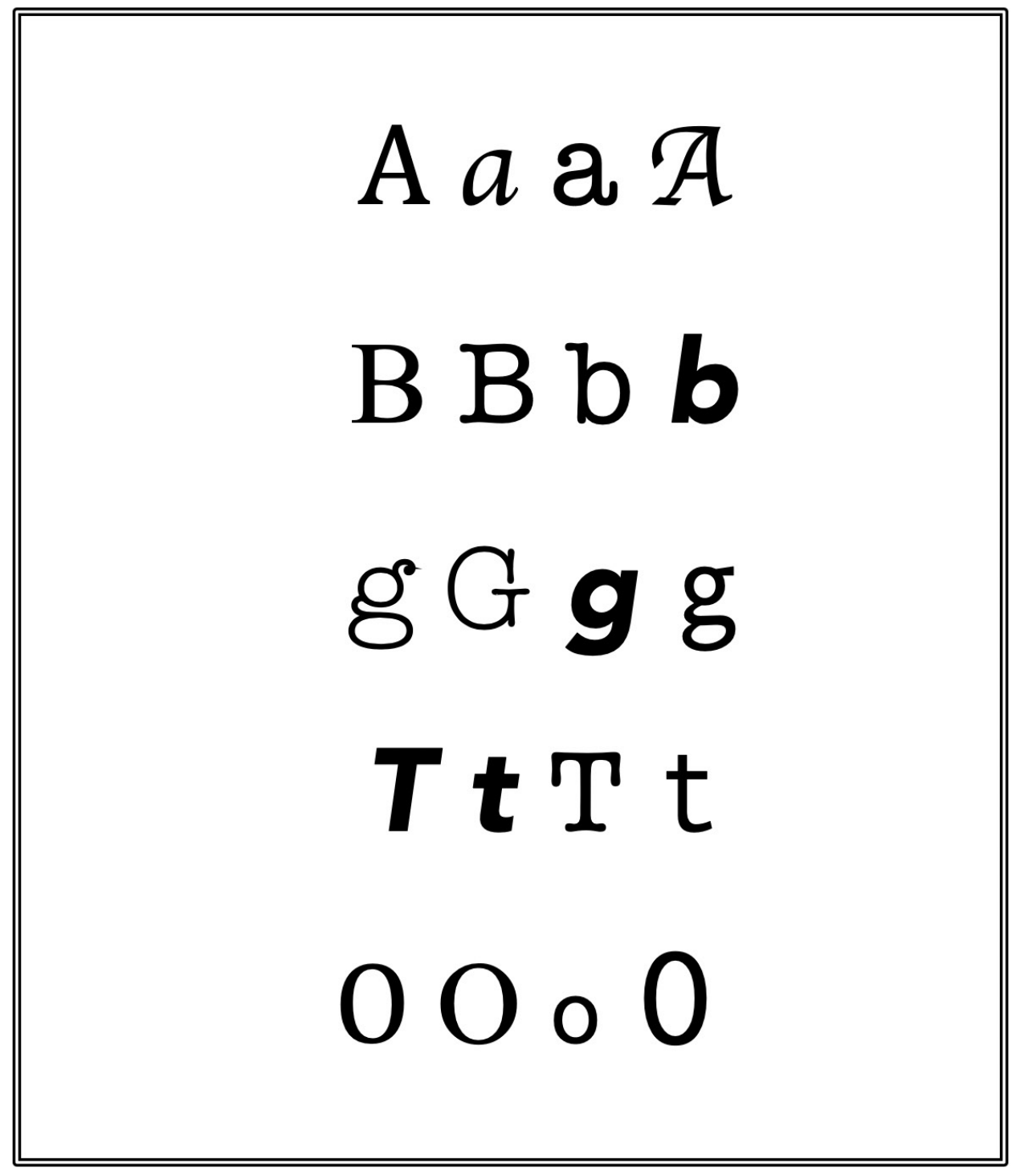


Ficha $\mathbf{N}^{\mathbf{0} 10}$

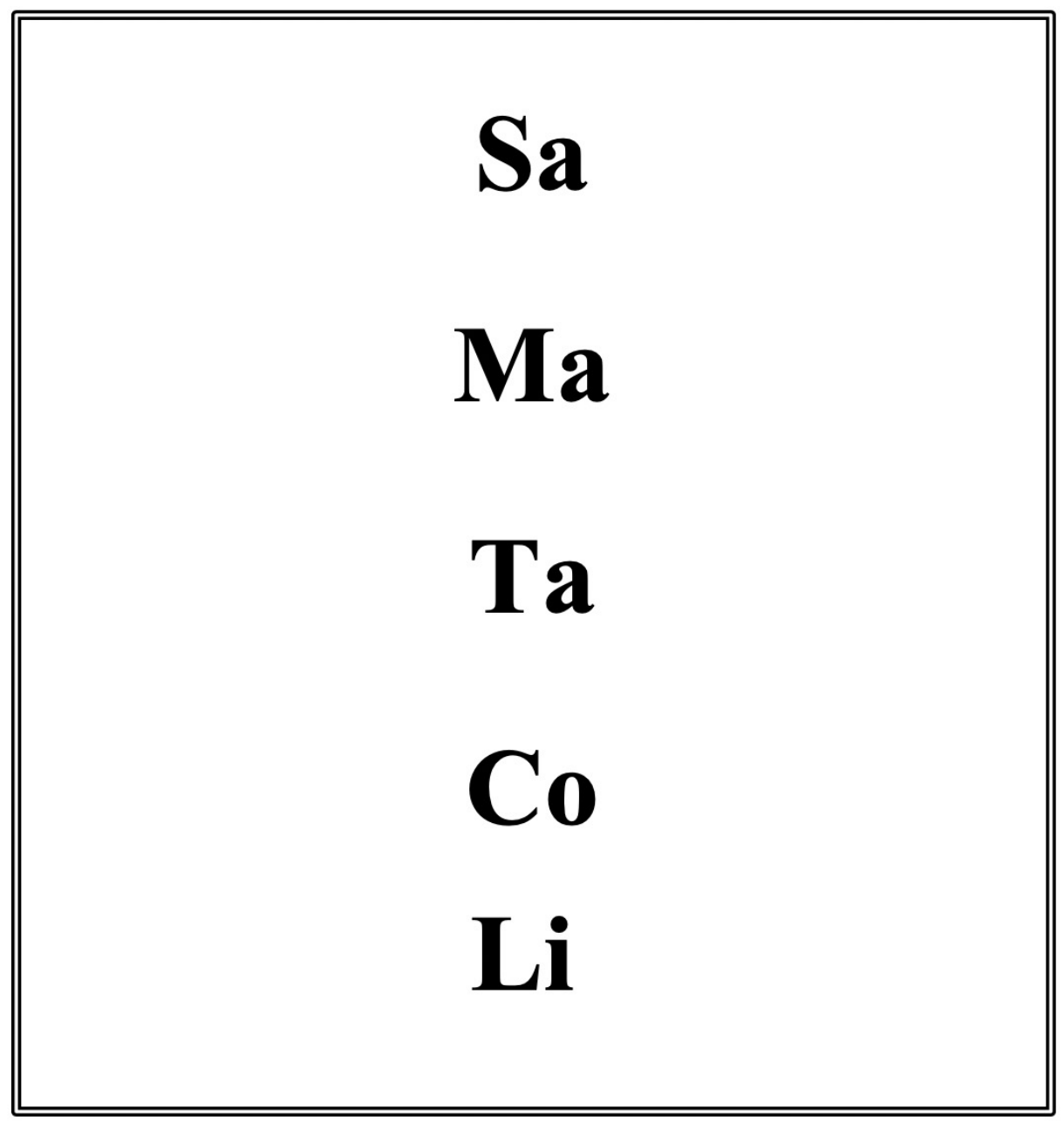


Ficha $\mathbf{N}^{\circ} 11$

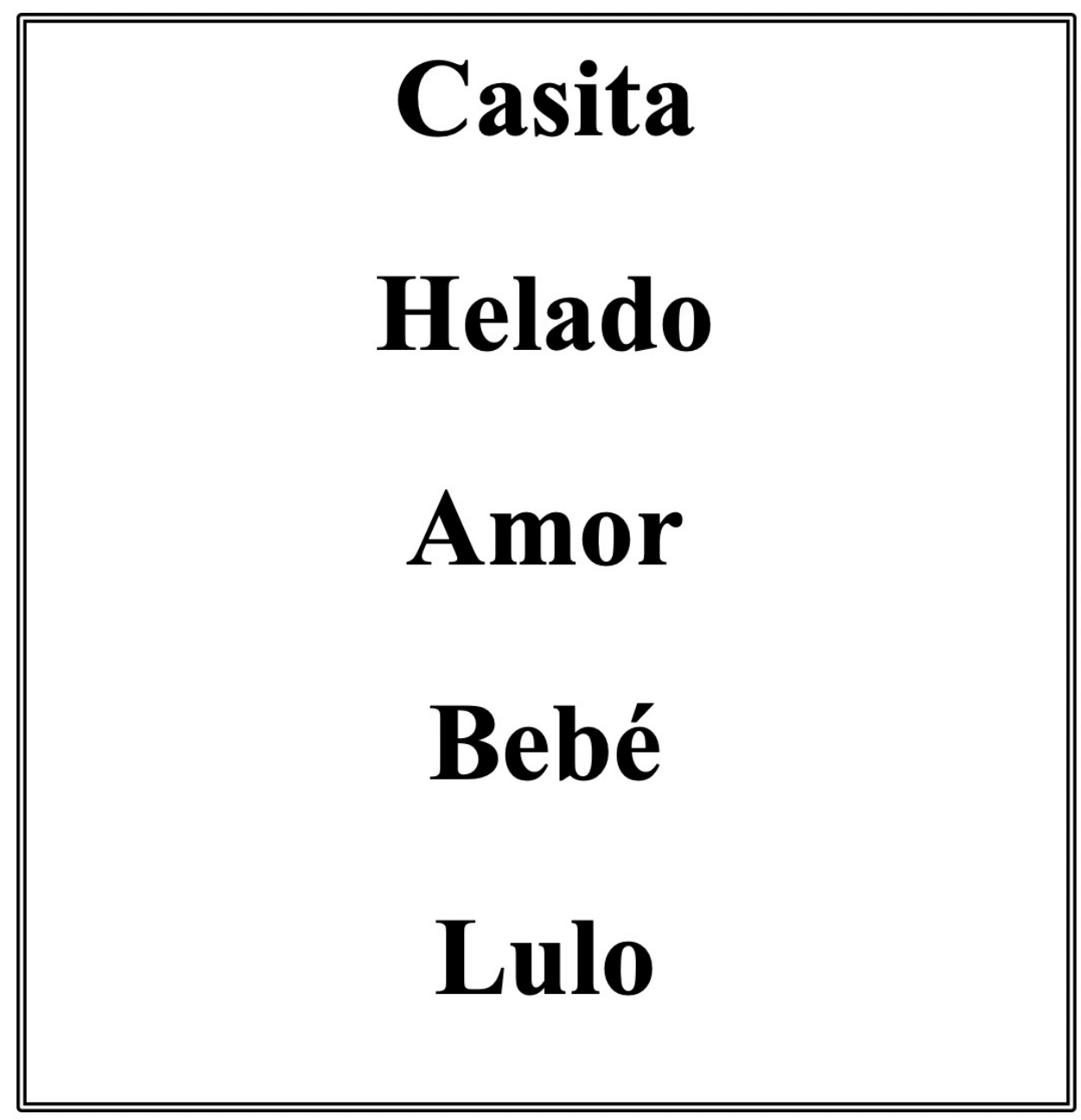


Ficha $\mathbf{N}^{\circ} 12$

La rata se come el queso.

Los patitos van al agua.

Marisol pasea por el bosque.

La señora compra zapatos para estrenar.

Julio juega con sus amigos un partido de fútbol. 
Ficha $N^{0} 13$

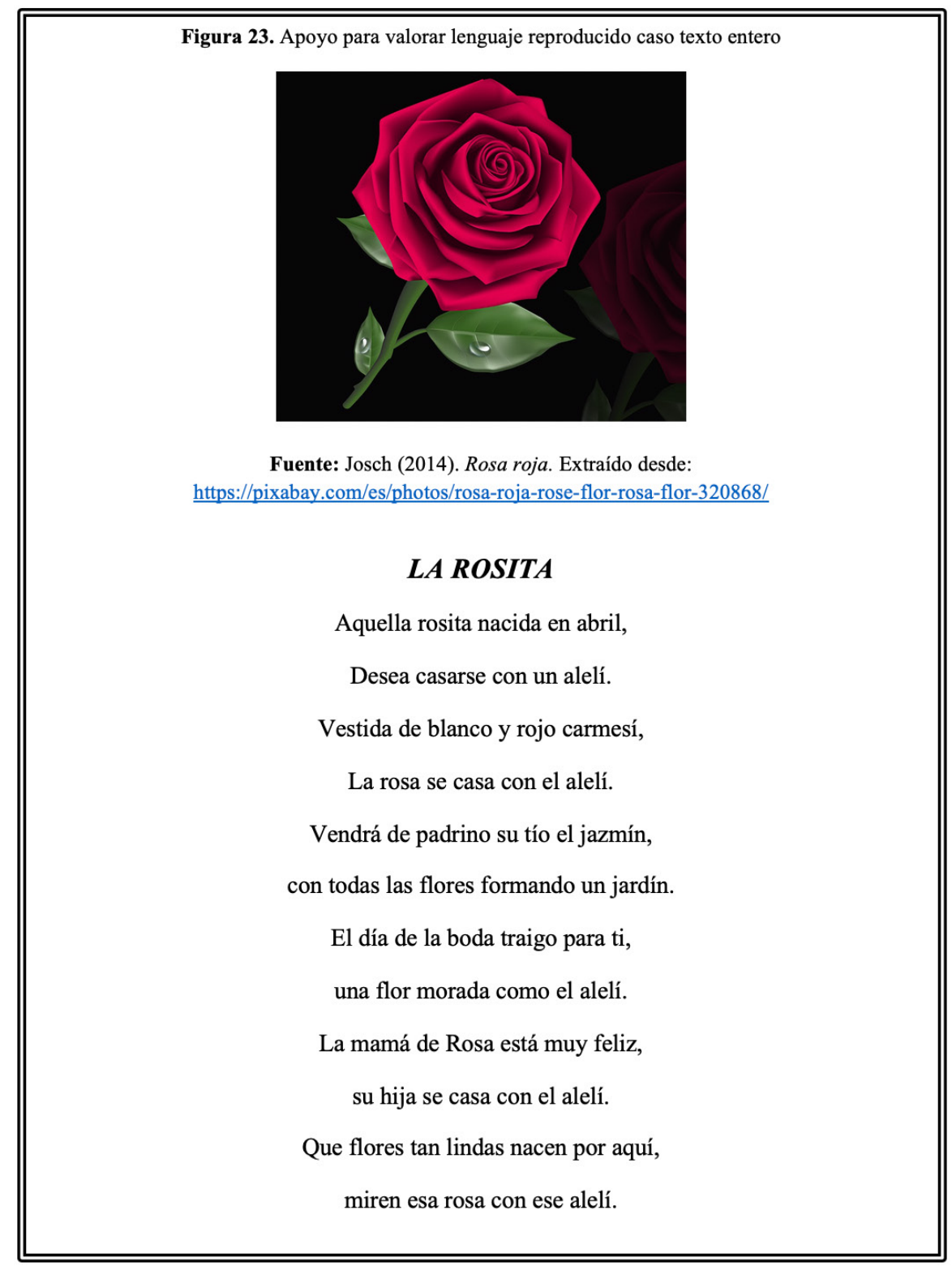




\subsection{Evaluación de las afasias}

\subsubsection{Calificación de las pruebas}

Una vez se tiene diligenciada la anamnesis y se tienen las respuestas a las preguntas de la prueba (registros cualitativos), se procede a su calificación, lo cual permitirá el análisis cuantitativo y cualitativo de los resultados obtenidos por cada uno de los H-OP valorados. Así, en el numeral 2.5.1.1. se presentarán los tipos de registro cuantitativo y en el numeral 2.5.1.2 se establecerá el diagnóstico como producto del análisis de los registros mencionados.

\subsubsection{Formatos de calificación para el análisis cuantitativo}

\subsection{Rendimiento deficitario en cada subproceso psicolingüístico evaluado:}

Al aplicar la prueba, de cada una de las respuestas del H-OP hay que registrar las valoraciones obtenidas en términos de adecuado o inadecuado, según la pregunta formulada. Así, en las tablas 5, 6, 7 y 8 pueden apreciarse las tablas de registro de dichos valores correspondiente respectivamente a los procesos evaluados: expresión verbal, comprensión verbal, almacenamiento y reproducción de la expresión verbal. Estos registros se deben realizar teniendo en cuenta las siguientes equivalencias:

- 0: Cuando la condición de inadecuado es mínima o no se presentan limitaciones significativas en la respuesta, o cuando esta se considera adecuada.

- 1: Cuando hay una condición de inadecuado en un término medio o de manera fragmentada.

- 2: Cuando hay una alta condición de inadecuado en una respuesta, o hay carencia o ausencia de lenguaje.

Así entonces, las calificaciones obtenidas con puntajes 1 y 2 son deficitarias. 
Una vez se anoten estos valores en los cuadros de registro, y se termine de aplicar la prueba, se hace el conteo de errores, el cual se llamará rendimiento deficitario $(\mathrm{RD})$ y, acto seguido, se hará el cálculo del porcentaje de rendimiento deficitario (PRD), por cada uno de los subprocesos valorados.

Finalmente, se calcula el promedio del rendimiento deficitario (PRD) de cada uno de los cuatro procesos evaluados, con el fin de trasladar los datos a un perfil de puntajes.

Tabla 5. Rendimiento deficitario en cada subproceso del lenguaje Receptivo (Comprensión verbal) /Hoja 1 de 2

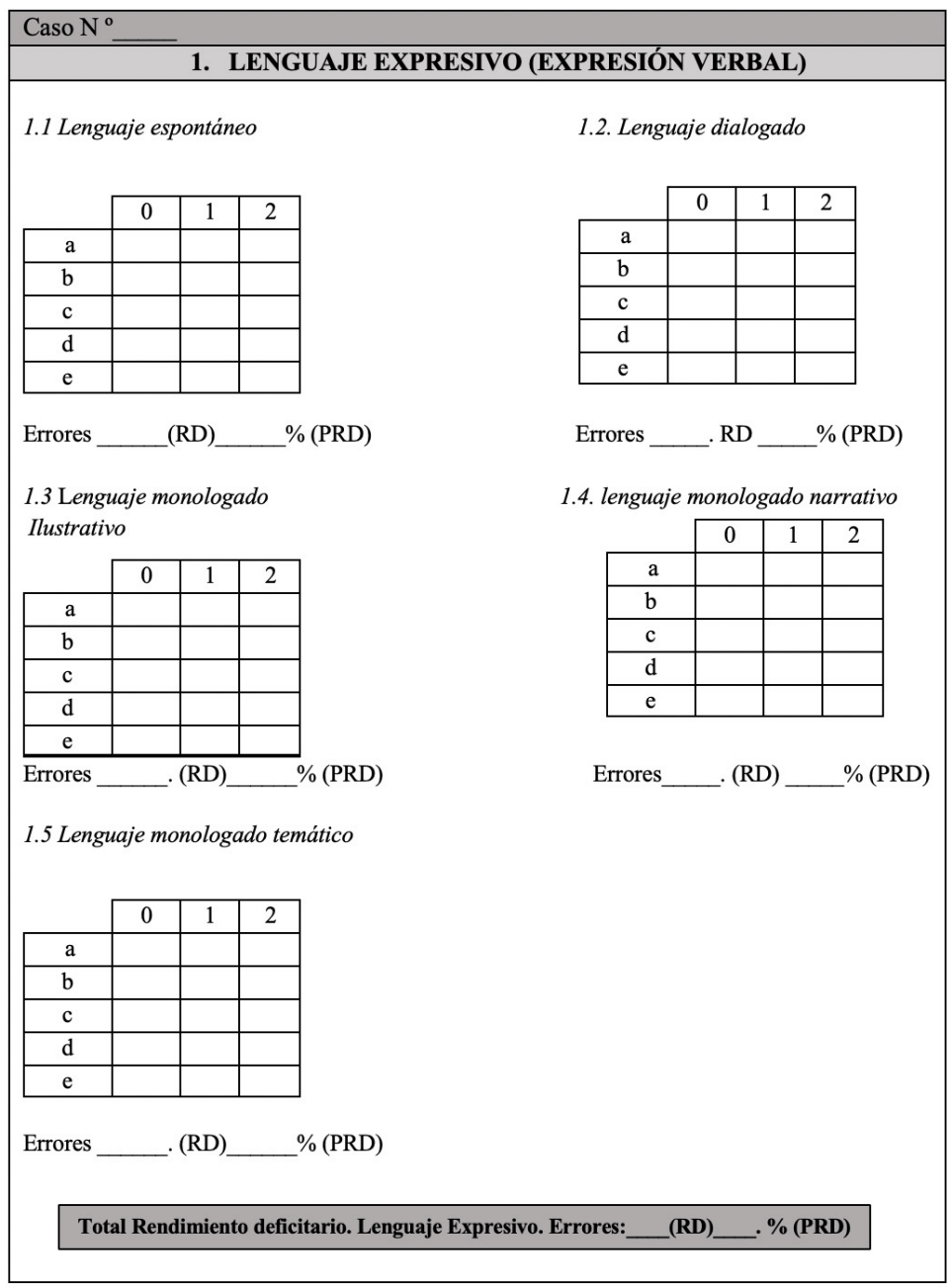


Tabla 6. Rendimiento deficitario en cada subproceso del lenguaje Receptivo (Comprensión verbal)/Hoja 1 de 2

\section{LENGUAJE RECEPTIVO (COMPRENSIÓN VERBAL)}

2.1 Comprensión fonémica

\begin{tabular}{|c|c|c|c|}
\cline { 2 - 4 } \multicolumn{1}{c|}{} & 0 & 1 & 2 \\
\hline $\mathbf{a}$ & & & \\
\hline $\mathbf{b}$ & & & \\
\hline $\mathbf{c}$ & & & \\
\hline $\mathbf{d}$ & & & \\
\hline $\mathbf{e}$ & & & \\
\hline
\end{tabular}

Errores (RD) $\%$ (PRD)

2.3 comprensión de estructuras gramaticales simples

\begin{tabular}{|c|c|c|c|}
\cline { 2 - 4 } \multicolumn{1}{c|}{} & 0 & 1 & 2 \\
\hline $\mathrm{a}$ & & & \\
\hline $\mathrm{b}$ & & & \\
\hline $\mathrm{c}$ & & & \\
\hline $\mathrm{d}$ & & & \\
\hline $\mathrm{e}$ & & & \\
\hline
\end{tabular}

Errores (RD) $\%(\mathrm{PRD})$

\subsection{Comprensión de estructuras complejas}

\begin{tabular}{|c|c|c|c|}
\cline { 2 - 4 } \multicolumn{1}{c|}{} & 0 & 1 & 2 \\
\hline $\mathrm{a}$ & & & \\
\hline $\mathrm{b}$ & & & \\
\hline $\mathrm{c}$ & & & \\
\hline $\mathrm{d}$ & & & \\
\hline $\mathrm{e}$ & & & \\
\hline
\end{tabular}

Errores (RD) $\%(\mathrm{PRD})$

\subsection{Comprensión de las palabras}

\begin{tabular}{|c|c|c|c|}
\cline { 2 - 4 } \multicolumn{1}{c|}{} & 0 & 1 & 2 \\
\hline $\mathbf{a}$ & & & \\
\hline $\mathbf{b}$ & & & \\
\hline $\mathbf{c}$ & & & \\
\hline $\mathbf{d}$ & & & \\
\hline $\mathbf{e}$ & & & \\
\hline
\end{tabular}

Errores ( $\mathrm{RD})$ $\%(\mathrm{PRD})$

2.4 comprensión de estructuras gramaticales compuestas

\begin{tabular}{|c|c|c|c|}
\cline { 2 - 4 } \multicolumn{1}{c|}{} & 0 & 1 & 2 \\
\hline $\mathrm{a}$ & & & \\
\hline $\mathrm{b}$ & & & \\
\hline $\mathrm{c}$ & & & \\
\hline $\mathrm{d}$ & & & \\
\hline $\mathrm{e}$ & & & \\
\hline
\end{tabular}

Errores (RD) $\%$ (PRD) 
Tabla 6. Rendimiento deficitario en cada subproceso del lenguaje Receptivo (Comprensión verbal)/Hoja 2 de 2

\section{LENGUAJE RECEPTIVO (COMPRENSIÓN VERBAL)}

\subsection{COMPRENSIÓN DE ESTRUCTURAS LÓGICO-GRAMATICALES}

Relaciones espaciales

\begin{tabular}{|c|c|c|c|}
\cline { 2 - 4 } \multicolumn{1}{c|}{} & 0 & 1 & 2 \\
\hline $\mathrm{a}$ & & & \\
\hline $\mathrm{b}$ & & & \\
\hline $\mathrm{c}$ & & & \\
\hline $\mathrm{d}$ & & & \\
\hline $\mathrm{e}$ & & & \\
\hline
\end{tabular}

Errores . (RD) $\%$ (PRD)

Comparaciones

\begin{tabular}{|c|c|c|c|}
\cline { 2 - 4 } \multicolumn{1}{c|}{} & 0 & 1 & 2 \\
\hline $\mathrm{a}$ & & & \\
\hline $\mathrm{b}$ & & & \\
\hline $\mathrm{c}$ & & & \\
\hline $\mathrm{d}$ & & & \\
\hline $\mathrm{e}$ & & & \\
\hline
\end{tabular}

(RD) $\%$ (PRD)

Absurdos

\begin{tabular}{|c|c|c|c|}
\cline { 2 - 4 } \multicolumn{1}{c|}{} & 0 & 1 & 2 \\
\hline $\mathrm{a}$ & & & \\
\hline $\mathrm{b}$ & & & \\
\hline $\mathrm{c}$ & & & \\
\hline $\mathrm{d}$ & & & \\
\hline $\mathrm{e}$ & & & \\
\hline
\end{tabular}

Errores . (RD)
Relaciones temporales

\begin{tabular}{|c|c|c|c|}
\cline { 2 - 4 } \multicolumn{1}{c|}{} & 0 & 1 & 2 \\
\hline $\mathrm{a}$ & & & \\
\hline $\mathrm{b}$ & & & \\
\hline $\mathrm{c}$ & & & \\
\hline $\mathrm{d}$ & & & \\
\hline $\mathrm{e}$ & & & \\
\hline
\end{tabular}

Errores . (RD) $\%$ (PRD)

Caso atributivo genitivo

\begin{tabular}{|c|c|c|c|}
\cline { 2 - 4 } \multicolumn{1}{c|}{} & 0 & 1 & 2 \\
\hline $\mathrm{a}$ & & & \\
\hline $\mathrm{b}$ & & & \\
\hline $\mathrm{c}$ & & & \\
\hline $\mathrm{d}$ & & & \\
\hline $\mathrm{e}$ & & & \\
\hline
\end{tabular}

Errores RD $\%(\mathrm{PRD})$ 
Tabla 7. Rendimiento deficitario en cada subproceso del lenguaje memorizado (almacenamiento de la expresión verbal) Hoja 1 de 2

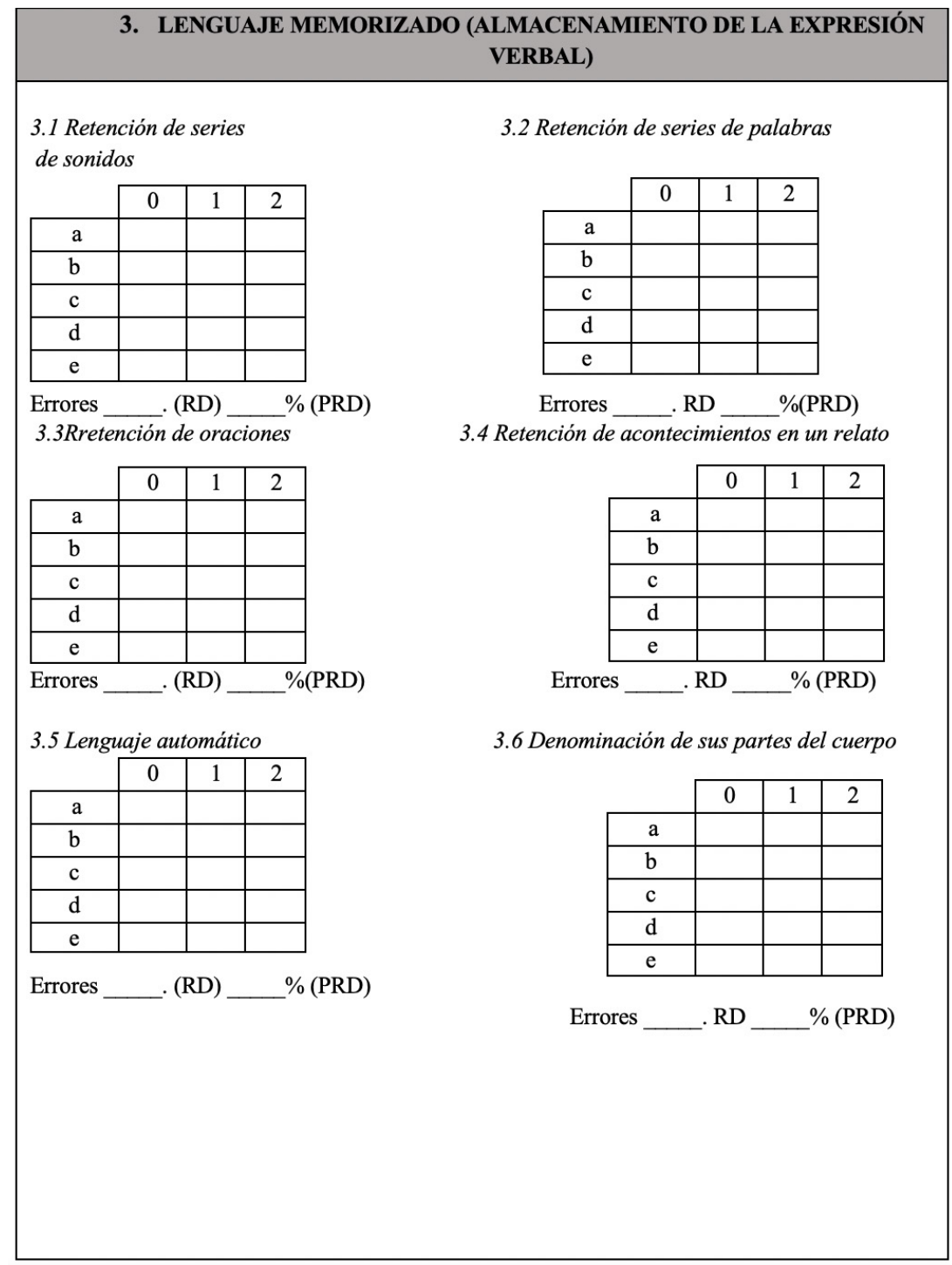


Tabla 7. Rendimiento deficitario en cada subproceso del lenguaje memorizado (almacenamiento de la expresión verbal) Hoja 2 de 2

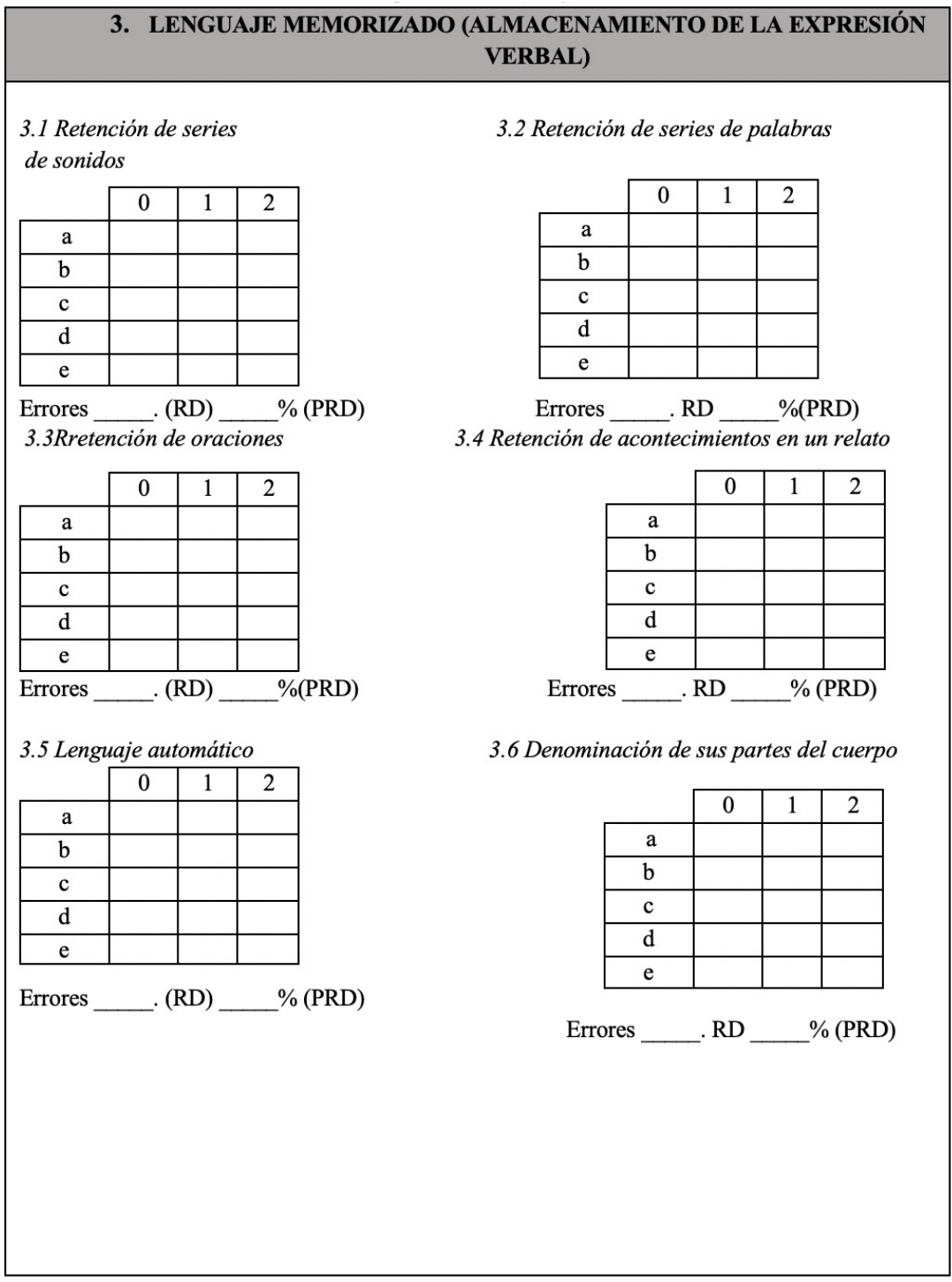


Tabla 8. Rendimiento deficitario en cada subproceso del lenguaje reproducido (Proceso reproductivo de la expresión verbal) Hoja 1 de 3

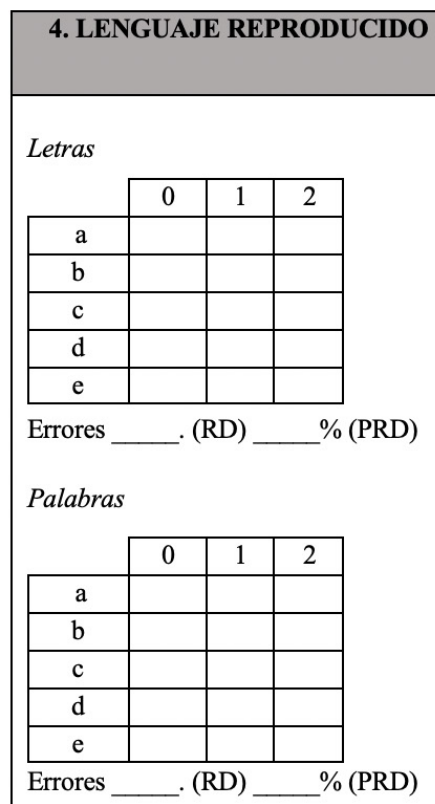

\section{VERBAL)}

4.1 LECTURA

\section{Sílabas}

\begin{tabular}{|l|l|l|l|}
\cline { 2 - 4 } \multicolumn{1}{c|}{} & 0 & 1 & 2 \\
\hline $\mathrm{a}$ & & & \\
\hline $\mathrm{b}$ & & & \\
\hline $\mathrm{c}$ & & & \\
\hline $\mathrm{d}$ & & & \\
\hline $\mathrm{e}$ & & & \\
\hline
\end{tabular}

Oraciones

\begin{tabular}{|c|c|c|c|}
\hline & 0 & 1 & 2 \\
\hline A & & & \\
\hline B & & & \\
\hline c & & & \\
\hline $\mathrm{d}$ & & & \\
\hline $\mathrm{e}$ & & & \\
\hline
\end{tabular}

Texto

\begin{tabular}{|c|c|c|c|}
\cline { 2 - 4 } \multicolumn{1}{c|}{} & 0 & 1 & 2 \\
\hline $\mathrm{a}$ & & & \\
\hline $\mathrm{b}$ & & & \\
\hline $\mathrm{c}$ & & & \\
\hline $\mathrm{d}$ & & & \\
\hline $\mathrm{e}$ & & & \\
\hline
\end{tabular}

Errores . (RD) $\%$ (PRD) 
Tabla 8. Rendimiento deficitario en cada subproceso del lenguaje reproducido (Proceso reproductivo de la expresión verbal) Hoja 2 de 3

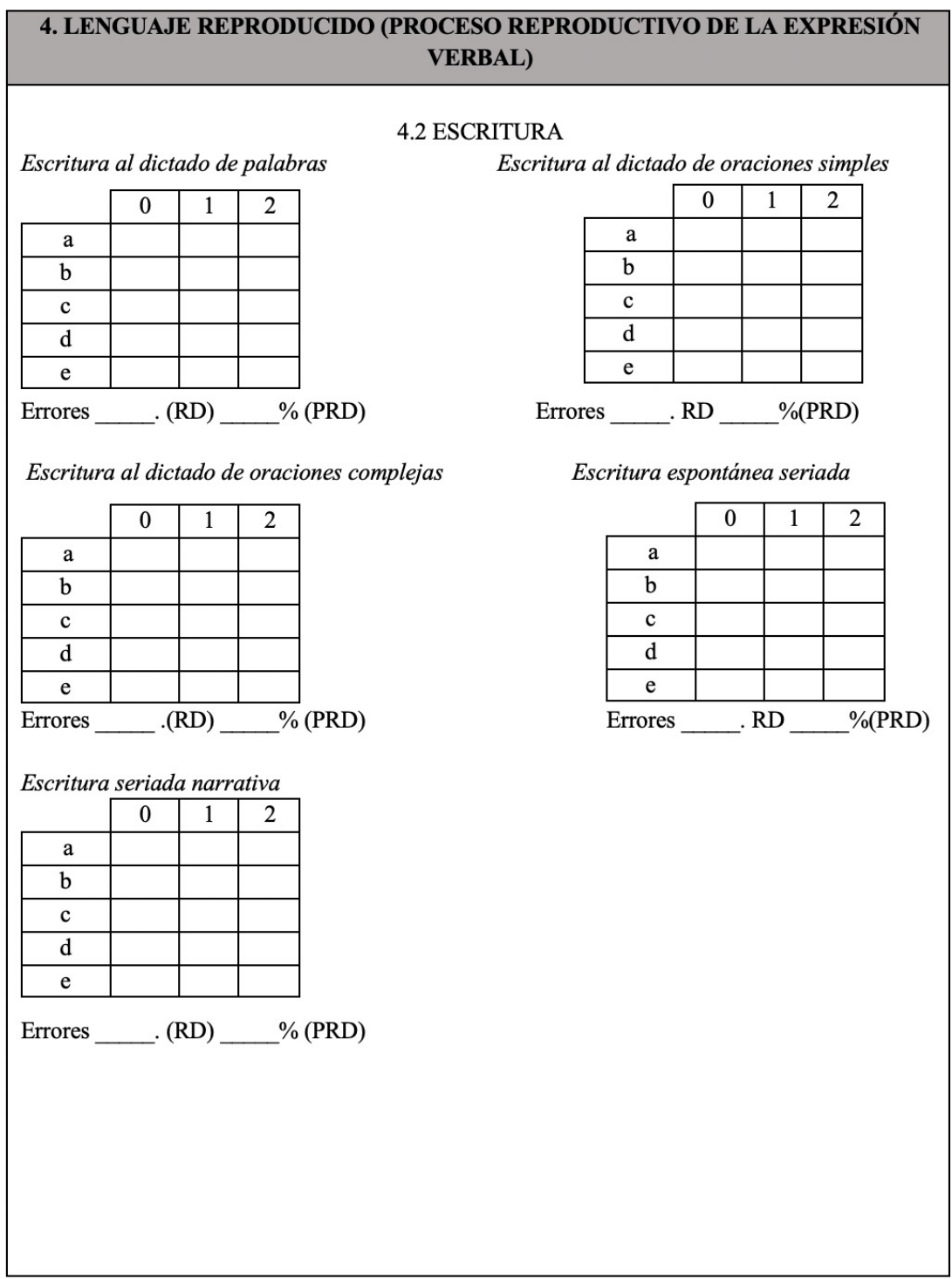


Tabla 8. Rendimiento deficitario en cada subproceso del lenguaje reproducido (Proceso reproductivo de la expresión verbal) Hoja 3 de 3

\begin{tabular}{l} 
4. LENGUAJE REPRODUCIDO (PROCESO REPRODUCTIVO DE LA EXPRESIÓN \\
VERBAL) \\
4.3 REPETICIÓN \\
Repetición de palabras \\
\cline { 2 - 4 } \\
\hline
\end{tabular}

\subsection{Rendimiento deficitario en cada proceso psicolingüístico evaluado: representación gráfica}

Una vez se tienen los porcentajes de rendimiento deficitario en cada subproceso de cada proceso psicolingüístico evaluado, se procede a representar de manera gráfica este rendimiento por el proceso mismo, en su conjunto de subprocesos. Como lo muestran las Figuras 24, 25, $26,27,28,29$ y 30 . 
Figura 24. Perfil del rendimiento deficitario en su Expresión verbal. Caso $\mathrm{N}^{\circ}$

Perfil de rendimiento deficitario Caso $\mathrm{N}_{-}$

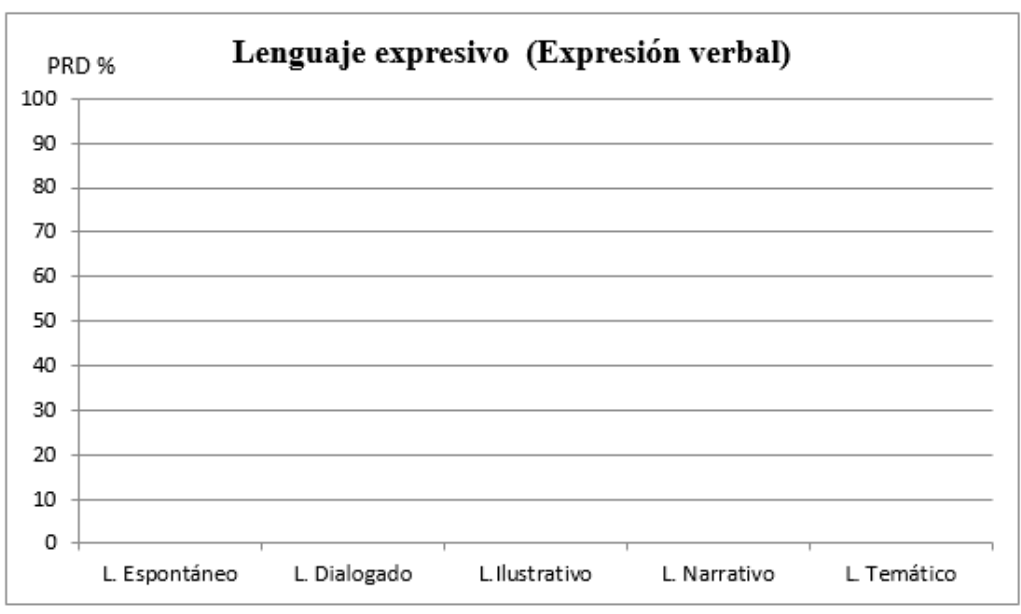

Figura 25. Perfil del rendimiento deficitario en su Comprensión verbal. Caso $\mathrm{N}^{\circ}$

Perfil de rendimiento deficitario Caso $\mathrm{N}^{\circ}$

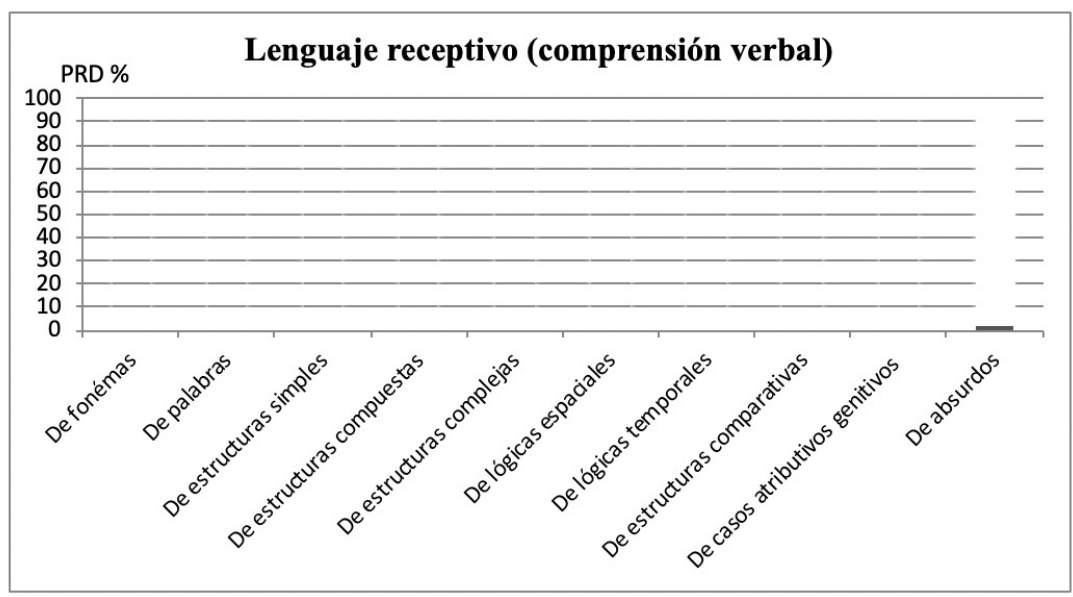


Figura 26. Perfil del rendimiento deficitario en su Almacenamiento de expresión verbal. Caso $\mathrm{N}^{\circ}$

Perfil de rendimiento deficitario Caso $\mathrm{N}^{\circ}$

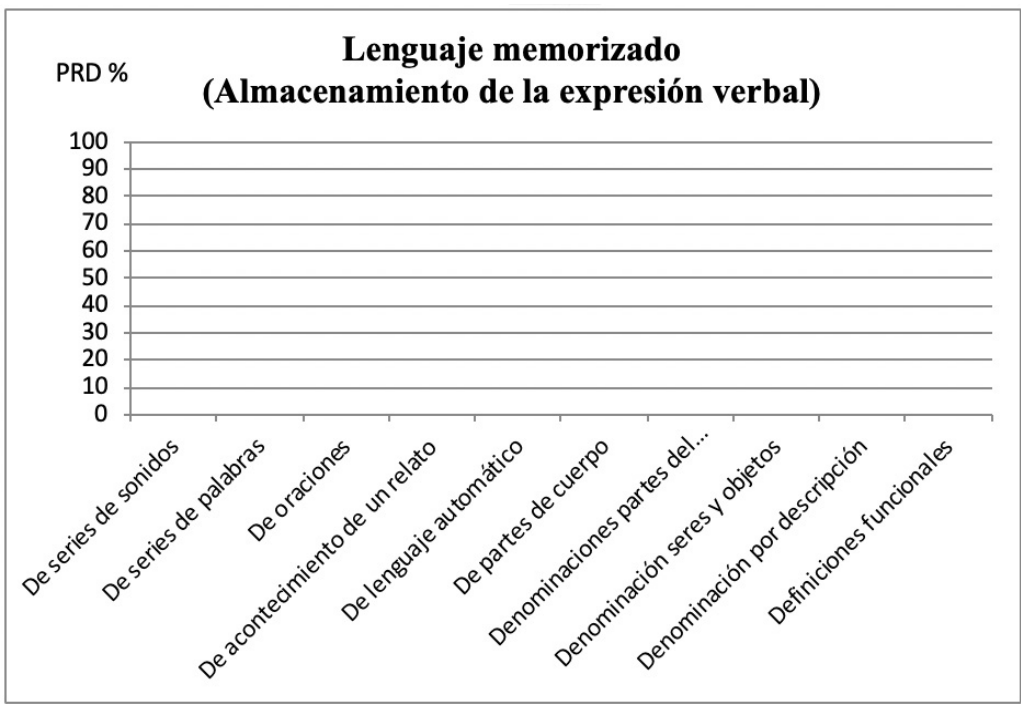

Figura 27. Perfil del rendimiento deficitario en su Reproducción de la expresión verbal: Lectura. Caso No

Perfil de rendimiento deficitario Caso No

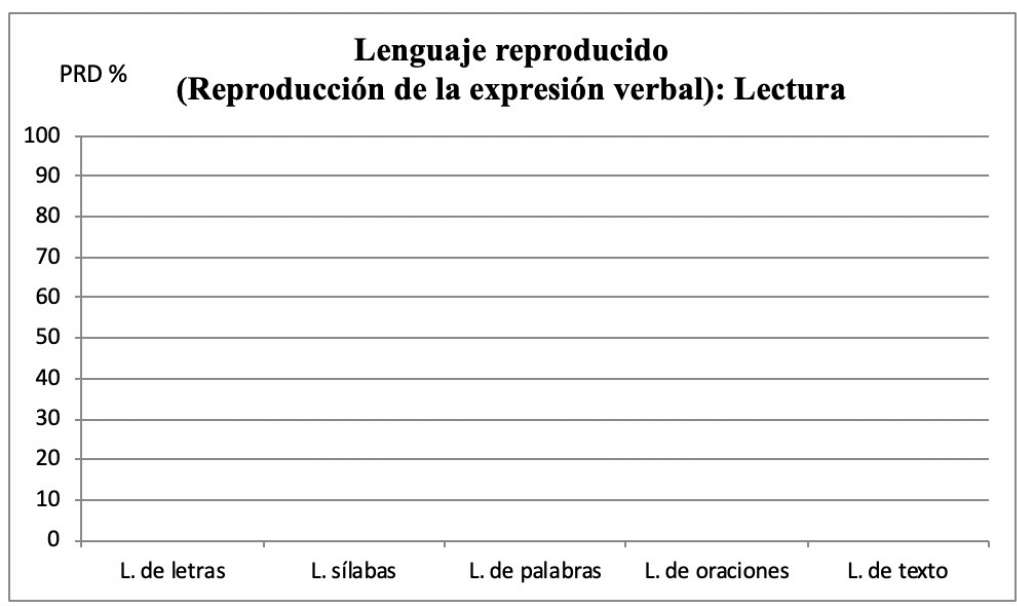


Figura 28. Perfil del rendimiento deficitario en su Reproducción de la expresión verbal: Escritura. Caso No

Perfil de rendimiento deficitario Caso $\mathrm{N}^{\circ}$

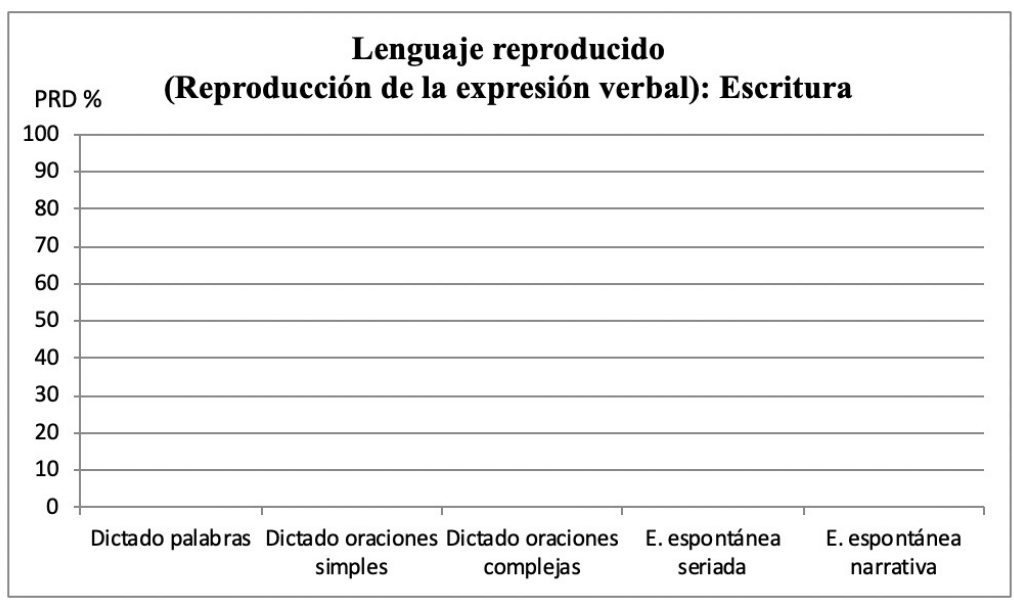

Figura 29. Perfil del rendimiento deficitario en su Reproducción de la expresión verbal: Repetición. Caso No

Perfil de rendimiento deficitario Caso $\mathrm{N}^{\circ}$

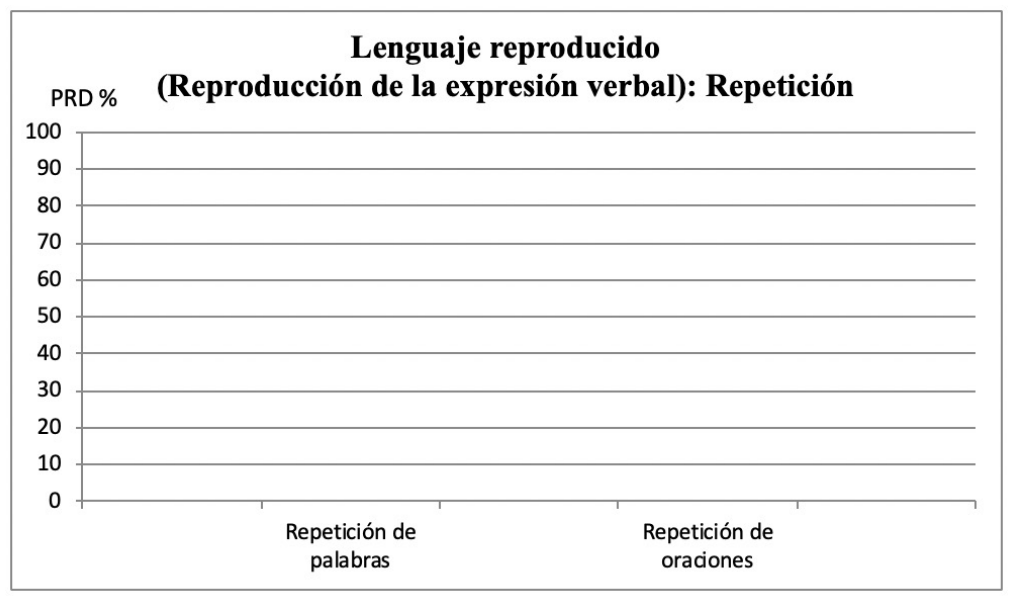


Figura 30. Perfil del rendimiento deficitario en su Reproducción de la expresión verbal. Caso №

Perfil de rendimiento deficitario Caso No

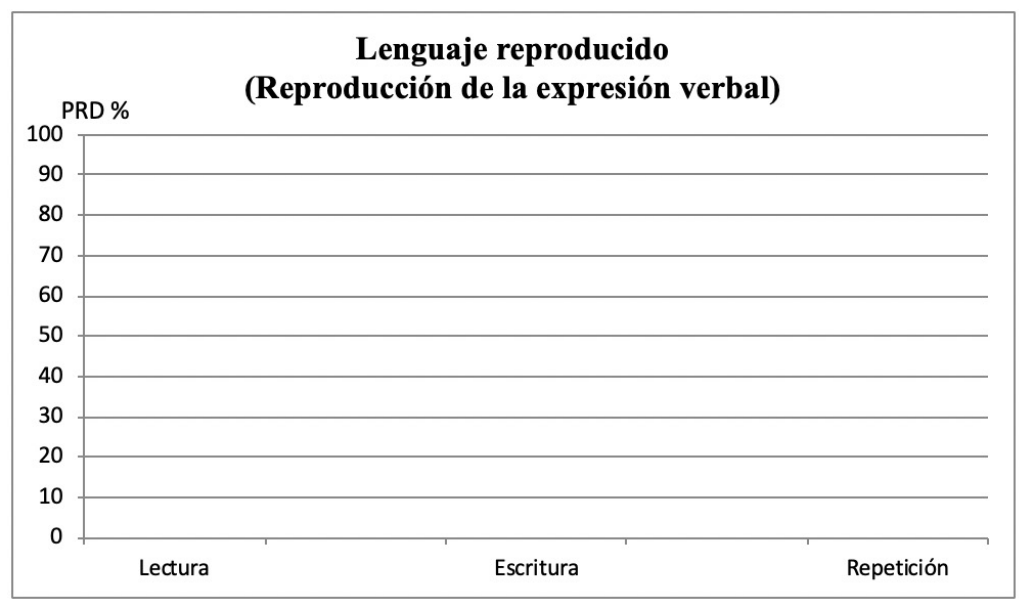

2.5.1.1.3. Rendimiento deficitario en los procesos psicolingüísticos: representación gráfica unificada

Una vez se tienen los porcentajes de rendimiento deficitario en cada proceso psicolingüístico evaluado, se procede a representar de manera gráfica este rendimiento de manera unificada, como lo muestra la Figura 31 . 
Figura 31. Perfil del rendimiento deficitario en sus Procesos psicolingüísticos. Caso $\mathrm{N}^{\circ}$

Perfil de rendimiento deficitario Caso No

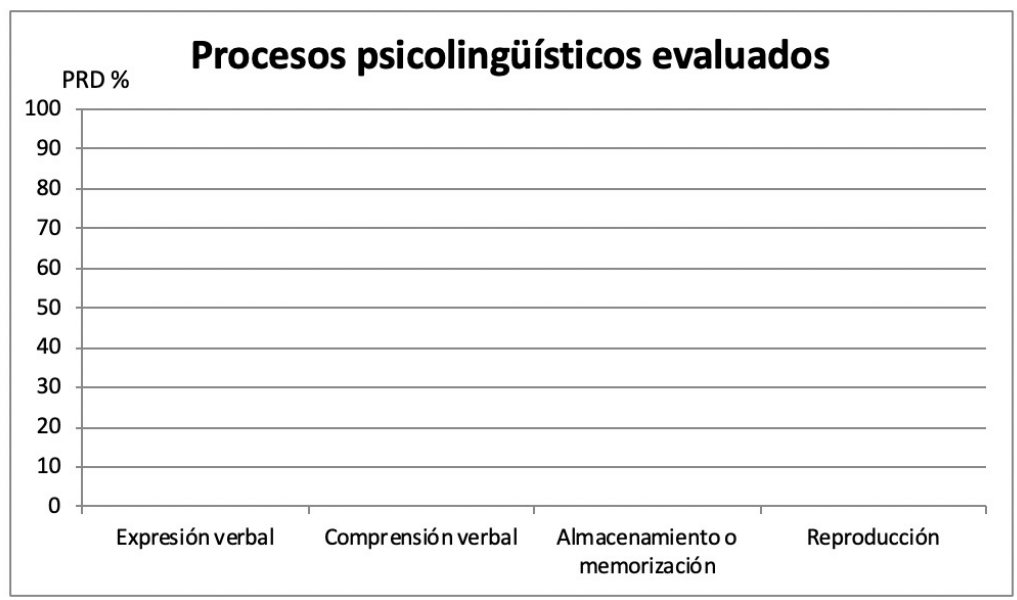

\subsubsection{Observaciones para el análisis cualitativo}

Una vez terminada la prueba, y realizados los cálculos cuantitativos del rendimiento deficitario, se registran las apreciaciones sobre los factores del lenguaje conservados y los alterados, con base en los porcentajes totales de rendimiento deficitario obtenido. Esta apreciación se registra a manera de prosa, teniendo en cuenta los subprocesos de los procesos psicolingüísticos evaluados. En las Tablas 9 y 10 se da una idea de lo que se pretende hacer para aportar al análisis cualitativo de la prueba aplicada. 
Tabla 9. Subprocesos de los procesos psicolingüísticos conservados. Caso $\mathrm{N}^{\circ}$

Subprocesos de los procesos psicolingüísticos

Conservados. Caso $\mathbf{N}^{\circ}$

Lenguaje expresivo (expresión verbal)

Nota: En esta parte se registran los subprocesos, respectivos, que resultan conservados, es decir, aquellos que se mantienen con CERO PUNTOS en rendimiento deficitario. Y así con todos y cada uno de los procesos psicolingüísticos evaluados.

Lenguaje receptivo (comprensión verbal)

Lenguaje memorizado (almacenamiento de la expresión verbal)

Lenguaje reproducido (reproducción de la expresión verbal) 
Tabla 10. Subprocesos de los procesos psicolingüísticos alterados. Caso $\mathrm{N}^{\circ}$

\section{Subprocesos de los procesos psicolingüísticos}

Alterados Caso $\mathbf{N}^{\circ}$

Lenguaje expresivo (expresión verbal)

Nota: En esta parte se registran los subprocesos, respectivos, que resultan alterados, es decir, aquellos que superan el $70 \%$ en rendimiento deficitario. Fuera de registrar los subprocesos, se citan las manifestaciones, las formas o las modalidades de los mismos, que están siendo alteradas. $\mathrm{Y}$ así con todos y cada uno de los procesos psicolingüísticos evaluados.

Lenguaje receptivo (comprensión verbal)

Lenguaje memorizado (almacenamiento de la expresión verbal)

Lenguaje reproducido (reproducción de la expresión verbal) 


\subsubsection{Análisis de los resultados: Diagnóstico}

El análisis de los resultados pretende legitimar la cantidad y la calidad de las observaciones realizadas y sirve como evidencia o falsación de la idea inicial de estar frente a una persona afásica, porque tiene como antecedente una lesión cerebral, de origen interno o externo, y porque se hace notoria en dicha persona, una dificultad para comprender o producir lenguaje.

El análisis de resultados se presenta en dos sistemas de notación diferentes; dos maneras de reconstruir y recuperar el mundo del hablante-oyente. Son métodos presentados por Rojas (1999, p. 180):

El método de análisis cuantitativo permite una comprensión general del fenómeno y permitirá un acercamiento a otras comunidades científicas. Hace énfasis este método en la objetividad y en la validez de los procesos investigativos. Pretende matematizar, formalizar en números, cuadro y figuras los rendimientos negativos de la actuación lingüística del hablanteoyente. Igual pasa, siguiendo la línea del análisis factorial, con el fin de establecer correlaciones entre los procesos del lenguaje y las alteraciones en los niveles de la lengua. Estas correlaciones son significativas como índices de trastornos en la estructura y funcionamiento del lenguaje.

El método de análisis cualitativo permite la comprensión caso por caso. Es un esfuerzo intelectual flexible y versátil que hace énfasis en la intensidad y en la profundidad en el sentimiento del caso. Puede ser "caso paradigmático" en cuanto confrontación con otros casos del mismo tipo de afasia. No convierte las observaciones en cifras sino en un código lingüístico significativo.

Según la naturaleza de la investigación, se sigue la línea de trabajo del método neurolingüístico en el análisis cualitativo o la línea del método factorial en el análisis cuantitativo.

En relación con los métodos de análisis mencionados: cuantitativo y cualitativo, en esta investigación se sigue la línea de trabajo del método neurolingüístico en el análisis cualitativo o la línea del método factorial 
en el análisis cuantitativo, como lo concibe también Rojas (1999, p. 180) en estas consideraciones.

Una vez analizada la información: la contemplada en la anamnesis y los resultados cualitativos y cuantitativos, por cuanto unos son la base de los otros para establecer los subprocesos conservados y los alterados, se procede a realizar el diagnóstico del caso que se esté analizando. Este se puede estructurar tal como aparece en la Tabla 11, allí se darán también las explicaciones del caso para cada una de las partes que lo conforman.

Tabla 11. Diagnóstico Caso _ después de aplicación de Batería de Diagnóstico y Caracterización de las afasias

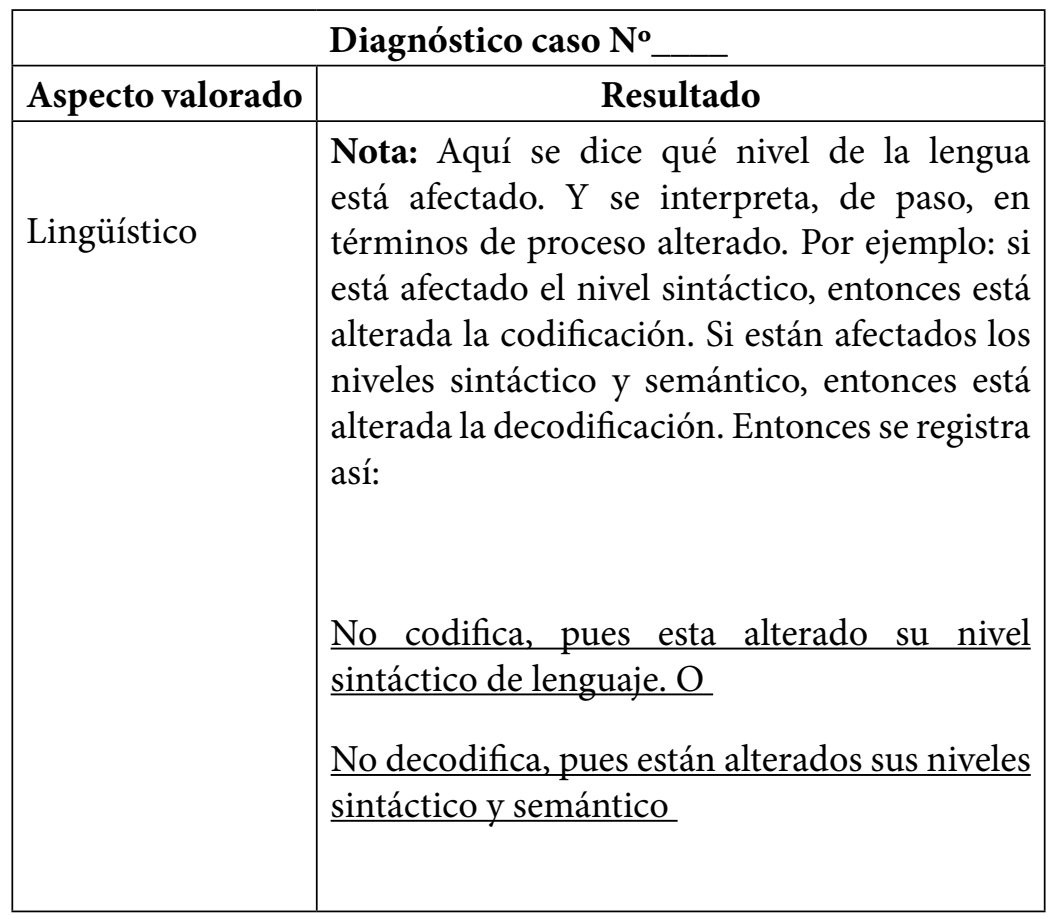




\begin{tabular}{|c|c|}
\hline Psicolingüístico & $\begin{array}{l}\text { Nota: Aquí se dice qué procesos } \\
\text { psicolingüísticos, de los valorados en la } \\
\text { prueba (expresión verbal, recepción verbal, } \\
\text { almacenamiento verbal y reproducción de } \\
\text { la expresión verbal), están afectados. Y se } \\
\text { menciona cuál o cuáles lo están. Así: } \\
\text { Están alterados todos los procesos, en } \\
\text { especial el de la Expresión verbal y el de la } \\
\text { Reproducción. }\end{array}$ \\
\hline Neurolingüístico & 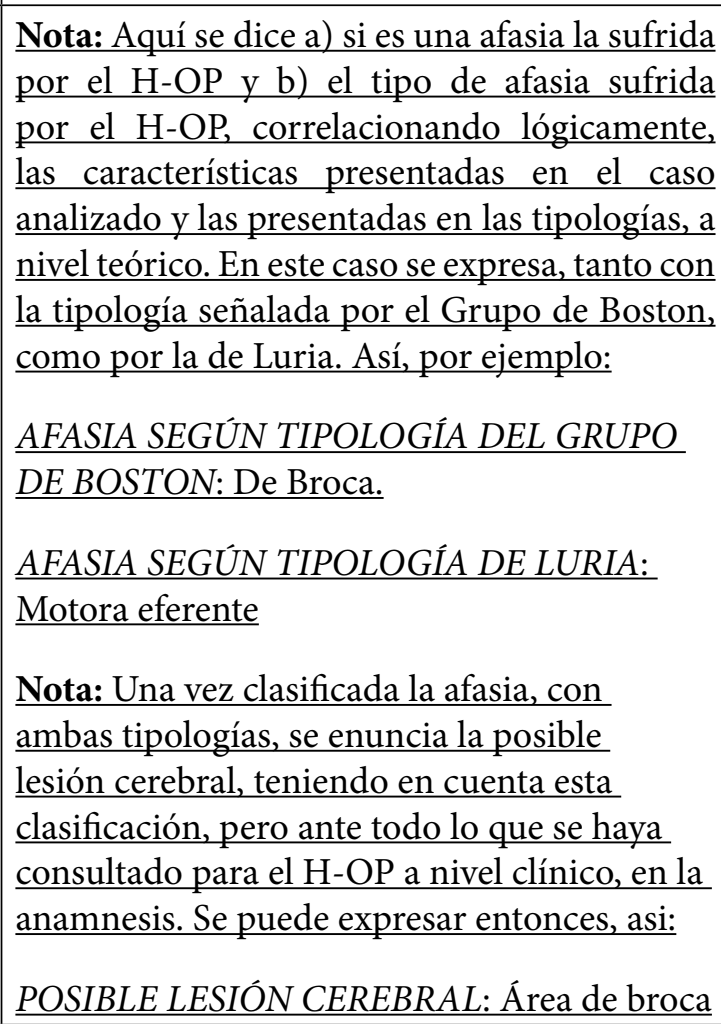 \\
\hline
\end{tabular}




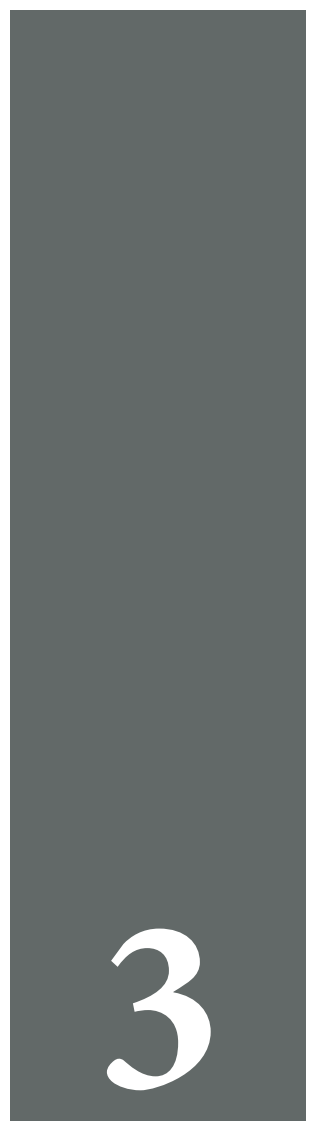

CAPÍTULO TRES 



\section{Resultados Obtenidos}

1 primer acercamiento a los $\mathrm{H}-\mathrm{OP}$ fue indirecto: a sus
historias clínicas, a sus anamnesis. Allí se encontraron
diferencias en cuanto a: edad, estrato social, formación académica, origen de su lesión cerebral (interna o externa), ubicación de su lesión cerebral (temporal, frontal, occipital, parietal, entre otras) y calidad de sus realizaciones lingüísticas al momento de comunicarse. También se encontró una condición común en ellos: todos tenían dificultades al expresarse, ya de manera oral, ya de manera escrita, o en su comprensión.Y finalmente se procedió a tener el acercamiento más definitivo con ellos: se aplicó la batería diseñada para el diagnóstico y la caracterización lingüística de las afasias, a diez de ellos, ubicados así: algunos todavía recluidos en un centro hospitalario, y otros que ya no estaban teniendo ningún tratamiento.

En este capítulo se presentará un caso de manera exhaustiva, es decir:

- Su anamnesis, teniendo en cuenta que los datos de identificación personal no van incluídos por ser información privada, y que por disposiciones legales no puede divulgarse. Los espacios del caso se marcan con asteriscos $\left(^{\star * *}\right)$.

- Las tablas de registro de la calificación obtenida después de habérsele aplicado la prueba de desempeño de su actuación lingüística. 
- La representación gráfica de sus porcentajes de rendimiento deficitario en los cuatro procesos psicolingüísticos evaluados.

- Las apreciaciones que dan cuenta de los subprocesos (de dichos procesos psicolingüísticos) conservados en su actuación lingüística, y también de los alterados.

- El diagnóstico final que ubica el desempeño en la actuación lingüística del H-OP desde el punto de vista lingüístico, en el nivel de la lengua alterado; desde el punto de vista psicolingüístico, en el proceso o los procesos que tenga alterados; y desde el punto de vista neurolingüística, en la tipología de afasia, que haya adquirido.

Luego se hará alusión a los demás casos, presentando apenas sus resultados, para no hacer tan voluminosa esta publicación. De hecho, todos estos registros se tienen guardados en los archivos de las investigadoras.

\subsection{Presentación de los Resultados Caso № 1}

\subsubsection{Anamnesis: Caso $\mathrm{N}^{\circ} 1$}

\section{Caso $\mathbf{N}^{\circ} 1$}

Lugar de la entrevista: Hospital Universitario San Jorge

\section{Identificación Personal}

Nombres y apellidos: $* * * * * * * * * * * * * * * * * * * * * * * * * * * * * * * * * *$

Dirección y teléfono: $* * * * * * * * * * * * * * * * * * * * * * * * * * * * * * * * * * *$

Fecha de nacimiento: 28 de octubre de 1974

Edad: 21 años

Lugar de nacimiento: $\underline{\text { Cartago (Valle) }}$

Sexo: Femenino

Estado civil: Soltera Número de hijos: $\underline{0 \text { hijos }}$

Lateralidad Diestra. 


\section{Información Complementaria}

Educación formal: Hasta grado $5^{\mathrm{a}}$ de Educación básica primaria Ocupación: $\underline{\text { Ama de casa }}$

\section{Entrevista Familiar}

Nombres y apellidos del informante:

Parentesco: Madre

Edad del informante: $\underline{44 \text { años Tel: }}$

Conformación de la familia nuclear (padres, hermanos, entre otros):

Madre de 44 años, un hermano de 15 años y otro de 13.

Con qué miembros de su familia nuclear vive:

Su madre y sus dos hermanos.

Profesión u oficio de las personas con quienes vive:

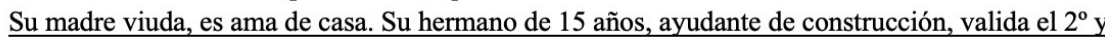

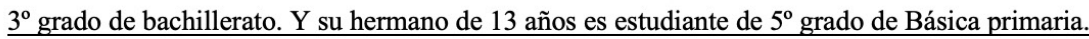

\section{Historia Clínica}

Remitido por (Entidad de salud que atiende el caso):

Clínica particular

Motivo de consulta:

Paciente remitida de clínica particular a donde fue llevada por su madre porque al levantars presentó emesis, mareo y dificultad para la marcha y para la articulación de la palabra.

Historia clínica - Etiología (Traumática, vascular, tumoral, entre otras):

Presentó vómito, imposibilidad para caminar y hablar, no control de esfínteres y convulsionó.

Infarto izquémico.

Según TAC CEREBRAL CONTRASTADO:

Hipodensidad paramediana frontal izquierda y marcado reforzamiento de giros en región fronta] izquierda, sin evidencia de masa. Calcificación frontal izquierda. Sistema ventricular normal, nc hay desviaciones de la línea media. La fosa posterior es normal. IDx infarto en región cerebra izquierda.

Trastornos Concomitantes a las Alteraciones de Lenguaje:

Hemiparesia derecha y alexia. 
Atención psicológica:

No referencia

Terapia del lenguaje:

No referencia

\section{Condiciones Premórbidas}

Antes de la lesión ¿cómo eran sus procesos comunicativos? Descríbalos a continuación:

De expresión (al hablar con los demás):

$\underline{\text { Sostenía conversaciones corrientes con familiares y amigos de la zona rural donde habita. }}$

Al leer

Referencia que sí sabe leer.

Al escribir

$\underline{\text { Referencia que sí sabe escribir. }}$

\section{Cambios lingüísticos después de la lesión}

Después de la lesión ¿cómo están sus procesos comunicativos? Descríbalos a continuación: Cuando conversa con nosotros o nos responde algo solo dice SI o NO o dice algunas palabras sueltas.

¿Cómo es su trato hacia los demás y específicamente sus conversaciones con la familia? En algunas ocasiones presenta disgusto y malestar con sus hermanos sin razón aparente.

\section{Entrevista al paciente}

Cuénteme que le pasó

H-OP No responde

¿Dónde estamos?

H-OP No responde

¿Qué día es hoy?

H-OP No responde 


\subsubsection{Análisis cuantitativo}

\subsubsection{Porcentaje de rendimiento deficitario (PRD): Calificación de la prueba Caso $\mathrm{N}^{\circ} 1$}

Una vez aplicada esta prueba se procedió a calcular los rendimientos deficitarios del H-OP valorado (ver Tablas 12, 13, 14 y 15), suproceso por subproceso, de cada proceso observado. Esto permitió establecer los respectivos perfiles de rendimiento deficitario, los cuales se muestran en las Figuras 32, 33, 34, 35, 36, 37, 38 y 39.

Tabla 12. Rendimiento deficitario en cada subproceso del lenguaje expresivo (Expresión verbal): Caso $\mathrm{N}^{\circ} 1$

\begin{tabular}{|c|c|c|c|c|c|c|c|}
\hline \multicolumn{8}{|c|}{ Caso $\mathrm{N}^{\circ} \underline{1}$} \\
\hline \multicolumn{8}{|c|}{ 1. LENGUAJE EXPRESIVO (EXPRESIÓN VERBAL) } \\
\hline \multicolumn{4}{|c|}{ 1.1 Lenguaje espontáneo } & \multicolumn{4}{|c|}{ 1.2. Lenguaje dialogado } \\
\hline & $\mathbf{0}$ & 1 & 2 & & $\mathbf{0}$ & 1 & 2 \\
\hline a & & 1 & & $\mathbf{a}$ & & 1 & \\
\hline b & & & \multirow[t]{2}{*}{2} & b & & 1 & \\
\hline $\mathbf{c}$ & & 1 & & $\mathbf{c}$ & & 1 & \\
\hline d & & & \multirow[t]{2}{*}{2} & d & 0 & & \\
\hline e & & 1 & & $\mathbf{e}$ & 0 & & \\
\hline \multicolumn{4}{|c|}{ Errores: $\underline{7}$ (RD). $14 \%$ (PRD) } & \multicolumn{4}{|c|}{ Errores: $\underline{3}$ RD. $\underline{6} \%$ (PRD) } \\
\hline \multicolumn{4}{|c|}{$\begin{array}{l}\text { 1.3 Lenguaje monologado } \\
\text { Ilustrativo }\end{array}$} & \multicolumn{4}{|c|}{ 1.4. lenguaje monologado narrativo } \\
\hline & $\mathbf{0}$ & 1 & 2 & & $\mathbf{0}$ & 1 & 2 \\
\hline $\mathbf{a}$ & 0 & & & $\mathbf{a}$ & & 1 & \\
\hline b & & & 2 & b & & 1 & \\
\hline $\mathbf{c}$ & 0 & & & $\mathbf{c}$ & & & 2 \\
\hline $\mathbf{d}$ & & & 2 & $\mathbf{d}$ & & & 2 \\
\hline $\mathbf{e}$ & & & 2 & $\mathbf{e}$ & & & 2 \\
\hline \multicolumn{4}{|c|}{ Errores: $\underline{6}(\mathrm{RD}) . \underline{12} \%(\mathrm{PRD})$} & \multicolumn{4}{|c|}{ Errores: $\underline{8}(\mathrm{RD}) .16 \%$ (PRD) } \\
\hline \multicolumn{8}{|c|}{1.5 Lenguaje monologado temático } \\
\hline & $\mathbf{0}$ & 1 & \multirow[t]{2}{*}{2} & & & & \\
\hline $\mathbf{a}$ & & 1 & & & & & \\
\hline $\mathbf{b}$ & & 1 & & & & & \\
\hline $\mathbf{c}$ & & & 2 & & & & \\
\hline d & & & 2 & & & & \\
\hline $\mathbf{e}$ & & & 2 & & & & \\
\hline \multicolumn{8}{|c|}{ Errores: $\underline{8}(\mathrm{RD}) . \underline{16} \%$ (PRD) } \\
\hline \multicolumn{8}{|c|}{ Total Rendimiento deficitario. Lenguaje Expresivo. Errores: 32 (RD)._64 \% (PRD) } \\
\hline
\end{tabular}


Tabla 13. Rendimiento deficitario en cada subproceso del lenguaje Receptivo (Comprensión verbal) Caso $\mathrm{N}^{\circ} 1$ / Hoja 1 de 2

\begin{tabular}{|c|c|c|c|c|c|c|}
\hline \multicolumn{7}{|c|}{2 LENGUAJE RECEPTIVO (COMPRENSIÓN VERBAL) } \\
\hline \multicolumn{4}{|c|}{ 2.1 Comprensión fonémica } & \multicolumn{3}{|c|}{ 2.2 Comprensión de las palabras } \\
\hline & $\mathbf{0}$ & 1 & 2 & $\mathbf{0}$ & 1 & 2 \\
\hline $\mathbf{a}$ & 0 & & & 0 & & \\
\hline $\mathbf{b}$ & & & 2 & 0 & & \\
\hline $\mathbf{c}$ & & & 2 & 0 & & \\
\hline d & 0 & & & & & 2 \\
\hline e & 0 & & & & 1 & \\
\hline \multicolumn{4}{|c|}{ Errores: $\underline{4}(\mathrm{RD}) . \underline{4} \%$ (PRD) } & \multicolumn{3}{|c|}{ Errores: $\underline{3}(\mathrm{RD}) \cdot \underline{3} \%$ (PRD) } \\
\hline \multicolumn{4}{|c|}{$\begin{array}{l}2.3 \text { comprensión de estructuras } \\
\text { gramaticales simples }\end{array}$} & \multicolumn{3}{|c|}{2.4 comprensión de estructuras gramaticales compuestas } \\
\hline & 8 & 7 & 2 & $\mathbf{0}$ & 1 & 2 \\
\hline $\mathbf{a}$ & 0 & & & 0 & & \\
\hline $\mathbf{b}$ & 0 & & & 0 & & \\
\hline $\mathbf{c}$ & 0 & & & 0 & & \\
\hline d & 0 & & & 0 & & \\
\hline $\mathbf{e}$ & 0 & & & 0 & & \\
\hline \multicolumn{4}{|c|}{ Errores: $\underline{0}(\mathrm{RD}) . \underline{0} \%(\mathrm{PRD})$} & \multicolumn{3}{|c|}{ Errores: $\underline{0}(\mathrm{RD}) \cdot \underline{0} \%(\mathrm{PRD})$} \\
\hline \multicolumn{7}{|c|}{2.5 Comprensión de estructuras complejas } \\
\hline & $\mathbf{0}$ & 1 & 2 & & & \\
\hline $\mathbf{a}$ & 0 & & & & & \\
\hline b & 0 & & & & & \\
\hline $\mathbf{c}$ & 0 & & & & & \\
\hline d & 0 & & & & & \\
\hline $\mathbf{e}$ & 0 & & & & & \\
\hline \multicolumn{7}{|c|}{ Errores: $\underline{0}$ (RD). $\underline{0} \%$ (PRD) } \\
\hline
\end{tabular}


Tabla 13. Rendimiento deficitario en cada subproceso del lenguaje Receptivo (Comprensión verbal) Caso $\mathrm{N}^{\circ} 1$ / Hoja 2 de 2

\begin{tabular}{|c|c|c|c|c|c|c|c|}
\hline \multicolumn{8}{|c|}{2 LENGUAJE RECEPTIVO (COMPRENSIÓN VERBAL) } \\
\hline \multicolumn{8}{|c|}{ 2.6 COMPRENSIÓN DE ESTRUCTURAS LÓGICO-GRAMATICALES } \\
\hline \multicolumn{4}{|c|}{ Relaciones espaciales } & \multicolumn{4}{|c|}{ Relaciones temporales } \\
\hline & $\mathbf{0}$ & 1 & 2 & & $\mathbf{0}$ & 1 & 2 \\
\hline $\mathbf{a}$ & & & 2 & $\mathbf{a}$ & & & 2 \\
\hline $\mathbf{b}$ & & & 2 & $\mathbf{b}$ & & 1 & \\
\hline $\mathbf{c}$ & & & 2 & $\mathbf{c}$ & & & 2 \\
\hline $\mathbf{d}$ & 0 & & & $\mathbf{d}$ & & & 2 \\
\hline $\mathbf{e}$ & 0 & & & e & & & 2 \\
\hline \multicolumn{4}{|c|}{ Errores: $\underline{6}(\mathrm{RD}) . \underline{6} \%(\mathrm{PRD})$} & \multicolumn{4}{|c|}{ Errores: $\underline{9}(\mathrm{RD}) . \underline{9} \%(\mathrm{PRD})$} \\
\hline \multicolumn{4}{|c|}{ Comparaciones } & \multicolumn{4}{|c|}{ Caso atributivo genitivo } \\
\hline & & & & & $\mathbf{0}$ & 1 & 2 \\
\hline & $\mathbf{0}$ & 1 & 2 & $\mathbf{a}$ & 0 & & \\
\hline $\mathbf{a}$ & 0 & & & b & & & 2 \\
\hline $\mathbf{b}$ & & & 2 & $\mathbf{c}$ & & & 2 \\
\hline $\mathbf{c}$ & 0 & & & d & & & 2 \\
\hline d & 0 & & & $\mathbf{e}$ & & & 2 \\
\hline e & & & 2 & \multirow{2}{*}{\multicolumn{4}{|c|}{ Errores: $\underline{8} \mathrm{RD} . \underline{8} \%(\mathrm{PRD})$}} \\
\hline \multicolumn{4}{|c|}{ Errores: $\underline{4}(\mathrm{RD}) . \underline{4} \%(\mathrm{PRD})$} & & & & \\
\hline \multicolumn{4}{|c|}{ Absurdos } & & & & \\
\hline & $\mathbf{0}$ & 1 & 2 & & & & \\
\hline $\mathbf{A}$ & 0 & & & & & & \\
\hline B & 0 & & & & & & \\
\hline $\mathbf{C}$ & 0 & & & & & & \\
\hline $\mathbf{D}$ & 0 & & & & & & \\
\hline $\mathbf{E}$ & 0 & & & & & & \\
\hline \multicolumn{8}{|c|}{ Errores: $\underline{0}(\mathrm{RD}) . \underline{0} \%(\mathrm{PRD})$} \\
\hline \multicolumn{8}{|c|}{ Total Rendimiento deficitario. Lenguaje Receptivo. Errores: 34 (RD)_34 \% (PRD) } \\
\hline
\end{tabular}


Tabla 14. Rendimiento deficitario en cada subproceso del lenguaje memorizado (almacenamiento de la expresión verbal) Caso $\mathrm{N}^{\circ} 1 /$. Hoja 1 de 2

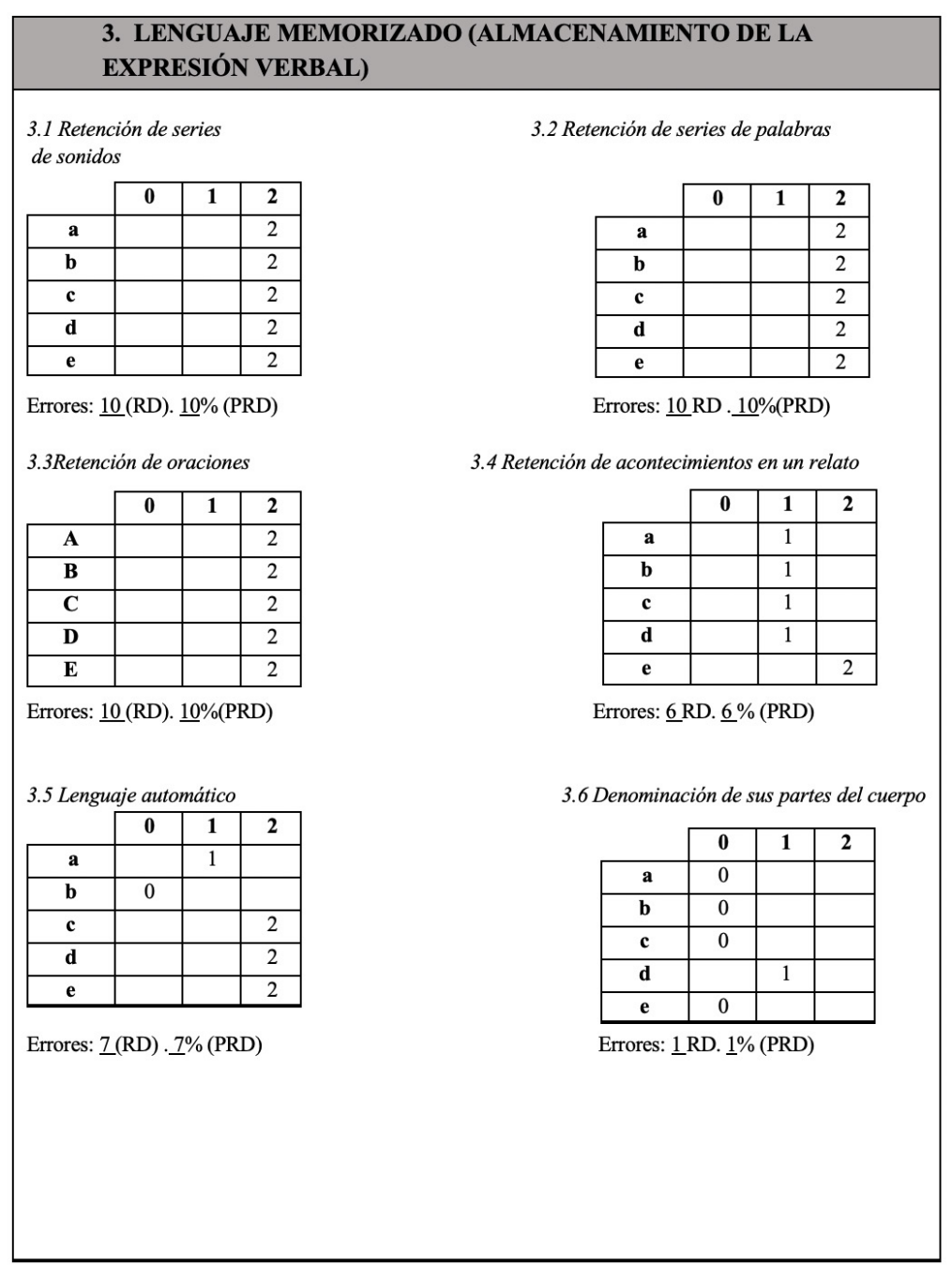


Tabla 14. Rendimiento deficitario en cada subproceso del lenguaje memorizado (almacenamiento de la expresión verbal) Caso $\mathrm{N}^{\circ} 1 /$ Hoja 2 de 2

\begin{tabular}{|c|c|c|c|c|c|c|c|}
\hline \multicolumn{8}{|c|}{$\begin{array}{l}\text { 3. LENGUAJE MEMORIZADO (ALMACENAMIENTO DE LA } \\
\text { EXPRESIÓN VERBAL) }\end{array}$} \\
\hline \multicolumn{4}{|c|}{$\begin{array}{l}3.7 \text { Denominación de las } \\
\text { partes del cuerpo en una imagen }\end{array}$} & \multicolumn{4}{|c|}{ 3.8 Denominación de seres y objetos en dibuj } \\
\hline & $\mathbf{0}$ & $\mathbf{1}$ & 2 & & $\mathbf{0}$ & 1 & 2 \\
\hline $\mathbf{a}$ & 0 & & & a & & & 2 \\
\hline $\mathbf{b}$ & & 1 & & b & & 1 & \\
\hline c & & 1 & & $\mathbf{c}$ & & & 2 \\
\hline d & 0 & & & d & & & 2 \\
\hline $\mathbf{e}$ & 0 & & & $\mathbf{e}$ & & & 2 \\
\hline \multicolumn{4}{|c|}{ Errores: $\underline{2}$ (RD). $\underline{2} \%$ (PRD) } & \multicolumn{4}{|c|}{ Errores: $\underline{9}$ RD. $\underline{9} \%(\mathrm{PRD})$} \\
\hline \multicolumn{4}{|c|}{ 3.9 Denominación por descripciones } & \multicolumn{4}{|c|}{3.10 definiciones funcionales } \\
\hline & $\mathbf{0}$ & 1 & 2 & & $\mathbf{0}$ & 1 & 2 \\
\hline $\mathbf{a}$ & & & 2 & $\mathbf{a}$ & & 1 & \\
\hline b & 0 & & & $\mathbf{b}$ & & 1 & \\
\hline c & & & 2 & c. & & 1 & \\
\hline $\mathbf{d}$ & 0 & & & d. & & 1 & \\
\hline $\mathbf{e}$ & 0 & & & e. & & 1 & \\
\hline \multicolumn{4}{|c|}{ Errores: $\underline{4}$ (RD). $\underline{4} \%$ (PRD) } & \multicolumn{4}{|c|}{ Errores: $\underline{5}$ RD $\underline{5} \%(P R D)$} \\
\hline \multicolumn{8}{|c|}{ Total Rendimiento deficitario. Lenguaje Memorizado. Errores: 64 (RD). $64 \%$ (PRD) } \\
\hline
\end{tabular}


Tabla 15. Rendimiento deficitario en cada subproceso del lenguaje reproducido (Proceso reproductivo de la expresión verbal). Caso $\mathrm{N}^{\circ} 1 . /$ Hoja 1 de 3

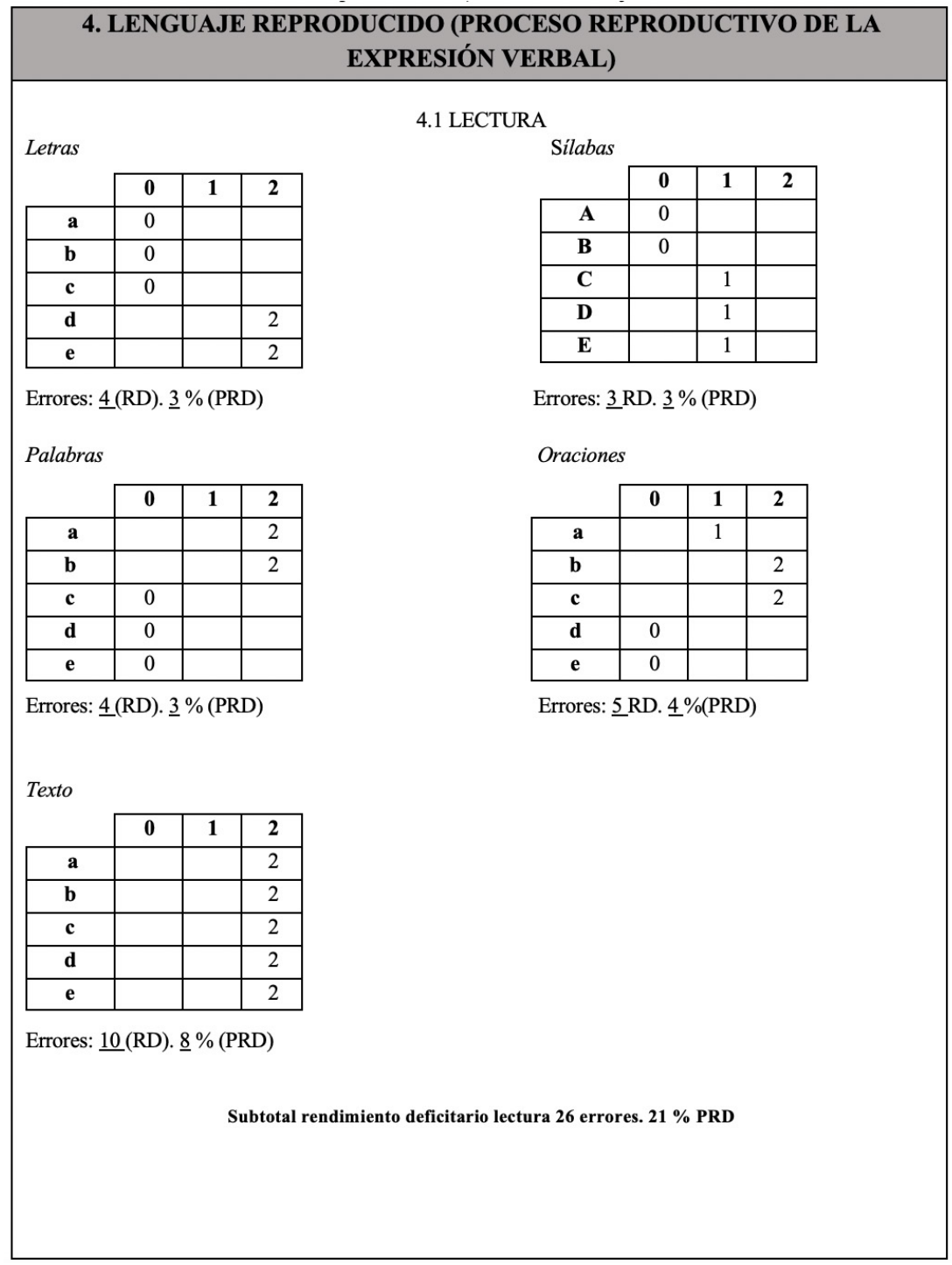


Tabla 15. Rendimiento deficitario en cada subproceso del lenguaje reproducido (Proceso reproductivo de la expresión verbal). Caso $\mathrm{N}^{\circ} 1$. / Hoja 2 de 3

\begin{tabular}{|c|c|c|c|c|c|c|c|c|}
\hline \multicolumn{9}{|c|}{$\begin{array}{l}\text { 4. LENGUAJE REPRODUCIDO (PROCESO REPRODUCTIVO DE LA } \\
\text { EXPRESIÓN VERBAL) }\end{array}$} \\
\hline \multicolumn{9}{|c|}{ 4.2 ESCRITURA } \\
\hline \multicolumn{4}{|c|}{ Escritura al dictado de palabras } & & \multicolumn{4}{|c|}{ Escritura al dictado de oraciones simples } \\
\hline & $\mathbf{0}$ & 1 & 2 & & & $\mathbf{0}$ & $\mathbf{1}$ & 2 \\
\hline $\mathbf{a}$ & & & 2 & & $\mathbf{a}$ & & & 2 \\
\hline $\mathbf{b}$ & & & 2 & & b & & & 2 \\
\hline $\mathbf{c}$ & & & 2 & & $\mathbf{c}$ & & & 2 \\
\hline $\mathbf{d}$ & & & 2 & & d & & & 2 \\
\hline $\mathbf{e}$ & & & 2 & & $\mathbf{e}$ & & & 2 \\
\hline \multicolumn{4}{|c|}{ Errores: $\underline{10}(\mathrm{RD}) . \underline{8} \%(\mathrm{PRD})$} & & \multicolumn{4}{|c|}{ Errores: $\underline{10}$ RD. $\underline{8} \%(\mathrm{PRD})$} \\
\hline \multicolumn{5}{|c|}{ Escritura al dictado de oraciones complejas } & \multicolumn{4}{|c|}{ Escritura espontánea seriada } \\
\hline & $\mathbf{0}$ & 1 & 2 & & & $\mathbf{0}$ & $\mathbf{1}$ & 2 \\
\hline $\mathbf{a}$ & & & 2 & & $\mathbf{a}$ & & & 2 \\
\hline b & & & 2 & & b & & & 2 \\
\hline c & & & 2 & & c & & & 2 \\
\hline d & & & 2 & & $\mathbf{d}$ & & & 2 \\
\hline $\mathbf{e}$ & & & 2 & & $\mathbf{e}$ & & & 2 \\
\hline \multicolumn{4}{|c|}{ Errores: $\underline{10}(\mathrm{RD}) . \underline{8} . \%(\mathrm{PRD})$} & & \multicolumn{4}{|c|}{ Errores: $\underline{10}$ RD. $\underline{8} \%(\mathrm{PRD})$} \\
\hline \multicolumn{4}{|c|}{ Escritura seriada narrativa } & & & & & \\
\hline & $\mathbf{0}$ & 1 & 2 & & & & & \\
\hline $\mathbf{a}$ & & & 2 & & & & & \\
\hline b & & & 2 & & & & & \\
\hline c & & & 2 & & & & & \\
\hline d & & & 2 & & & & & \\
\hline $\mathbf{e}$ & & & 2 & & & & & \\
\hline \multicolumn{9}{|c|}{ Errores: $\underline{10}(\mathrm{RD}) . \underline{8} \%$ (PRD) } \\
\hline
\end{tabular}


Tabla 15. Rendimiento deficitario en cada subproceso del lenguaje reproducido (Proceso reproductivo de la expresión verbal) Caso $\mathrm{N}^{\circ} 1 /$ Hoja 3 de 3

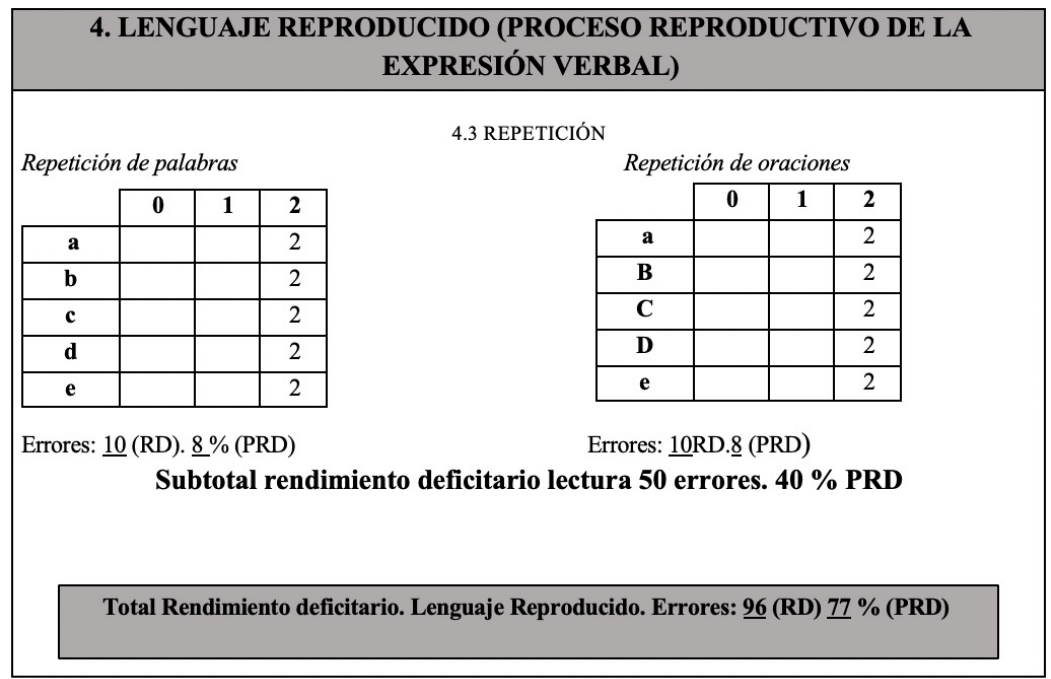

\subsubsection{Porcentaje de rendimiento deficitario (PRD):} Representación gráfica Caso $\mathrm{N}^{\circ} 1$

Figura 32. Perfil del rendimiento deficitario en su Expresión verbal. Caso $\mathrm{N}^{\circ} 1$

Perfil de rendimiento deficitario: Caso $\mathrm{N}^{\circ} 1$

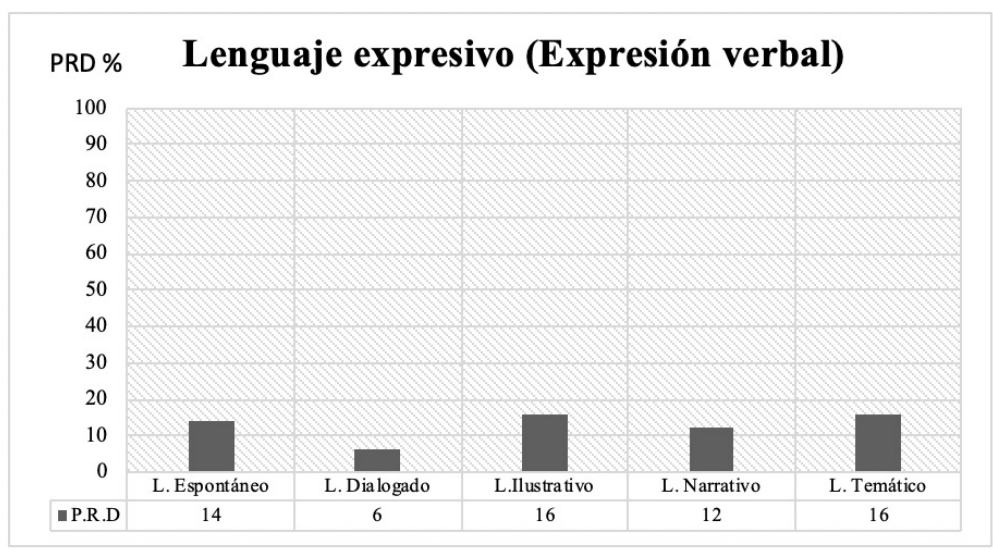


Figura 33. Perfil del rendimiento deficitario en su Comprensión verbal. Caso No 1

Perfil de rendimiento deficitario Caso № 1 .

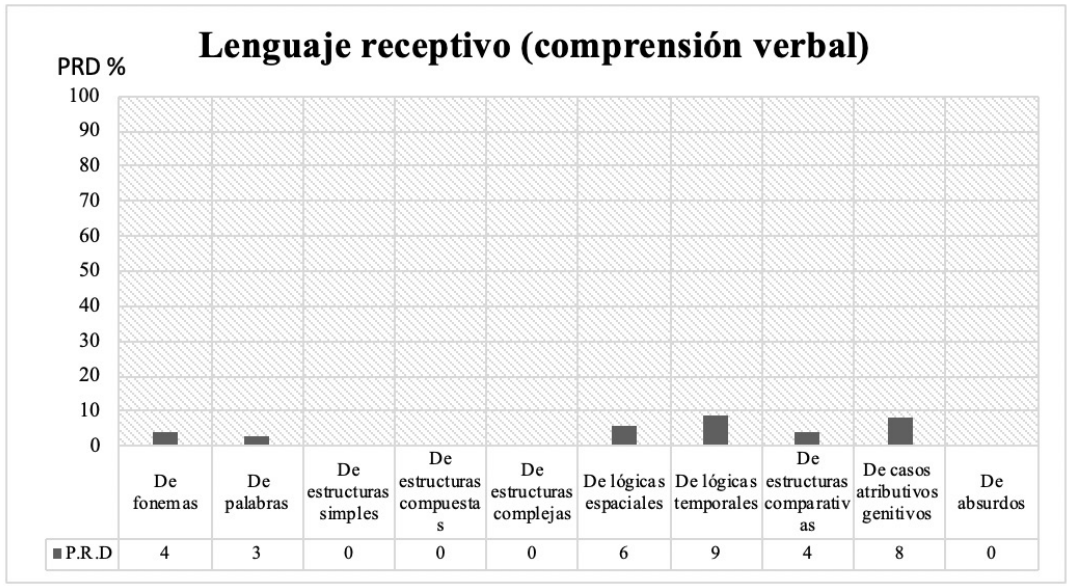

Figura 34. Perfil del rendimiento deficitario en el Almacenamiento de su expresión verbal. Caso $\mathrm{N}^{\circ} 1$

Perfil de rendimiento deficitario Caso No 1

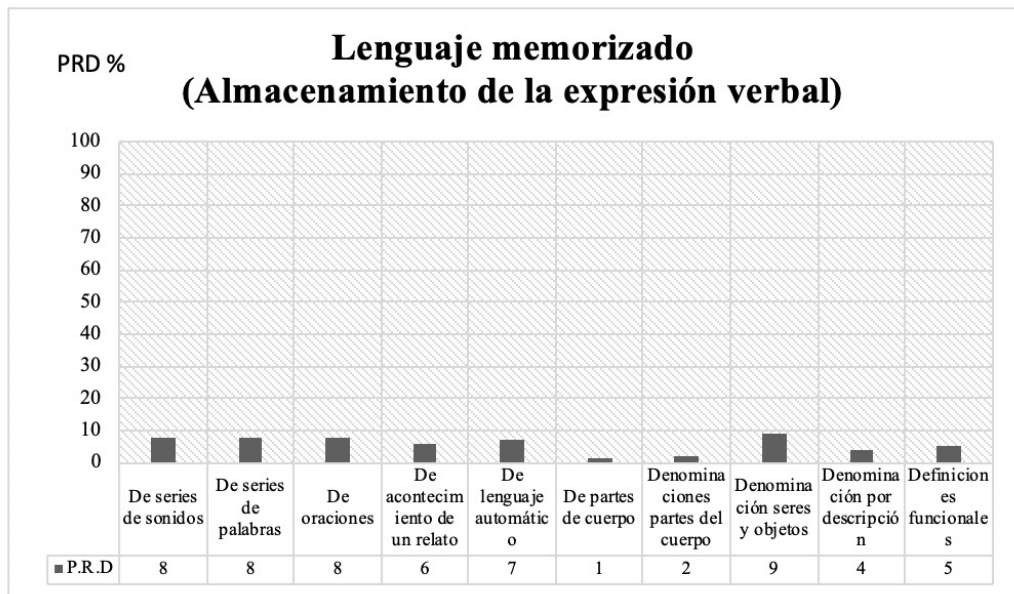


Figura 35. Perfil del rendimiento deficitario en la Reproducción de su expresión verbal: Lectura. Caso № 1

Perfil de rendimiento deficitario Caso No 1

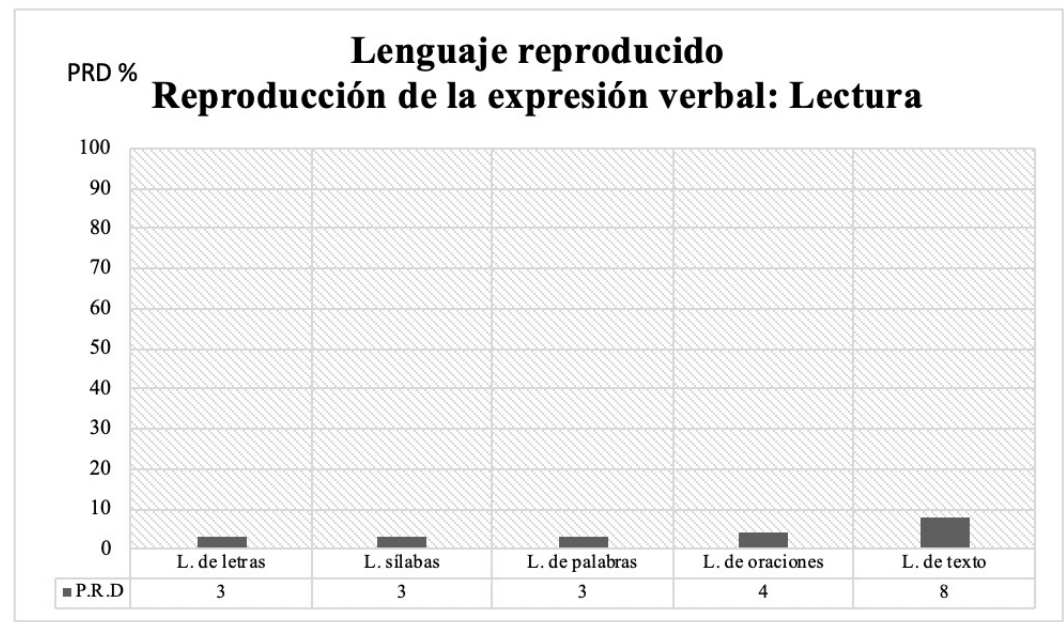

Figura 36. Perfil del rendimiento deficitario en la Reproducción de su expresión verbal: Escritura. Caso No 1.

Perfil de rendimiento deficitario Caso No 1

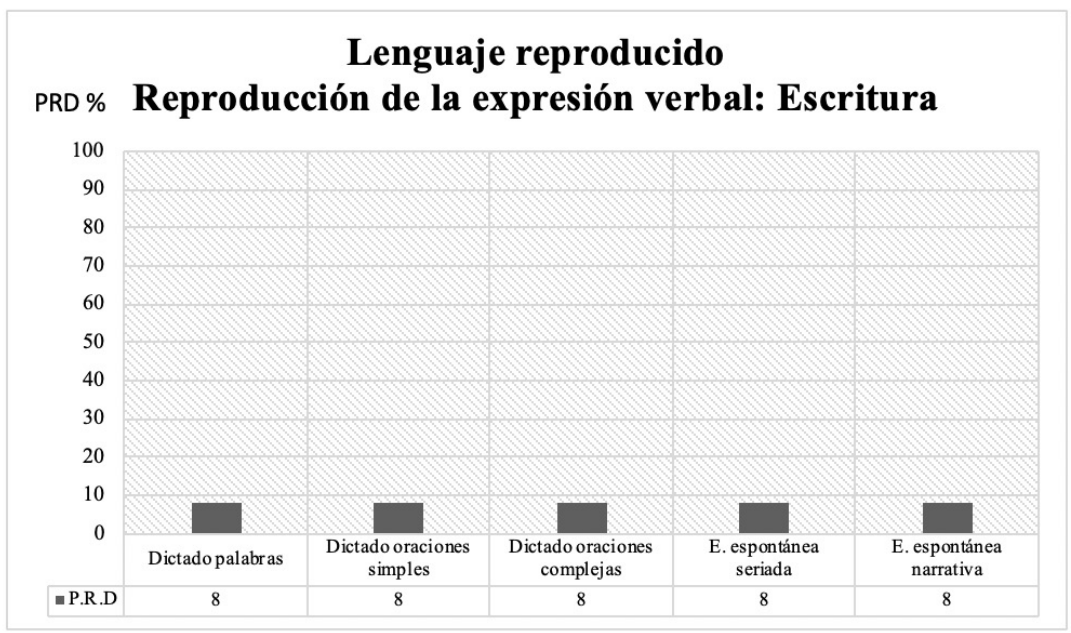


Figura 37. Perfil del rendimiento deficitario en la Reproducción de su expresión verbal: Repetición. Caso № 1

Perfil de rendimiento deficitario Caso № 1 .

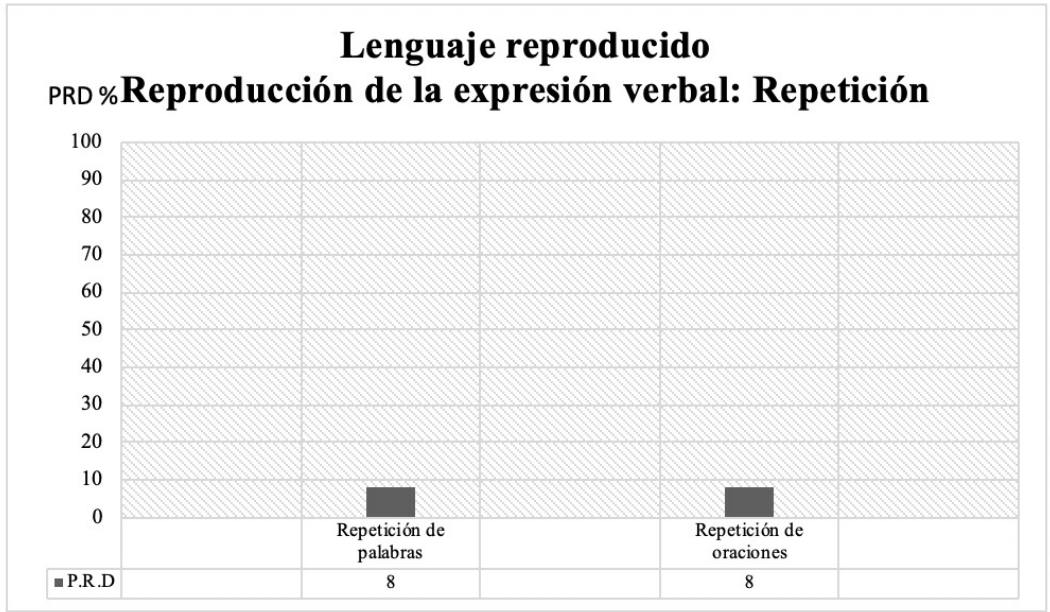

Figura 38. Perfil del rendimiento deficitario en la Reproducción de su expresión verbal - Caso $\mathrm{N}^{\circ} 1$

Perfil de rendimiento deficitario Caso № 1 .

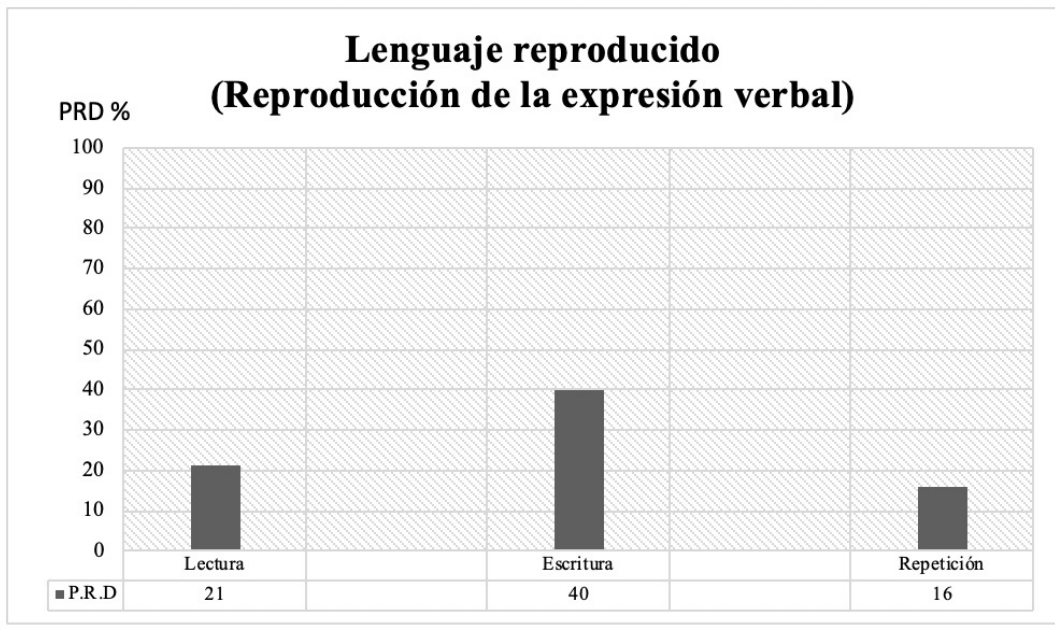


Figura 39. Perfil del rendimiento deficitario en sus Procesos psicolingüísticos. Caso № 1

Perfil de rendimiento deficitario. Procesos psicolingüísticos evaluados. Caso № 1.

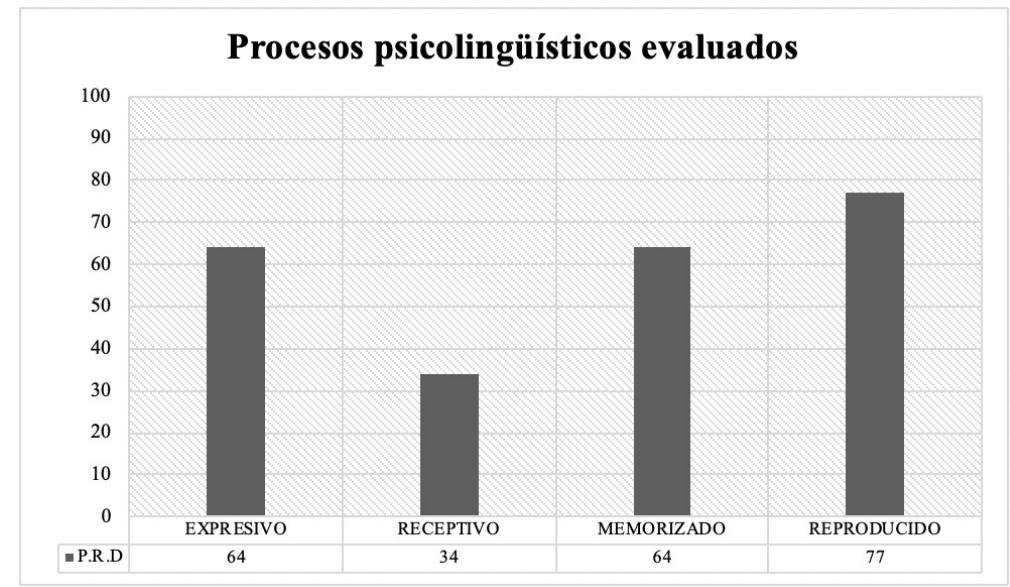

\subsubsection{Análisis cualitativo: Procesos psicolingüísticos conservados y alterados. Caso $\mathrm{N}^{\circ} 1$}

\subsubsection{Procesos psicolingüísticos conservados. Caso $\mathrm{N}^{\circ} 1$}

La H-OP tiene intacta su sensibilidad auditiva y su grado de concentración y atención durante la aplicación del test fue satisfactorio. Presentó una actitud receptiva y su orientación en cuanto a persona, espacio y tiempo fue adecuada. En cuanto al lenguaje expresivo: señala fácilmente objetos separados y responde con fragmentos aislados a preguntas que se le formulan. El lenguaje receptivo está conservado en lo que se refiere al fonema aislado y a la ejecución de órdenes de menor a mayor grado de complejidad (oraciones simples y complejas). Comprende, dando juicios de veracidad o falsedad a los absurdos que se le presentan, hay comprensión de estructuras complejas, evidenciada en las respuestas cortas (nombres) que da a las preguntas del examinador. En el lenguaje memorizado: identifica las partes del cuerpo tanto en ausencia como en presencia de ellas (láminas). La nominación como respuesta a descripciones está conservada.En el lenguaje reproducido: lee bien grafemas aislados. 


\subsubsection{Procesos psicolingüísticos alterados. Caso $\mathrm{N}^{\circ} 1$}

\section{Lenguaje expresivo}

No tiene iniciativa para iniciar una conversación, ni para desarrollarla. No puede hablar con soltura. Contesta a las cuestiones muy escuetamente y le es muy difícil formular nuevos términos. Nunca responde a preguntas que se le formulan, ni siquiera con una frase simple, sólo con verbos en infinitivo o sustantivos en forma aislada, sin uso de preposiciones (lenguaje telegráfico). La expresión "la bandera de Colombia" la reproduce como "banra lo lombia". La oración "la rata se come el queso" la reproduce como "rata come queso" eludiendo el pronombre reflexivo "se".

\section{Lenguaje receptivo}

No puede identificar pares de sonidos como " $\mathrm{p} / \mathrm{b}$ " “ $\mathrm{d} / \mathrm{t}$ " en situaciones de repetición y lectura. Los experimenta como idénticos o apenas distinguibles.

Las tareas complicadas como repetir series de sonidos superan completamente sus posibilidades. Lo mismo ocurre con la repetición de palabras complejas de las cuales solamente reproduce los fonemas finales e iniciales, tornándose en ambos casos reiterativas sus respuestas.

De "ensimismado" repitió: "enmado"

De "epíteto" repitió: "opito"

Tiene graves dificultades para organizar secuencias largas de sonidos, especialmente con el orden en que se pronuncian sus series:

De "pan/sol/rey" repite: "rey/la"

De "o/a/t/r" repite: "r/a/r"

De "bi/kg/dn" repite: "b/a/d"

La retención de oraciones simples y complejas presenta serias dificultades, evidenciadas en la repetición de sólo nombres y acciones en las condiciones aisladas ya mencionadas: 
De "el hombre busca una sonrisa" repite: "hombre ro"

De "el hombre y el niño aman íntimamente la poesía como alimento de sus vidas" repite: "niño hombre inmanente sía vidas". Respuestas obtenidas después de repetirle varias veces el enunciado.

De acuerdo a lo anterior, no hay retención de pasajes y fragmentos, ya que al leérselos sólo refiere palabras aisladas (señor, dientes, jeans, camisa) que sí hacen parte de ellos.

El paciente puede señalar el objeto que se le pida, pero no consigue hacerlo en los casos en que aparecen relaciones gramaticales, así:

De "Florero debajo de la mesa" señala "florero al lado de la mesa"

No puede captar la esencia de las construcciones preposicionales. Tiene dificultades en las construcciones invertidas.

No analiza las asociaciones que contienen las instrucciones y muestra una tendencia ecopráxica a seguir el orden de las palabras en la oración:

De "la bicicleta atropelló al niño: ¿antes del accidente, en el accidente o después del accidente?" responde: bicicleta, niño.

\section{Lenguaje memorizado}

Se presenta como síntoma defectuoso dominante. La paciente experimenta grandes dificultades para repetir series de sonido, palabras complejas, series de palabras, frases simples y complejas. Pierde la secuencia de palabras que forman la serie dada, persevera en palabras presentadas con anterioridad. Repite sin dificultades palabras simples e individuales, pero no puede repetir series de palabras. Se concluye un trastorno de la organización serial o sintagmático. Puede reproducir series cortas de palabras (días de la semana, dígitos del 1 al 10), pero le es difícil recitar series largas (meses del año) y lenguaje automatizado como rezos y cantos; no puede recitar las series en orden invertido. Tiene dificultad para encontrar los nombres requeridos: anomia. Si se le induce con la primera sílaba, encuentra la palabra rápidamente. No explícita verbalmente predicados referidos a las definiciones funcionales de palabras, pero lo indica a través de gestos de una manera adecuada. 


\section{Lenguaje reproducido}

Hay sustituciones al leer algunas sílabas y palabras:

Al leer "co" lee: "ro"

Al leer "li" lee: "la"

Al leer "rosita" lee: "cocino"

En su lectura hay omisiones, adiciones y sustituciones:

Al leer "la rata se come el queso" lee: "patitos ga guía"

No lee textos largos

Después de los análisis cuantitativo y cualitativo del Caso valorado, incluyendo procesos psicolingüísticos conservados y alterados, se procedió a realizar el respectivo diagnóstico (Tabla 16).

\subsubsection{Diagnóstico}

Tabla 16. Diagnóstico Caso $\mathrm{N}^{\circ} 1$ después de aplicación de Batería de Diagnóstico y Caracterización de las afasias

\begin{tabular}{|c|l|}
\hline \multicolumn{2}{|c|}{ Diagnóstico caso No 1_ } \\
\hline Aspecto valorado & \multicolumn{1}{c|}{ Resultado } \\
\hline Lingüístico & $\begin{array}{l}\text { Codificación: Nivel sintáctico } \\
\text { Dificultad para expresarse verbalmente; se evidencia } \\
\text { en la no utilización de predicados verbales, recurriendo } \\
\text { al uso continuo de monosílabos y palabras aisladas } \\
\text { (nombres) para sus respuestas. Incapacidad de } \\
\text { concatenación de palabras. } \\
\text { Decodificación: Nivel sintáctico / Nivel semántico } \\
\text { No hay comprensión de pasajes o fragmentos, sólo } \\
\text { refiere palabras aisladas que sí hacen parte de ellos. Al } \\
\text { alterarse el componente sintáctico, por ende, también } \\
\text { se alteran las estructuras lógico gramaticales que } \\
\text { comportan un nivel semántico. }\end{array}$ \\
\hline
\end{tabular}




\begin{tabular}{|c|c|}
\hline Psicolingüístico & $\begin{array}{l}\text { Están alterados todos los procesos, en especial el } \\
\text { expresivo y memorizado. }\end{array}$ \\
\hline Neurolingüístico & $\begin{array}{l}\text { Afasia según tipología del grupo de Boston: } \\
\text { Afasia de Broca. } \\
\text { Afasia según tipología de Luria: } \\
\text { Afasia motora eferente } \\
\text { Posible lesión cerebral: } \\
\text { Área de broca (H.C refiere Infarto en región anterior } \\
\text { cerebral izquierda; hipodensidad paramediana frontal } \\
\text { izquierda) }\end{array}$ \\
\hline
\end{tabular}

De los demás casos valorados, se presentan en el apartado 3.2 a manera de resultados los correspondientes de los casos 2 al 11, únicamente sus diagnósticos previa identificación del caso (ver Tablas $17,18,19,20,21,22,23,24,25,26)$.

\subsection{Resultados casos 2 al 11: Diagnósticos}

\subsubsection{Caso $\mathrm{N}^{\circ} 2$}

\section{Caso $\mathbf{N}^{\circ} 2$}

Lugar de la entrevista: Domicilio ubicado en B/Cuba-Pereira

\section{Identificación Personal}

Nombres y apellidos

Dirección y teléfono:

Fecha de nacimiento:

Edad: $\underline{40}$

Lugar de nacimiento: Armenia

Sexo: Masculino

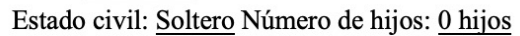

Lateralidad: Diestra

\section{Información Complementaria}

Educación formal: Ingeniero civil

Ocupación: Ingeniero 
Tabla 17. Diagnóstico Caso $\mathrm{N}^{\circ} 2$ después de aplicación de Batería de Diagnóstico y Caracterización de las afasias

\begin{tabular}{|l|l|}
\hline \multicolumn{2}{|c|}{ Diagnóstico caso No 2} \\
\hline \multicolumn{1}{|c|}{ Aspecto valorado } & \multicolumn{1}{c|}{ Resultado } \\
\hline Lingüístico & $\begin{array}{l}\text { Codificación: Nivel sintáctico } \\
\text { No se expresa verbalmente; emite algunos sonidos y } \\
\text { partes de las palabras. } \\
\text { Decodificación: Nivel sintáctico / Nivel semántico }\end{array}$ \\
\hline Psicolingüístico & $\begin{array}{l}\text { Alteración fundamental en el proceso expresivo, } \\
\text { además en los procesos receptivos, memorizados y } \\
\text { reproducidos. }\end{array}$ \\
\hline Neurolingüístico & $\begin{array}{l}\text { Afasia según tipología del grupo de Boston:- } \\
\text { Afasia de Broca. } \\
\text { Afasia según tipología de luria: } \\
\text { Afasia motora eferente } \\
\text { Posible lesión cerebral: } \\
\text { Área de broca (H.C refiere hemorragia fronto-parietal } \\
\text { izquierda) }\end{array}$ \\
\hline
\end{tabular}

\subsubsection{Caso $\mathrm{N}^{\circ} 3$}

\section{Caso $\mathbf{N}^{\circ} 3$}

Lugar de la entrevista: Domicilio ubicado en barrio San Luis, Pereira

\section{Identificación Personal}

Nombres y apellidos:

Dirección y teléfono:

Fecha de nacimiento:

Edad: 38 años

Lugar de nacimiento: Pereira (Risaralda)

Sexo: Femenino

Estado civil: Casada Número de hijos: $\underline{6 \text { hijos }}$

Lateralidad: Diestra

\section{Información Complementaria}

Educación formal: Hasta grado $5^{\mathrm{a}}$ de Educación básica primaria Ocupación: Ama de casa 
Tabla 18. Diagnóstico Caso $\mathrm{N}^{\circ} 3$ después de aplicación de Batería de Diagnóstico y Caracterización de las afasias

\begin{tabular}{|l|l|}
\hline \multicolumn{2}{|c|}{ Diagnóstico caso No 3 } \\
\hline Aspecto valorado & \multicolumn{1}{|c|}{ Resultado } \\
\hline Lingüístico & $\begin{array}{l}\text { Codificación: Nivel fonético } \\
\text { Presenta parafasias literales, pues está alterado el nivel } \\
\text { fonético especialmente. } \\
\text { Presenta dificultades en la organización sintáctica de } \\
\text { oraciones compuestas y complejas } \\
\text { Decodificación: Nivel sintáctico } \\
\text { Presenta dificultades en la comprensión de construcciones } \\
\text { gramaticales compuestas y complejas. }\end{array}$ \\
\hline Psicolingüístico & $\begin{array}{l}\text { Alterados sobre todo los procesos: memorización y } \\
\text { reproducción, especialmente en la repetición. }\end{array}$ \\
\hline Neurolingüístico & $\begin{array}{l}\text { Afasia según tipología del grupo de Boston: } \\
\text { Afasia de conducción } \\
\text { Afasia según tipología de luria: } \\
\text { Afasia Motora aferente } \\
\text { Posible lesión cerebral: } \\
\text { Área temporal (H.C refiere solo hemorragia cerebral) }\end{array}$ \\
\hline
\end{tabular}

\subsubsection{Caso $\mathrm{N}^{\circ} 4$}

\section{Caso $\mathrm{N}^{\circ} 4$}

Lugar de la entrevista: Domicilio ubicado en Parque industrial, Pereira

\section{Identificación Personal}

Nombres y apellidos: $* * * * * * * * * * * * * * * * * * * * * * * * * * * * * * * * * * * *$

Dirección y teléfono: $* * * * * * * * * * * * * * * * * * * * * * * * * * * * * * * * * *$

Fecha de nacimiento: $* * * * * * * * * * * * * * * * * * * * * * * * * * * * * * * * * *$

Edad: 21 años

Lugar de nacimiento: Pereira

Sexo: Masculino

Estado civil Soltero Número de hijos: $\underline{0 \text { hijos }}$

Lateralidad Diestro.

\section{Información Complementaria}

Educación formal: Bachiller

Ocupación: Estudiante 
Tabla 19. Diagnóstico Caso $\mathrm{N}^{\circ} 4$ después de aplicación de Batería de Diagnóstico y Caracterización de las afasias

\begin{tabular}{|l|l|}
\hline \multicolumn{2}{|c|}{ Diagnóstico caso No 4_ } \\
\hline \multicolumn{1}{|c|}{ Aspecto valorado } & \multicolumn{1}{c|}{ Resultado } \\
\hline Lingüístico & $\begin{array}{l}\text { Codificación: Nivel sintáctico } \\
\text { Muestra alteración en el eje sintagmático del } \\
\text { lenguaje. No hay fluencia en su discurso, el cual no es } \\
\text { estructurado. Su habla es agramatical e incoherente. } \\
\text { Con gestos evidencia su intención de comunicarse. } \\
\text { Decodificación: Nivel sintáctico / nivel semántico } \\
\text { Presenta dificultades en la comprensión de } \\
\text { construcciones gramaticales compuestas y complejas. }\end{array}$ \\
\hline Psicolingüístico & $\begin{array}{l}\text { Alterados los cuatro procesos psicolingüísticos, sobre } \\
\text { todo el proceso de Expresión verbal. }\end{array}$ \\
\hline Neurolingǘstico & $\begin{array}{l}\text { Afasia según tipología del grupo de Boston: } \\
\text { Afasia de Broca } \\
\text { Afasia según tipología de luria: } \\
\text { Afasia Motora eferente } \\
\text { Posible lesión cerebral: } \\
\text { Área de Broca (H.C refiere hematoma subdural } \\
\text { epidural derecho y hematoma intracerebral temporal } \\
\text { izquierdo) }\end{array}$ \\
\hline
\end{tabular}

\subsubsection{Caso $\mathrm{N}^{\circ} 5$}

\section{Caso $\mathbf{N}^{\circ} 5$}

Lugar de la entrevista: $\underline{\text { Hospital Universitario San Jorge }}$

\section{Identificación Personal}

Nombres y apellidos:

Dirección y teléfono:

Fecha de nacimiento:

Edad: $\underline{57 \text { años }}$

Lugar de nacimiento: Belén de Umbría

Sexo: Masculino

Estado civil: Casado Número de hijos: $5 \underline{\text { hijos }}$

Lateralidad: $\underline{\text { Diestro }}$

\section{Información Complementaria}

Educación formal: $\underline{\text { Hasta grado } 3^{\circ} \text { de Educación básica primaria }}$

Ocupación: Mecánico 
Tabla 20. Diagnóstico Caso $N^{\circ} 5$ después de aplicación de Batería de Diagnóstico y Caracterización de las afasias

\begin{tabular}{|l|l|}
\hline \multicolumn{1}{|c|}{ Diagnóstico caso No $\mathbf{5}$} \\
\hline Aspecto valorado & \multicolumn{1}{|c|}{ Resultado } \\
\hline Lingüístico & $\begin{array}{l}\text { Codificación: Nivel sintáctico alterado. } \\
\text { Presenta agramaticalidades e incoherencias en sus } \\
\text { construcciones verbales. } \\
\text { Decodificación: Niveles sintáctico y semántico } \\
\text { alterados. } \\
\text { No comprende estructuras complejas ni estructuras } \\
\text { lógico-gramaticales que refieran relaciones espaciales, } \\
\text { temporales, y de comparación. }\end{array}$ \\
\hline Psicolingüístico & $\begin{array}{l}\text { Alterados los cuatro procesos psicolingüísticos, sobre } \\
\text { todo el proceso de Expresión verbal. }\end{array}$ \\
\hline Neurolingüístico & $\begin{array}{l}\text { Afasia según tipología del grupo de Boston: } \\
\text { Afasia de Broca } \\
\text { Afasia según tipología de luria: } \\
\text { Afasia Motora eferente } \\
\text { Posible lesión cerebral: } \\
\text { Área de Broca (H.C refiere accidente cerebro-vascular, } \\
\text { ACV, del hemisferio izquierdo). }\end{array}$ \\
\hline
\end{tabular}

\subsubsection{Caso $\mathrm{N}^{\circ} 6$}

\section{Lugar de la entrevista: $\underline{\text { Hospital Universitario San Jorge }}$}

Identificación Personal

Nombres y apellidos: $* * * * * * * * * * * * * * * * * * * * * * * * * * * * * * * * * * * *$

Dirección y teléfono: $* * * * * * * * * * * * * * * * * * * * * * * * * * * * * * * * * *$

Fecha de nacimiento:

Edad: $\underline{54 \text { años }}$

Lugar de nacimiento: Salamina (Caldas)

Sexo: Masculino

Estado civil: Casado Número de hijos: $\underline{5 \text { hijos }}$

Lateralidad: $\underline{\text { Diestro }}$

\section{Información Complementaria}

Educación formal: Hasta grado $3^{\circ}$ de Educación básica primaria

Ocupación: $\underline{\text { Conductor }}$ 
Tabla 21. Diagnóstico Caso $\mathrm{N}^{\circ} 6$ después de aplicación de Batería de Diagnóstico y Caracterización de las afasias

\begin{tabular}{|l|l|}
\hline \multicolumn{2}{|c|}{ Diagnóstico caso No 6_ } \\
\hline Aspecto valorado & \multicolumn{1}{c|}{ Resultado } \\
\hline Lingüístico & $\begin{array}{l}\text { Codificación: Están alterados todos los niveles del } \\
\text { lenguaje. } \\
\text { No logra dar cuenta de las definiciones funcionales de } \\
\text { los objetos (nivel sintáctico y nivel semántico). } \\
\text { Decodificación: Están alterados todos los niveles del } \\
\text { lenguaje. } \\
\text { No puede denominar objetos presentes, ni suminis- } \\
\text { trándole descripciones. }\end{array}$ \\
\hline Psicolingüístico & \begin{tabular}{l} 
Alterados los cuatro procesos psicolingüísticos. \\
\hline Neurolingǘstico
\end{tabular} \\
$\begin{array}{l}\text { Afasia según tipología del grupo de Boston: } \\
\text { Afasia global } \\
\text { Afasia según tipología de luria: } \\
\text { Posible lesión cerebral: } \\
\text { Área perisilviana (H.C refiere accidente cerebro-vas- } \\
\text { cular, ACV, que causó derrame cerebral). }\end{array}$ \\
\hline
\end{tabular}

\subsubsection{Caso $\mathrm{N}^{\circ} 7$}

\section{Caso $\mathrm{N}^{\circ} 7$}

Lugar de la entrevista: Hospital Universitario San Jorge

\section{Identificación Personal}

Nombres y apellidos:

Dirección y teléfono:

Fecha de nacimiento:

Edad: $\underline{43 \text { años }}$

Lugar de nacimiento: Pereira, Risaralda

Sexo: Masculino

Estado civil: Casado Número de hijos: 2 hijos

Lateralidad: Ambidiestro

\section{Información Complementaria}

Educación formal: $\underline{\text { Hasta grado } 5^{\text {a }} \text { de Educación básica primaria }}$

Ocupación: $\underline{\text { Ama de casa }}$ 
Tabla 22. Diagnóstico Caso $\mathrm{N}^{\circ} 7$ después de aplicación de Batería de Diagnóstico y Caracterización de las afasias

\begin{tabular}{|l|l|}
\hline \multicolumn{2}{|c|}{ Diagnóstico caso No 7 } \\
\hline Aspecto valorado & \multicolumn{1}{|c|}{ Resultado } \\
\hline Lingǘstico & $\begin{array}{l}\text { Codificación: El componente sintáctico está alterado. No } \\
\text { presenta fluidez verbal. Sus emisiones para responder se } \\
\text { limitan a expresar sonidos aislados y sílabas. } \\
\text { Decodificación: Los componentes sintáctico y semántico } \\
\text { están alterados. No comprende estructuras lógico- } \\
\text { gramaticales referidas a relaciones espaciales, temporales y } \\
\text { de comparación. }\end{array}$ \\
\hline Psicolingǘstico & $\begin{array}{l}\text { El proceso expresivo está severamente alterado. Los demás } \\
\text { también presentan alteraciones. }\end{array}$ \\
\hline Neurolingüístico & $\begin{array}{l}\text { Afasia según tipología del grupo de Boston: } \\
\text { Afasia de Broca } \\
\text { Afasia según tipología de luria: } \\
\text { Afasia motora eferente } \\
\text { Posible lesión cerebral: } \\
\text { Área de Broca (H.C refiere lesión cerebral orgánica } \\
\text { extensa de predominio anterior mayor izquierdo). }\end{array}$ \\
\hline
\end{tabular}

\subsubsection{Caso $\mathrm{N}^{\circ} 8$}

Tabla 23. Diagnóstico Caso $\mathrm{N}^{\circ} 8$ después de aplicación de Batería de Diagnóstico y Caracterización de las afasias

\begin{tabular}{|l|l|}
\hline \multicolumn{2}{|c|}{ Diagnóstico caso No 8 } \\
\hline Aspecto valorado & \multicolumn{1}{|c|}{ Resultado } \\
\hline Lingüístico & $\begin{array}{l}\text { Codificación: El nivel sintáctico está alterado. Su discurso } \\
\text { es agramatical. No elabora oraciones simples correctas. } \\
\text { Decodificación: Está muy comprometido el nivel } \\
\text { sintáctico, al igual que el semántico y el fonológico. }\end{array}$ \\
\hline Psicolingüístico & $\begin{array}{l}\text { El proceso memorístico está severamente alterado. Los } \\
\text { demás también presentan alteraciones. }\end{array}$ \\
\hline
\end{tabular}




\begin{tabular}{|l|l|}
\hline Neurolingüístico & $\begin{array}{l}\text { Afasia según tipología del grupo de Boston: } \\
\text { Afasia transcortical mixta. (Afasis mixta según Goldstein) } \\
\text { Afasia según tipología de luria: }\end{array}$ \\
\hline $\begin{array}{l}\text { Posible lesión cerebral: } \\
\text { Región frontal izquierda y parito-occipital del mismo } \\
\text { lado (H.C refiere lesiones hiperdensas a nivel de la región } \\
\text { frontal izquierda y parieto-occipital del mismo lado). }\end{array}$ \\
\hline
\end{tabular}

\subsubsection{Caso $\mathrm{N}^{\circ} 9$}

\section{Caso $\mathbf{N}^{0} 9$}

Lugar de la entrevista: Domicilio ubicado en el municipio de Santa Rosa de Cabal

\section{Identificación Personal}

Nombres y apellidos: $* * * * * * * * * * * * * * * * * * * * * * * * * * * * * * * * * * * *$

Dirección y teléfono: $* * * * * * * * * * * * * * * * * * * * * * * * * * * * * * * * * *$

Fecha de nacimiento: $* * * * * * * * * * * * * * * * * * * * * * * * * * * * * * * * * *$

Edad: 35 años

Lugar de nacimiento: Santa Rosa de Cabal

Sexo: Masculino

Estado civil: Casado Número de hijos: 2 hijos

Lateralidad: Diestro

Información Complementaria

Educación formal: Hasta grado $5^{\mathrm{a}}$ de Educación básica primaria

Ocupación: Jubilado de la Policía nacional.

Tabla 24. Diagnóstico Caso $\mathrm{N}^{\circ} 9$ después de aplicación de Batería de Diagnóstico y Caracterización de las afasias

\begin{tabular}{|l|l|}
\hline \multicolumn{1}{|c|}{ Diagnóstico caso No 9 } \\
\hline Aspecto valorado & \multicolumn{1}{c|}{ Resultado } \\
\hline Lingüístico & $\begin{array}{l}\text { Codificación: El nivel sintáctico está alterado, debido al } \\
\text { aminoramiento de la memoria verbal. En su discurso } \\
\text { hay una tendencia a no conjugar los verbos que usa y } \\
\text { tendencia a la agramaticalidad (en el sentido del no uso } \\
\text { de preposiciones). } \\
\text { Decodificación: El nivel sintáctico está alterado, debido } \\
\text { al aminoramiento de la memoria verbal. Presenta } \\
\text { dificultad para entender estructuras lógico-gramaticales } \\
\text { que expresen relaciones temporales, comparativas y de } \\
\text { caso atributo-genitivo, puesto que estas últimas implican } \\
\text { procesamiento de más información ordenada. }\end{array}$ \\
\hline
\end{tabular}




\begin{tabular}{|l|l|}
\hline Psicolingüístico & $\begin{array}{l}\text { El proceso memorístico está severamente alterado y en } \\
\text { menor proporción el expresivo. }\end{array}$ \\
\hline Neurolingüístico & $\begin{array}{l}\text { Afasia según tipología del grupo de Boston:- } \\
\text { Afasia de conducción aferente } \\
\text { Afasia según tipología de luria: } \\
\text { Afasia acústico amnésica } \\
\text { Posible lesión cerebral: } \\
\text { Región temporal media (H.C refiere hematoma parietal } \\
\text { izquierdo con orificio de salida en la región parieto- } \\
\text { occipital) }\end{array}$ \\
\hline
\end{tabular}

\subsubsection{Caso $\mathrm{N}^{\circ} 10$}

\section{Caso $\mathrm{N}^{\circ} 10$}

Lugar de la entrevista: Domicilio ubicado en zona céntrica de Pereira

Identificación Personal

Nombres y apellidos:

Dirección y teléfono:

Fecha de nacimiento:

Edad: 71 años

Lugar de nacimiento: Salento (Quindío)

Sexo: Femenino

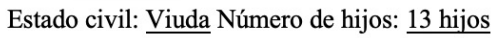

Lateralidad: Diestra

Información Complementaria

Educación formal: Hasta grado $5^{\mathrm{a}}$ de Educación básica primaria

Ocupación: Modista

Tabla 25. Diagnóstico Caso $\mathrm{N}^{\circ} 10$ después de aplicación de Batería de Diagnóstico y Caracterización de las afasias

\begin{tabular}{|c|c|}
\hline \multicolumn{2}{|r|}{ Diagnóstico caso No 10} \\
\hline Aspecto valorado & Resultado \\
\hline Lingüístico & $\begin{array}{l}\text { Codificación: El nivel morfo-sintáctico está alterado, } \\
\text { pues en sus emisiones hay sustitución, omisión y adición } \\
\text { de letras. } \\
\text { Decodificación: Alterados los niveles sintáctico y } \\
\text { semántico alterado, pues no da cuenta de estructuras } \\
\text { complejas. }\end{array}$ \\
\hline
\end{tabular}




\begin{tabular}{|c|c|}
\hline Psicolingüístico & $\begin{array}{l}\text { El proceso expresivo está severamente alterado y en } \\
\text { menor proporción los demás. }\end{array}$ \\
\hline Neurolingüístico & $\begin{array}{l}\text { Afasia según tipología del grupo de Boston: } \\
\text { Afasia de Broca } \\
\text { Afasia según tipología de Luria: } \\
\text { Afasia motora eferente } \\
\text { Posible lesión cerebral: } \\
\text { Àrea de Broca (H.C refiere lesión cerebral orgánica sobre } \\
\text { el hemisferio izquierdo...) }\end{array}$ \\
\hline
\end{tabular}

\subsubsection{Caso $\mathrm{N}^{\circ} 11$}

\section{Caso $\mathbf{N}^{0} 11$}

Lugar de la entrevista: Domicilio ubicado en zona céntrica de Pereira

\section{Identificación Personal}

Nombres y apellidos:

Dirección y teléfono: $* * * * * * * * * * * * * * * * * * * * * * * * * * * * * * * * * *$

Fecha de nacimiento: $* * * * * * * * * * * * * * * * * * * * * * * * * * * * * * * * * *$

Edad: 39 años

Lugar de nacimiento: Cartago (Valle)

Sexo: Masculino

Estado civil: Soltero Número de hijos: $\underline{0 \text { hijos }}$

Lateralidad: Diestro.

\section{Información Complementaria}

Educación formal: Médico cirujano

Ocupación: Medico cirujano

Tabla 26. Diagnóstico Caso $\mathrm{N}^{\circ} 11$ después de aplicación de Batería de Diagnóstico y Caracterización de las afasias

\begin{tabular}{|l|l|}
\hline \multicolumn{1}{|c|}{ Diagnóstico caso No 11 } \\
\hline Aspecto valorado & \multicolumn{1}{c|}{ Resultado } \\
\hline Lingüístico & $\begin{array}{l}\text { Codificación: No hay soltura en su fluidez verbal, pues presen- } \\
\text { ta una alteración de tipo soplo y de tipo fonación. No hay alte- } \\
\text { ración en el nivel sintáctico. } \\
\text { Decodificación: Los niveles sintáctico y semántico están con- } \\
\text { servados, pues solo presenta las dificultades que caracterizan } \\
\text { a un hablante-oyente normal (en relación con el ideal, referido } \\
\text { por Chomsky). }\end{array}$ \\
\hline
\end{tabular}




\begin{tabular}{|c|c|}
\hline Psicolingüístico & Alterado el proceso expresivo, solo en la forma fonética. \\
\hline Neurolingüístico & 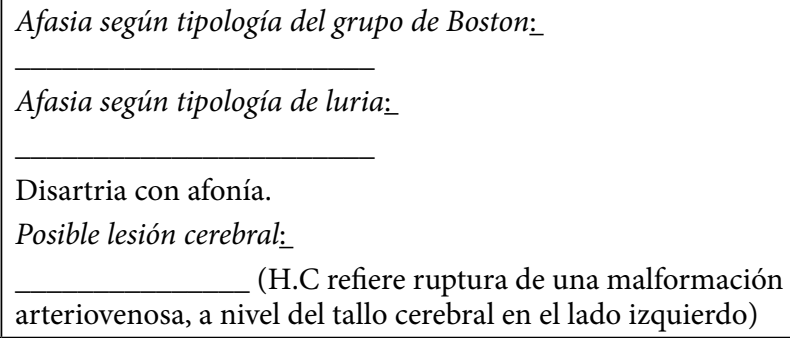 \\
\hline
\end{tabular}

\subsection{Discusión y análisis:}

\subsubsection{Tipo de afasia predominante}

De los 10 casos evaluados, 6 corresponden a la afasia motora eferente (casos: 1, 2, 4, 5, 7 y 10). El descubrimiento de esta afasia por Paúl Broca, en abril de 1861, constituye no solo el inicio de los estudios en afasiología sino también el origen de la neurología. Desde entonces esta pérdida del lenguaje: afemia, lleva el nombre de su descubridor. Tradicionalmente se le ha reconocido con los nombres de: afasia expresiva, afasia motriz, afasia gramática, afasia verbal y afasia motora.

El lapso previsto para la evaluación, de acuerdo al calendario académico y a la planeación del trabajo de investigación fue de seis meses.

De los seis casos presentados:

Según el sexo:

4 son de sexo masculino

2 son de sexo femenino

Según la edad:

2 son de 21 años

1 es de 71 años

3 tienen un promedio de edad de 46 años 
Según la escolaridad:

4 han hecho la primaria

1 es bachiller

1 es profesional

Según la lateralidad:

5 son diestros

1 es zurdo

Según la etiología:

5 tienen como causa: la vascular (ACV)

1 tiene como causa: la traumática (TEC).

En todos los casos está comprometido el lóbulo frontal izquierdo y se postula el área de Broca como la zona afectada por la lesión. El promedio de rendimiento deficitario en el uso del lenguaje fue de 64\%. En todos los casos hay hemiparesia derecha y alexia. El proceso psicolingüístico alterado en todos los casos, es el de la Expresión Lingüística, en la cual se determinan trastornos de la competencia lingüística. Este defecto conlleva modificaciones notables en los procesos receptivo, memorizado y reproducido.

La actuación lingüística resulta defectuosa por la incapacidad sintáctica o agramatical de los pacientes, lo que influye notablemente en la forma fonética, resultando una producción con articulación pobre en la ejecución de los movimientos del habla, en un discurso no fluente, con esfuerzo en la ejecución de sonidos, sílabas, palabras y oraciones. En la recepción, la incapacidad sintáctica dificulta la compresión, por lo cual se altera el componente semántico. En todos los casos la comprensión discursiva está muy comprometida, consideración que va en contra de lo que tradicionalmente se considera como decodificación conservada. El proceso de almacenamiento, aunque variable de caso a caso, también está comprometido.

La reproducción del lenguaje en lectura en voz alta está seriamente deteriorada.

Este cuadro clínico de Afasia Motora Eferente se produce entonces por lesiones en la llamada zona Broca, responsable de la descomposición de la actividad verbal lineal del lenguaje. 
Actualmente, se reconoce que Dax había reportado, pero sin publicar, un caso similar al de Broca y como este, relacionaba la afemia con una localización neuroanatómica: la tercera circunvolución frontal del hemisferio izquierdo.

Luria (1980) distingue otro síndrome de afasia relacionado con el proceso expresivo debido también a lesiones frontales, concretamente en las porciones anteriores (prefrontales) de la zona de Broca. Es la llamada afasia dinámica. En este caso, las alteraciones tienen un carácter específico. El síntoma fundamental es la pérdida del lenguaje espontáneo, aunque no presentan alteraciones fonéticas ni morfológicas. Comprenden el lenguaje dirigido a ellos, denominan objetos, repiten sonidos y palabras individuales. Conservan las relaciones lógico gramaticales y conservan la lectura y la escritura. Su gran dificultad es el paso del pensamiento a la expresión verbal abierta, lo que supone un trastorno del lenguaje interior. Por eso, estos pacientes fracasan en el lenguaje narrativo y monologado.

A diferencia del cuadro anterior, Luria (1980) sitúa la afasia motriz eferente en elgrupo de alteraciones inespecíficas de eslabones particulares de la codificación verbal (el esquema lineal de las oraciones). En esta afasia, el carácter inespecífico afecta el conjunto de la neurodinámica del paciente, extendiéndose a sus movimientos y a su lenguaje, como ocurrió con los seis pacientes descriptos aquí, gracias a la investigación neurolingüística.

El grupo de Boston (Ardila y Rosselli, 1992) caracteriza la afasia de Broca por un lenguaje expresivo no fluente, pobremente articulado, compuesto por expresiones cortas y agramaticales y producido con gran esfuerzo. La repetición, la denominación y la lectura en voz alta son anormales. Aunque el nivel de la comprensión nunca es normal, siempre es superior de la expresión, y presentan fallas en la comprensión de estructuras gramaticales. La escritura está seriamente afectada. En síntesis, el Grupo de Boston, orientado a las distinciones neuroanatómicas de las afasias, siguiendo a Wernicke, estaría de acuerdo con la orientación del análisis del lenguaje, en forma singular de afasia de Luria, en que el defecto fundamental de la afasia motriz eferente es la incapacidad de los pacientes de producir un lenguaje coherente con un paso fluido de unos elementos lingüísticos a otros. De esta manera, se hace aceptable la propuesta de Jakobson, incorporada por Luria, en 
la cual el defecto fundamental es el deterioro del eje sintagmático del lenguaje.

Los casos aquí tratados muestran la tendencia por la cual, un síntoma fundamental tiende, no solamente a alertar diversos niveles de la lengua hablada, sino también diversos procesos del lenguaje, aunque lógicamente una alteración puede explicarse por otra.

Una forma económica tradicional de aclarar este problema ha sido la utilización de dicotomías tales como: afasias prerolándicas o postrolándicas, anteriores o posteriores, expresivas o receptivas, de tipo motor o sensorial, fluentes o no fluentes. Jakobson (1975) propone la tipología lingüística, incorporada por Luria, entre desórdenes sintagmáticos y paradigmáticos o alteraciones de la codificación y la decodificación. Ya, Henry Head (1926) había propuesto una clasificación puramente lingüística de las afasias: verbal, sintáctica, nominal y semántica. Pero las clasificaciones más ampliamente aceptadas han sido las de Luria (1980) y el grupo de Boston (Benson y Geschwind, 1971; Goodglass y Kaplan, 1974). La una en la Unión Soviética y en Europa Oriental y la otra en el mundo angloparlante. El grupo de Boston desarrolla los conceptos de Wernicke para distinguir las afasias fluentes de las no fluentes, y la distinción neuroanatómica de afasias corticales (Broca, Wernicke y Conducción), transcorticales (motora transcortical y sensorial transcortical, áreas limítrofes del lenguaje) y subcorticales (afasias atípicas, tálamo, putamen, núcleo caudado y cápsula interna).

Por la naturaleza de este trabajo, se incorpora la clasificación de Luria porque parte del análisis del lenguaje en alguna forma singular de afasia. Se trata de siete tipos diferentes de afasias, cuyos nombres se desprenden del componente lingüístico alterado: acústico agnósica (discriminación fonémica), acústico amnésica (memoria lexical), amnésica (selección lexical), semántica (comprensión de relaciones entre palabras), motriz eferente (secuencialidad de elementos y realización de movimientos finos del habla), y dinámica (iniciativa verbal). Estas alteraciones encontraron correlaciones clínico-anatómicas por considerar el lenguaje un sistema funcional. 


\subsubsection{Discusión y análisis: otros casos presentados}

El diagnóstico para el Caso 3 de todos los casos presentados, fue afasia motora aferente:

esta afasia fue postulada en 1874 por Wernicke y aún hoy sigue siendo tema de discusión. El grupo de Boston conserva el nombre original de afasia de conducción, aunque Goldstein la llamó afasia central.En términos generales, las alteraciones de este paciente coinciden con las características básicas del lenguaje descritas por el Grupo de Boston (Ardila y Rosselli, 1992). El daño cerebral aún se discute: Wernicke había postulado una lesión en el fascículo arqueado, lóbulo temporal, haz de fibras que unen la zona de Broca (expresiva) y la zona de Wernicke (comprensiva) y de ahí, la incapacidad de la repetición debido a esta desconexión, ya que el examen neurológico de la afasia motriz aferente es variable, existen también formas diferentes de apreciación e incluso, formas variables de la misma afasia que originan defectos en la repetición.

Ardila y Rosselli (1992) caracterizan el tipo eferente/reproducción que implica la organización fonológica y la representación de las palabras, cuyo correlato neuroanatomico sería parietal e insular. Al tipo aferente/repetición, implicaría defectos en la memoria verbal a corto plazo, que afectaría la repetición de consecuencias largas por daño en el lóbulo temporal. Luria (1980) al revisar la afasia de conducción concluye que tiene un origen complejo y variado, ya que en algunos casos aparece asociada al trastorno del análisis acústico articulatorio, mientras en otra forma, parte de un síndrome de alteraciones de la memoria verbal.

El caso aquí presentado sorprende, ya que fue prducto de combinar estas dos formas de observación. La conclusión de Wernicke, luego de 30 años de observaciones, aún sigue vigente: "es prácticamente imposible describir un único cuadro clínico de esta forma de afasia con base en los datos empíricos" (Luria, 1980). Para Bustamante, Lopera y Rojas (1987) la causa de la apraxia verbal en casos de afasia motriz aferente, interpretada como un déficit propioceptivo es tan evidente que el paciente puede mejorar la calidad del enunciado si utiliza un espejo para conocer la posición de sus labios durante la pronunciación.

El diagnóstico para el caso 6 de todos los casos presentados, fue 
afasia global, correlacionando esta forma de afasia con la lesión cerebral, Bustamante, Lopera y Rojas (1985) clasifican tres tipos de lesiones a nivel del hemisferio dominante para el lenguaje: lesiones masivas, múltiples y perisilvianas, y recomiendan el análisis después del periodo agudo (60 días después de la lesión cerebral con el fin de correlacionar mejor las alteraciones del lenguaje con las lesiones escanográficas).

En este paciente, como en los veinte estudiados por los autores citados, están severamente alteradas rodas las funciones del lenguaje y todos los niveles de la lengua, y son aléxicos y agráficos. Hemos podido comprobar, además, que todos los procesos psicolingüísticos del lenguaje también están severamente comprometidos. Este cuadro es clasificado como "global" en la tipología del Grupo de Boston y no tiene correlato en la nomenclatura de Luria.

El diagnóstico para el Caso 8 de todos los casos presentados, fue Afasia Mixta: las variables mixtas de afasias son comunes y se presentan cuando una misma lesión afecta áreas adyacentes del cerebro, relacionadas con determinados tipos de afasias.Así, lesiones frontales pueden extenderse a la región de integración temporo-parieto-occipital, alterando notablemente la emisión y la recepción del lenguaje, y por ende todos sus procesos psicolingüísticos.

La lesión frontal explica el déficit expresivo y la lesión parietooccipital explica los trastornos del lenguaje almacenado y reproducido, pese a que todos los procesos están alterados, la comprensión es la más conservada y la región responsable de esta función (lóbulo temporal) está aparentemente intacta. El paciente combina síntomas más variados de afasia motriz eferente $8 y$ dinámica) con síntomas de afasia nominal (y amnésica).

El diagnóstico para el caso 9 de todos los casos presentados, fue afasia acústico-amnésica:

Se trata aquí de una afasia amnésica muy específica. El paciente puede reproducir fonemas, palabras, oraciones a condición de que sean aisladas, ya que el análisis fonológico es correcto. El síntoma fundamental es su total incapacidad de reproducir series de sonidos, 
series de palabras y series de oraciones. Además, es incapaz de reproducir algún detalle de un pasaje, e incluso, está alterado su lenguaje automático. Olvida rápidamente la información verbal presentada por el examinador por una inadecuada ordenación, como ocurre también con las comparaciones, el caso atributivo genitivo y las relaciones temporales que también exigen una adecuada ordenación, como la ejecución de órdenes simultáneas que tampoco realiza.

Para Ardila (1984) estos pacientes presentan una profunda inhibición retroactiva, mecanismo aparentemente responsable de la caída del volumen de la memoria verbal. Por eso, para el paciente es difícil repetir estructuras complejas o pasajes, ya que existe una incapacidad de relación de elementos presentados en una determinada secuencia (característica fundamental de la memoria a corto plazo). Las parafasias señaladas en los ejemplos en medio de paragramatismo son signo de alteración de la estructura fonológica. Llama la atención en este paciente la conservación de la denominación. Esto puede deberse a la terapia iniciada hace ya siete años.

Luria (1980) distinguió otra variedad de afasia amnésica que llamó "nominal" o "afasia amnésica", caracterizada por la incapacidad de denominar objetos por la disociación entre el significante y el significado del signo lingüístico. Un síntoma asociado a éste es la incapacidad de reconocer estructuras lógico gramaticales (afasia semántica).

\subsubsection{Reporte de un caso de disartria}

El diagnóstico para el caso 11, de todos los casos reportados, fue disartria: las patologías del habla o la "palabra" deben diferenciarse de las patologías del lenguaje (afasias). Azcoaga (1981) llama disartria a las dificultades articulatorias que afectan la dicción de modo bastante generalizado. Son trastornos motores de los órganos utilizados para la articulación del habla. Una deficiencia en la articulación es la dislalia que puede ser sistematizada, selectiva, o puede ser no sistematizada, se deben éstas a un aprendizaje inadecuado en el medio familia. Las disfasias se refieren a trastornos afásicos del desarrollo, madurez y crecimiento del lenguaje. La afonía se refiere a los trastornos de la fonación verbal. 
Ahora bien, el caso de la anartria, donde no se puede articular lo que se quiere decir, es causado no por no por una apraxia articulatoria sino por un déficit en un analizador especializado: el analizador cenestésico motor verbal. En los niños observa retraso anártrico sin apraxia orofacial, apraxia orofacial sin retardo anártrico, o el síndrome de ambos componentes. 



\section{Conclusiones}

\section{Retrospectivas}

unque no desconocemos que cada caso de afasia es
único, nos permitimos establecer ciertas generalidades
donde participan variables concurrentes como: edad, sexo, lateralidad, etiología, educación formal y ocupación. Porque su interpretación, en conjunto nos reflejan ciertas características y circunstancias presentes en la población objeto de esta investigación, específicamente en los casos valorados.

Así, entonces, se encontró que los hombres fueron más propensos a sufrir afasias, en comparación con las mujeres, pues de los casos valorados y diagnosticados como tal, tres son femeninos y siete masculinos.

La edad en que más se presentaron afasias en esta población valorada es, en orden decreciente, así: en mayor proporción en el rango de 31 a 40 años (caso 2, 3 y 9), le sigue en menor proporción los rangos de 51 a 60 años (casos 5 y 6 ) y de 21 a 30 años (casos 1 y 4). Y se presentaron menos casos en los rangos de 10 a 20 años (caso 8), de 41 a 50 años (caso 7) y de 71 a 80 años (caso 10).

En los casos valorados se muestra que la población más afectada es la que ha estudiado la primaria únicamente o sólo algunos de sus grados (casos 1, 3, 5, 6, 7, 9 y 10), le sigue en menor proporción la población que se ubica dentro de la Educación Secundaria (caso 4 y 8 ) y la que se ubica en la Educación Superior (caso 2). 
De acuerdo con las profesiones, en la población valorada, se encuentran más afectados los empleados (mecánico, conductor y modista, casos 5, 6 y 10 respectivamente), les sigue las amas de casa (casos 1 y 3 ), los estudiantes (casos 4 y 8 ) y los jubilados (casos 7 y 9). Y en menor proporción resultaron afectados los profesionales (caso 2).Todos los casos de la población valorada son diestros, excepto el caso 7 que es ambidiestro.

La causa más frecuente de afasia en la población valorada fue: Etiología vascular ACV (accidente cerebro vascular), pues por dicha razón fueron remitidos a la Entidad de salud los casos: 1, 2, 3, 5, 6, 7 y 10 (70\%). Y en menor proporción la causa fueron los traumas ocasionados desde el entorno de la población valorada: casos 4 y 8 por accidente automovilístico y caso 9 por impacto de bala (30\%).

De los casos evaluados el 60\% corresponde, según la clasificación de Boston a la afasia de Broca, en equivalencia con la clasificación de Luria, afasia motora eferente: casos 1, 2, 4, 5, 7, y 10. Les sigue la afasia de conducción, casos 3 y 9 (20\%). Y en menor proporción la afasia global (tipología de Boston) y la afasia transcortical mixta (tipología de Boston) con los casos 6 y 8 respectivamente (10\% y $10 \%)$.

De acuerdo con el análisis de los resultados concluimos que:

- No existe una alteración pura de un solo proceso psicolingüístico. Siempre hay repercusiones de algún grado, sobre los demás procesos. En los casos 4, 7 y 10 de afasia motora eferente hay un mayor rendimiento deficitario en el proceso psicolingüístico expresivo. Sin embargo, los demás procesos psicolingüísticos (memorizado, receptivo y reproducido), también muestran rendimiento deficitario en menor grado.

- Algunos síntomas en la actuación lingüística de los pacientes afásicos, dificultan el diagnóstico neurolingüístico o ubicación dentro de las clasificaciones de afasia utilizadas tradicionalmente (Luria-Boston). En el caso 9 encontramos fluidez, comprensión, repetición y denominación, como relativamente conservados, producto de una lenta rehabilitación del estado de mutismo en el que se encontraba el paciente. Sin embargo, todos los procesos psicolingǘsticos tienen grado de rendimiento deficitario 
menores al 50\%, siendo el más notorio el proceso expresivo: se caracteriza por la ausencia de conectores, léxico al que no ha podido acceder. Por ser ese agramatismo casi el síntoma más dominante y que caracteriza además su expresión verbal, se torna difícil ubicar este caso en una de las tipologías existentes.

- La evaluación realizada a los $10 \mathrm{H}-\mathrm{OP}$ permitió un acercamiento y una familiarización con todos los síndromes afásicos establecidos en las tipologías tradicionales (Luria - Boston).

Como cumplimiento de los objetivos inicialmente propuestos, se concluye que:

- Con esta batería sí se logra evaluar, diagnosticar y caracterizar lingüísticamente las afasias a nivel general de los procesos psicolingüísticos que intervienen en la producción y comprensión del lenguaje.

- La competencia lingüística y la actuación lingüística del paciente proporcionan toda la información necesaria para llegar a determinar el tipo de afasia que sufre. Independientemente esto, de la focalización de la lesión cerebral. En los casos 3 y 6 aquí presentados no fue posible conocer la ubicación de la lesión, sin embargo se hizo el diagnóstico neurolingüístico.

\section{Proyectivas}

- Por la receptividad y confianza que depositaron y demostraron pacientes y familiares en nosotras como examinadoras y por la constante expectativa e interés por la prueba aplicada, ya que la vieron como un ejercicio dinámico y refrescante para el $\mathrm{H}-\mathrm{OP}$, consideramos esta batería como un punto de partida sólido para los profesionales interesados en efectuar rehabilitación de afasias, ya que ésta les permite acercarse al $\mathrm{H}$-OP y diagnosticar y caracterizar lingüísticamente la afasia que pueda estar sufriendo.

Un programa de rehabilitación donde se agoten todas las posibilidades de recuperación orientadas a restablecer el funcionamiento normal de los procesos psicolingüísticos $o$, en su defecto, dada la severidad de la lesión (desintegración), 
proceder a habilitar al paciente para que haga uso efectivo de los recursos comunicativos con los que aún cuenta.

- Después de aplicar labatería observamos cierto grado de dificultad generalizado, por parte de los pacientes, para suministrar y/o ejecutar las respuestas de algunos ítems:

-En comprensión de estructuras lógico gramaticales referidas a relaciones temporales, consideramos que se pueden replantear los términos "siesta" y "cena", pues para nuestra cotidianidad resultan acordes, pero algunos $\mathrm{H}-\mathrm{OP}$ no los usan con frecuencia.

-En la comprensión de oraciones simples y compuestas, referidas a señalar o coger objetos, se puede replantear el pedir al $\mathrm{H}-\mathrm{OP}$ que ejecute acciones con su mano derecha, porque la mayoría de $\mathrm{H}$-OP de esta población valorada, presentó hemiparesia derecha. 
Recomendaciones

- Las entidades de salud y los individuos que se ocupan de rehabilitación de afasias, deben apropiarse de un instrumento, ambientado al medio, que les permita evaluar y diagnosticar las afasias, orientando así sus programas de rehabilitación.

- Las entidades de salud deben hacer exámenes: neurológicos y psicológicos que brinden información específica sobre el estado del paciente en estos aspectos. Así mismo, remitirlos a terapia del lenguaje, como pacientes con el derecho a seguir siendo atendidos por dicha Entidad e inscribirse en un programa de rehabilitación.

- Se recomienda a las familias de los pacientes hacerlos participes de las actividades cotidianas, tratándolos así con normalidad, sin ignorarlos y sin hacerles tan evidente su dificultad de lenguaje. 

Glosario

\section{ACENTUACIÓN LINGÜÍSTICA}

Es el uso real de la lengua en situaciones concretas por un hablanteoyente particular. Las estructuras profundas de la competencia se transforman en las estructuras superficiales de la actuación.

\section{AFASIA}

Trastorno adquirido del lenguaje oral en pacientes que presentaban un lenguaje normal antes de una lesión cerebral que afecta un patrón selectivo de deterioro, preservando otros componentes de procesamiento del lenguaje asociados a la zona afectada por la lesión.

\section{AFASIOLOGÍA}

Práctica que pretende dar cuenta de las alteraciones del lenguaje en general, y de la comunicación en sentido específico, a causa de lesiones cerebrales focalizadas.

\section{AGNOSIA}

Incapacidad de transformar sensaciones en percepciones pese a que el paciente puede ver, oír y sentir, pero no puede reconocer los estímulos visuales, auditivos o táctiles. Es causada por lesiones en la corteza parietal, temporal y occipital.

\section{AGRAFIA}

Alteración específica en la escritura. Pérdida total o parcial en la capacidad para escribir resultante de un daño cerebral. 


\section{AGRAMATISMO}

Concatenación malformada de signos lingüísticos en la producción de una oración. Luria lo llama lenguaje nominativo, ya que predominan las palabras llenas (nombres, adjetivos, verbos y adverbios) con ausencia de palabras vacías (conjunciones y preposiciones) en una producción no fluente (lenguaje telegráfico).

\section{ALEXIA}

Alteración en la lectura. Pérdida total o parcial en la capacidad para leer, resultante de un daño cerebral.

\section{AMNESIA}

Pérdida de la retención (registro), almacenamiento (conservación) o evocación (recuperación) de las huellas de la memoria. La metamemoria es la capacidad del individuo para conocer y manejar su propia memoria.

\section{ANARTRIA}

Incapacidad total o casi total de producir lenguaje hablado. Se asocia a la afasia de Broca. Si existe una comprensión conservada, el paciente intenta compensar su incapacidad de expresión verbal con vocalizaciones reducidas, mímica o escritura. Es un trastorno motor del habla por parálisis de los músculos articuladores.

\section{ANOMIA}

Inhabilidad para nombrar utilizando sustantivos o nombres; es decir, dificultad para encontrar la palabra en el lenguaje espontáneo. Trastorno del lenguaje caracterizado por la dificultad del paciente de encontrar el significante del signo lingüístico correspondiente a su significado, dificultad que se manifiesta en una notoria incapacidad para denominar y en el empleo exagerado de parafasias y circunloquios.

\section{BATERÍA}

Es un instrumento que consiste en una serie de preguntas y otras indicaciones con el propósito de obtener información de los consultados formado por un conjunto de preguntas que deben estar redactadas de forma coherente, y organizadas, secuenciadas y estructuradas de acuerdo con una determinada planificación, con el fin de que sus respuestas nos puedan ofrecer toda la información. 
Su objetivo es profundizar en una información siguiendo el hilo de las sucesivas repuestas recopilando datos de gran importancia y/o intereses.

Se utiliza frecuentemente, como método de investigación o de análisis. En otras palabras, su función en el ámbito académico es recabar información de utilidad para la sustentación de una indagación formal que requiera de datos o tendencias de opinión4.

\section{CIRCUNLOQUIO}

Sustitución de una palabra por la descripción del objeto o por definiciones operativas.

\section{DISARTRIA}

Trastorno del habla que se manifiesta como una dificultad articulatoria que afecta la expresión abierta y desplegada.

\section{FOTOFOBIA}

Temor demasiado marcado a la luz.

\section{FUNCIÓN FÁTICA:}

El contacto es el medio, canal o forma concreta de relación entre el emisor y el receptor. Sirve para establecer la comunicación y mantenerla hasta el final.

\section{HABLA (ESTILO) TELEGRÁFICA}

Habla entrecortada con pausas largas y abundantes debida a la incapacidad de encontrar palabras de clase cerrada

\section{HABLANTE - OYENTE IDEAL}

Concepto matemático de la teoría lingüística chomskiana que supone un hablante-oyente en una comunidad lingüística del todo homogénea que sabe perfectamente su lengua y al que no afectan condiciones sin valor gramatical al aplicar conocimiento de la lengua al uso real.

\section{HABLANTE - OYENTE PATOLÓGICO}

Persona con alteración en su producción y comprensión lingüística debido a ataques cerebrales, enfermedades neurodegenerativas o

4 Y, Tabares. (2016). Batería de preguntas. Disponible en: https://prezi.com/lvvgqw2hwhi4/bateria-de-preguntas/ 
enfermedades mentales.

\section{JERGAFASIA}

Tipo de anomia caracterizada por flujo constante de palabras lleno de neologismos, parafasias y paragramatismo, con aparente conversación del componente sintáctico. Al paciente le es difícil recuperar la pronunciación de las palabras. La jergafasia infantil se llama idioglosia.

\section{LENGUAJE AUTOMÁTICO (FACILITADO)}

Capacidad moto-sensorial sin intención consciente para contar, recitar, cantar o rezar secuencias parciales automatizados del lenguaje hablado como los días de la semana, poemas infantiles, el himno nacional o el Padrenuestro. Hábitos verbales automatizados con incapacidad de sostener una conversación espontánea.

\section{LENGUAJE ESPONTÁNEO (ORDINARIO)}

Es el lenguaje natural de la vida cotidiana que se produce sin cuidados del hablante.

\section{LOGORREA}

Trastorno de la comunicación, a veces clasificado como enfermedad mental, caracterizado por una locuacidad incoherente. Como sinónimos se usa "verborrea" o "incontinencia verbal".

\section{MUTISMO}

Ausencia total de emisiones verbales que se presenta al inicio de la afasia y precede una reducción cuantitativa.

\section{NEOLOGISMO}

Transformaciones fonemáticas extremas que dan origen a un vocablo nuevo. Cuando hay un exceso de neologismo en medio de gran fluencia se habla de jergafasia.

\section{PARAFASIA}

Característica no intencionada de los pacientes fluentes que consiste en la violación de la estructura fónica o semántica de la palabra.

\section{PARAFASIA LITERAL (FONOLÓGICA O SINTAGMÁTICA)}

Es la alteración de un vocablo por adición, sustitución, omisión o permutación de fonemas. Los fonemas realizados pertenecen a la 
lengua, pero son inesperados.

\section{PARAFASIA VERBAL (SEMÁNTICA O PARADIGMÁTICA)}

Es la sustitución de una palabra por otra que se le parece en forma (morfológica) o en el concepto (semántica).

\section{PARAFASIA}

Distorsiones o lapsus persistentes en la producción de las palabras. Cuando se presenta en el contexto de un discurso no fluente, la distorsión en la emisión, probablemente se deba más bien a una falla antártica que se caracteriza por ser producida con dificultad, con esfuerzo; mientras que la transformación, propiamente de origen afásico se produce fácilmente en el contexto de un discurso fluente.

\section{PARAGRAFÍA}

Reducción cuantitativa o suspensión de grafemas en la expresión escrita. El desorden de la realización escrita del signo lingüístico en ausencia de trastornos motores o espaciales elementales se llama "agrafía pura".

\section{PARAGRAMATISMO (LENGUAJE PREDICATIVO, DISINTAXIA)}

Problema de control en la jerga afásica que se manifiesta por la incapacidad de inspeccionar y filtrar ciertos elementos de la lengua no pretendidos o inadecuados en la producción de la estructura sintáctica de la oración. Existen disociaciones entre parafasias semánticas, palabras no relacionadas, parafasias fonológicas y neologismos.

\section{PARALEXIA}

Dificultad para leer letras (alexia literal) y palabras (alexia verbal) en ausencia de trastornos perceptivos visuales. Cuando este trastorno se presenta sin otras alteraciones del lenguaje se llama alexia pura o ceguera verbal.

\section{PROSODIA}

Hace relación a la entonación, ritmo, melodía, acento y demás componentes no verbales que acompañan al discurso. Los pacientes con lenguaje gramatical no fluente, por lesiones prerolándicas generalmente pierden los aspectos prosódicos de la expresión; mientras que aquellos con lesiones posteriores los conservan. 

Bibliografía

Ardila, A. Bernal, B. y Rosselli, M. (2016). "Área cerebral del lenguaje: una reconsideración funcional”. Extraído desde:

https://aalfredoardila.files.wordpress.com/2013/07/2016ardila-bernal-rosselli-c3a1rea-cerebral-del-lenguaje-unareconsideracic $3 \mathrm{~b} 3 \mathrm{n}$-funcional.pdf

Ardila, A. (2005). Las afasias. México: Universidad de Guadalajara

Ardila, A (1981). Las afasias. Bogotá: Instituto Neurológico de Colombia.

Ardila, A y Ostrosky, S. (1991). El diagnóstico del daño cerebral: enfoque neuropsicológico. México: Editorial Trillas.

Ardila, A. y Rosselli, M. (2007). Neuropsicología clínica. México: Editorial Manual Moderno.

Ardila, A. \& Rosselli, M. (1992). Neuropsicología Clínica, Tomo I. Medellín: Editorial Prensa Creativa.

Ardila, A. (1985). Psicofisiología de los procesos complejos. México: Editorial Trillas.

Arroyo, F. (1992). Psicolingüística. Madrid: Editorial Morata

Azcoaga, J. E. (1981). Trastornos del lenguaje. México: Editorial El 
Ateneo S.A.

Barraquer, L.l. y Peña, J. (1983). "Formas clínicas de Afasia. Bases clínicas y neurolingüísticas”. En: Peña, J. y Ll. Barraquer, L.I., eds. Neuropsicología. Barcelona.

Bein, E.S. y Ovcharova P.A (1970). Clínica y rehabilitación de las afasias. Sofia: Medisina.

Benson, F. \& Geschwind (1992). Aphasia and related cortical disturbances. En: Ardila y Rosselli (1992). Neuropsicología Clínica. Medellín: Editorial Prensa Creativa.

Benson, D.F (1979). Aphasia, alexia and agraphia. Nueva York: Churchill Livingstone.

Benson, D.F. (1996). Aphasia: a clinical perspective. Nueva York: Oxford University Press.

Benton y Hamsher, K.S, Varney, N.R. y Spreen, O. (1983). Contributions to neuropsychological assessment. Nueva York: Oxford University Press.

Benton, A. (1991). Constructional apraxia. In Boller. En: Grafman, J. (eds). Handbook of Nueva York. Elservier.

Benton, A.L. (1971). Introducción a la neuropsicología. Barcelona: Fontanella.

Broca, P. (1863). Localisations des fonctions cérébrales. Siége de la faculté du langage articulé. Bulletin de la Société d"Anthropologie, 4, 200-208

Broca, P. (1861). Sur le principe des localisations cérébrales. Bulletin de la Société d"Anthropologie, 2, 190-204.

Bustamante, J. (1997). Neuroanatomía funcional. Bogotá: Fondo Educativo Interamericano.

Bustamante, J. Lopera F. y Rojas, J. (1987). El lenguaje: fundamentos de 
neurolingüística. Medellín: Editorial Prensa Creativa.

Castillero, O. (2019). Afasia global sintomas causas y tratamiento. Extraído desde: Https://psicologiaymente.com/clínica/afasia-global

Chomsky, N. (1977). El lenguaje y el entendimiento. Seix Barral: Barcelona

Chomsky, N. (1990). El lenguaje y los problemas del conocimiento. . Madrid: Visor.

Chomsky, N. (1976). Aspectos de la teoría de la sintaxis. Madrid: Editorial Aguilar.

Christensen, A. (1978). El diagnóstico neuropsicológico de Luria. Madrid: Editorial Pablo del Rio.

Christensen, A. y Luria, A. (1979). A practical application of the Luria methodology. Journal of Clinical Neuropsychology, 1(3), 241-247.

Conesa, F. y Nubiola J. (1999). Filosofía del lenguaje. Barcelona: Editorial: Herde

Crystal, D, Fletcher, P y German, M. (1983). Análisis gramatical de los trastornos del lenguaje. Barcelona: Editorial Médica y Técnica S.A.

Cuetos, F. (1998). Evaluación y Rehabilitación de los pacientes afásicos: una aproximación cognitiva. Madrid: Editorial Médica Panamericana.

Exner, S.y Conrad, E. (1881). Estudios sobre la localización de funciones en la corteza cerebral del hombre. Viena: W.BraumÜller

Fajardo, L.A. (2008). Aproximación a la relación entre cerebro y lenguaje.

Extraído desde: https://dialnet.unirioja.es/descarga/articulo/3324347. pdf

Fajardo. L.A. y Moya C. (1999). Fundamentos neuropsicológicos del lenguaje. Bogotá: Instituto Caro y Cuervo.

Geschwind, N. (1966). Language and the Brian. New York: Scientific 
American.

Goodglass, H. y Kaplan, E. (1972). The assessment of aphasia and related disorders. Philadelphia: Lea and Febier.

Goodglass, H. y Kaplan, E. (1979). Evaluación de la afasia y trastornos similares". Buenos Aires: Editorial Panamericana.

Geschwind N (1974). Selected papers on language and the brain. Boston: D. Reidel Publishing Company.

González, R. y Hornauer-Hughes, A. (2014). "Afasia: una perspectiva clínica"

Extraído desde:

https://www.redclinica.cl/Portals/0/Users/014/14/14/afasia2_una_ perspectiva-clinica.pdf

Head, H. (1926). Aphasia and kindred disorders of speech. London. Cambridge: Cambridge University Press.

Hécaen, H. (1977). Afasias y apraxias. Buenos Aires: Paidós.

Halliday, M. (1978). El Lenguaje como semiótica social. México: Fondo de Cultura Económica.

Head, H. (1926). Aphasia and kindred disorders of speech. London: Cambridge University.

Jiménez, J.L. (2001). Iniciación a la lingüística. Alicante: Club universitario.

Jakobson, R. (1974). Lenguaje infantil y afasia. Madrid: Editorial Ayuso.

Jakobson, R. (1975). Ensayos de lingüística general. Barcelona: Editorial Seix Barral.

Jakobson, R. (1963). Essais de linguistique genérale. Paris: minuitKertesz.

Elsevier, J. (1866). Notes on the physiology and pathology of lenguaje. 
London: Medical Times and Gazette.

Kaplan, E.F. Goodglass, H. y Weintraub, S. (1978). The Boston naming test. Philadelphia: Lippincott Williams y Wilkins, 1983-2001.

Kertesz, A. (1979). Aphasia and associated disorders. Nueva York: Grune and Stratton.

Kertesz, A. (1982). The Western aphasia battery. Nueva York: Grune y Stratton.

Lázaro, E, Quintanar, L y Solovieva, Y. (2010). Análisis neuropsicológico de pacientes con diferentes tipos de afasia. Neuropsicologia Latinoamericana. 2(1).33-46. Extraído desde:

http://pepsic.bvsalud.org/scielo.php?script=sci_ arttext\&pid=S2075-94792010000100005

Lecours, A. (1995). Conversatorio: "IV Congreso Latinoamericano de Neuropsicología". Cartagena de Indias: Asociación Latinoamericana de Neuropsicología.

Lopera, F. (1996). El cerebro: órgano del conocimiento. Medellín: Universidad de Antioquia,

Luria, A. R. (1971). Problemas y hechos de la neurolingüística. Buenos Aires: Nueva Visión.

Luria, A. R (1974). Cerebro y lenguaje; la afasia traumática: síndromes, exploración y tratamiento. Barcelona: Editorial Fontanella.

Luria, A. R. (1980). Fundamentos de Neurolingüística. Barcelona: Toray - Masson.

Luria A. R. (1984). Conciencia y lenguaje. Madrid: Visor-Libros.

Llinás, R. (1969). Neurobiology of Cerebellar Evolution and Development. Chicago: Am Med Association.

Llinás, R. (2003). El cerebro y el mito del yo. Bogotá: Editorial Norma. 
Marie, P. (1969). Revisión de la question de l'aphasie. Paris: Fammarion.

Omar, E., Pardo, V.M. y Antúnez, V.A. (2013). “Evolución histórica del concepto afasia: apuntes sobre su abordaje teórico en neuropsicología." En: Ruiz, L., Álvarez, M.R., Muñoz, A., eds. (2013). Actualizaciones en Comunicación Social. Vol. I. Santiago de Cuba: Centro de Lingüística Aplicada, 423-427.

Porch, B.E. (1983). Porch index of communicative ability. Manual. Palo Alto: Consulting Pychologists Press.

Pasuy, G., Cisneros, B y Cisneros, E. (2013). "Las afasias desde una mirada lingüístico-cognitiva.” Bogotá: Ediciones Ecoe. Recuperado de: https://media.utp.edu.co/referencias-bibliograficas/uploads/ referencias/libro/las-afasias-todopdf-W5eYx-libro.pdf

RAE (2017). Diccionario de la lengua española. Madrid: Espasa. Recuperado de: https://www.rae.es/

Quintanar. L. (2002) Análisis comparativo de las diferentes escuelas. Revista española de neuropsicología, 4(1), 72-100. ISSN: 11399872. Recuperado de: https://dialnet.unirioja.es/descarga/ articulo/2011210.pdf

Rojas, J. (1991). Modelo pragmático- comunicativo del discurso afásico; en neuropsicología: evaluación clínica y psicométrica. Medellín: Edit. Prensa Creativa.

Rojas, J. (1993). La psicolingüística. Medellín: Pragma Editores.

Rojas, J. (1999) "La teoría lingüística: historia, fundamentos, supuestos e implicaciones”. Medellín. Universidad de Antioquia (inédito).

Rojas, J. (1999). Tratado sobre el lenguaje: lingüística, psicolingüística, neuropsicolingüística, afasiología. Medellín: Pragma Editores.

Roselli, M. y Ostrosky, F. (1995, octubre). Seminario "afasias". IV Congreso Latinoamericano de Neuropsicología. Cartagena de Indias: 
Asociación latinoamericana de Neuropsicología.

Schuell H. (1953). Minnesota test for the differential diagnosis of aphasia. Minneapolis: University of Minnesota Press

Schuell H. (1973). Differential diagnosis of aphasia with the Minnesota test. Minneapolis: University of Minnesota Press.

Saussure, F. (1945). Curso de lingüistica general. Buenos Aires: Editorial Losada.

Gazzaniga, M. S., \& Sperry, R. W. (1967). Language after section of the cerebral commissures. Brain, 90(1), 131-148.

Tsvétkora, L.S (1977). Reeducación del lenguaje, la lectura y la escritura. Barcelona: Editorial Fontanella.

Vega, M. y Cuetos, F. (1999). Psicolingüistica del español. Madrid: Editorial Trotta.

Vendrell, J.M. (2001) Neuropsicología de lenguaje Las afasias: semiología y tipos clínicos. Revista de neurología, 32(10), 980-986. Extraído desde: www.sld.cu/galerias/pdf/sitios/rehabilitacion.../ afasia_semiologia_y_tipos_clinicos.pdf

Vicario, A. (Coor) (2007). Evaluación, diagnóstico y tratamiento de los trastornos cognitivos en pacientes con enfermedad vascular. Recomendaciones para la práctica clínica. Extraído desde: http:// www.med-informatica.net/TERAPEUTICA-STAR/2007-Guiascognicion-en-enfermos-vasculares.pdf

Vigotsky, L. (1997). Pensamiento y lenguaje. Buenos Aires: La Payade.

Wernicke, K. (1874). "Der aphasische Symptomencomplex". Eine psychologische Studie auf anatomischer Basis. Berlin: springer Verlag.

Weigl, I. (1986). Interdependencia de los factores neuropsicológicos y psicolinguísticos en afasias. En: Efectos psicológicos de los componentes del lenguaje (Compilación de Manfred Bierwisch). Buenos Aires: Editorial Paidós. 
Este libro se constituye en un acercamiento a las afasias, como patología del lenguaje, ocasionada por una lesión cerebral, de origen interno o externo al hablante-oyente. Acercamiento, tanto a nivel teórico como a nivel vivencial, pues se valoró a diez hablante-oyentes patológicos (H-OP) de la ciudad de Pereira, con el ánimo de diseñar una Batería que diagnosticara y caracterizara linguísticamente las afasias, orientada exclusivamente al contexto pereirano, y por extensión al risaraldense.

Es así como, a través de esta publicación, compartimos con los lectores información amplia acerca de este padecimiento que no elige género, edad, formación académica, ocupación laboral, ni estrato socio-económico y entregamos a las Entidades y a los Profesionales de la salud un instrumento que les permite:

*Acercarse a sus pacientes, y mediante entrevistas a ellos mismos 0 a sus familiares, y consulta a sus historias clínicas, identificarlos en cuanto a su condición personal, familiar y social, conocer sus actuaciones linguísticas antes y después de la pérdida en menor o mayor grado de la facultad de comprender y producir su lenguaje ya adquirido.

*Valorar, mediante una prueba de su actuación lingüistica en qué medida están afectados sus procesos neuropsicológicos del lenguaje: expresión y comprensión verbal, y almacenamiento y procesos reproductivos de la expresión verbal

*Diagnosticar y caracterizar linguísticamente el tipo de afasia que sufre el paciente, y con esta base procurar un plan de rehabilitación o una alternativa que le permita interactuar en su entorno familiar, social y por qué no, laboral. 